Ronald G. Asch

\title{
Herbst des Helden
}

Modelle des Heroischen und

heroische Lebensentwürfe in England und Frankreich von den Religionskriegen bis zum Zeitalter der Aufklärung

Ein Essay

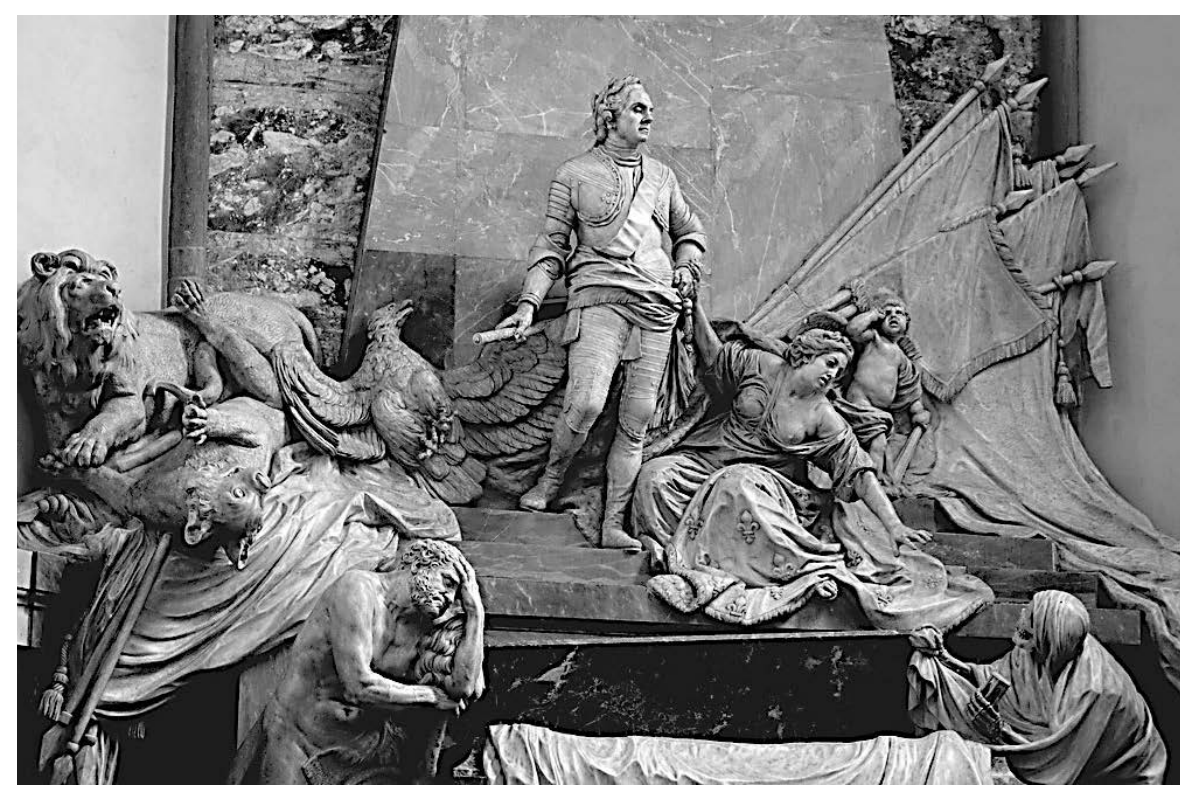


Ronald G. Asch

Herbst des Helden 


\title{
HELDEN - HEROISIERUNGEN - HEROISMEN
}

\author{
Herausgegeben von \\ Ronald G. Asch, Barbara Korte, Ralf von den Hoff \\ im Auftrag des DFG-Sonderforschungsbereichs 948 \\ an der Universität Freiburg
}

Band 3

ERGON VERLAG 
Ronald G. Asch

\section{Herbst des Helden}

Modelle des Heroischen und heroische Lebensentwürfe in England und Frankreich von den Religionskriegen bis zum Zeitalter der Aufklärung

Ein Essay 
Gefördert durch die Deutsche Forschungsgemeinschaft

\section{Umschlagabbildung: \\ Grabmal des Marschall von Sachsen, St. Thomas Straßburg (Jean-Baptiste Pigalle, 1777).}

Foto: Ronald G. Asch

Bibliografische Information der Deutschen Nationalbibliothek Die Deutsche Nationalbibliothek verzeichnet diese Publikation in der Deutschen Nationalbibliografie; detaillierte bibliografische Daten sind im Internet über http://dnb.d-nb.de abrufbar.

(C) 2016 Ergon-Verlag GmbH • 97074 Würzburg

Das Werk einschließlich aller seiner Teile ist urheberrechtlich geschützt.

Jede Verwertung außerhalb des Urheberrechtsgesetzes bedarf der Zustimmung des Verlages. Das gilt insbesondere für Vervielfältigungen jeder Art, Übersetzungen, Mikroverfilmungen und für Einspeicherungen in elektronische Systeme.

Umschlaggestaltung: Jan von Hugo

Satz: Thomas Breier, Ergon-Verlag GmbH

www.ergon-verlag.de

ISBN 978-3-95650-096-1

ISSN 2365-886X 
Für Brigitte 
Inhaltsverzeichnis

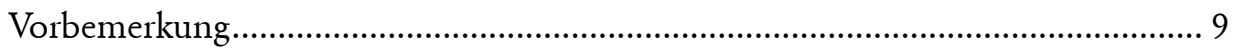

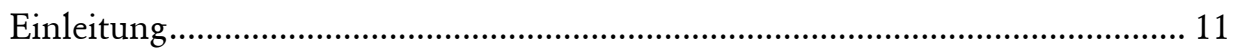

Die Konfessionalisierung des Helden oder die subversive Kraft des Heroischen im späten 16. Jahrhundert

Widerstreitende Modelle des Heroischen in England,

ca. $1603-1660$

Der Heroismus der Heiligkeit, der leidende König

und die Geste der Revolte: Frankreich 1610-1660.

Die Transformation des Helden in Frankreich in der zweiten Hälfte des 17. Jahrhunderts

Die Restauration und die Krise des Heroischen in England nach 1660

Der Held im 18. Jahrhundert zwischen Kritik

und Transformation....

Epilog

Quellen- und Literaturverzeichnis. 145

Personenregister .173 


\section{Vorbemerkung}

Dieser knappe Essay ist im Rahmen meiner Arbeit im Sonderforschungsbereich 948 „Helden - Heroisierungen - Heroismen“ entstanden. Ohne die großzügige Finanzierung unterschiedlicher Forschungsreisen durch die DFG, vor allem aber eines Freisemesters im Winter 2014/15 hätte ich dieses Buch nicht schreiben können, dafür bin ich der Deutschen Forschungsgemeinschaft und dem Sprecher des SFB, Herrn Kollegen von den Hoff, sowie dem Vorstand des Projekts dankbar. Zu Dank bin ich aber auch dem aus Mitteln der Exzellenzinitiative geförderten Kulturwissenschaftlichen Kolleg der Universität Konstanz und meinem dortigen Gastgeber Prof. Ulrich Gotter verbunden, die es mir gestatteten, an den Ufern des Bodensees in einer idealen Arbeitsatmosphäre ungestört dieses Buch zu Papier zu bringen. Wichtige Anregungen erhielt ich von Herrn Prof. Martin Wrede (Grenoble) und Herrn Kollegen Ulrich Heinen (Wuppertal), die beide als Gastwissenschaftler in Freiburg an der Arbeit des SFB teilgenommen haben, und von meinen Kollegen und Kolleginnen im gemeinsamen Projekt sowie meinen Mitarbeitern und Mitarbeiterinnen, die mir in unterschiedlicher Weise die Augen für manches Problem öffneten, das sich mir sonst nicht so leicht erschlossen hätte. Schließlich gewährte mir das von Herrn Prof. Thomas Maissen geleitete Deutsche Historische Institut in Paris im Rahmen eines Karl Ferdinand WernerFellowship im Herbst 2014 einen Forschungsaufenthalt in Paris, den ich wie schon einige Jahre zuvor sehr genossen habe und der Wesentliches zum Gelingen dieses Werkes beitrug.

Meinen Dank möchte ich auch Herrn Andreas Eder (zur Zeit Cambridge), Frau Magdalena Gybas (Freiburg), Frau Marie Kumpf (Freiburg) sowie Herrn Andreas Friedrich, dem Koordinator des SFB, für die sorgfältige Überarbeitung des Manuskriptes aussprechen.

Ich widme dieses Buch meiner Frau, die mit Geduld all die Jahre die vielen Belastungen und weniger erfreulichen Aspekte des Lebens eines deutschen Universitätslehrers zu Beginn des 21. Jahrhunderts mitertragen hat.

Manch einer mag sich fragen, wie viel die Geisteswissenschaften in der Gegenwart noch an Orientierung zu geben vermögen. Ihre Sinnstiftungsfunktion haben sie sicherlich weitgehend verloren, aber vielleicht helfen sie uns als Europäern doch, unsere gemeinsame konfliktreiche Geschichte besser zu verstehen. Dazu soll auch dieser Essay, der seinen Blick auf Frankreich und England richtet, einen Beitrag leisten. Nur wenn die europäischen Nationen sich ihrer sehr unterschiedlichen Geschichte, die auch die jeweiligen politischen Kulturen der Gegenwart noch sichtbar mitprägt - das gilt auch und gerade für die Inszenierung heroischer Figuren und Lebensentwürfe in Vergangenheit und Gegenwart - bewusst bleiben, können sie zu sinnvollen Formen des Zusammenlebens finden, und nicht, indem man an die Stelle dieser vielfältigen historischen Entwicklung 
die implizite oder explizite Verpflichtung zur selektiven oder auch vollständigen historischen Amnesie setzt, wie dies heute freilich gerade mit Blick auf die Epochen vor dem 20. Jahrhundert nicht unüblich geworden ist. Europa wird nur überleben können, wenn es seine in der Geschichte wurzelnde Vielfalt annimmt, nicht indem es sie verwirft.

Freiburg, im August 2015

Ronald G. Asch 


\section{Einleitung}

La démolition du héros est de toutes les époques ${ }^{1}$

Wir leben, das ist die vorherrschende Annahme, die einiges an Plausibilität für sich hat, in einem postheroischen Zeitalter - in der westlichen Welt im Allgemeinen und in Deutschland im Besonderen. ${ }^{2}$ Größe oder auch eine spezifische Form von Männlichkeit - zwar ist die Figur des Heros nicht notwendigerweise männlich, aber in der Vergangenheit wurde Männlichkeit doch sehr viel stärker auf klassische heroische Leitbilder bezogen als Weiblichkeit $-^{3}$ über eine heroische Lebenshaltung oder heroische Leistungen wie etwa die Bereitschaft zum Selbstopfer in einem Kampf gegen einen übermächtigen Gegner zu definieren, erscheint als Kennzeichen einer lange vergangenen Epoche. Diese Feststellung trifft freilich nicht in gleichem Umfang auf alle westlichen Länder zu. In Staaten wie Großbritannien oder den USA haben sich innerhalb einer auch dort eher postheroisch geprägten Zivilgesellschaft doch zumindest bestimmte Funktionseliten oder Gemeinschaften gehalten, deren heroisches Selbstbild sich an traditionellen Leitbildern wie dem des kriegerischen Helden orientiert. Diese sozialen Gruppen - man könnte hier an das Militär ebenso denken wie an die Feuerwehr - genießen durchaus öffentliche Anerkennung, sind keineswegs marginalisiert. Ein nochmals anderes Bild ergibt sich, wenn man auf das Bild von Helden in der Unterhaltungsindustrie von Filmen bis hin zu Computerspielen blickt. Die starke Präsenz von heroischen Figuren in diesen Medien ist zumindest in ihrer Auswirkung auf die Jugendkultur nicht zu unterschätzen. Dass das vorgebliche Feldgebrüll der Spartiaten bei den Thermopylen, wie es der Film „300“ (2007) in Szene setzte, von rechtsgerichteten Bewegungen in Deutschland und Österreich gelegentlich bei Demonstrationen gegen die vermeintlichen Feinde des Abendlandes imitiert wird, ist ein weiteres Beispiel für die residuale Attraktivität heroischer Verhaltensmuster in der westlichen Welt. ${ }^{4}$

1 „Die Zerstörung des Helden findet sich in allen Zeitaltern“, André Stegmann, L'ambiguïé du concept héroïque dans la littérature morale en France sous Louis XIII, in: Noémi Hepp / Georges Livet (Hrsg.), Héroisme et création littéraire sous les règnes d'Henri IV et de Louis XIII (Actes et colloques; 16), Paris 1974, S. 29-59, hier S. 30.

2 Siehe etwa Herfried Münkler, Heroische und postheroische Gesellschaften, in: Merkur 61, Heft 8/9, 2007, S. 742-752; vgl. Ute Frevert, Herren und Helden. Vom Aufstieg und Niedergang des Heroismus im 19. und 20. Jahrhundert, in: Richard van Dülmen (Hrsg.), Erfindung des Menschen. Schöpfungsträume und Körperbilder 1500-2000, Wien 1998, S. 323-346.

3 Siehe den Forschungsüberblick von Robert A. Nye, Western Masculinities in War and Peace, in: The American Historical Review 112, Heft 2, 2007, S. 417-438.

4 Zur Orientierung der sogenannten Identitären am Vorbild der Spartiaten siehe etwa Volker Weiss, Nicht links, nicht rechts, nur national, in: Die Zeit 13, 2013, http://www.zeit.de/ 2013/13/Die-Identitaeren, 1. August 2015. 
Man muss auch konstatieren, dass es trotz der mehr oder weniger deutlichen Ablehnung traditioneller Leitbilder des Heroischen doch durchaus eine gewisse öffentliche Debatte über Helden und Heroinen gibt, die in den letzten Jahren sogar an Intensität gewonnen hat. ${ }^{5}$ Zumindest Menschen, die ein ungewöhnlich hohes $\mathrm{Ma}$ an Zivilcourage zeigen und dafür Opfer bringen, eventuell sogar selbst ihr Leben opfern, können auch heute noch mit einer Bewunderung rechnen, die in der Vergangenheit traditionellen heroischen Figuren zukam, wobei auffällig ist, dass das Vorliegen gewisser äußerer Merkmale wie körperlicher Schönheit und Jugend die Heroisierbarkeit stets erleichtert, ganz so wie bei den klassischen Helden der Vergangenheit. ${ }^{6}$

Überdies erzwingt die Herausforderung durch fremde kulturelle und religiöse Traditionen wie den Islam in seinen militanteren Ausprägungen, denen das Ideal eines heroischen, bis zum Selbstopfer gehenden Kampfes keineswegs fremd geworden ist, eine Debatte über die politische und gesellschaftliche Rolle heroischer Leitbilder. ${ }^{7}$ Auch unabhängig von dieser besonderen Problematik gewinnt man den Eindruck, dass der Untergang des klassischen Helden eine psychologische Leerstelle hinterlassen hat, die nicht leicht durch andere Leitbilder oder Rollenmodelle zu füllen ist, namentlich für jüngere Männer, die nach Orientierung suchen in einer Epoche, in der traditionelle Vorstellungen von Männlichkeit problematisch geworden sind oder sogar offen tabuisiert werden.

Grundsätzlich kann aber kein Zweifel daran bestehen, dass in der Gegenwart in Westeuropa die Figur des Heros zumindest dann, wenn sie in der Tradition des kriegerischen Helden oder auch nur einer prononcierten agonalen Männlichkeit steht, durchweg eher kritisch gesehen wird. Das wird kaum verwundern können, denn die unterschiedlichen faschistischen Bewegungen der ersten Hälfte des

5 Ein hier - mehr oder weniger willkürlich gewähltes - Beispiel ist die Debatte darüber, ob der Whistleblower Snowden zu den eigentlichen Helden des 21. Jahrhunderts zu rechnen sei. Siehe http://www.faz.net/aktuell/feuilleton/medien/tv-kritik/in-der-ard-enzensbergerzu-snowden-ein-held-des-21-jahrhunderts-12537881.html, 20. Juli 2015. Zu vergleichen wäre die freilich unergiebig gebliebene Diskussion über „Das Heroische und die Moderne“ auf dem Historikertag 2014, http://www.br.de/fernsehen/ard-alpha/sendungen/alphacampus/auditorium/historikertag-heros-moderne100.html, 20. Juli 2015.

6 Dies zeigt etwa der Fall der Lehramtsstudentin Tuğçe Albayrak, die in Offenbach im November 2014 auf tragische Weise ums Leben kam. In den sozialen Medien wurde sie explizit als Heldin tituliert, vgl. http://web.de/magazine/panorama/tod-tugce-a-weckt-starke-gefuehlepsychologe-wunsch-heldin-30252014, 20. Juli 2015. Auffällig ist, dass Dominik Brunner, ein Mann, der nicht ganz den Glanz und die Aura der jungen Studentin besaß, aber in einer ähnlichen Situation 2009 zu Tode geprügelt wurde, von den Medien nach seinem Tod zum Teil als eher ambivalente Figur dargestellt wurde. Hier überwog dann doch die Tendenz, potenzielle Helden grundsätzlich zu deheroisieren. Einer Frau fällt es freilich auch leichter, zugleich Opfer und Heldin zu sein oder in diesen Rollen dargestellt zu werden. Vgl. http://www.welt.de/vermischtes/weltgeschehen/article8509029/Ist-Dominik-Brunner-jetztnoch-ein-Held.html, 20. Juli 2015, Datum des ursprünglichen Artikels 18. Juli 2010.

7 Vgl. Thomas Scheffler, Helden, Märtyrer, Selbstmordattentäter. Zur religiösen Semantik des Heldentods, in: Amr Hamzawy / Ferhad Ibrahim (Hrsg.), Religion, Staat und Politik im Vorderen Orient. Festschrift für Friedemann Büttner, Münster 2003, S. 88-109. 
20. Jahrhunderts hatten die heroische Geste und die heroische Lebenshaltung zum Selbstzweck erhoben. Der Kampf - auch bis zum Untergang - und die Gewalterfahrung wurden als ultimate experience, als Königsweg der Selbsterfahrung und der Selbstfindung angepriesen, eine Philosophie, die auch Schriftsteller mit einer Affinität zur Verherrlichung des Krieges und zum Faschismus propagierten. ${ }^{8}$ In welche Abgründe dieser nihilistische Heroismus des beständigen Kampfes führte, ist in den 30er und 40er Jahren des vergangenen Jahrhunderts nur allzu deutlich geworden und es ist daher verständlich, dass die Gegenwart viel eher im Opfer als im Helden ein moralisches Leitbild sieht, zumal auch die heroischen Gestalten des revolutionären Sozialismus ihre Strahlkraft spätestens seit den späten 1980er Jahren weitgehend verloren haben.

Die Priorität des Opfers gegenüber dem Helden in der Gegenwart wird auch in der wissenschaftlichen Literatur oft genug betont. Das gilt zum Beispiel für Bernhard Giesens soziologische Phänomenologie der Ausnahme, die im Helden den souveränen Täter schlechthin sieht, in dessen Leben und Taten die kollektiven Werte einer Gruppe ihren Ausdruck finden. Aber in der jüngsten Vergangenheit sei aus einem Vorbild, das von einer Verehrergemeinschaft konstruiert wird, der „dämonische[] Täter“ geworden, „dessen bloße Existenz ein Verbrechen darstellte“. ${ }^{9}$ Die moderne politische Ordnung lasse für ein heroisches Individuum, das dem Anspruch nach stets über dem Gesetz und dem Kanon der Regeln stünde, die für andere Menschen gelten, keinen wirklichen Raum mehr. Die Herrschaft von Geld, Wissenschaft und Recht verbannen nach Giesen den Helden bestenfalls in die Welt der reinen Fiktion, eine Fiktion, die anders als früher keine Relevanz mehr für die politische und soziale Wirklichkeit habe. ${ }^{10}$ Gleichzeitig entstehe aber in dieser neuen Welt objektiver überpersönlicher Ordnungen eine moralische Affinität der Gesellschaft zu jenen, die stets den Gegenpol zu den heroischen Figuren gebildet hätten, zu den Opfern, also zu Menschen, die, so Giesen, anders als die Helden weder eine individuelle Stimme, noch ein Gesicht hätten und auch keinen spezifischen Ort, der an sie als Individuen erinnere.

Dieser von Giesen konstruierte radikale Gegensatz zwischen dem Helden als dem Täter, der die Souveränität des Individuums verkörpere, und dem gesichtslosen, gänzlich passiven Opfer orientiert sich allerdings, so scheint es, stark an

8 Yuval N. Harari, The Ultimate Experience. Battlefield Revelations and the Making of Modern War Culture 1450-2000, Basingstoke 2008, S. 240-298. Als eine von vielen Publikationen zum Faschismus sei hier nur genannt Sven Reichardt, Faschistische Kampfbünde. Gewalt und Gemeinschaft im italienischen Squadrismus und in der deutschen SA (Industrielle Welt; 63), Köln 2002.

9 Bernhard Giesen, Zwischenlagen. Das Außerordentliche als Grund der sozialen Wirklichkeit, Weilerswist 2010, S. 82; vgl. Ders. Triumph and Trauma (The Yale Cultural Sociology Series), Boulder, CO 2004, S. 15-44.

10 Vgl. Giesen, Triumph and Trauma, S. 41-42. Hier lehnt sich Giesen allerdings an Thesen an, die schon Hegel zu Beginn des 19. Jahrhunderts formuliert hatte; Georg Friedrich Wilhelm Hegel, Vorlesungen über die Ästhetik, Bd. 1, hrsg. von Eva Moldenhauer und Karl M. Michel, Frankfurt am Main 1970, S. 243-245. 
der deutschen Geschichte des 20. Jahrhunderts und letztlich sogar am Massenmord und Genozid, die zum historischen Trauma Deutschlands geworden sind. In früheren Epochen konnte gerade auch der Märtyrer zum Helden werden, der durch seinen Tod und durch sein Leiden zur Tat und zum Kampf aufrief, ja unter Umständen eine bestehende politische Ordnung delegitimierte. Dieses Potenzial haben Märtyrer sicherlich auch heute noch, nur dass zumindest im europäischchristlichen Kulturkreis die Skepsis gegenüber einer solchen Deutung des Martyriums größer geworden ist als früher, gerade weil der Weg von der Trauer über das Opfer zur Wut gegen die Täter und damit auch zu neuen Gewalttaten oft kurz ist. Es ist bezeichnend, dass der Trappistenprior Christan de Chergé, der zusammen mit seinen Mitbrüdern 1996 in Algerien ermordet wurde - ob von der Armee oder von islamischen Fundamentalisten, das ist bis heute unklar -, es gerade vermeiden wollte, als christlicher Märtyrer im Kampf gegen den Islam zu gelten, obwohl er den Weg in den Tod bewusst ging. ${ }^{11}$

Es bleibt die Erkenntnis, dass sich namentlich in Europa moderne Gesellschaften mit der Verehrung der Opfer, wie immer man sie im Einzelnen definieren mag, leichter tun als mit der Verehrung von Helden, die selbst dann, wenn es sich nicht um klassische Gestalten des agonalen Kampfes oder gar der gewaltsamen, kriegerischen Auseinandersetzung handelt, doch im gesellschaftlichen Diskurs rasch demontiert und entzaubert werden können, da in der modernen Medienwelt die notwendige Distanz zu einer Figur, die Anspruch auf Bewunderung erhebt, nicht mehr aufrechterhalten werden kann. Die Betrachtung aus der Nähe hat dem Helden und seiner Aura immer schon geschadet. Im Gegensatz dazu lassen sich Opfer heute deutlich leichter als Helden oder Heldinnen so darstellen, dass ihnen dauerhaft Anerkennung und Respekt zuteilwerden. Dies ist ein Aspekt, der auch von anderen Autoren wie Jean-Marie Apostolidès betont worden ist, der diese Analyse mit einer umfassenden kulturpessimistischen Kritik am Opferkult der Gegenwart verbindet. Für die Anhänger dieser uneingeschränkten Verehrung der Opfer der Geschichte bestehe die Vergangenheit, so Apostolidès, eigentlich nur aus Eroberungen und Gewalttaten, identitätskonstituierend in einem positiven Sinne könne sie nie sein. Und dort, wo die Figur des Helden im Zentrum eines Netzes symbolischer Beziehungen stand, die dem Heros Macht über die anderen Menschen verliehen, beruhe die culture de la victimatisation auf dem Prinzip der Gleichheit aller Mitglieder einer Gemeinschaft. Während in den heroischen Gemeinschaften und Gesellschaften der Vergangenheit das Blut die Menschen verbunden habe - denn der Heros sei derjenige, der Blut vergieße, das eigene oder fremde - würden heutige Gesellschaften durch Tränen und nicht durch Blut zusammengehalten: „Le liquide unissant les individus entre eux n'est plus le sang mais les larmes. Il faut

11 Den Hinweis auf diese Haltung de Chergés verdanke ich dem Nachwort zu David El Kenz, Les bûchers du roi. La culture Protestante des martyrs 1523-1572 (Époques), Seyssel 1997, S. 235 und dem Film „Des hommes et des dieux“ von Xavier Beauvois (2010). 
pleurer pour montrer son adhésion aux valeurs de la fratrie. Verser des larmes, être contrit, avoir pitié, [...] devient un devoir civique“. ${ }^{12}$ Das mag polemisch stark zugespitzt, ja überspitzt sein, aber kein Zweifel kann daran bestehen, dass unsere Kultur mit Opfern anders und affirmativer umgeht als mit Helden.

Den Opfern kommt nicht zuletzt zugute, dass sie der Tendenz der modernen Kultur- und Sozialwissenschaften, alle sozialen Phänomene von gemeinsamen Identitäten bis hin zum Unterschied zwischen den Geschlechtern ausschließlich als bloße Konstruktionen ohne jedes Fundament in einer Realität außerhalb der Welt symbolischer Kommunikation zu interpretieren, bislang weitgehend entgangen sind. Das Charisma einer heroischen Figur, wie immer man sie im Einzelnen bewertet, kann leicht als bloße Zuschreibung von außen charakterisiert werden, die Eigenschaft, Opfer eines politischen Gewaltverbrechens oder gar eines Genozids zu sein, auch so zu deuten, stößt zu Recht auf schärfste Abwehr außer vielleicht bei den Tätern oder denen, die sich in ihrer Tradition sehen und man gerät hier rasch in ein politisches Minenfeld. Hier halten sich die Anwälte einer postmodernen Dekonstruktion jeglicher Wirklichkeit dann auch in der Regel eher zurück. Ob im Übrigen ein derart konstruktivistischer Ansatz, der voraussetzt, dass der Mensch seine Geschichte (im Sinne von historischer Erinnerung) in freier Entscheidung einfach nach seinem Geschmack macht, ja im Grunde genommen erfinden und dann eben auch wieder verwerfen kann, der Wirkmacht heroischer Gestalten wirklich gerecht wird, sei dahingestellt. Ist die Heroisierung einer historischen Figur - die oft auch eine Selbstheroisierung oder sogar Selbstmythisierung sein kann - einmal gelungen, wird sie selbst zum Teil der Wirklichkeit. ${ }^{13}$ Man kann sich der Wirkung eines solchen Mythos dann nicht mehr ohne weiteres entziehen, es sei denn die kulturellen und politischen Rahmenbedingungen wandeln sich wirklich so tiefgreifend, dass die Vergangenheit ihre Relevanz für die Gegenwart verliert.

Ein solcher Zustand mag heute im 21. Jahrhundert, so könnte es zumindest bei oberflächlicher Betrachtung besonders aus einer deutschen Perspektive scheinen, eingetreten sein und angesichts dieser Konstellation stellt sich die Frage, ob der Niedergang des Helden (oder der Heldin) und die Verbannung solcher Figuren in das Reich der Fiktion und der reinen Unterhaltung, vom Film bis hin zum Com-

12 Jean-Marie Apostolidès, Héroïsme et victimisation. Une histoire de la sensibilité, Paris 2003, S. 192-194, „Die Flüssigkeit, welche die Individuen miteinander verbindet, ist nicht mehr das Blut, es sind die Tränen. Man muss weinen, um seine Verbundenheit mit den Werten der brüderlichen Gemeinschaft zu zeigen. Tränen zu vergießen, zerknirscht zu sein, Mitleid zu haben, [...] all das wird zu einer bürgerlichen Pflicht“.

$13 \mathrm{Zu}$ diesem Phänomen: Hans Blumenberg, Präfiguration. Arbeit am politischen Mythos, Berlin 2014, und Ders., Arbeit am Mythos, Frankfurt am Main 1979. Blumenberg kommt sogar zur Feststellung: „In der Präfiguration geht die Mythisierung an die Grenze der Magie heran oder überschreitet diese gar, sobald mit dem ausdrücklichen Akt der Wiederholung eines Präfigurats die Erwartung der Herstellung des identischen Effekts verbunden wird“, Blumenberg, Präfiguration, S. 9. 
puterspiel, in der modernen westlichen Welt nicht ganz folgerichtig ist? Was kann die moderne oder gar die postmoderne Welt noch mit Helden anfangen? Auf diese Frage hat in den 1970er Jahren der Berliner Religionswissenschaftler Klaus Heinrich in bewusster Auseinandersetzung mit dem Missbrauch des heroischen Leitbildes durch den Faschismus und einen übersteigerten Nationalismus versucht, eine Antwort zu finden. Heinrich sieht das Spezifische des Heros darin, dass er eine Spannung zwischen Kräften auszuhalten vermag, die durch ratio und logos gerade nicht miteinander zu versöhnen sind. In der Figur des Heros, seinem Bild und der ihm zugeschriebenen Biographie werden Konflikte eingehegt und lebbar gemacht, die sich sonst der Beherrschung entziehen würden und sich jedenfalls nicht logisch auflösen lassen. ${ }^{14}$ Allzu rationalistische oder auch konsequent christliche Entwürfe des Heroischen verfehlen hingegen nach Heinrich den Kern der heroischen Figur. Sie versuchten, die Kräfte der Natur so stark zu spiritualisieren und zu sublimieren und setzten so stark auf den logos statt auf Tat und Geste, dass man sich damit „der Fähigkeit des Zugriffs auf die Naturmächte" begebe. ${ }^{15}$

Diese Interpretation orientiert sich zwar sehr spezifisch an der Figur des Herakles, der in der antiken Mythologie zugleich Zivilisationsbringer und Zerstörer ist, trifft aber doch einen Kern jener heroischen Leitbilder und Heldenfiguren, die zumindest in der von der Antike beeinflussten europäischen Tradition maßgeblich waren. Einerseits verkörperten sie die zentralen Werte einer größeren Gemeinschaft, ja vielleicht einer ganzen Gesellschaft, andererseits war das Heroische doch immer auch mit einem Element der Transgressivität, des Überschreitens von Grenzen und Normen verbunden, wie es ja auch Bernhard Giesen in seiner Phänomenologie des Heroischen betont. Sonst wäre der Held keine Ausnahmefigur, die alle anderen Menschen überragt. Dies ist ein Punkt, der schon im 17. Jahrhundert in einschlägigen Werken betont wurde. So hob der französische Jesuit Pierre Le Moyne in der Vorrede zu seinem poème héroïque auf Ludwig den Heiligen hervor, dass Helden ohne ein Übermaß an Leidenschaft, quasi „brave Stoiker“, nicht mehr seien als „mit Eisen beschlagene Holzblöcke“. ${ }^{16}$ Gerade die Jesuiten traten in der Frühen Neuzeit für ein Ideal der heroischen Heiligkeit ein, dessen Fundament nicht die gänzliche Überwindung und Negation

14 Siehe dazu Klaus Heinrich, Arbeiten mit Herakles. Zur Figur und zum Problem des Heros. Antike und moderne Formen seiner Interpretation und Instrumentalisierung (Dahlemer Vorlesungen; 9), Frankfurt am Main 2006, S. 7, vgl. S. 208-211, S. 218, S. 285-286, S. 307.

Ebd., S. 319, vgl. den Satz: „Daß Herakles widersprüchliche Funktionen, Positionen und Rollen zugemutet werden, und er dennoch diese eine Figur bleibt, zeigt, daß in ihm ein Konfliktzusammenhang, den er halten soll, vorgestellt wird [...]. Wenn die Beschäftigung mit der Figur des Heros einen Sinn haben soll, dann den, daß das in ihr konzentrierte, scheinbar zeitlich entfernte Konfliktpotential als noch immer virulent erkannt [...] werden kann“, ebd., S. 208-209.

16 Pierre Le Moyne, Preface. Saint Louys ou la sainte couronne reconquise, Poëme herö̈que, Paris 1658, sign. $\mathrm{O}$ vi verso, siehe auch $\mathrm{O}$ ii verso. 
menschlicher Leidenschaft war, sondern ihre Zähmung, so dass sie in den Dienst einer heroischen Tugend, einer heroica virtus, gestellt werden konnte. ${ }^{17}$

Als Helden bewunderte oder verehrte historische oder fiktive Personen sind oft Gestalten, die zugleich an der Grenze einer Gesellschaft stehen und ihre Normen überschreiten und doch zugleich ihre wesentlichen Werte zur Anschauung bringen und verkörpern. ${ }^{18}$ Das Spannungsverhältnis, das sich aus dieser doppelten Positionierung der heroischen Figur ergab, wurde durchaus schon vor der oft beschworenen Entzauberung der Welt durch Säkularisierung, Technisierung und Rationalisierung als problematisch empfunden. Die Kritik an der Maßlosigkeit des Helden, seinem Narzissmus, ${ }^{19}$ findet sich, wie ja auch das Zitat hervorhebt, das dieser Einleitung vorangestellt ist, auch in der Epoche und in dem Land, in dem Corneille seine heroischen Tragödien schrieb. ${ }^{20}$

Die Destruktion des Helden durch Kritik oder auch durch Ironie und Satire ist von daher in der Tat ein in allen Zeiten gegenwärtiges Problem und keineswegs grundsätzlich auf das späte 20. und das 21. Jahrhundert beschränkt. Dennoch war die Epoche zwischen dem Ende der Französischen Religionskriege und der Mitte des 18. Jahrhunderts, um die es in diesem Essay zentral gehen soll, eine Zeit, in der eine Orientierung der Gesellschaft oder zumindest ihrer Eliten am Ideal des Heroischen noch eine umfassende normative Geltung für sich beanspruchen konnte, die ihr im Zeitalter der Aufklärung zunehmend verloren ging. Die politisch-sozialen Eliten handelten ihre Werte und Normen über einen Diskurs aus, in dessen Mittelpunkt der Held und der heroische Lebensentwurf standen. Der Held, ob nun im Einzelfall kontrovers oder allgemein anerkannt, gehörte unbestreitbar zum imaginaire der Gesellschaft. Er ist ein Beispiel für die Produktion kultureller Ordnungen und Wahrnehmungsmuster durch prägnante Figuren, die als kulturelle „Überlieferungsträger“ fungieren, aber auch der Selbstbeschreibung einer Gesellschaft dienen. ${ }^{21}$ Ihre Taten und ihr Leben, soweit sie der Geschichte oder dem Mythos angehören, können zugleich als normative Präfiguration der

17 Marc Fumaroli, L'héroïsme cornélien et l'éthique de la magnamité, in: Marc Fumaroli (Hrsg.), Héros et orateurs. Rhétorique et dramaturgie cornéliennes (Histoire des idées et critique littéraire; 277), Genf 1996, S. 323-348, hier S. 329-337. Siehe S. 8.

18 Vgl. zur Figur des Helden und seiner Definition auch Ronald G. Asch, The Hero in the Early Modern Period and Beyond. An Elusive Cultural Construct and an Indispensable Focus of Social Identity?, in: helden. heroes. héros. E-Journal on Cultures of the Heroic, Special Issue 1, 2014, S. 5-14, DOI 10.6094/helden.heroes.heros./2014/QM/02.

19 Vgl. Jan Philipp Reemtsma, Der Held, das Ich und das Wir, in: Mittelweg 36, Heft 4, 2009 , S. 41-64, http://www.his-online.de//fileadmin/verlag/leseproben/978-3-93609-645-3_01.pdf, 20. Juli 2015.

20 Vgl. zu entsprechenden Konflikten in England Joshua Scodel, Excess and the Mean in Early Modern English Literature (Literature in History), Princeton, NJ 2002.

21 Joel B. Lande / Robert Suter, Einleitung, in: Joel B. Lande [et al.] (Hrsg.), Dynamische Figuren. Gestalten der Zeit im Barock (Rombach-Wissenschaften / Reihe Litterae; 192), Freiburg 2013, S. 9-25, hier S. 10. 
Gegenwart gedeutet werden. Der Bezug auf den Helden als eine besonders prägnante Figur kann dabei zu einem ,singuläre[n] Instrument der Rechtfertigung in schwach begründeten Handlungssituationen" werden, um hier Hans Blumenberg zu zitieren. Ja, es kann „im Maße ihrer Prägnanz“ schwierig werden, „die Bezugsfigur in sachlich nicht abgestützten Entscheidungssituationen ungenutzt liegen zu lassen, schon deshalb [...], weil sie potenziell immer auch anderen zur Verfügung steht". 22 Blumenberg denkt hier an Gestalten wie Alexander den Großen oder Friedrich II., den Stauferkaiser, aber auch an Napoleon, der freilich seine eigene Selbstdarstellung schon an solchen Präfigurationen orientierte.

Für die Herrscher des 17. Jahrhunderts war der Bezug auf solche Präfigurate eine Selbstverständlichkeit und ein fester Bestandteil der höfischen Kultur und der politischen Legitimation. Noch war es für Fürsten, die sich in Gestalt der Helden (und Heldinnen) der antiken Mythologie, der Bibel oder auch der römischen und griechischen Geschichte darstellen ließen, möglich, in den Augen ihrer Untertanen und des Publikums die Züge dieser Helden anzunehmen, ohne dass dies nur wie eine billige theatralische Inszenierung wirkte. ${ }^{23}$ Allerdings wurden hier, das ist nicht zu leugnen, bereits Krisensymptome sichtbar. Immer mehr wurde in der staatstheoretischen Literatur der Zeit, etwa auch in Abhandlungen über die Staatsräson oder den idealen Herrscher, die Notwendigkeit für den Fürsten betont, eine heroische Reputation zu erwerben. Als ein Königsweg zu einer solchen Reputation wurde die Inszenierung der Herrschaft des Monarchen als Geheimnis gesehen, denn wirkliche heroische Größe, die Bewunderung erzwang, war, so schien es, nur möglich, wenn die arcana imperii den Blicken der Untertanen entzogen blieben und nur erahnt werden konnten. ${ }^{24}$ Indes, dieses Insistieren auf dem zur Schau gestellten Geheimnis der Macht drohte selbst wieder ein Glaubwürdigkeitsproblem zu schaffen - oder wie es Martin Disselkamp in seiner grundlegenden Arbeit zum Barockheroismus formuliert hat:

„Die Kunst der Mystifikation hat jedenfalls ihre eigene Dialektik: Gerade das Vorweisen des fürstlichen Mysteriums läßt auf der anderen Seite die Inszenierungstaktik immer unverhüllter sichtbar werden. [...] Indirekt darf man deshalb die Theatralik fürstlicher Größe überhaupt als Signal für die Auflösung durch die Tradition verbürgter Orientierungspunkte in der Politik bewerten“ ${ }^{25}$

22 Blumenberg, Präfiguration, S. 14.

Siehe dazu etwa Friedrich Polleroß, From the "exemplum virtutis" to the Apotheosis. Hercules as an Identification Figure in Portraiture. An Example of the Adoption of Classical Forms of Representation, in: Allan Ellenius (Hrsg.), Iconography, Propaganda, and Legitimation (The Origins of the Modern State in Europe; G), Oxford 1998, S. 37-62.

$24 \mathrm{Zu}$ diesem Phänomen siehe auch Andreas Gestrich, Absolutismus und Öffentlichkeit. Politische Kommunikation in Deutschland zu Beginn des 18. Jahrhunderts (Kritische Studien zur Geschichtswissenschaft; 103), Göttingen 1994, S. 34-74.

25 Martin Disselkamp, Barockheroismus. Konzeptionen „politischer“ Größe in Literatur und Traktatistik des 17. Jahrhunderts (Frühe Neuzeit; 65), Tübingen 2002, S. 221. 
Der theatralische Aufwand, der betrieben werden musste, um einem Herrscher heroische Größe zuzusprechen, stieg praktisch in dem Maße, wie der Verlust an Glaubwürdigkeit einer solchen Inszenierung größer zu werden drohte. ${ }^{26}$

Allerdings, so sehr die heroische Geste des Herrschers, aber auch des Heerführers oder des Kriegers, sich durch ihre eigene Theatralik unglaubwürdig zu machen drohte, so sehr galt es andererseits im 16. und 17. Jahrhundert noch als weithin selbstverständlich, dass die heroische Reputation - mit der Ausnahme der Sphäre des Religiösen und des konfessionellen Kampfes - vor allem ein Privileg der Fürsten und des Adels war. Grundlegend war die Vorstellung, es gäbe eine natürliche Ordnung der Gesellschaft, in der eine Aristokratie, die sich durch Großzügigkeit, Edelmut (générosité) und Seelengröße auszeichne, dazu berufen sei, die Welt durch ihre Tatkraft, ihren Mut, aber auch durch ihre Fähigkeit zu dominieren, aus dem eigenen Leben eine Art ästhetisches Kunstwerk werden zu lassen. Sicherlich gab es namentlich in Krisenzeiten auch eine dezidierte Adelskritik, nicht zuletzt, insbesondere im Protestantismus, von kirchlicher Seite und bisweilen von Seiten der humanistischen Gelehrten, aber in der Praxis wurde die Herrschaft einer adligen Elite, die eben diese heroischen Eigenschaften für sich in Anspruch nahm, kaum ernsthaft, außer vielleicht aus der Perspektive eines konfessionellen Rigorismus, infrage gestellt. Das galt selbst im England der 1640er und 1650er Jahre während des Bürgerkrieges und der anschließenden republikanischen Herrschaft mit gewissen Einschränkungen, denn die bestehende soziale Ordnung stand nie ernsthaft zur Diskussion. ${ }^{27}$

Nun gibt es natürlich auch in demokratischen Gesellschaften eine Sehnsucht nach Helden oder Heldinnen, aber die radikale Ungleichheit, welche die Vorstellung, jemand könne zum Helden geboren sein, voraussetzt, wird doch in der Regel negiert. In diesem Punkt ist Jean-Marie Apostolidès recht zu geben. In einer egalitären Gesellschaft ist der Held daher noch stärker eine Ausnahmeerscheinung mit transgressiven Zügen als in einer aristokratischen. ${ }^{28}$ Dort, wo es sich um demokratisch gewählte Amtsinhaber oder die Feldherren einer Republik handelt, ist die Heroisierung allenfalls dann mit der politischen Kultur der Demokratie vereinbar, wenn der Held, nachdem er seine Taten vollbracht hat, gänzlich zurück in die Gemeinschaft der Bürger tritt, wie es in der Antike von römischen Konsuln oder selbst Diktatoren (im Sinne des Staatsrechtes der römischen Republik) erwartet wurde und von amerikanischen Präsidenten seit der Amtszeit George Washingtons immer noch erwartet wird, gerade weil sie zugleich als Ver-

26 Vgl. ebd., S. 21-22.

27 Zur Selbstbehauptung des Adels in der frühen Neuzeit siehe Ronald G. Asch, Europäischer Adel in der frühen Neuzeit. Eine Einführung, Köln [u.a.] 2008.

28 David R. Sorensen, Introduction, in: David R. Sorensen / Brent E. Kinser (Hrsg.), Thomas Carlyle. On Heroes, Hero-Worship and the Heroic in History (Rethinking the Western Tradition), New Haven, CT 2013, S. 1-16, hier S. 2-3; vgl. Lucy Hughes-Hallett, Heroes. Saviours, Traitors and Supermen, London 2005. 
körperung bürgerlicher Tugend fast von Amts wegen heroisiert werden. In den neu begründeten USA verstand sich das Urmodell für diese Art von Bürgerheld, Washington, selbst allerdings durchaus noch als Mitglied einer Elite von gentlemen, deren Sinn für Ehre und deren Sehnsucht nach überzeitlichem Ruhm er teilte. ${ }^{29}$

Sonst dominieren in demokratischen Epochen unter Umständen Vorstellungen eines kollektiven Heldentums - die gesamte Nation wird potenziell heroisiert oder wird doch dazu aufgerufen, sich an einem heroischen Leitbild zu orientieren oder aber der Held wird als Produkt außerordentlicher Herausforderungen und Umstände, also einer zumindest in Teilen kontingenten Biographie, gesehen, aber nicht oder nicht primär einer natürlichen Überlegenheit. Überdies gerät die Aura des Helden in Gefahr, durch den skeptischen Blick aus der Nähe geschwächt zu werden, wenn der Nimbus einer wie immer definierten Aristokratie, sei es der Herkunft und des Standes oder aber des Geistes und Charakters und ihrer natürlichen Überlegenheit, einmal zerstört ist. ${ }^{30}$ Moderne celebrities, Berühmtheiten und Stars sind deshalb meist kurzlebige Erscheinungen, weil ihre Popularität und Faszination oft gerade darauf beruht, dass ihre Verehrergemeinde ihnen nahezukommen vermag, obwohl diese Nähe oft bloß eine medial inszenierte ist. Aber auch so zerstört der Blick aus der Nähe die Aura des Bewunderten auf Dauer, der freilich heutzutage in der Regel auch gar nicht mehr wirklich den Ruhm in der Nachwelt, sondern Berühmtheit im Hier und Jetzt sucht.

Die Anfänge eines Wandels, der Popularität und Berühmtheit an die Stelle der Idee des Ruhmes treten ließ, liegen ohne Zweifel, das hat Antoine Lilti jüngst gezeigt, im 18. Jahrhundert, auch wenn die Entwicklung keineswegs gradlinig verlief und Elemente einer älteren Tradition lange eine erhebliche Bedeutung behielten. ${ }^{31}$ Der grand homme, dem die transgressiven Züge des Helden, sein Narzissmus, seine Ruhmsucht und seine Maßlosigkeit, sei es in der Anwendung von Gewalt oder im Ausleben der eigenen Leidenschaften, fehlten, ersetzte im 18. Jahrhundert das Bild des traditionellen Helden zwar nicht durchweg, überlagerte es aber doch. ${ }^{32}$ Überdies wurde nun auch erstmals auf breiter Front das Ideal eines postaristokratischen Helden, der auch ein normaler Bürger sein konnte,

29 Antoine Lilti, Figures publiques. L’Invention de la célébrité 1750-1850, Paris 2014, S. 264280; vgl. Michael Butter, Cincinnatus Popularized. The Heroization of William Henry Harrison during the Election Campaign of 1840, in: helden. heroes. héros. E-Journal zu Kulturen des Heroischen 2, Heft 1, 2014, S. 16-28, DOI 10.6094/helden.heroes.heros./ 2014/01/03.

30 Lucien Braun, Polysémie du concept de héros, in: Noémi Hepp / Georges Livet (Hrsg.), Héroisme et création littéraire sous les règnes d'Henri IV et de Louis XIII (Actes et colloques; 16), Paris 1974, S. 19-28, hier S. 23: „Tout récit héroïque implique une telle distanciation, tant il est vrai qu'il n'y a pas de héros dans la proximité".

31 Lilti, Figures publiques, S. 123-153.

32 Siehe S. 119-120. 
propagiert. Zugleich sprach das Zeitalter der Aufklärung zunehmend auch dem einfachen Soldaten die potenzielle Heroisierbarkeit zu. ${ }^{33}$

In einer Epoche, in der Ehre so vielfältig ständisch abgestuft blieb, wie in der Frühen Neuzeit, konnten derartige egalisierende Tendenzen zunächst allenfalls in einem primär religiösen Kontext wirksam werden, wie das in England freilich in den 1640er und 1650er Jahren zum Teil auch geschah. Auch deshalb ist das 17. Jahrhundert wohl die letzte Epoche des klassischen, eben des aristokratischen Helden und verdient unser Interesse, weil die Umdeutung des Heros und des Heroischen in der Aufklärung nur vor diesem Hintergrund in ihrer ganzen Tragweite verstehbar wird. Zugleich griffen spätere Entwürfe des Heroischen lange Zeit auf die alteuropäischen Traditionen der Antike und des Mittelalters, aber eben auch der Frühen Neuzeit zurück. Das galt für die Heroisierung von Herrschern und von Politikern ebenso wie für den Bereich des Militärischen. Aber auch andere Leitbilder des Heroischen wie das des Entdeckers oder des Retters in der Gefahr bis hin zu Freiheitshelden und -heldinnen blieben zumindest im Ansatz oft noch einer gewissen, allerdings ständisch entgrenzten Idee von Adeligkeit verbunden. ${ }^{34}$ Namentlich die Idee des heldenhaften Ritters übte auch im 19. Jahrhundert eine große Faszination aus, das galt selbst für den kolonialen Bereich. Sir James Outram, einer der ,Helden` der 1857 niedergeschlagenen Great Mutiny in Indien, führte zum Beispiel stets eine Ausgabe des Lebens von Bayard, des ,edlen Ritters' schlechthin, sowie der Chroniken Froissarts mit sich. Sein Grabmal in der Westminster Abbey trägt die Aufschrift „The Bayard of India“. ${ }^{35}$

Aber auch über den kolonialen Bereich und das 19. Jahrhundert hinaus behielt die Idee einer exklusiven heroischen Gemeinschaft eine gewisse faszinierende Kraft, gerade als Gegengewicht zu den egalisierenden Tendenzen der modernen Gesellschaft. Im frühen 20. Jahrhundert versuchten in Deutschland Autoren wie Walther Rathenau oder Coudenhove-Kalergi, aber auch der Denker der Konservativen Revolution, Edgar Jung, eine neue Elite zu konzipieren, die einen aristokratischen Anspruch auf Überlegenheit mit einer heroischen Lebenshaltung

33 Siehe etwa Hervé Drévillon, Secondary Heroes. War and the Making of the Individual in Eighteenth-Century France, erscheint in: Markus Menmann (Hrsg.), The Military in the Early Modern World. A Comparative Approach, Münster 2016; Jay M. Smith, Nobility Reimagined. The Patriotic Nation in Eighteenth-Century France (Cornell paperbacks), Ithaca, NY 2005, S. 143-156.

34 Zur Neudefinition von Adel im 19. Jahrhundert siehe etwa Ewald Frie, Adelsgeschichte des 19. Jahrhunderts? Eine Skizze, in: Geschichte und Gesellschaft 33, Heft 3, 2007, S. 398415; vgl. Heinz Reif, Der Adel im „langen 19. Jahrhundert“. Alte und neue Wege der Adelsforschung, in: Gabriele B. Clemens [et al.] (Hrsg.), Hochkultur als Herrschaftselement. Italienischer und deutscher Adel im langen 19. Jahrhundert (Villa Vigoni; 25), Berlin 2011, S. 19-37.

35 John McKenzie (Hrsg.), Popular Imperialism and the Military 1850-1950 (Studies in Imperialism), Manchester 1992; Ders., Heroic Myths of Empire, in: John McKenzie (Hrsg.), Popular Imperialism and the Military 1850-1950 (Studies in Imperialism), Manchester 1992, S. 109-138, hier besonders S. 177. 
verband, ob nun als „Mutmensch“ wie bei Rathenau oder in eher sublimierter Form, die dem gentleman den Vorzug vor dem reinen Tatmenschen gab. ${ }^{36} \mathrm{Zu}$ denken wäre aber in Deutschland auch an den George-Kreis, für den die Verehrung heroischer Gestalten in dem Bemühen, ihnen nachzueifern und sich von einer vulgären Welt abzusetzen, geradezu konstitutiv war. ${ }^{37}$

Die Geschichte mag aus heutiger Sicht über diese Versuche hinweggegangen sein, aber sie zeigen, welche Faszination ältere heroische Traditionen auch noch in einem bürgerlichen Zeitalter auszuüben vermochten. Seit der Aufklärung und der Französischen Revolution, noch mehr aber seit der Mitte des 20. Jahrhunderts, ist das Verhältnis zu Helden allerdings ein zutiefst gespaltenes:

„We all have a problem with heroes. We want them so badly that we keep inventing new ones, and yet our political culture tells us that naturally exceptional individuals should not be either possible or desirable, because we are all equal and equally the products of our environment". 38

Zugleich ist das traditionelle Vokabular der Heroisierung, das die antike Mythologie und Geschichte, aber auch die Bibel bereitstellten, weitgehend verloren gegangen, und umstritten sind nun nicht mehr nur die Helden oder Heldinnen selbst, sondern auch die Modelle, an denen Helden überhaupt gemessen werden. Schon im Laufe des 18. und 19. Jahrhunderts kam es zu einer Pluralisierung dieser Modelle, die nun auch Erfinder und Wissenschaftler ebenso wie Künstler und Helden des Alltags einschloss. Dazu traten dann stärker als in der Vergangenheit, die freilich auch ihre femmes fortes, ihre Amazonen und heroischen Herrscherinnen gekannt hatte, auch Frauen.

Die hier angedeuteten Entwicklungen sind in England und Frankreich, die eben deshalb den Gegenstand dieses Essays bilden, in vielen Aspekten deutlicher und früher zu erkennen als in anderen Ländern Europas. In Frankreich erreichte die Heroisierung und Glorifizierung des Monarchen unter Ludwig XIV. Ausmaße wie kaum je zuvor. Der König okkupierte nun, auch und gerade auf Kosten des Adels, die Figur des Heros für sich allein, so zumindest mochte es scheinen. Die Ablehnung der Figur des traditionellen kriegerischen Helden, die schon Fénelon,

36 Vgl. Alexandra Gerstner, Neuer Adel. Aristokratische Elitenkonzeptionen zwischen Jahrhundertwende und Nationalsozialismus, Darmstadt 2008, S. 240-248, S. 251-254.

37 Siehe dazu unter anderem Melissa S. Lane / Martin A. Ruehl (Hrsg.), A Poet's Reich. Politics and Culture in the George Circle (Studies in German Literature, Linguistics, and Culture), Rochester, NY 2011; vgl. Jan Steinhaußen, ,Aristokraten aus Not' und ihre ,Philosophie der zu hoch hängenden Trauben'. Nietzsche-Rezeption und literarische Produktion von Homosexuellen in den ersten Jahrzehnten des 20. Jahrhunderts. Thomas Mann, Stefan George, Ernst Bertram, Hugo von Hofmannsthal u.a. (Epistemata; 326), Würzburg 2001, S. 270. Vgl. Ann-Christin Bolay, Maximin und Cäsar. Adorationsmodelle im Stefan George-Kreis, in: Ronald G. Asch / Michael Butter (Hrsg.), Bewunderer, Verehrer, Zuschauer: Die Helden und ihr Publikum (Helden - Heroisierungen - Heroismen; 2), Würzburg 2015.

38 Colin Burrow, "They make things happen", Rezension: Lucy Hughes-Hallett, Heroes. Saviours, Traitors and Supermen, London 2004, http://www.theguardian.com/books/2004/ oct/09/highereducation.biography, 6. Dezember 2014. 
Erzbischof von Cambrai und Tutor des französischen Thronfolgers, 1699 in seinem „Télémaque“ antizipiert hatte, ${ }^{39}$ durch die französische Aufklärung lässt sich auch als Reaktion auf den Kult eines Monarchen verstehen, der sich ganz dem Ruhm und dem Krieg als vornehmster Aufgabe eines Herrschers verschrieben hatte. In England war es schon Jahrzehnte zuvor zu einem politischen Umbruch gekommen, der dem Königtum die sakralen Fundamente seiner Legitimation entzogen und an die Stelle der Monarchie - erstmals im Europa der Neuzeit eine Form des Cäsarismus gesetzt hatte, die sich wesentlich auch über die Reputation Oliver Cromwells, des neuen Herrschers, als Kriegsheld legitimierte. Cromwell mag ein zögerlicher Cäsar gewesen sein, aber er antizipierte mit seiner Form von heroischer Herrschaft doch zahlreiche revolutionäre, postrevolutionäre und kontrarevolutionäre Regime des 19. und 20. Jahrhunderts. Zugleich gewann seine Herrschaft jedoch Legitimität, indem sie beanspruchte, sich in einen quasi heilsgeschichtlichen Kontext einschreiben zu können, und sich als Instrument der göttlichen Vorsehung darstellte. ${ }^{40}$

Religiöse Helden und Heldinnen, ob sie nun in Gestalt des Propheten, des Märtyrers oder des Heiligen Kriegers auftraten, stellten für die politische Ordnung der dynastischen Erbmonarchie im Zeitalter der Konfessionskriege tatsächlich eine gefährliche Herausforderung dar und konnten eine erhebliche subversive Kraft entfalten. Das 17. Jahrhundert ist auch durch den Versuch gekennzeichnet, diese subversive Kraft einzudämmen und zu kanalisieren. In Frankreich gelang dies nach dem Ende der Religionskriege weitgehend durch die Sublimierung und Neudefinition des militanten gegenreformatorischen Katholizismus, der nun seine Manifestation eher in Askese und Mystik, auch in der Fürsorge für Kranke und Hilfsbedürftige fand und weniger in der kriegerischen Auseinandersetzung mit dem konfessionellen Gegner. In England, dem freilich ein religiöser Bürgerkrieg im 16. Jahrhundert erspart blieb, so dass die konfessionellen Konflikte zunächst weniger explosiv zu sein schienen, verlief dieser Prozess komplexer und langsamer. Erst gegen Ende des 17. Jahrhunderts wurden die religiösen Märtyrer und die anderen Helden eines Kampfes gegen das Papsttum und einer mit dem Katholizismus vermeintlich im Bunde stehenden königlichen Tyrannis stärker im Sinne eines säkularisierten Republikanismus oder eines pragmatischen und zugleich dezidiert antiklerikalen Eintretens für weltliche Freiheitsrechte umdefiniert. Soweit dies nicht gelang, wurden sie in der historischen Erinnerung marginalisiert, auch wenn der Antikatholizismus für lange Zeit ein bestimmendes Element der englischen politischen Kultur blieb. ${ }^{41}$

39 Vgl. Patrick Riley, Fénelon's 'Republican' Monarchism in Telemachus, in: Hans Blom [et al.] (Hrsg.), Monarchisms in the Age of Enlightenment. Liberty, Patriotism and the Common Good (UCLA Clark Memorial Library Series; 6), Toronto 2007, S. 78-100.

40 Siehe S. 60-62.

41 Blair Worden, Roundhead Reputations. The English Civil Wars and the Passions of Posterity, London 2001. 
Die politischen Kulturen Englands und Frankreichs entwickelten sich im Laufe des 17. Jahrhunderts in unterschiedliche Richtungen, allerdings im Kontext eines starken Austausches zwischen den beiden Ländern und einer ständigen Auseinandersetzung mit der Entwicklung im jeweils anderen Land, unabhängig davon, ob es nun als Vorbild oder eher als abschreckendes Gegenbeispiel gesehen wurde. Man kann in diesem Sinne durchaus von entangled histories sprechen. Der Vergleich zwischen dem protestantischen England, in dem der Hof schon nach 1660 nur noch eines von vielen unterschiedlichen kulturellen Zentren war, und dem katholischen Frankreich mit seiner zeitweilig hegemonialen höfischen Kultur erscheint daher besonders sinnvoll auch und gerade mit Blick auf die Transformation traditioneller Leitbilder und Muster des Heroischen im 17. Jahrhundert. Es ist diese vergleichende Perspektive, von der dieser Essay ausgehen wird, und die mit einem anderen Fokus schon an anderer Stelle versucht worden ist. ${ }^{42}$ Wesentlich ist dabei auch die Frage, wie sich die adligen Führungsschichten in den beiden Ländern an die sich wandelnden heroischen Leitbilder bzw. an die Krise überkommener Repräsentationen des Heroischen anpassten. In England schuf das gentleman-Ideal, wie es im 18. Jahrhundert in den Debatten über Umgangsformen und politeness neu definiert wurde, eine kulturelle Konfiguration, die die Spannungen zwischen traditionellen Leitbildern des Heroischen und der entstehenden commercial society wesentlich abmilderte. Indem Aristokratie und gentry sich in ihrem sozialen Verhalten und in ihrem Rollenverständnis namentlich im Militär professionalisierten, zum Teil auch, zumindest in ihren unteren Rängen (man denke an die nachgeborenen Söhne), verbürgerlichten, konnte die Kritik am traditionellen heroischen Leitbild des Adels entkräftet werden. Militärische Helden wurden überdies seit dem frühen 18. Jahrhundert zunehmend als patriotische Verteidiger ihres Landes und nicht so sehr als treue Diener des Monarchen dargestellt. Auch das steigerte ihre Akzeptanz durch eine öffentliche Meinung, die sonst nicht mehr ohne weiteres bereit gewesen wäre, den Führungsanspruch der traditionellen Eliten zu akzeptieren. ${ }^{43}$ In Frankreich gestaltete sich dieser Übergang vom heroischen Kämpfer für den Ruhm des Königshauses und des eigenen adligen Namens zu Nationalhelden sehr viel schwieriger, zumal die sozialgeschichtlichen Voraussetzungen andere waren. Denn hier bestand traditionell eine Trennung zwischen dem Schwertadel und der städtischen Elite der noblesse de robe. Deutlich ist aber auch, dass in Frankreich die englischen Entwicklungen intensiv beobachtet und spätestens seit der Mitte des 18. Jahrhunderts als Vorbild gesehen wurden. Dieser Einfluss des englischen Modells wurde etwa in dem Theaterstück „Die Belagerung von Calais“, das nach dem Siebenjährigen Krieg entstand, ${ }^{44}$ ebenso deutlich wie in der Debatte über die noblesse commerçante

42 Ronald G. Asch, Sacral Kingship between Disenchantment and Re-enchantment. The French and English Monarchies 1587-1688, New York 2014.

43 Siehe S. 110.

44 Siehe S. 128. 
und die noblesse militaire. ${ }^{45}$ Zugleich stand die Diskussion in Frankreich im 18. Jahrhundert, wie schon angedeutet, auch unter dem Eindruck der überbordenden Selbstheroisierung Ludwigs XIV., deren kriegerischen Triumphalismus man im Zeitalter der Aufklärung zunehmend ablehnte.

Ludwig XIV. hatte in seiner Regierungszeit den aristokratischen Helden in den Hintergrund treten lassen oder zumindest dafür gesorgt, dass adlige Selbstheroisierungen sich nun sehr viel subtiler und verhaltener artikulieren mussten als in der Vergangenheit. Es wäre allerdings ein Fehler anzunehmen, dass die absolute Monarchie ohne die Figur des militärischen Heros ausgekommen wäre. Ohne entsprechende Vorbilder wäre es unmöglich gewesen, den Schwertadel dazu zu motivieren, sein Leben auf dem Schlachtfeld für den Monarchen und sein Königreich zu opfern. Das Verhältnis zwischen der Heroisierung des Monarchen und der heroischen Selbstinszenierung des Adels war freilich nie spannungsfrei, was unter anderen Voraussetzungen auch für England galt, wo freilich zwischen dem späten 16. und dem frühen 18. Jahrhundert nur Wilhelm III. ganz der Figur des klassischen roi connétable entsprach. Die Stuarts hatten sehr viel eher versucht, den gefährlichen Handlungszwängen, die von einem heroischen Rollenmodell für den Monarchen ausgehen konnten, zu entkommen. Das galt besonders für Jakob I. und Karl II. Dabei schufen sie freilich einen Entfaltungsraum für andere Modelle des Heroischen, die als Gegenentwurf zur monarchischen Selbstdarstellung konzipiert wurden; eine potenziell für die Legitimation von Herrschaft gefährliche Konstellation. Ein spezifisch republikanisches Modell des Heroischen wurde in dieser Form im 17. Jahrhundert jedenfalls nur in England entwickelt, es blieb Frankreich fremd. Erst im 18. Jahrhundert schuf der Ruf nach einem patriotischen, eine Nation aus Bürgern einigenden politischen Ethos für die Figur des Helden auch hier eine ganz neue politische und kulturelle Konfiguration, die bis zu einem gewissen Grade die Problemlagen des 19. Jahrhunderts mit seiner Tendenz vorwegnahm, die gesamte Nation zu einer „nation of heroes“ (Carlyle) zu stilisieren.

Die angesprochenen Entwicklungen können hier nicht erschöpfend behandelt werden. Dieser Essay will dennoch einen Beitrag zum besseren Verständnis der Umdeutung älterer Modelle des Heroischen im 17. und 18. Jahrhundert leisten. Auch wenn diese Entwicklungen nicht einfach auf den Nenner des Untergangs und der Zerstörung des klassischen aristokratischen Helden gebracht werden können, so sind doch Tendenzen zur Verbürgerlichung des Helden und zu seiner Indienstnahme für den Patriotismus und für das Nationalbewusstsein einer ganzen Nation im 18. Jahrhundert sowohl in Frankreich als auch in England unverkennbar. In diesem Sinne kann man dann in der Tat von einem Herbst des Helden sprechen, wenn man darunter Figuren wie den Grand Condé (gest. 1686), den Sieger von Rocroi, versteht, dessen Handlungshorizont noch ganz durch Adelsstolz und aristokratisches Streben nach Ruhm und Ehre bestimmt worden

45 Smith, Nobility Reimagined, S. 104-142. 
war. Ein Condé war sich letztlich selbst genug und fühlte sich an kaum eine Regel ohne Vorbehalte gebunden; so vermochte er auch für Spanien genauso zu kämpfen, wie für sein eigenes Land. Der Charakter des Transgressiven blieb zwar für die Figur des Helden auch nach der Mitte des 18. Jahrhunderts charakteristisch - trotz aller Versuche der Aufklärung, den Helden zu domestizieren -, aber sehr viel stärker wurde von ihm nun verlangt, Symbolfigur für eine Sache oder eine Bewegung zu sein. Nur dann konnte man ihm den Regelbruch und die Maßlosigkeit seiner Taten nachsehen, die nun, da sie nicht mehr Ausdruck des Privilegs des Aristokraten oder professionellen Kriegers waren, freilich auch potenziell zum Maßstab für das Verhalten aller Menschen werden konnten und damit eine zutiefst destabilisierende Kraft entfalteten, die ihnen in älteren Epochen gefehlt hatte. 


\section{Die Konfessionalisierung des Helden oder die subversive Kraft des Heroischen im späten 16. Jahrhundert}

Im Jahre 1594 versuchte ein katholischer Attentäter, Jean Châtel, den französischen König Heinrich IV. zu ermorden. Anders als 16 Jahre später, als es Ravaillac wirklich gelang, den Monarchen tödlich zu verletzen, misslang dieses Attentat und Châtel starb als potenzieller Königsmörder eines qualvollen Todes, aber seine Tat fand dennoch ihre Verteidiger. Einer der führenden Theologen der Liga, Jean Boucher, der 1589 schon die religiöse Rechtfertigung für die Ermordung Heinrichs III. geliefert hatte, sich aber nun im Exil in den spanischen Niederlanden aufhielt, schrieb eigens eine Apologie für Jean Châtel, in der er nochmals eingehend begründete, warum es sich hier um einen - so wörtlich - „acte hérö̈que“ handelte. Heroisch sei eine Handlung, die durch ihre Tugendhaftigkeit, aber auch durch „magnanimité, force, courage“ und „constance“ (Seelengröße, Kraft, Mut und Standhaftigkeit) das Normalmaß des Menschlichen deutlich überschreite und den Menschen gewissermaßen göttlich werden lasse: „rend l'homme divin en quelque sorte ". ${ }^{1}$ Vorausgesetzt war dabei zugleich, dass solche Märtyrer-Attentäter unmittelbar göttlich inspiriert waren. ${ }^{2}$ Mit dem Hinweis darauf, dass Châtel ein Held sei, sollte ihm auch die Vollmacht zugeschrieben werden, eine Tat zu vollbringen, die sonst nach menschlichem Ermessen als Mord und Majestätsverbrechen hätte gelten müssen. Auch die widerstandsrechtlichen Theorien, die die Konfessionskriege hervorgebracht hatten, rechtfertigten normalerweise nicht die Tat eines Einzelnen, sondern versuchten, das Widerstandsrecht auf die korporativ verfassten Stände oder das wie auch immer definierte Volk einzuschränken, wobei auf katholischer Seite auch das Recht des Papstes, weltliche Herrscher abzusetzen, eine erhebliche Rolle spielte. Die katholische Haltung zur Möglichkeit des Tyrannenmords hatte sich freilich seit den 1580er Jahren erheblich radikalisiert. Schon das Attentat auf Wilhelm von Oranien war 1584 von katholischer Seite gepriesen

1 Jean Boucher, Apologie pour Iehan Chastel. Parisien, executé à mort, par François de Verone Constantin [Pseudonym für Jean Boucher], Teil 2, [s. 1.] ORT 1610, S. 26.

$2 \mathrm{Zu}$ dieser Problematik siehe auch Paul-Alexis Mellet, L'ange et l'assassin. Les vocations extraordinaires et le regicide jusq'au 1610, in: Marie-Luce Demonet (Hrsg.), Hasard et providence $\mathrm{XIV}^{\mathrm{e}}-\mathrm{XVII}{ }^{\mathrm{e}}$ siècles. Actes du cinquantenaire de la fondation du CESR et XLIX ${ }^{\mathrm{e}}$ Colloque International d'études Humanistes, Tours, 3-9 juillet 2006, 2007, http://umr6576. cesr.univ-tours.fr/Publications/HasardetProvidence/, 20. Juli 2015. Zur Hinrichtung von Châtel, der dieser mit heroischer Standhaftigkeit entgegenging, siehe auch: Mathilde Bernard, Écrire la peur à l'époque des guerres de Religion. Une étude des historiens et mémorialistes contemporains des guerres civiles en France 1562-1598 (Collection Savoir : Lettres), Paris 2010, S. 138. 
worden als „a holy and living sacrifice offered to God the Lord his creator". ${ }^{3}$ Und als 1589 der Mönch Jacques Clément Heinrich III. von Frankreich umbrachte, äußerte sich der Papst lobend über den Attentäter und verglich nach einigen Darstellungen seine Tat sogar mit dem Wunder der Inkarnation, ${ }^{4}$ während der spanische Jesuit Mariana den Attentäter in einem seiner Werke „aeternum Galliae decus" („eine ewige Zierde Frankreichs") nannte. ${ }^{5}$ Dies waren keine vereinzelten Stimmen. Der spanische Botschafter in Paris war überzeugt, dass Clément ein Werk von übermenschlicher Größe vollbracht habe, andere sprachen von einem Zeichen Gottes oder verglichen Clément mit den Helden und Heldinnen der Bibel. So predigte der Prior der Dominikaner in Paris, Edmond Bourgoing, ein besonders fanatischer Anhänger der Heiligen Liga, nach der Ermordung des letzten Valois 15 Tage lang über die Gestalt der biblischen Judith, deren Tat er als Präfiguration der Tat Jacques Cléments sah, der jedoch ebenso mit David, Samson oder Ehud verglichen wurde. Clément verkörperte auf diese Weise eine bestimmte Variante des heroischen Glaubenskämpfers, zugleich Märtyrer und Tyrannenmörder und überdies noch Priester, der in der Nachfolge Christi stand. ${ }^{6}$

Im Zuge der Religionskriege war es auf beiden Seiten, auf der katholischen wie auf der protestantischen, zu einer Umdeutung des religiösen Martyriums gekommen. War der Märtyrer in der Tradition der Kirche in erster Linie als unschuldiger Dulder gesehen worden, der sein Leben für seinen Glauben opferte und der allenfalls in der Standhaftigkeit des Leidens heroische Größe entfaltete, so wurde das Martyrium nun zunehmend zur Tat umgedeutet. Namentlich von katholischer Seite wurde das Martyrium als Aufforderung zur Bekehrung derjenigen dargestellt, die seine Zeugen wurden. ${ }^{7}$ Dieser Aspekt mochte bei der Darstellung der protestantischen Opfer religiöser Verfolgung geringer ausgeprägt sein. Die stoische Apathie des Märtyrers wurde hier generell stärker betont als im katholischen Bereich, wo namentlich die Jesuiten auf die Indienstnahme der menschlichen Lei-

3 Brad S. Gregory, Salvation at Stake. Christian Martyrdom in Early Modern Europe (Harvard Historical Studies; 134), Cambridge, MA 1999, S. 295-296.

4 Jacques Auguste de Thou, Historia sui temporis, Bd. 4, London 1733, Liber XCVI, § X, S. 767-768; vgl. Nicola M. Sutherland, Henry IV of France and the Politics of Religion, Bd. 1, Henry of Navarre, Bristol 2002, S. 265.

5 Juan Mariana, De Rege et eius institutione, Toledo 1599, S. 69; vgl. Harro Höpfl, Jesuit Political Thought. The Society of Jesus and the State, c. 1540-1630 (Ideas in Context; 70), Cambridge 2004, S. 319-320.

6 Nicolas Le Roux, Le roi, la cour, l'état. De la Renaissance à l'absolutisme (Époques), Seyssel 2013, S. 252-256.

7 Peter Burschel, Sterben und Unsterblichkeit. Zur Kultur des Martyriums in der Frühen Neuzeit (Ancien Régime. Aufklärung und Revolution; 35), München 2004, S. 281-282: „So wird in der Tat deutlich, daß die Märtyrerinnen und Märtyrer auf den Jesuitenbühnen im Vergleich mit ihren protestantischen [...] nicht leiden, sondern ,gegenleiden', nicht dulden, sondern agieren, nicht loslassen, sondern kämpfen, nicht überwinden, sondern überzeugen. Ihr Martyrium wird zur Tat, und erst in der Tat zum Triumph.“ 
denschaften für die Sache des Glaubens und nicht auf ihre gänzliche Überwindung setzten. ${ }^{8}$ Aber auch hier konnte der Opfertod eines Mannes oder einer Frau, die von konfessionellen Feinden wegen ihres Glaubens getötet wurden, leicht eine politische Dimension erhalten. Foxes „Book of Martyrs“ etwa, das die Erinnerung an die rund 300 Engländer und Engländerinnen wachhielt, die unter Maria Tudor wegen ihres Bekenntnisses zum Protestantismus hingerichtet worden waren, wurde im späten 16. und im 17. Jahrhundert als Aufforderung gelesen, einer möglichen katholischen Machtergreifung in England einen entschiedenen Widerstand entgegenzusetzen. ${ }^{9} \mathrm{Ob}$ diese Machtergreifung sich nun auf dem Wege der dynastischen Erbfolge vollzog oder durch einen gewaltsamen Umsturz oder gar durch den Abfall eines Herrschers vom wahren Glauben, war dafür von untergeordneter Bedeutung. ${ }^{10}$ Zum Fanal wurde der Tod der Opfer der marianischen Verfolgungen vor allem im Kontext einer Interpretation, die sich von der Offenbarung des Johannes inspirieren ließ und dieses Buch der Bibel als Aufforderung zur aktiven Beteiligung auch des einfachen Gläubigen am eschatologischen Kampf zwischen Licht und Finsternis las. ${ }^{11}$

Auf katholischer Seit erhielt diese Politisierung des Martyriums jedoch noch eine stärkere und konkretere Zuspitzung. Protestanten neigten etwa während der französischen Religionskriege in Frankreich in der Regel nicht dazu, Adlige oder andere Laien, die im aktiven Kampf gegen den konfessionellen Gegner umgekommen oder auch Opfer eines politischen Attentates geworden waren, als Märtyrer zu verehren, was zum Teil auch daran gelegen haben mag, dass etwa die politischen Anführer der Hugenotten in Frankreich, die sich eher den traditionellen Idealen einer spezifisch adligen Lebenshaltung verpflichtet sahen, sich nur mit Mühe als Verkörperung einer leidenschaftlichen Frömmigkeit darstellen ließen. ${ }^{12}$ Den Vorkämpfern des Protestantismus, die während der Religionskriege umkamen,

8 Vgl. ebd., S. 278, S. 282; vgl zu den Jesuiten und ihrer Vorstellung des Heroischen auch Marc Fumaroli, Héros et orateurs. Rhétorique et dramaturgie cornéliennes, Genf 1996, S. 329-337.

9 Vgl. David Loades (Hrsg.), John Foxe at Home and Abroad, Aldershot 2004; Thomas P. Anderson / Ryan Netzley (Hrsg.), Acts of Reading. Interpretation, Reading Practices, and the Idea of the Book in John Foxe's Actes and Monuments, Newark, Del. 2010; vgl. Alice Dailey, The English Martyr from Reformation to Revolution (Reformations), Notre Dame, IN 2012, S. 53-97.

10 Thomas S. Freeman, 'Imitatio Christi with a Vengeance': The Politicisation of Martyrdom in Early-Modern England, in: Thomas S. Freeman / Thomas F. Mayer (Hrsg.), Martyrs and Martyrdom in England, c. 1400-1700 (Studies in Modern British Religious History; 15), Woodbridge 2007, S. 35-69.

11 Zum Einfluss der Apokalypse auf das politische Denken siehe Ronald G. Asch, The Revelation of the Revelation. Die Bedeutung der Offenbarung des Johannes für das politische Denken in England im späten 16. und frühen 17. Jahrhundert, in: Kai Trampedach / Andreas Pečar (Hrsg.), Die Bibel als politisches Argument. Voraussetzungen und Folgen biblizistischer Herrschaftslegitimation in der Vormoderne (Historische Zeitschrift; Beihefte N.F. 43), München 2007, S. 315-331.

12 El Kenz, Les bûchers du roi, S. 209-212. 
wurden zwar heroische Tatkraft, ritterlicher Mut und wohl auch die Seelengröße des Aristokraten, der mit stoischem Gleichmut die Unbill der Welt ertrug, zugeschrieben, aber man zögerte, ihnen einen wirklichen Märtyrerkult zu widmen, wie es auf katholischer Seite zum Beispiel mit den 1588 ermordeten Brüdern Guise durchaus geschah. Ein Held auf dem Schlachtfeld zu sein und zugleich ein Märtyrer, das war aus protestantischer Sicht, zumindest zu diesem Zeitpunkt, nur schwer vereinbar, selbst wenn man am Ende einem Mordanschlag zum Opfer fiel, ganz abgesehen von der Tatsache, dass es natürlich im Protestantismus keinen Heiligenkult gab. ${ }^{13}$

Es mag hinzugekommen sein, dass die Protestanten, die in Frankreich anders als in England nur eine Minderheit der Bevölkerung darstellten, nie hoffen konnten, die Mehrheit der Franzosen für ihren Kampf zu gewinnen, es sei denn, sie stellten diesen vor allem auch als eine politische Auseinandersetzung dar, in der es um die Freiheit des Landes und die Rechte der Stände, vor allem des Adels ging. Und so war die Argumentation der Hugenotten im Krieg, wie man etwa an der „FrancoGallia“" François Hotmans sehen kann, auch ausgerichtet. ${ }^{14}$ Mit der Berufung auf religiöse Märtyrer konnte man die gemäßigten Katholiken kaum für sich gewinnen, mit rein politischen und historischen Argumenten aber vielleicht bis zu einem gewissen Grade doch.

Vor diesem Problem stand die katholische Seite im konfessionellen Kampf nicht. Sie war aber seit den 1580er Jahren mit der Herausforderung konfrontiert, ihre grundsätzliche Treue gegenüber einer katholischen Monarchie mit dem Widerstand gegen einen König, Heinrich III., zu verbinden, der zwar Katholik war, aber im Kampf gegen die Ketzer den Eindruck nicht vermeiden konnte, lau und unentschlossen zu sein, und der überdies die Möglichkeit offen ließ, dass ein Protestant, Heinrich von Navarra, sein Nachfolger sein könnte. ${ }^{15}$ Die heroische Geste des Märtyrers brachte vielleicht auch deshalb die Botschaft der Heiligen Liga - des Zusammenschlusses der militanten Katholiken - besser zum Ausdruck als jede Predigt und jede theoretische Abhandlung, weil der Märtyrer als Figur die internen Konflikte der katholischen Position lebbar machte und gewissermaßen aufhob. ${ }^{16}$

Bei der Zuspitzung der konfessionellen Konflikte in Frankreich spielte der Verweis auf das Leiden und den heroischen Tod der katholischen Glaubenszeugen je-

13 Zu den Problemen, die sich für die Protestanten daraus ergaben, dass es während der Religionskriege keine klassischen Märtyrer - also etwa Opfer von Häresieverfahren - mehr gab, siehe auch Bernard, Écrire la peur, S. 289.

François Hotman, Franco-Gallia, in: Jürgen Dennert (Hrsg.), Beza, Brutus, Hotman. Calvinistische Monarchomachen (Klassiker der Politik; 8), Köln 1968, S. 203-327.

15 Zu Heinrich III. siehe jetzt Robert J. Knecht, Hero or Tyrant? Henry III, King of France, 1574-89, Farnham 2014, besonders S. 39-58 zur Rolle Heinrichs als katholischer Held in der Zeit als Thronfolger.

16 Diese These vertritt sinngemäß David El Kenz, Les usages subversifs du martyre dans la France des troubles de religion. De la parole au geste, in: Frank Lestringant (Hrsg.), Martyrs et martyrologes (Revue des Sciences Humaines; 269), Lille 2003, S. 33-51, hier S. 46. 
denfalls eine entscheidende Rolle. Als 1587 in England Maria Stuart hingerichtet wurde, instrumentalisierte die Liga in Frankreich deren Tod, um den eigenen König anzugreifen, weil er nicht versucht habe, die Hinrichtung dieser früheren Königin von Frankreich (Maria Stuart war die Witwe Franz II. von Frankreich) zu verhindern. Zugleich wurden in einer Pariser Kirche Bilder zur Schau gestellt, die den qualvollen Tod der katholischen Priester darstellten, die in England unter Elisabeth I. wegen ihres Glaubens hingerichtet worden waren, um so die Franzosen vor der Möglichkeit des Übergangs der Krone an einen Protestanten zu warnen. ${ }^{17}$ Wenig später kam es in Paris zu einem Volksaufstand radikaler Katholiken, vor dem sich der König nur mühsam durch Flucht in Sicherheit bringen konnte. Doch auch außerhalb der Hauptstadt war er seines Lebens nicht sicher. 1589 wurde er - wie bereits erwähnt - in Saint Cloud vom den Jakobinermönch Jacques Clément, der dabei selbst umkam, ermordet.

In der Propaganda der Liga wurde Clément mit Judith und anderen Heldinnen und Helden des Alten Testamtes verglichen. ${ }^{18}$ In seinem Falle stellte sich natürlich die Frage, ob ein Mönch und Priester wirklich berechtigt sein könne, selbst zum Schwert zu greifen, mit besonderem Nachdruck, denn es galt ja das Prinzip „ecclesia non sitit sanguinem“ („die Kirche trinkt kein Blut"). Indes betonten die Traktate der Liga, dass ja auch der Prophet Elias vierhundert Baalspriester getötet habe und Samson unter Opferung seines Lebens an die dreitausend Philister mit sich in den Tod gerissen habe. ${ }^{19}$

Gefährlich für die Monarchie waren in Frankreich jedoch nicht nur radikalisierte Einzeltäter wie Jacques Clément, die durch die eine große heroische Tat das Land vor der Gefahr der Häresie zu retten versuchten, sondern auch jene Adligen, die sich an die Spitze der streitenden konfessionellen Parteien setzten. Die Motivation dafür war sicherlich eine recht unterschiedliche. Für manche mögen Konflikte mit feindlichen Klientelnetzwerken oder der Versuch, sich zu profilieren, eine Rolle gespielt haben, aber man sollte ein anderes Motiv nicht unterschätzen: Die Suche nach einer Legitimation für die eigene gesellschaftliche Position und nach einer Mission, der man dienen konnte. Denis Crouzet hat mit Nachdruck die These vertreten, das Ende der Kriege gegen die äußeren Feinde Frankreichs im Frieden von Cateau-Cambrésis 1559 sei für viele Adlige ein Trauma gewesen, denn für sie habe

17 Stuart Carroll, Martyrs and Murderers. The Guise Family and the Making of Europe, Oxford 2009, S. 257; vgl. Alexander S. Wilkinson, Mary Queen of Scots and French Public Opinion 1542-1600, Basingstoke 2004, S. 110, S. 111-127; vgl. John D. Staines, The Tragic Histories of Mary Queen of Scots, 1560-1690. Rhetoric, Passions and Political Literature, Farnham 2009, S. 102; vgl. Paul Arblaster, Antwerp and the World. Richard Verstegan and the International Culture of Catholic Reformation (Avisos de Flandes; 9), NeuLöwen 2004, S. 41-43.

18 Jacques Baron, Origine, généalogie et démonstration de ceste excellente, et hérö̈que maison de Lorraine, et Guyse en dépendente. Avec les martyrs de Henry et Louys, Duc et Cardinal de Guise, Paris 1589, S. 36.

19 Charles Pincelet, Le martyre de frère Jacques Clément de l'ordre S. Dominique, Troyes 1589, S. 59, S. 61. 
der Krieg fast die Bedeutung eines sakralen Selbstopfers angenommen. In mythenumwobenen Kämpfen wie dem Zweikampf zwischen dem Chevalier Bayard und dem Spanier Alonzo de Sotomayor im Februar 1503 während der Kriege in Italien glaubte man die Hand Gottes zu erkennen, die dem scheinbar Schwächeren den Sieg verlieh, so wie ein David über Goliath gesiegt hatte. Dieses ganze Feld heroischer Taten schien mit dem Ende der Kriege gegen das Haus Habsburg und andere Gegner dem Vergessen anheim gegeben zu sein und die Begeisterung, mit der sich Teile des Adels in die Religionskriege stürzten, wäre dann gewissermaßen eine Kompensation für den unpopulären äußeren Frieden, eine notwendige Suche nach einer heroischen Existenz in einer unheroischen Zeit gewesen. ${ }^{20}$ Eine solche Interpretation mag die Dinge zu sehr zuspitzen, trifft aber doch ein wesentliches Element des adligen Engagements in den Religionskriegen, wobei man gleichzeitig betonen muss, dass die meisten weniger wohlhabenden Adligen in der Provinz sich nur vorübergehend oder gar nicht an den Kämpfen beteiligten. ${ }^{21}$ Adlige aber, die so dachten, wie es Crouzet skizziert, setzten dem Bild eines schwankenden und entscheidungsschwachen Monarchen, Heinrichs III., eine Selbstinszenierung entgegen, die sie als heroische milites Christi, als Streiter Christi, erschienen ließ. Auf protestantischer Seite ließ sich das traditionelle Adelsethos freilich auch unter den Vorzeichen eines heroischen Kampfes für den wahren Glauben nicht ohne weiteres mit den Idealen eines gottesfürchtigen Lebens zur Deckung bringen, wie es die Pastoren der reformierten Kirche propagierten. Eine Figur wie Heinrich von Navarra, der spätere Heinrich IV., lässt dies ja deutlich genug werden. ${ }^{22}$

Leichter tat sich die katholische Seite damit, einen Kompromiss zwischen konfessioneller Militanz und adligem Ehrgefühl zu finden, zumal hier stärker zwischen der Rolle von Geistlichen und Laien in der konfessionellen Auseinandersetzung differenziert werden konnte. Die Doktrin des Priestertums aller Gläubigen war dem Katholizismus ja fremd. Es gab freilich auch Adlige, wie den Grafen von Bouchage, später Herzog von Joyeuse, die in einer Person in unterschiedlichen Lebensphasen die Rolle des Geistlichen, der durch eine heroische Askese und aufrüttelnde Predigten der Kirche diente, und des bewaffneten Kämpfers, der auf den Schlachtfeldern des Religionskrieges für den wahren Glauben eintrat, verbanden. Henri de Joyeuse (geb. 1563, gest. 1608) war der Bruder eines der mignons (Favoriten) Heinrichs III., Anne de Joyeuse, und gehörte selbst zu den Höflingen und Freunden des Königs. 1587 trat Henri nach dem Tode seiner jungen Frau in ein

20 Denis Crouzet, La genèse de la Réforme française, Paris 1999, S. 539-541, S. 545.

21 Jean-Marie Constant, Les barons français pendant les guerres de religion, in: Association Henri IV (Hrsg.), Quatrième centenaire de la bataille de Courtras (Colloque de Coutras organisé par le GRAHC 1987), Pau 1989, S. 49-62, besonders S. 54-60; vgl. Ders., The Protestant Nobility in France during the Wars of Religion. A Leaven of Innovation in a Traditional World, in: Philip Benedict [et al.] (Hrsg.), Reformation, Revolt and Civil War in France and the Netherlands, 1555-1585, Amsterdam 1999, S. 69-82.

22 Zu Heinrich IV. siehe Vincent J. Pitts, Henri IV of France. His Reign and Age, Baltimore 2009. 
Kloster ein und wurde Kapuziner, ließ sich aber 1592 von seinen Gelübden als Mönch entbinden, um mit dem Status eines Malteserritters am Kampf gegen die Protestanten teilzunehmen. Nach dem Ende der Religionskriege trat er erneut ins Kloster ein und erlangte durch seine Predigten und seine Neigung zum Mystizismus eine gewisse Berühmtheit. ${ }^{23}$ Es ist bezeichnend, dass Joyeuse in seiner Rolle als Kapuziner auch an einer großen Prozession teilnahm, welche die Liga im Mai 1588 in Paris veranstaltete. Sie stellte den Weg Christi zum Kalvarienberg dar und sollte die Bevölkerung gegen den König mobilisieren, ihn aber auch zur Rückkehr aus Blois nach Paris bewegen. In der Prozession, in der die Henkersknechte besonders brutal agierten, um das Ganze lebensnah wirken zu lassen, wurde die Rolle des gequälten Christus von Joyeuse gespielt. ${ }^{24}$ Im Leben des Kapuziners Père Ange (so hieß Joyeuse als Mönch) verband sich das heroische Leiden für den wahren Glauben in unterschiedlichen Phasen mit dem bewaffneten Kampf für die Kirche. Eine solche Synthese war natürlich eher die Ausnahme. Andere Adlige waren weltlichen Freuden weit stärker zugetan als Joyeuse und wurden dennoch als Glaubensstreiter und am Ende auch als Märtyrer heroisiert.

Das galt etwa für den Führer der Liga in den 1580er Jahren, den Herzog von Guise. Henri de Guise entstammte einer Nebenlinie des Hauses Lothringen, einer Dynastie, die Gottfried von Bouillon, den Kreuzfahrer und ersten König von Jerusalem, zu ihren Vorfahren rechnete und im Kampf gegen die Ungläubigen ihre besondere Mission sah. ${ }^{25}$ In den späten 1550er Jahren hatten die Guise den französischen Hof faktisch dominiert, nach dem Tode Franz II. 1560 war ihre Machtstellung jedoch ins Wanken geraten. Die Vertreibung Maria Stuarts, die mütterlicherseits eine Guise war, aus Schottland im Jahre 1567 war für ihre Macht und ihr Ansehen ein weiterer Schlag. Die Guise reagierten darauf, indem sie sich immer stärker mit der Sache der militanten Katholiken identifizierten und sich einer engen Zusammenarbeit mit Philip II. von Spanien verschrieben. Die Identifikation mit dem militanten Katholizismus wurde auch von Antoinette de Bourbon gefördert, der fanatisch frommen Gattin der ersten Herzogs von Guise und Großmutter von Henri de Guise. Ihr Sohn François de Guise wurde zu Beginn der Religionskriege 1563 bei der Belagerung von Orléans von dem Protestanten Jean de Poltrot aus dem Hinterhalt erschossen oder - aus der Sicht der Katholiken - er-

23 Luigi Gonzaga di Castiglione, Le Père Ange de Joyeuse, frère mineur capucin, maréchal de France (1563-1608), Paris 1928.

24 Antoinette Gimaret, Extraordinaire et ordinaire des Croix. Les représentations du corps souffrant 1580-1650 (Bibliothèque littéraire de la Renaissance, Sér. 4; 82), Paris 2011, S. 69.

25 Denis Crouzet, Capital identitaire et engagement religieux. Aux origines de l'engagement militant de la maison de Guise ou le tournant des années 1524-1525, in: Joël Fouilheron [et al.] (Hrsg.), Sociétés et idéologies des Temps modernes. Hommage à Arlette Jouanna, Bd. 2, Montpellier 1996, S. 573-589; Ders., Un texte fondateur? Note sur "L'Histoire et recueil de la triomphante et glorieuse victoire... ", in: Brigitte Maillard (Hrsg.), Foi, fidelité, amitié en Europe à la période moderne. Mélanges offerts à Robert Sauzet, Bd. 2, Sensibilité et pratiques religieuses, Tours 1995, S. 311-331; vgl. zur Kreuzzugsidee auch unten, S. 67, Anm. 6. 
mordet und seine Witwe verschrieb sich ganz der Mission, diesen Tod zu rächen. Sein Sohn Henri galt als einer der besten Kämpfer unter den Adligen seiner Zeit und zeichnete sich durch seine Beteiligung an zahlreichen Duellen ebenso aus wie durch seinen Mut auf dem Schlachtfeld, auf dem er mehrmals verwundet wurde, was ihm den Beinamen „Le Balafré“, Narbengesicht, eintrug. ${ }^{26}$ Seine Arroganz und seine Neigung, politisch gefährliche Liebesaffären mit Frauen von Stand, etwa mit der Schwester des Königs, anzufangen, verwickelten ihn allerdings auch schon frühzeitig in Konflikte mit der Krone bzw. dem Haus Valois. Er war im Übrigen wie seine Mutter besessen von dem Gedanken, den Tod seines Vaters zu rächen, für den er den Admiral Coligny verantwortlich machte, und galt als einer der Hintermänner der Bartholomäusnacht von 1572.

In den 1580er Jahren wurde er vor allem zum Gegenspieler des Königs Heinrich III. Im Vergleich zu der eher morbiden und nach innen gekehrten Frömmigkeit Heinrichs III. war Henri de Guise ein Mann der Tat, dessen Kampf gegen die Häresie und für die Römische Kirche nicht frei war von politischem Kalkül. Spätestens als die Guise in den 1580er Jahren die Führung der Heiligen Liga übernahmen, war jedoch ihre Treue zur Kirche zu einem Identitätskapital geworden, auf das man kaum verzichten konnte, wenn man das Netzwerk der zahlreichen Klienten, die man besaß, durch den Appell an gemeinsame ideelle Ziele zusammenhalten wollte.

Guise war daher mehr als ein malkontenter Höfling, er stand an der Spitze einer politischen Bewegung. Er spielte Ende der 1580er Jahre offenbar durchaus mit den Gedanken, den König gefangen zu nehmen oder ihn sogar in ein Kloster einzuweisen, um dann als Statthalter oder Reichsverweser an seiner Stelle zu herrschen. ${ }^{27}$ An die Stelle eines verweiblichten Königs wäre damit ein adliger Krieger getreten, der das Ideal heroischer Männlichkeit und doch zugleich durch die katholischen Märtyrer, die seine Familie in Gestalt seines Vaters und Maria Stuarts aufzuweisen hatte, glaubwürdig das Anliegen des reinen Katholizismus verkörperte. Durch seine offene Auflehnung gegen Heinrich III., wie sie in der Vertreibung des Königs aus Paris im Jahr 1588 zum Ausdruck kam, hatte Guise jedoch sein Blatt überreizt. Im Dezember 1588 ließ ihn der König bei einer Audienz in Blois von seiner Leibgarde niederstechen. Auch sein Bruder, der Kardinal de Lorraine, wurde gefangen gesetzt und ohne förmliches Verfahren im Kerker umgebracht.

Die propagandistischen Schriften der Liga stellten den Tod der Herzogs von Guise und seines Bruders nicht einfach nur als Mord dar, sondern als ein wahres Martyrium, als ob die beiden im Kampf für den wahren Glauben von einem heidnischen Herrscher umgebracht worden wären, während umgekehrt der Tod Heinrichs III. als Richterspruch Gottes gedeutet wurde. ${ }^{28}$

26 Carroll, Martyrs and Murderers, S. 185-187, S. 222-223.

27 Vgl. ebd., S. 283-284.

28 Baron, Origine, généalogie et démonstration, S. 36; vgl. Le Roux, Le roi, la cour, l'état, S. 243-246. 
Dass Guise überhaupt eine so prominente Rolle als heroischer Führer der katholischen Partei im Bürgerkrieg hatte spielen können, lag wesentlich auch daran, dass der König selbst zwischen den streitenden Parteien zu vermitteln versuchte oder doch zumindest eine Festlegung auf das Ziel der Ausrottung der Häresie mit Stumpf und Stil sichtbar vermied. Heinrich III. hatte zu Lebzeiten seines älteren Bruders Karl IX., als er selbst noch den Titel eines Herzogs von Anjou trug, durchaus die Rolle des heroischen Kämpfers gegen die Hugenotten übernommen. Er war 1569, also noch in sehr jungen Jahren (er war 1551 geboren), an den Siegen von Jarnac und Montcontour maßgeblich beteiligt und diese Tatsache erlaubte es ihm, für sich ein symbolisches Kapital' zu schaffen, das auf seiner Selbstdarstellung als vorbildlicher katholischer Ritter (,,chevalier catholique exemplaire“) beruhte, wie Nicolas Le Roux hervorgehoben hat. ${ }^{29}$ Als Heinrich jedoch König wurde, änderten sich sowohl seine Selbstinszenierung als auch die Wahrnehmung seiner Rolle als Herrscher zwischen den streitenden Parteien. Seine Versuche, Frankreich den Frieden wiederzubringen, wurden von den militanten Katholiken zunehmend als Verrat am wahren Glauben gesehen. Die Stellung des Königs wurde zusätzlich dadurch geschwächt, dass er kinderlos war. Die intensiven Freundschaften, die er mit einem ausgesuchten Kreis von Höflingen pflegte, wurden als Indiz für homoerotische Neigungen gesehen..$^{30}$ Heinrich selbst suchte solche Defizite zu kompensieren, indem er seine katholische Frömmigkeit ganz besonders spektakulär zu demonstrieren suchte, etwa indem er im Büßergewand an öffentlichen Prozessionen von besonders strenggläubigen Brüderschaften wie der Gemeinschaft der Confrères de la Mort oder der Pénitents Blancs teilnahm. Aber diese Negation der Aura der Majestät stieß weitgehend auf Ablehnung und wurde entweder als lächerlich oder als Heuchelei betrachtet. Der Versuch des Königs, die heroische Rolle des miles christianus gegen diejenige des Büßers einzutauschen, war jedenfalls kein Erfolg, diesem Rollentausch fehlte die Plausibilität. ${ }^{31}$ Sein kurzfristig vollzogener Wechsel zu einer Politik rücksichtsloser Brutalität gegenüber seinen Gegnern - in diesem Fall gegenüber den Brüdern Guise, die er in Blois umbringen ließ - vermochte ihn jedoch auch nicht zu retten. ${ }^{32}$

29 Ders., L'héroïsme impossible des derniers Valois, in: Martin Wrede (Hrsg.), Die Inszenierung der heroischen Monarchie. Frühneuzeitliches Königtum zwischen ritterlichem Erbe und militärischer Herausforderung (Historische Zeitschrift, Beihefte N.F.; 62), München 2014, S. 152-169, hier S. 160-161.

30 Ders., La faveur du roi. Mignons et courtisans au temps des derniers Valois, vers 1547-vers 1589 (Époques), Seyssel 2001.

31 Ders., L'héroïsme impossible, S. 165, S. 169; Knecht, Hero or Tyrant?, S. 215-220; vgl. Alain Tallon, Conscience nationale et sentiment religieux en France au XVI ${ }^{\mathrm{e}}$ siècle (Le noeud gordien), Paris 2002, S. 125-132.

32 Anita M. Walker / Edmund H. Dickerman, The King Who Would be Man. Henri III, Gender Identity, and the Murders at Blois, 1588, in: Historical Reflections 24, Heft 2, 1998, S. 253-281. 
Sein Nachfolger, Heinrich IV., entsprach sehr viel mehr als der letzte Valois dem Bild des roi connétable, denn er führte seine Truppen selbst in die Schlacht und verkörperte ganz und gar das Ethos eines Adels, für den der Krieg das Zentrum der eigenen Existenz war. Auch seine zahlreichen erotischen Affären konnten als Zeichen einer besonderen Maskulinität gedeutet werden, ${ }^{33}$ jedenfalls hätte keine Kritik ihm unterstellt, seine Neigungen würden eher jungen Männern gelten. Aber die Heroisierung des neuen Herrschers ging weit über das hinaus, was man etwa auch bei adligen Heerführern finden konnte. Wiederholt wurde die Bereitschaft des Bourbonen betont, sich für sein Land, Frankreich, und für die gerechte Sache zu opfern, gegebenenfalls auch in einem Zweikampf mit seinen Gegnern. Wie Denis Crouzet argumentiert hat, diente die prononcierte Heroisierung des neuen Herrschers auch dem Zweck, ihm eine Sakralität zuzuschreiben, die nicht unmittelbar von seiner Rechtgläubigkeit abhängig war. Entscheidend war auch der Umstand, dass es Heinrich erst 1594 gelang, sich zum König krönen zu lassen, fast fünf Jahre nach seiner offiziellen Thronbesteigung. Die Legitimation, die ihm Salbung und Krönung nicht zu geben vermochten, mussten ihm in dieser Übergangzeit seine militärischen Siege verschaffen, in denen seine Anhänger das Werk der Vorsehung sahen. Die Heroisierung Heinrichs IV. als Heerführer, Herrscher und Friedensstifter hatte für seine Legitimation also eine viel zentralere Bedeutung als für Monarchen, deren Erbrecht unbestritten war. ${ }^{34}$

Aus der Perspektive eines christlichen Stoizismus war Heinrich in diesem Kontext der neue Herkules, der seine eigenen Leidenschaften genauso wie die Dämonen der Zwietracht überwunden hatte. An die Stelle des Mysteriums eines Priesterkönigtums mit quasi magischer Kraft - ein Bild des Königtums, das unter den Vorgängern Heinrichs IV. eine erhebliche Rolle gespielt hatte und auch neoplatonische Konnotationen besaß - trat ein „heroisches Epos“, das den Weg Frankreichs in ein Goldenes Zeitalter zeigte, wie Denis Crouzet dies interpretiert hat, und der Held dieses Epos war der König selbst. ${ }^{35}$ Der Neustoizismus mit seiner Betonung

33 Katherine B. Crawford, The Politics of Promiscuity. Masculinity and Heroic Representation at the Court of Henry IV, in: French Historical Studies 26, Heft 2, 2003, S. 225-252.

34

35 Crouzet schreibt: „une royauté stö̈cienne se mythifie dans la personne d'un roi qui n'est autre que la reincarnation du mythique héros du renvouveau du monde“ und „le stoicisme fut l'élément refondateur d'une sacralité de la personne monarchique. Le roi incarne la vie, le principe de la vie qu'est la Raison. Dieu ou demi-Dieu, il ne peut mourir“, Denis Crouzet, Dieu en ses royaumes. Une histoire des Guerres de Religion (Époques), Seyssel 2008, S. 456-457, hier S. 455, S. 457; vgl. Ders., Les Guerriers de Dieu. La violence au temps des troubles de religion (vers 1525-vers 1610), Bde 2, Seyssel 1990, S. 779-782; Ders., Les fondements idéologiques de la royauté d'Henri IV, in: Jacques Pérot / Pierre Tucoo-Chala (Hrsg.), Henri IV. Le Roi et la reconstruction du royaume, Pau 1990, S. 165-194. Skeptischer gegenüber diesen Deutungen ist Denise Carabin, Les idées stoïciennes dans la littérature morale des XVI e et XVII e siècles 1575-1642 (Études et essais sur la Renaissance; 51), Paris 2004, S. 519-521. 
der Kontrolle der Leidenschaften, auf den die königliche Propaganda sich berief,36 war zugleich eine Ideologie, die eine Distanzierung der Untertanen des Monarchen von der Tagespolitik begünstigte. Der einzig kämpfende Held in dieser Welt war der König selbst - alle anderen Spieler auf der Bühne demonstrierten ihre heroische Kraft eher im Ertragen des Unvermeidlichen und Schicksalhaften und in der Selbstdisziplin, aber nicht primär im agonalen Kampf. Zugleich bot die starke Berufung auf die Sprache und die Bilder der antiken Mythologie für die Legitimation der Herrschaft des ersten Bourbonen noch weitere Vorteile, denn sie blieb hinreichend vieldeutig, um es unterschiedlichen Gruppen und Bewegungen zu ermöglichen, ihre Hoffnungen auf den königlichen Heros zu projizieren. Für die Katholiken, die ihn als Herrscher akzeptiert hatten, sich aber in der Tradition der Liga sahen, war es möglich, die Bekehrung des Königs zum Katholizismus als seine größte Heldentat zu feiern, während Protestanten oder politiques den König als Verkörperung einer ratio feiern konnten, die eher philosophische als theologische Züge trug. An der Heroisierung Heinrichs IV. wird in der Tat deutlich, wie sehr der Held eine Figur ist, die als Chiffre für die ,Aufhebung', das heißt die Suspension von Gegensätzen, Konflikte erträglich macht, die sonst Ordnung und Frieden bedrohen müssen. ${ }^{37} \mathrm{Im}$ Übrigen dominierte die Figur des Herkules die Darstellung des Königs zumindest bis in die 1590er Jahre nicht gänzlich, zumal erst der Opfertod des Königs (seine Ermordung, in der man eine Parallele zum Tod des Herkules auf dem Berge Oeta sehen konnte) sein irdisches Leben mit dem Mythos quasi zur Deckung brachte, ähnlich wie die Verbannung Napoleons nach St. Helena diesen endgültig als modernen Prometheus erscheinen ließ.$^{38}$ In den 1590er Jahren war Heinrich aber auch noch oft genug als Perseus dargestellt worden, ${ }^{39}$ der die Andromeda Frankreich vor dem Seeungeheuer Ketos (wahlweise die Liga oder der Bürgerkrieg an sich) rettete, oder aber als christlicher Ritter, der die Liga in Gestalt des Königsmörders Clément niedertrat und sich mit dem Königreich vermählte. ${ }^{40}$ Die Idee einer Vermählung zwischen König und Königreich spielte auch im Krönungsritual der Epoche eine wichtige Rolle. ${ }^{41}$ Als Feldherren und roi connétable lässt

36 Zum Neustoizismus siehe etwa Bernard, Écrire la peur, S. 61-64, S. 318-324; Carabin, Les idées stoïciennes; Jacqueline Lagrée, Just Lipse et la restauration du stoïcisme (Philologie et Mercure), Paris 1994.

37 Siehe S. 16.

38 Vgl. Blumenberg, Arbeit am Mythos, S. 504-566: „Prometheus wird Napoleon, Napoleon Prometheus".

39 Henri IV nouveau Persée délivrant la France-Andromede, Holzschnitt zum Einblattdruck „La délivrance des la France par le Persßee françois“, Paris 1594, BNF Recueil de l’Estoile, Gd. FORés. $\operatorname{La}^{25}$ 6, FO 31.

40 Henri IV tenant la France par la main, Holzschnitt, 1590er Jahre, BNF, Inv. Qb 1589 Hennin 920.

41 Aurélie du Crest, Modèle familial et pouvoir monarchique. XVI ${ }^{\mathrm{e}}-\mathrm{XVIII}{ }^{\mathrm{e}}$ siècles $($ Collection d'histoire des institutions et des idées politiques), Aix-en-Provence 2002, S. 47-53. 
den Herrscher auch das heroisierende Reiterstandbild auf dem Pont Neuf erscheinen, das erste derartige Standbild überhaupt für einen französischen Herrscher. ${ }^{42}$

Ein ähnliches Standbild für Elisabeth I. von England wäre nicht nur deshalb undenkbar gewesen, weil sie eine Frau war und daher ihre Truppen nicht selbst in den Krieg führen konnte, sondern auch, weil die Tudor-Herrscherin es sorgfältig vermied, sich zu klar und eindeutig auf eine kriegerisch-heroische Selbstdarstellung festzulegen, auch wenn ihr eine solche Rolle immer wieder von anderen, von Geistlichen ebenso wie von Dichtern und ihren eigenen Höflingen und Ratgebern, nahelegt wurde. „At best she was a half-hearted heroine in the apocalyptic struggle beween Christ and Antichrist", wie Alexandra Walsham konstatiert hat. ${ }^{43}$ Dort, wo Elisabeth von Dichtern, Predigern und Höflingen heroisiert wurde, wurde sie, obwohl sie eine Frau war, im Übrigen keineswegs durchgehend mit weiblichen Vorbildern wie den Heldinnen der Bibel (Deborah oder Judith zum Beispiel) verglichen, sondern oft genug auch mit Männern, wie etwa mit David oder anderen Heroen. ${ }^{44}$ Dabei ist klar zu erkennen, dass diese Heroisierung auch als Abwehrstrategie gegen mögliche Attentate gedacht war, die von radikalen Katholiken als ein Akt des Tyrannenmordes legitimiert wurden. So wies der Geistliche William Leigh in einer seiner Predigten, die er in den 1590er Jahren am Tag der Thronbesteigung der Königin hielt, darauf hin, Katholiken sähen im Königsmord einen „heroicall acte“ ${ }^{45}$ Dagegen versuchte er zu zeigen, dass allein die Königin wirklich heroische Größe besitze. Wie Josiah habe sie die Feinde ihres Landes in der Schlacht geschlagen - eine Anspielung auf den Sieg über die Armada. Allerdings war Elisabeth ja nicht selbst in den Kampf gezogen, ihr Geschlecht hatte ihr das unmöglich gemacht. Indes, gerade weil Elisabeth eine schwache Frau sei, könne man in ihren Siegen die Hand Gottes erkennen. Nicht durch körperliche Kraft und mit dem Schwert, sondern durch die Kraft ihres Gebetes habe die Königin ihre Feinde und die ihres Landes besiegt, oder wie Leigh es formulierte:

„David killed Goliah in his weake strength with prayer in his mouth and a pebble stone in his hand [...] Queen Elizabeth in her weake, and feminine [sic] sex, to give God the glorie, hath subdued that great Giant of Gath, I meane that man of Rome, with the

42 Dazu Gérard Sabatier, Le cavalier de bronze, in: Gérard Sabatier, Le Prince et les arts. Stratégies figuratives de la monarchie française de la Renaissances aux Lumières (Époques), Seyssel 2010, S. 281-302, hier S. 283-288; Volker Hunecke, Europäische Reitermonumente. Ein Ritt durch die Geschichte Europas von Dante bis Napoleon, Paderborn 2008.

43 Alexandra Walsham, "A Very Deborah?" The Myth of Elizabeth I as a Providential Monarch, in: Susan Doran / Thomas S. Freeman (Hrsg.), The Myth of Elizabeth, Basingstoke 2003, S. 143-168, hier S. 146.

44 Zur Verherrlichung der Königin in England siehe Kevin Sharpe, Selling the Tudor Monarchy. Authority and Image in Sixteenth-Century England, New Haven, CT 2009, S. 358-473; Louis Montrose, The Subject of Elizabeth. Authority, Gender, and Representation, Chicago 2006.

45 William Leigh, Queene Elizabeth Paralleld in her Princely vertues with David, Iosua and Hezekia [...] in three Sermons, London 1612, preface, sign. A 4 verso. 
sweete perfume of prayer in her mouth and the power of the word of god in her blessed hand $[\ldots]$ in the spirit and speech of David hath been her royall march" ${ }^{46}$

Die heroische Größe der Königin wurde dargestellt als die Frucht ihres protestantischen Glaubens: „This heroicall vertue of Magnanimite ever springs out of the fountaine of faith ". ${ }^{47}$ In den Predigten eines William Leigh war Elisabeth somit eine wahre Glaubensheldin und die Idee heroischer Stärke war in ihrer Gestalt vollständig konfessionalisiert worden. Leigh predigte jedoch über die Königin nicht in ihrem Auftrag. Elisabeth selbst scheint die Versuche, sie für die Sache des militanten Protestantismus zu vereinnahmen, eher mit Skepsis gesehen zu haben. In ihren letzten beiden Regierungsjahrzehnten ließ sie sich, soweit sie solche Darstellungen zu kontrollieren vermochte, dann auch nicht mehr vorrangig als neue Deborah oder Judith oder als Nachfolgerin Davids, der Goliath besiegt hatte, feiern, sondern eher im Kostüm antiker Göttinnen oder anderer Figuren der Mythologie. Auch die mittelalterliche Dichtung in Gestalt der Artus-Sage oder das Arkadien der neu-lateinischen Poesie spielten eine Rolle, aber die Figuren der Bibel traten als Vorbilder zumindest bei Hof ganz in den Hintergrund, wie Donald Stump betont hat. ${ }^{48}$ Die Bilderwelt der Bibel mochte nun einerseits angesichts der außerordentlich bedrohlichen Lage, in der England sich befand, als zu realistisch erscheinen; der Rückzug in die rein fiktive Welt der Mythologie und der Ritterromanzen bot hier eine größere Sicherheit. Anderseits legte die Königin auch Wert darauf, nicht von den Anwälten eines militanten Protestantismus, der jeden Kompromiss mit dem Gegner ablehnte, vereinnahmt zu werden. Sie sollte und wollte als heroische Herrscherin erscheinen, versuchte aber Handlungszwänge zu umgehen, die ein solches Selbstbild mit sich brachte. ${ }^{49}$ Das war ein Drahtseilakt der Selbstinszenierung, der ihr selbst noch leidlich gelang, ihren beiden Nachfolgern aus dem Hause Stuart jedoch nicht mehr in gleicher Weise.

Selbst unter Elisabeth waren nicht alle Untertanen der Königin bereit, sich ohne Vorbehalte auf dieses Selbstverständnis der Monarchin einzulassen oder sich damit zufriedenzugeben, aggressivere Identifikationsangebote an die Monarchin in Predigten und literarischen oder künstlerischen Werken heranzutragen, ohne wirklich hoffen zu können, dass die Königin sich auf solche Rollenmodelle einließ. Es gab insbesondere eine Reihe von Adligen, die sehr viel stärker als Elisabeth selbst auf eine konsequent bellizistische Politik gegenüber dem spanischen Weltreich setzten und auch noch in den späteren 1590er Jahren jeden möglichen Ausgleich mit dem

46 Ebd., S. 52-53, vgl. S. 69.

47 Ebd., S. 119.

48 Donald Stump, Abandoning the Old Testament. Protestant Dissent and the Shift in Court Paradigms for Elizabeth, in: Donald Stump [et al.] (Hrsg.), Elizabeth I and the „Sovereign Arts". Essays in Literature, History and Culture (Medieval and Renaissance Texts and Studies; 407), Tempe, AZ 2011, S. 281-299.

49 Siehe dazu auch Linda Shenk, Learned Queen. The Image of Elizabeth I in Politics and Poetry (Queenship and Power), Basingstoke 2010, S. 123-158. 
alten Feind ablehnten. Das Heroismus-Defizit, das die Anhänger der Liga in Frankreich in der Persönlichkeit und in der Politik Heinrichs III. zu erkennen glaubten, vermuteten manche militante Protestanten auch hinter der nie ganz eindeutigen Haltung Elisabeths I., auch wenn ein solcher Vorwurf in der Regel nur verklausuliert formuliert wurde, anders als in Frankreich gegenüber dem letzten Valois. ${ }^{50}$

Ein Mann, der mit der Politik der Königin lange gehadert hatte und dessen Leben selbst postum als Paradigma einer heroischen Biographie gedeutet wurde, war der Dichter Philip Sidney. Im Jahre 1586 starb er in den Niederlanden nach einer Verwundung, die er in einer Schlacht erhalten hatte. Sidney galt schon zu Lebzeiten als ein Mann, der die Manieren des vollendeten Cortegiano mit einer umfassenden humanistischen Bildung und den Tugenden des christlichen Ritters verband. Sein Hauptwerk, die Schäferdichtung „The Countess of Pembroke's Arcadia“ gehört zu den wichtigsten Werken der elisabethanischen Blütezeit der englischen Literatur. Sidney, der die Bartholomäusnacht in Paris selbst miterlebt hatte, sah sich als Mitglied eines europaweiten Netzwerkes von militanten Protestanten. Die Politik seiner eigenen Königin hingegen stellte ihn selten zufrieden, zu sehr war sie durch die Suche nach Kompromissen bis hin zu möglichen Eheverbindungen der Königin mit katholischen Prinzen geprägt. ${ }^{51}$ Den Hof erlebte Sidney als Ort von Intrigen und menschlicher Niedertracht. Als der Führer des niederländischen Freiheitskampfes, in dem Sidney sicherlich ein Vorbild sah, 1584 ermordet wurde, gingen eine ganze Reihe von englischen Edelleuten in die Niederlande, um gegen Spanien zu kämpfen, dazu gehörte auch Sidney. Als er seinen Verwundungen erlag, die er sich in einem eigentlich recht banalen Gefecht zugezogen hatte, ordnete die Königin ein großes Staatsbegräbnis für ihn an, das allerdings erst 1587 stattfand. Der enorme Aufwand, der dafür betrieben wurde, war sicherlich zum Teil auch eine Reaktion auf den Tod Maria Stuarts im Februar 1587. Um diesem Märtyrerkult, in dessen Mittelpunkt die schottische Königin stand, etwas entgegenzustellen, brauchten auch die Protestanten in England einen Helden - und das war Sidney, obwohl zu Lebzeiten seine Beziehungen zur Königin gespannt gewesen waren. Er wurde in der St. Paul's Kathedrale bestattet, als sei er ein Mitglied des Oberhauses und Träger höchster Ämter gewesen. ${ }^{52}$ Man könnte sagen, die Vereh-

50 Ilona Bell, "Souvereaigne Lord or Lordly Lady of this Land". Elizabeth, Stubbs and the Gaping Gulf, in: Julia M. Walker (Hrsg.), Dissing Elizabeth. Negative Representations of Gloriana, Durham, NC 1998, S. 99-116; Peter E. McCullough, Out of Egypt. Richard Fletcher's Sermon before Elizabeth I after the Execution of Mary Queen of Scots, in: Julia M. Walker (Hrsg.), Dissing Elizabeth. Negative Representations of Gloriana (British Literature \& History: Woman's Studies), Durham, NC 1998, S. 118-148; vgl. Thomas S. Freeman, Providence and Prescription: The Account of Elizabeth in Foxe's 'Book of Martyrs', in: Susan Doran / Thomas S. Freeman (Hrsg.), The Myth of Elizabeth, Basingstoke 2003, S. 27-55.

51 Zu Sidney siehe Blair Worden, The Sound of Virtue. Philip Sidney's "Arcadia” and Elizabethan Politics, New Haven, CT 1996.

52 J. F. R. Day, Death be Very Proud. Sidney, Subversion and Elizabethan Heraldic Funerals, in: Dale Hoak (Hrsg.), Tudor Political Culture, Cambridge 1995, S. 179-203. 
rung, die Sidney nach seinem Tode zuteilwurde, sei ein typisches Beispiel dafür gewesen, wie ein Außenseiter zum Helden umdefiniert wurde, weil plötzlich ein politisches Bedürfnis bestand, den englischen Widerstand gegen Spanien und Rom in einer solchen heroischen Figur seinen Ausdruck finden zu lassen. Allerdings darf man nicht übersehen, dass Sidney sein Leben und sein literarisches Werk durchaus bewusst auf ein Ideal heroischer Tugend ausgerichtet und in seinen Dichtungen und Schriften die Voraussetzungen eines solchen Lebensentwurfes immer wieder reflektiert hatte. Und in der Tat wurde er offenbar schon zu seinen Lebzeiten von gleichaltrigen Adligen als Vorbild angesehen. ${ }^{53}$

Man kann bei Sidney von einer Selbststilisierung als Mitglied eines Bundes heroischer Kämpfer für die Sache des internationalen Protestantismus und der Freiheit sprechen, einer sehr spezifischen heroischen Gemeinschaft, zu der Franzosen ebenso gehörten wie Niederländer und Deutsche. Insoweit ist Sidney auch ein gutes Beispiel dafür, wie ein älteres Ideal einer ritterlich-heroischen Lebenshaltung konfessionalisiert wurde, eine Konfessionalisierung, die auch darin zum Ausdruck kam, dass der englische Ritterorden des Hosenbands seit 1578 nur noch Protestanten offen stand, obwohl es sich dem Anspruch nach um eine transnationale ritterliche Gemeinschaft handelte. Hier zeigen sich deutliche Parallelen zum französischen Orden vom Heiligen Geist, der von Heinrich III. 1578 allerdings von Anfang an mit dem Ziel begründet wurde, loyale Katholiken um die Krone zu scharen..$^{54}$

Sidney selbst versuchte in seinen Schriften wohl auch unter dem Einfluss seiner gelehrten Freunde wie des französischen Diplomaten Hubert Languet, das traditionelle Ideal einer heroischen Männlichkeit und den Gewalthabitus des adligen Kriegers nicht nur an konfessionelle Werte zu binden, sondern auch zu sublimieren, oder wie es Mervyn James vor vielen Jahren formuliert hat: „Sidney's object was to show that the magnanimity of the Aristotelian hero, admirable in itself, was ineffectual to set 'a stay upon the exorbitant smilings of chance' unless transcended by wisdom and religion" ${ }^{55}$ Der Verweis auf das Lächeln der Fortuna nimmt dabei eine Formulierung wieder auf, die aus einem Brief von Sidneys Freund Fulke Greville stammt. ${ }^{56}$

Kein Zweifel kann darin bestehen, dass Sidneys Werk namentlich in seinen späteren Lebensjahren stark durch den Neustoizismus beinflusst wurde und er nun

53 Worden, The Sound of Virtue, S. 68.

54 Rory Rapple, Martial Power and Elizabethan Political Culture. Military Men in England and Ireland, 1558-1594 (Cambridge Studies in Early Modern British History), Cambridge 2009, S. 88-94. Zum Ordre de Saint-Esprit siehe Knecht, Hero or Tyrant?, S. 197-198.

55 James Mervyn, Society, Politics and Culture. Studies in Early Modern England (Past and Present Publications), Cambridge 1986, S. 389.

56 William Craft, Labyrinth of Desire. Invention and Culture in the Work of Sir Philip Sidney, Newark, NJ 1994, S. 75; vgl. Joan Rees, Fulke Greville, Lord Brooke, 1554-1628. A Critical Biography, London 1971, S. 50. 
neben den Heroismus der Tat die Größe des Duldens und Ertragens setzte. Seine Weltsicht war deutlich pessimistischer geworden. ${ }^{57}$ Gerade dies verstärkte jedoch die Wirkung seines Lebens und seines Werkes nach seinem Tode. Zwar war seine Bestattung der für den Moment erfolgreiche Versuch gewesen, den Außenseiter zu integrieren und die Legitimität des elisabethanischen Regimes auf diese Weise zu stärken, doch spätestens nach dem Ende des Krieges gegen Spanien 1604, wenn nicht schon in den späten 1590er Jahren, schien Sidney vielen als Beispiel für einen Helden, dessen kämpferische Tugend vom Monarchen nie wirklich anerkannt worden war. Namentlich Sidneys Freund Fulke Greville, der sich als Verwalter seines Ruhmes betrachtete, betonte immer wieder, dass von Monarchen wirkliche Anerkennung für Tugend nicht zu erwarten sei. ${ }^{58}$

Diese Stimmung malkontenter Adliger, deren Karrieren nicht den gewünschten Verlauf genommen hatten, wurde in den 1590er Jahren von niemandem so nachhaltig artikuliert wie von Robert Devereux, dem zweiten Earl of Essex, der passenderweise Sidneys Witwe geheiratet und dessen Schwert geerbt hatte. Vielen erschien er als Heerführer und als Ritter, der für seine spektakulären Auftritte bei den höfischen Turnieren berühmt war, ${ }^{59}$ als Verkörperung jener heroischen vita activa, die bei Hofe nicht jene Anerkennung zu finden schien, die sie verdiente. Die Hoffnungen einer wachsenden Klientel von Dichtern, Historikern aber auch von Offizieren, die befürchteten, England sei durch Dekadenz und den Verfall alter Tugenden bedroht, richteten sich auf Essex, der mit Achill aber auch mit Scipio Africanus und anderen Helden der Antike verglichen wurde, wie unter anderem Alexandra Gajda vor kurzem noch einmal hervorgehoben hat. ${ }^{60}$ Die Historiker und Publizisten, die zum Umfeld des Earl of Essex gehörten, ließen sich in ihrer Kritik an höfischer Korruption, aber auch in ihrer Hoffnung auf einen Aristokraten, der durch seine „heroicall vertues“ hervorstach, stark von Tacitus aber auch vom Neustoizismus inspirieren. ${ }^{61}$ Während in Frankreich der Stoizismus mit seinem Appell an die Selbstdisziplin, die Zügelung der Leidenschaften und mit seiner Botschaft von einer inneren Freiheit des Menschen, die von seiner äußeren Lage ganz unab-

57 Worden, The Sound of Virtue, S. 363-367. Generell zum Stoizismus in England: Adriana McCrea, Constant Minds. Political Virtue and the Lipsian Paradigm in England, 1584-1650 (The Mental and Cultural World of Tudor and Stuart England), Toronto 1997.

58 Fulke Greville, Baron Brooke. The Life of the Renowned Sir Philip Sidney, o.O. 1652 (Nachdr. Delmar, NY 1984); Charles H. Larson, Fulke Greville, Boston 1980.

59 Paul E. J. Hammer, Upstaging the Queen. The Earl of Essex, Francis Bacon and the Accession Day Celebrations of 1595, in: David Bevington / Peter Holbrook (Hrsg.), The Politics of the Stuart Court Masque, Cambridge 1998, S. 41-66; vgl. generell Ders., The Polarisation of Elizabethan Politics. The Political Career of Robert Devereux, $2^{\text {nd }}$ Earl of Essex, 1585-1597 (Cambridge Studies in Early Modern British History), Cambridge 1999.

60 Alexandra Gajda, The Earl of Essex and Late Elizabethan Political Culture (Oxford Historical Monographs), Oxford 2012, S. 220-221.

61 Ebd., S. 226, S. 232. Der Begriff, heroicall virtues' geht auf die Tacitus-Übersetzung von Henry Savile zurück: Henry Savile, The End of Nero and Beginning of Galba. Foure Bookes of the Histories of Cornelius Tacitus, The Life of Agricola, London 1612. 
hängig war, eher politisch stabilisierend wirkte und von Heinrich IV., der sich als neustoischer Herrscher der Vernunft (roi de raison) stilisierte, auch für seine Zwecke instrumentalisiert werden konnte, ${ }^{62}$ wurde in England derselbe Neustoizismus mit seinem Ideal heroischer Unerschütterlichkeit oft in einer spezifischen Verbindung mit einem calvinistischen Protestantismus eher zu einer Philosophie, ${ }^{63}$ die es dem Mann von Stand erlaubte, seine Tugend der Korruption und den machiavellistischen Kompromissen des höfischen Lebens gegenüberzustellen. ${ }^{64}$

Essex selbst, dessen Klienten versucht hatten, ihn als die Verkörperung dieser stoischen Tugenden darzustellen, scheiterte politisch allerdings. Bei der Königin in Ungnade gefallen, versuchte er 1601, durch einen Putsch am Hof wieder Fuß zu fassen, um seine Gegner auszuschalten, vielleicht auch um die Königin faktisch gefangen zu setzen. Aber der halbherzige Aufstand schlug fehl und anders als dem Herzog von Guise, mit dem er gelegentlich verglichen wurde, gelang es ihm nicht, sich der Hauptstadt zu bemächtigen; er blieb aber auch nach seiner Hinrichtung eine populäre Figur. Sidney und Essex waren wichtige Orientierungspunkte für eine Tradition des, wie Andrew Shifflett es genannt hat, „stoical protestant militarism", der zugleich eng mit dem Versuch verbunden war, eine Vorstellung von adliger Ehre zu entwickeln, die unabhängig war von der Gunst oder Ungunst des Monarchen und daher potenziell ein gewisses subversives Potenzial entfalten konnte. ${ }^{65}$ Das galt besonders für Zeiten, in denen der Monarch selbst der Rolle des heroischen Streiters für den wahren Glauben und die Freiheit seines Landes tatsächlich oder scheinbar nicht gerecht wurde, und solche Zeiten schienen in England 1603 mit der Thronbesteigung Jakobs I. anzubrechen, jedenfalls aus der Sicht derjenigen, die - wie die überlebenden Anhänger des Earl of Essex - schon Elisabeth I. einen Mangel an Bellizismus vorgeworfen hatten.

62 Shenk, Learned Queen, S. 181-182.

$63 \mathrm{Vgl}$. Geoffrey Aggeler, "Sparkes of Holy things". Neostoicism and the English Protestant Conscience, in: Renaissance and Reformation 14, Heft 3, 1990, S. 223-240.

Blair Worden, Ben Jonson among the Historians, in: Kevin Sharpe / Peter Lake (Hrsg.), Culture and Politics in Early Stuart England (Problems in Focus), Basingstoke 1994, S. 67-90, hier S. 76-89; vgl. Malcolm Smuts, Court-Centred Politics and the Uses of Roman Historians c. 1590-1630, in: Kevin Sharpe / Peter Lake (Hrsg.), Culture and Politics in Early Stuart England (Problems in Focus), Basingstoke 1994, S. 21-43.

65 Andrew Shifflett, Stoicism, Politics and Literature in the Age of Milton. War and Peace Reconciled, Cambridge 1998, S. 34, S. 15. Zum Fortleben der Erinnerung an Essex siehe etwa Christine Sukic, The Earl of Essex. From one Reign to the Next, in: Jean-Christophe Mayer (Hrsg), The Struggle for the Succession in Late Elizabethan England. Politics, Polemics and Cultural Representations (Collection Astraea; 11), Montpellier 2004, S. 417432, die unter anderem auf die Bedeutung von Essex als paradigmatischem Helden für den Homer-Übersetzer George Chapman verweist. Zum Fortleben des Neustoizismus im Kreis um Prinz Henry siehe auch Jonathan Gibson, Civil War in 1614. Lucan, Gorges and Prince Henry, in: Stephen Clucas / Rosalind Davies (Hrsg.), The Crisis of 1614 and the Addled Parliament. Literary and Historical Perspectives, Aldershot 2003, S. 161-176. 


\section{Widerstreitende Modelle des Heroischen in England, ca. $1603-1660$}

Wie wir gesehen haben, verband Elisabeth I. eine heroische Selbstinszenierung mit dem Versuch, eine solche Selbstdarstellung im Bereich des politisch Unverbindlichen zu halten. Auf das Programm eines Krieges gegen Spanien à l'outrance wollte sie sich nicht festlegen lassen, auch wenn es erst ihrem Nachfolger Jakob VI. von Schottland, der als Jakob I. 1603 den englischen Thron bestieg, gelang, den Streit mit dem alten Gegner 1604 beizulegen. Während für andere Herrscher der Epoche die Inszenierung als siegreicher Heerführer oder Imperator schon fast ein Pflichtprogramm war, hatte der Stuartkönig es schon in Schottland vermieden, sich auf ein solches Rollenmodell festzulegen. Jakob sah sich vor 1603 in Schottland, wo er formal seit 1567, in der Praxis aber seit den späten 1580er Jahren regierte, mit einem kriegerischen Adel konfrontiert, der durch eine Kultur der Gewalt geprägt war. Anders als seine Vorgänger auf dem schottischen Thron, von denen in den letzten rund 150 Jahren kaum einer eines natürlichen Todes gestorben war, trat Jakob bewusst nicht als heroischer Kämpfer auf, sondern eher als Gelehrter und Theologe, bisweilen auch als Dichter auf dem Königsthron. Das war ein deutlicher Gegenentwurf zum herrschenden Adelsideal, aber auch - auf subtilere Weise - zum Leitbild des gottesfürchtigen Streiters für den rechten Glauben, wie es Genf und Rom auf je unterschiedliche Weise beide propagierten. Durch eine bewusst friedfertige, unheroische Haltung versuchte Jakob VI und I., den konfessionellen Radikalismus ebenso wie den Gewalthabitus der schottischen Aristokratie zu desavouieren und zu unterlaufen. ${ }^{1}$ In gewisser Hinsicht könnte man ihn fast mit Heinrich III. von Frankreich vergleichen, der ja ebenfalls aus Worten Taten werden lassen wollte. Wie Heinrich III. sah sich Jakob I. dann auch in späteren Jahren mit dem Vorwurf konfrontiert, kein wahrhaft

1 Vgl. Ronald G. Asch, Jakob I. (1566-1625). König von England und Schottland, Stuttgart 2005; Michael Lynch, Court Ceremony and Ritual during the Personal Reign of James VI, in: Julian Goodare / Michael Lynch (Hrsg.), The Reign of James VI, East Linton 2000, S. 71-92; Malcolm Smuts, The Making of Rex Pacificus: James VI and I and the Problem of Peace in an Age of Religious War, in: Daniel Fischlin / Mark Fortier (Hrsg.), Royal Subjects. Essays on the Writings of James VI and I, Detroit, MI 2002, S. 371-387. Vgl. Nick Myers, Hercule Gaulois, Great Britain's Solomon. Myths of Persuasion, Styles of Authority, in: Eveline Cruickshanks (Hrsg.), The Stuart Courts, Stroud [u.a.] 2000, S. 29-42. Zur Identifikation Jakobs mit Salomon auch David Howarth, Images of Rule. Art and Politics in the English Renaissance, 1485-1649, Basingstoke [u.a.] 1997, S. 120-124. Vgl. auch Ronald G. Asch, Märtyrer, Mörder und Monarchen. Das Königtum zwischen Heroismus und Heroismus-Defizit. Ein Vergleich zwischen England und Frankreich (1589-1628), in: Achim Aurnhammer / Manfred Pfister (Hrsg.), Heroen und Heroisierungen in der Renaissance (Wolfenbütteler Abhandlungen zur Renaissanceforschung; 28), Wiesbaden 2013, S. 283-302. Die folgenden Ausführungen beruhen zum Teil auf diesem Aufsatz. 
männlicher Herrscher zu sein, zumal er um sich Favoriten versammelte, zu denen er eine deutlich homoerotisch gefärbte Freundschaft unterhielt.

Dennoch war Jakob I. lange Jahre deutlich erfolgreicher als es Heinrich III. in Frankreich je gewesen war. Der Stuart-König inszenierte sich nicht zuletzt schon in jungen Jahren als Ausleger der Heiligen Schrift; er machte seinen Theologen auf ihrem eigenen Gebiet Konkurrenz. Dabei stilisierte er sich als ein neuer König David, der ja nicht nur der Sieger über Goliath, sondern auch der Psalmendichter gewesen war. ${ }^{2}$ Am liebsten war dem Monarchen freilich die Rolle des gelehrten Königs, der wie Salomon durch seine Weisheit herrschte und in einer Welt des Krieges dem Frieden eine Chance verschaffte. ${ }^{3}$

Allerdings, ein König, der sich vor allem als Friedensfürst, also gerade nicht als kriegerischer Held verstand, konnte leicht mit dem Problem eines strukturellen Heroismus-Defizits konfrontiert werden, wenn man das so formulieren will. Denn in der politischen Führungsschicht, aber auch in der Bevölkerung insgesamt, lebten die alten Feindbilder weiter, das päpstliche Rom und das katholische Spanien vor allem, die durch salomonische Weisheit und die prophetengleiche Schriftauslegung des Königs vielleicht doch nicht ganz zu bändigen waren. Unter diesem Umständen konnte es ein Vorteil, aber auch eine Gefahr sein, wenn der Monarch von Verwandten und Gefolgsleuten umgeben war, die das verkörperten, was er für seine Person ablehnte, einen kämpferisch heroischen Habitus. Sie konnten gewissermaßen eine komplementäre Rolle spielen, die seine eigene ergänzte. Am stärksten galt dies wohl für den 1612 in jungen Jahren verstorbenen Thronfolger, den Prinzen Henry, den ältesten Sohn des Königs. Er ließ sich um 1610 bei Turnieren und in Maskenspielen als Erbe der Ideale des nun freilich konfessionell überformten mittelalterlichen Rittertums feiern, das in der elisabethanischen Zeit schon eine bemerkenswerte Renaissance erlebt hatte. In seinem von Ben Jonson entworfenen Maskenspiel von 1610 „Prince Henry's Barriers“ oder „The Lady of the Lake" wurde die Welt des König Artus und seiner Ritter beschworen. Allerdings ließ Ben Jonson den Zauberer Merlin auch betonen, dass der König - also Jakob I. - selbst der wahre Herkules sei, denn der größte Sieg sei der über sich selbst oder wie Martin Butler, der Interpret dieses Maskenspiels, es formuliert hat, „true Herculean virtue, said Merlin, was not physical fighting but the secret heroics inside James’s breast“. ${ }^{4}$ Dies war eine bemerkenswerte Psychologisierung und Sub-

2 Vgl. John N. King, James I and King David. Jacobean Iconography and its Legacy, in: Daniel Fischlin / Mark Fortier (Hrsg.), Royal Subjects. Essays on the Writings of James VI and I, Detroit, MI 2002, S. 421-453; Jane Rickard, Authorship and Authority. The Writings of James VI and I, Manchester 2007.

3 Vgl. Lori A. Ferrell, Government by Polemic. James I, the King's Preachers, and the Rhetoric of Conformity, 1603-1625, Stanford, CA 1998, S. 116-125, S. 136-137.

4 Martin Butler, The Stuart Court Masque and Political Culture, Cambridge 2008, S. 183. $\mathrm{Zu}$ Prince Henry siehe auch Roy C. Strong, Henry, Prince of Wales and England's Lost Renaissance, London 1986; Catherine MacLeod (Hrsg.), The Lost Prince. The Life and Death of Henry Stuart, London 2012. 
limierung des Heroischen, die aber nicht jeden Zuschauer überzeugt haben wird, zumal Jakob I. anders als Heinrich IV. von Frankreich nicht der kriegerische Herrscher war, der nach vielen Siegen auf dem Schlachtfeld am Ende auch sich selbst überwand, sondern als eher furchtsam galt.

Längerfristig hätte die heroisch-kriegerische Selbstinszenierung des Thronfolgers für den König zur Gefahr werden können, aber Henry starb, wie gesagt, in jungen Jahren. Dichter wie George Chapman, der englische Übersetzer Homers, der 1598 diese Übersetzung dem Earl of Essex als dem letzten Helden der Gegenwart gewidmet hatte, ${ }^{5}$ priesen ihn nach seinem Tode als einen ,absolute man“, der die Stärke und den Mut eines Achill mit der Intelligenz und Klugheit des Odyssseus vereinte, dabei aber doch jede machiavellistische Verstellung abgelehnt habe. ${ }^{6}$

In gewisser Weise wurde Henrys Schwester Elisabeth, die 1613 den Kurfürsten von der Pfalz heiratete, Erbin dieser heroisch-ritterlichen Tradition, die bis in den Dreißigjährigen Krieg hineinreichen sollte und nach 1618 als gefährliches Gegenbild zur Appeasement-Politik ihres Vaters wirkte. ${ }^{7}$ Auch der nach 1616 rasch zu einer fast monopolartigen Machtstellung aufsteigende Favorit des Königs, der jugendliche Marquess und Duke of Buckingham, der seit 1618 auch die höchste militärische Kommandostelle, die eines Lord Admiral, innehatte, versuchte sich gegen Ende der Regierungszeit Jakobs I., besonders nach dem Scheitern des Ausgleichs mit Spanien 1623, eine kriegerische Pose zu eigen zu machen. Den Höhepunkt erreichte diese Selbstinszenierung zwar erst nach dem Tode Jakobs I. 1625, aber erste Ansätze waren schon vorher zu erkennen. Auch in Buckinghams Fall wird freilich erkennbar: Helden mögen konstruiert sein, aber solche Konstruktionen sind immer in einem kulturellen Umfeld angesiedelt, das der Glaubwürdigkeit von heroischen Tugend-Zuschreibungen Grenzen setzt.

Der Herzog von Buckingham trat ab 1624 zunehmend als Feldherr und Krieger auf. Ein großes Reiterporträt von Rubens, dessen Entwurf aus dem Jahre 1625 stammte, stellte Buckingham als Feldherr und Admiral - die Flotte war im Hintergrund zu sehen - dar, der Gestus war nahezu königlich oder imperial. ${ }^{8} \mathrm{Als} \mathrm{Bu-}$ ckingham 1627 vom Krieg gegen Spanien auf einen Feldzug gegen Frankreich umschwenkte, berief sich seine Kriegspropaganda ausdrücklich auf das Vorbild des

\footnotetext{
Vgl. Sukic, The Earl of Essex, S. 418-432.

6 Vgl. Gilles Bertheau, Prince Henry as Chapman's 'Absolute Main', in: Timothy Wilks (Hrsg.), Prince Henry Revived. Image and Exemplarity in Early Modern England, Southampton 2007, S. 134-145, besonders S. 140.

7 Zu Elisabeth siehe Sara Smart / Mara R. Wade (Hrsg.), The Palatine Wedding of 1613. Protestant Alliance and Court Festival (Wolfenbütteler Abhandlungen zur Renaissanceforschung; 29), Wiesbaden 2013; Ronald G. Asch, Art. Elizabeth of Bohemia, in: Oxford Dictionary of National Biography, 2004, DOI 10.1093/ref:odnb/8638.

8 Alastair Bellany, Buckingham's Painted Selves, in: Kevin Sharpe / Steven N. Zwicker (Hrsg.), Writing Lives. Biography and Textuality, Identity and Representation in Early Modern England, Oxford 2008, S. 127-160, hier S. 154.
} 
Hundertjährigen Krieges und das der Schlacht von Agincourt. ${ }^{9}$ Allerdings, die militärischen Erfolge blieben aus. Dass Buckingham das Projekt eines militärischen Sieges, ob nun gegen Spanien oder gegen Frankreich, dennoch mit Leidenschaft, ja mit Fanatismus weiter verfolgte, mag, wie Alastair Bellany gemeint hat, auch der Tatsache geschuldet gewesen sein, dass er zum Gefangenen seiner eigenen Rolle wurde. Wenn er wirklich begonnen hatte, sich selbst mit den Augen eines Rubens zu sehen, der ihn in großer heroischer Pose mehr als einmal gemalt hatte, dann war es allerdings fast unmöglich, einen erfolglosen Waffengang einfach abzubrechen, um zur Tagesordnung überzugehen, was freilich auch in der Öffentlichkeit sein Renommee endgültig zerstört hätte. ${ }^{10} 1628$ bereitete der Dolch eines Attentäters dem Leben des Favoriten ein vorzeitiges Ende. Gerade der missglückte Versuch des Favoriten, sich als kriegerischer Heros zu inszenieren, hatte diese Reaktion provoziert. ${ }^{11}$

Ein Grundproblem für Jakob I. war, dass er sich mit einem militanten Protestantismus im eigenen Land konfrontiert sah, der im heroischen Kampf gegen die Mächte der Finsternis die eigentliche Berufung der Gottesfürchtigen, der godly, aber eben auch der englischen Nation als Ganzer sah, eine Einstellung, die von strengen Calvinisten in Schottland und in Irland mutatis mutandis durchaus geteilt wurde. In Frankreich kam es in den Jahren nach dem Ende der Religionskriege zu einer Internalisierung und Sublimierung der konfessionellen Militanz. Die Askese und die mystische Versenkung, die oft auch als ein Kampf mit dämonischen Kräften gesehen wurde, boten denjenigen, die den heroischen Kampf für die wahre Kirche führen wollten, auch noch nach dem Ende der Religionskriege eine Möglichkeit, sich als Glaubenskrieger zu fühlen, ohne zum Schwert zu greifen - Männern ebenso wie Frauen. ${ }^{12}$ Ein heroisches Frömmigkeitsideal konnte sich auf diese Weise durchaus mit der Bereitschaft verbinden, eine pragmatische Politik zu unterstützen, die Kompromisse mit dem konfessionellen Gegner nicht ausschloss. Der Berater Richelieus, der Kapuziner Père Joseph, ist dafür das beste Beispiel. ${ }^{13}$ Ein Äquivalent zu diesem catholicisime d'état fehlte in England. Wer die auf kon-

9 Thomas Cogswell, The People's Love. The Duke of Buckingham and Popularity, in: Thomas Cogswell [et al.] (Hrsg.), Politics, Religion and Popularity in Early Stuart Britain. Essays in Honour of Conrad Russell, Cambridge 2002, S. 211-234, hier S. 226-227.

10 Thomas Cogswell / Peter Lake, Buckingham Does the Globe. Henry VIII and the Politics of Popularity in the 1620s, in: Shakespeare Quarterly 60, Heft 3, 2009, S. 253-278, hier S. 278.

11 Zum Attentat Alastair Bellany, "The Enigma of the World". Memorializing and Remembering George Villiers, First Duke of Buckingham in the Aftermath of Assassination, c. 16281642, in: Martin Wrede / Horst Carl (Hrsg.), Zwischen Schande und Ehre. Erinnerungsbrüche und die Kontinuität des Hauses, Legitimationsmuster und Traditionsverständnis des frühneuzeitlichen Adels in Umbruch und Krise (Veröffentlichungen des Instituts für Europäische Geschichte Mainz, Abt. Universalgeschichte; 73), Mainz 2007, S. 27-52; Thomas Cogswell, John Felton, Popular Political Culture, and the Assassination of the Duke of Buckingham, in: Historical Journal 49, Heft 2, 2006, S. 357-385.

12 Siehe S. 48.

13 Siehe S. 71, Anm. 28. 
fessionellen Ausgleich und Frieden angelegte Politik des Königs unterstützte, der distanzierte sich meist auch theologisch vom strengen Calvinismus. Das galt ganz sicherlich für die Gruppe der sogenannten Ceremonialists oder Conformists unter den Theologen und Prälaten der Church of England, die oft auch die Prädestinationslehre in ihrer strengen Form verwarfen und zum Arminianismus neigten. ${ }^{14}$ Rom war hier zwar immer noch ein Gegner, aber nicht notwendigerweise stärker als Genf, also der militante Calvinismus. Nicht der heroische Kampf auf Leben und Tod gegen die Hure Babylon stand für die Advokaten einer theologischen via media in der Church of England auf der Tagesordnung, sondern eine Politik, die versuchte, durch begrenzte Zugeständnisse gemäßigte Katholiken und KryptoKatholiken in die Church of England zu integrieren. ${ }^{15}$ Das manichäische Weltbild der Puritaner, das nur Schwarz und Weiß kannte, wurde von den Conformists bewusst verworfen.

Auch der Puritanismus hatte sich freilich seit dem späten 16. Jahrhundert gewandelt. Die Hoffnung, in näherer Zukunft die Kirchenverfassung der Church of England tiefgreifend verändern und durch eine zweite Reformation die erste vollenden zu können, hatte man schon in den 1590er Jahren begraben müssen. Die führenden puritanischen Theologen mussten sich nun darauf einstellen, dass die godly, die Gottesfürchtigen, nur eine Minderheit in einem Land waren, in dem die ,Lauen' und Kompromissler, deren Protestantismus sich nicht am Ideal des heroischen Kampfes und am Vorbild der Märtyrer der Vergangenheit orientierte, sondern eher am Ideal einer Ökumene der Moderaten, immer mehr an Einfluss gewannen. Eine Verinnerlichung der puritanischen Frömmigkeit und eine Beschränkung der reformatio vitae auf eine Elite der wahrhaft Bekehrten lassen sich daher im frühen 17. Jahrhundert durchaus feststellen. Es ging jetzt nicht mehr primär darum, die Struktur der Kirche zu verändern, sondern einen neuen, wahrhaft christlichen Menschen zu schaffen. Eine jüngere Studie hat dies auf den Nenner gebracht: „Never before, never in Zurich, Geneva, Heidelberg or Scotland, has so ambitious a campaign been mounted to hammer and resculpt the self“. ${ }^{16}$ Für die Puritaner

$14 \mathrm{Zu}$ diesen Strömungen siehe Nicholas Tyacke, Anti-Calvinists. The Rise of English Arminianism, c. 1590-1640 (Oxford Historical Monographs), Oxford 1987, S. 19; Calvin Lane, The Laudians and the Elizabethan Church. History, Conformity and Religious Identity in Post-Reformation England Religious Cultures in the Early Modern World), London 2013; Charles W. A. Prior, Defining the Jacobean Church. The Politics of Religious Controversy, 1603-1625 (Cambridge Studies in Early Modern British History), Cambridge 2005; Peter Lake, Lancelot Andrewes, John Buckeridge and Avant-garde Conformity at the Court of James I, in: Linda L. Peck (Hrsg.), The Mental World of the Jacobean Court, Cambridge 1991, S. 113-133; ferner Kenneth Fincham / Nicholas Tyacke, Altars Restored. The Changing Face of English Religious Worship, 1547-c. 1700, Oxford 2007, S. 126-273.

15 Dazu Ferrell, Government by Polemic; Anthony Milton, Catholic and Reformed. The Roman and Protestant Churches in English Protestant Thought, 1600-1640 (Cambridge Studies in Early Modern British History), Cambridge 1995.

16 Theodore D. Bozeman, The Precisianist Strain. Disciplinary Religion and Antinomian Backlash in Puritanism to 1638, Chapel Hill, NC 2004, S. 92, vgl. S. 63-83. 
des frühen 17. Jahrhunderts war das ganze Leben ein einziger heroischer Kampf gegen die eigene Schwäche, aber auch gegen die Versuchungen einer gottlosen Welt. ${ }^{17}$ Hier gab es durchaus Parallelen zur Internalisierung des militanten Katholizismus in Frankreich nach 1598. ${ }^{18}$ Strenge Calvinisten kämpften in England nun nicht mehr für die Einschränkung der Autorität der Bischöfe und für ein umfassendes System der Sündenzucht nach dem Vorbild Genfs und anderer reformatorischer Kirchen, sondern begnügten sich damit, sich in Gebetskreisen und Konventikeln zusammenzuschließen. Die strenge Sittenzucht, die durchaus auch Züge einer innerweltlichen Askese trug, blieb nun - jedenfalls für den Moment - beschränkt auf die Minderheit der wirklich Frommen. Allerdings, die agonalen, kämpferischen Züge der puritanischen Bewegung verloren ihr Destabilisierungspotenzial deshalb nicht, denn zugleich mit dieser Verinnerlichung der Frömmigkeit spitzte sich die apokalyptische Weltsicht der godly zu. ${ }^{19}$ Immer lauter wurden im frühen 17. Jahrhundert die Stimmen derjenigen, die einen nahenden eschatologischen Endkampf heraufbeschworen, der all diejenigen vernichten würde, die dem Beispiel Laodiceas aus der Offenbarung des Johannes folgten, also versuchten, sich nicht festzulegen und sich der Pflicht zum Kampf zu entziehen. Die Figur des heroischen Märtyrers, die die Offenbarung des Johannes heraufbeschwor, etwa in Gestalt der zwei Zeugen in Kapitel 11, wurde sehr nachdrücklich als Präfiguration des eigenen Handelns in der Gegenwart verstanden, ${ }^{20}$ sei es, dass man nun die Gottesfürchtigen kollektiv in der Rolle der Zeugen sah, die für Gottes Wort litten und erst im Moment des Sieges über den Teufel triumphierten, oder dass sogar das Leben und die Taten einzelner Kämpfer gegen die weltliche und kirchliche Tyrannis vor dieser Folie interpretiert wurden. Sir Henry Vane der Jüngere, einer der Wortführer des Unterhauses im Kampf gegen Karl I. zwischen 1640 und 1649 und später des Par-

17 Vgl. ebd., S. 103.

18 Patrick Collinson, The Religion of Protestants. The Church in English Society 1559-1625 (The Ford Lectures Delivered in the University of Oxford 1979), Oxford 1982, Kap. 6, Voluntary Religion; Tom Webster, Early Stuart Puritanism, in: John Coffey / John C. H. Lim (Hrsg.), The Cambridge Companion to Puritanism (Cambridge Companions to Religion), Cambridge 2008, S. 48-66; Ders., Godly Clergy in Early Stuart England. The Caroline Puritan Movement, c. 1620-1643 (Cambridge Studies in Early Modern British History), Cambridge 1997; Leif Dixon, Practical Predestinarians in England, c. 1590-1640, Farnham 2014. Zur Entwicklung in der Kirche siehe jetzt auch Andrew Foster, The Church of England 1570-1640 [1994], Abingdon 22013.

19 Siehe dazu Milton, Catholic and Reformed, S. 93-104; Patrick Collinson, The Birthpangs of Protestant England. Religious and Cultural Change in the Sixteenth and Seventeenth Centuries (The Anstey Memorial Lectures in the University of Kent at Canterbury; 3), Basingstoke 1988, S. 1-27; Jeffrey K. Jue, Heaven upon Earth. Joseph Mede (1586-1638) and the Legacy of Millenarianism (Archives internationals d'histoire des idées; 194), Dordrecht 2006. Zur Ambilanz der Idee, England sei eine oder die „auserwählte Nation“: Alexandra Walsham, Providence in Early Modern England, Oxford 1999, S. 281-325. Siehe ferner John Coffey, The Impact of Apocalyptism during the Puritan Revolution, in: Perichoresis 4, Heft 2, 2006, S. 117-147.

20 Rodney L. Petersen, Preaching in the Last Days. The Theme of "Two Witnesses" in the $16^{\text {th }}$ and $17^{\text {th }}$ Centuries, Oxford 1993, S. 203-212. 
laments der Republik in den Jahren 1649 bis 1653, sah sich offenbar gegen Ende seines Lebens selbst in der Rolle eines der beiden Zeugen und ähnliche Deutungen hatte es auch gegenüber den Opfern der ,Eleven Years Tyranny', der autokratischen Herrschaft Karls I. in den 1630er Jahren, zeitweilig gegeben. ${ }^{21}$

Für diejenigen, die glaubten, das Ende der Zeiten nahe und damit der Kampf zwischen dem Antichristen und der wahren Kirche, war es jedenfalls unmöglich, sich auf eine Politik des Ausgleichs gegenüber der Römischen Kirche und der spanischen Monarchie, der wichtigsten katholischen Macht in Europa, einzulassen. Das galt namentlich nach Ausbruch des Dreißigjährigen Krieges, eines Ereignisses, welches das manichäische Weltbild vieler Puritaner zu bestätigen schien und von ihnen als Aufforderung verstanden wurde, den Kampf gegen Rom mit umso größerem Nachdruck zu führen. Selbst der Erzbischof von Canterbury, Abbot, deutete das politische Geschehen ähnlich und schrieb: „Methinks I do in this, [...] foresee the work of God, that by piece and piece, the Kings of the Earth, that gave their power unto the Beast (all the word of God must be fulfilled) shall now tear the 'Whore and make her desolate', as St. John in his Revelation hath foretold".22

Zwischen dem heroischen Kampf gegen die Mächte der Finsternis und einem Verrat am wahren Glauben schien es nun erst recht keinen dritten Weg mehr zu geben. Dies stellte für den König, der 1625 den englischen Thron bestieg, für Karl I., ein erhebliches Problem dar. Er hatte sich zwar zunächst auf einen Krieg gegen Spanien eingelassen, diesen aber nach einigen Misserfolgen rasch wieder abgebrochen. Sein Kampf für die französischen Hugenotten in den Jahren 1627/28 - gegen die französische Krone - blieb ebenfalls erfolglos. Als Anführer eines protestantischen Kreuzzugs war er überdies wenig glaubwürdig, denn vor seiner Thronbesteigung war er nach Spanien gereist, um dem Projekt einer Heirat mit einer spanischen Infantin Nachdruck zu verleihen. Zu dieser Eheverbindung war es zwar nie gekommen, doch heiratete er später eine Katholikin, eine Schwester des französischen Königs. Nachdem er sich 1629/30 endgültig von einer kriegerischen Außenpolitik abgewandt hatte, stellte sich umso nachhaltiger die Frage, wie er sich darstellen sollte. Als Gelehrter, Theologe und Prophet, aber auch als Friedensfürst wie sein Vater wollte er sich nicht inszenieren, schon deshalb, weil er eben kein Mann des Wortes war, sondern in seiner Selbstdarstellung eher auf Bil-

21 Henry Burton, einer der Theologen, der wegen seiner Opposition gegen die königliche Kirchenpolitik in den 1630er Jahren von der Star Chamber hart bestraft worden war, sah anscheinend sich selbst 1640/41 in der Rolle eines der beiden Zeugen. Siehe Henry Burton, The Sounding of the Two Last Trumpets, the Sixth and Seventh or Meditations by Way of Paraphrase upon the $9^{\text {th }}, 10^{\text {th }}$ and $11^{\text {th }}$ Chapters of the Revelation, as containing a Prophecie of these Last Times, London 21641, Preface, keine Seitenzahlen; Petersen, Preaching in the Last Days, S. 213-216; zu Vane unten, S. 101-102.

22 Erzbischof Abbot an Naunton, ohne Datum [1619], in: Cabala sive scrinia sacra: Mysteries of State and Government in Letters of [...] Great Ministers of State, London 1691, S. 102-103. 
der und Gesten setzte. Er sah, wie betont wurde, „visual symbolism and outward ceremony“ als wirksamere Mittel an, um seine Herrschaft zu legitimieren, als Reden oder Traktate. ${ }^{23}$ Stärker und nachhaltiger als sein Vater trat Karl I. als Kunstmäzen auf und ließ sich als solcher feiern. Man könnte sagen, dass er in dieser Hinsicht mit dem klassischen Gestus des ,Kunsthelden ${ }^{6}$ auftrat, ${ }^{24}$ dies verband er jedoch mit dem Anspruch auf eine imperiale Rolle. Das berühmte Reiterbild van Dycks von 1633 („Charles I with M. de St Antoine“) 25 zeigte ihn nicht nur unter einem römischen Triumphbogen, das Pferd konnte auch als Anspielung auf die eigenen Leidenschaften gedeutet werden, die der König erfolgreich gezähmt hatte. ${ }^{26}$ Aber Karl I. trat auch selbst in Maskenspielen als römisch-britischer Kaiser auf, so Anfang der 1630er Jahre als britischer Imperator Albanactus in „Albion's Triumph". Wie in der Forschung betont worden ist, diente dem Dichter des Maskenspiels, Aurelian Townsend, ganz offenbar der letzte der Severer, Alexander Severus (reg. 222-235), als Vorbild für die Figur des Albanactus. Alexander hatte wenig große militärische Erfolge errungen, wurde in der „Historia Augusta“ aber als vorbildlicher Herrscher und Förderer der Künste dargestellt. Moralisch über jeden Zweifel erhaben, nahm er seine Pflichten als pontifex maximus sehr ernst (hier ergaben sich Parallelen zu Karls Rolle als supreme governor der englischen Kirche) und war doch zugleich tolerant gegenüber dem Christentum. ${ }^{27}$ Jedenfalls war die Imperatorenrolle, die Karl I. in den masques, die bei Hof aufgeführt wurden, aber auch in der bildenden Kunst spielte, eher die eines inneren Herrschertums. Seine heroische Größe bestand im Sieg über sich selbst, in seiner Tugend im Glanz eines sittenstrengen Hofes, weniger in großen militärischen Triumphen, die er nicht vorzuweisen hatte. ${ }^{28}$ Das Vokabular, auf das Dichter und Künstler zurückgriffen, um den König zu heroisieren, konnte dabei wahlweise das der antiken Mythologie und Geschichte oder das der ritterlichen Tradition sein. So erschien der König im Maskenspiel „Coelum Britannicum“ 1633 als ein neuer König Artus umgeben von , ancient heroes', während Rubens ihn als St. Georg malte, der

23 Kenneth Fincham / Peter Lake, The Ecclesiastical Policies of James I and Charles I, in: Kenneth Fincham (Hrsg.), The Early Stuart Church 1603-1642 (Problems in Focus), Basingstoke 1993, S. 23-50, hier S. 48; vgl. Kevin Sharpe, Image Wars. Promoting Kings and Commonwealths in England, 1603-1660, New Haven, CT 2010, S. 144-190.

24 Zum Kunsthelden siehe Christina Posselt-Kuhli, Der ,Kunstheld“ im Spannungsfeld zwischen Krieg und Frieden. Ein herrscherliches Tugendexempel im Deutschland des 17. Jahrhunderts, in: helden. heroes. héros. E-Journal zu Kulturen des Heroischen 2, Heft 2, 2014, S. 17-35, DOI 10.6094/helden.heroes.heros./2014/02/03.

25 Das Bild ist im Besitz der britischen Königin und befindet sich in Windsor Castle, siehe auch http://www.royalcollection.org.uk/collection/405322/charles-i-1600-1649-with-m-dest-antoine, 20. Juli 2015.

26 Vgl. John Peacock, The Image of Charles I as a Roman Emperor, in: Ian Atherton / Julie Sanders (Hrsg.), The 1630s. Interdisciplinary Essays on Culture and Politics in the Caroline Era (Politics, Culture and Society in Early Modern Britain), Manchester 2006, S. 50-73.

27 Vgl. ebd., S. 59-67.

28 Vgl. Butler, The Stuart Court Masque and Political Culture, S. 183. 
Schutzpatron Englands und des Hosenbandordens, aber eben auch ein exemplarischer Ritter und Held. ${ }^{29}$ Karl I. wurde von der höfischen Kunst und Dichtung faktisch ein virtuelles Heldentum zugeschrieben. Es sollte gezeigt werden, dass der König dachte und fühlte wie ein Held und sich auch so verhielt, auch wenn er keine wirklichen Heldentaten in der realen Welt der Politik und des Krieges vollbrachte. ${ }^{30}$ Nun war es gerade im Zeitalter der Spätrenaissance und des Barock nicht unüblich, dass der Herrscher in heroischer Pose inszeniert wurde, ohne dass eine solche Pose einen unmittelbaren Realitätsbezug haben musste. Das galt ja bis zu einem gewissen Grade später auch für Ludwig XIV. Das Heroische wurde hier zu einer rhetorischen Geste. Wer die heroische Rolle überzeugend spielte, der war eben ein Held, auch wenn er nie im Krieg gekämpft hatte. ${ }^{31}$ Karl I. befand sich freilich in der unglücklichen Lage, sich einem Vergleich mit Herrschern stellen zu müssen, die eben wirkliche Gegner - nicht nur Fabeltiere und Bühnen-Unholde mit dem Schwert besiegt hatten und womöglich sogar im Kampf gefallen waren. Das galt ganz besonders für den protestantischen Helden dieser Epoche schlechthin, für Gustav Adolf von Schweden. Er war zwar schon 1632 gefallen, aber gerade in England und noch mehr in Schottland, das als Rekrutierungsgebiet für die schwedischen Armeen der 1630er Jahre eine ganz zentrale Bedeutung hatte, blieb er unvergessen. Es waren frühere Offiziere Gustav Adolfs, die sich 1639 an die Spitze der Armee der schottischen Covenanters setzten, und damit die Herrschaft Karls. I. zu Fall brachten. ${ }^{32}$

Die Herausforderung durch den Aufstand in Schottland, vor allem aber durch den Ausbruch des Bürgerkrieges in England 1642 nötigte den König, seine Selbstdarstellung zu ändern. Porträts oder Grafiken, die ihn oder den Thronerben im Harnisch des ritterlichen Kriegers zeigten, bestimmten nun das Bild des Königs. ${ }^{33}$ Was den Darstellungen des Königs dabei meist fehlte, war der Gestus

29 Sharpe, Image Wars, S. 242; Richard Cust, Charles I. A Political Life, Harlow 2005, S. 161; Roberta F. Brinkley, Arthurian Legend in the $17^{\text {th }}$ Century [1932], Abingdon ${ }^{3} 2014$, S. 101-102.

30 Vgl. Peacock, The Image of Charles I, S. 55; Claudia Blümle, Souveränität im Bild. Anthonis van Dycks Reiterporträt Karls I., in: Horst Bredekamp / Pablo Schneider (Hrsg.), Visuelle Argumentationen. Die Mysterien der Repräsentation und die Berechenbarkeit der Welt (Kulturtechnik), München 2006, S. 79-102.

31 Dazu auch Disselkamp, Barockheroismus, S. 180-185.

32 Zur Bedeutung Schwedens namentlich für die Revolution in Schottland Ende der 1630er Jahre siehe Alexia Grosjean, General Alexander Leslie, The Scottish Covenanters and the Riksrad Debates, 1638-1640, in: Allan I. Macinnes [et al.] (Hrsg.), Ships, Guns and Bibles in the North Seas and Baltic States, c. 1350-1700, East Linton 2000, S. 115-138, besonders S. 124-126; vgl. Steve Murdoch (Hrsg.), Scotland and the Thirty Years' War 1618-1648 (History of Warfare; 6), Leiden 2001. Zur Verherrlichung des Königs siehe Achim Aurnhammer, Der intermediale Held. Heroisierungsstrategien in den Epicedien auf König Gustav II. Adolf von Paul Fleming, Johann Rist und Georg Rodolf Weckherlin, in: Achim Aurnhammer / Manfred Pfister (Hrsg.), Heroen und Heroisierungen in der Renaissance (Wolfenbütteler Abhandlungen zur Renaissanceforschung; 28), Wiesbaden 2013, S. 303-332.

33 Vgl. Sharpe, Image Wars, S. 340-342. 
des flamboyanten Draufgängertums, durch den sich viele royalistische Offiziere und Kommandeure sonst auszeichneten. Das Bild, das der Maler William Dobson von John Byron, dem ersten Lord Byron, während des Krieges malte, ist dafür bezeichnend. Byron stand hier vor einer geschwungenen barocken Säule und deutete mit großer Geste auf ein Schlachtfeld. Neben ihm hielt ein afrikanischer Diener ein Schlachtross, wohl in Anlehnung an entsprechende Bilder van Dycks, die den König in einer vergleichbaren Pose gezeigt hatten. ${ }^{34}$

Die Royalisten ließen sich stark von einem Ideal der individuellen Ehre leiten, das im Verlauf des Krieges zu einer agonalen Konkurrenz und zu erheblichen Konflikten innerhalb des königstreuen Lagers führte. Duelle waren in den royalistischen Garnisonen an der Tagesordnung. Das spezifisch royalistische Ideal von Ehre verband sich mit einem Leitbild der persönlichen Tapferkeit und der spektakulären militärischen Tat. Doch erwies sich die Überlegenheit des kriegerischen Helden gegenüber normalen Sterblichen auch durch den Regelbruch und die Verletzung von Normen. Transgression und Heroismus gingen hier eine enge Verbindung ein, die der Gegenseite auch zahlreiche Angriffsflächen bot und aus ihrer Sicht diese Form des Heroismus generell desavouierte. Panegyrische Schriften von royalistischer Seite versuchten hingegen, ein Bild heroischen Verhaltens zu schaffen, das auch von der kontinentaleuropäischen Adelskultur inspiriert war. Die heroische Leistung sollte dabei besonders im Fall katholischer Offiziere auch die mangelnde konfessionelle Anpassung kompensieren. ${ }^{35}$

Royalisten waren von Anfang an stark durch persönliche Loyalität gegenüber dem König motiviert und durch ein Ehrgefühl, das es ihnen als unmöglich erscheinen ließ, sich der Pflicht, für ihren Herrscher zu kämpfen, zu entziehen, selbst wenn sie seine Politik vielleicht nicht ohne Vorbehalte billigen konnten. ${ }^{36}$ Dieses persönliche Ehrgefühl erschwerte aber auch eine reibungslose Zusammenarbeit zwischen den Offizieren des Königs. Wer dem Prinzip folgte „nemo me impune lacessit“" (,niemand reizt mich ungestraft“), mochte sich durch besonderen Mut im Kampf gegen den Gegner auszeichnen, aber er konnte auch plötzlich die Seiten wechseln, weil er sich durch einen anderen Offizier oder durch seinen Kommandeur beleidigt fühlte - falls er es nicht vorzog, für eine solche Beleidigung Genugtuung in einem Zweikampf zu fordern. Die Tatsache, dass eine Fülle

34 Vgl. Andrew Wilton, The Swagger Portrait. Grand Manner Portraiture in Britain from Van Dyck to Augustus John, 1630-1930, London 1992, S. 80-81; zu Byron siehe auch Ronald Hutton, The Royalist War Effort, 1642-1646, London 1982, S. 120-128.

35 Vgl. Ian Roy, Royalist Reputations: the Cavalier Ideal and the Reality, in: Jason McElligott / David L. Smith (Hrsg.), Royalists and Royalism during the English Civil Wars, Cambridge 2007, S. 89-111; vgl. Edward Walsingham, Alter Britanniae Heros, Oxford 1645; Ders., Britannicae Virtutis Imago, Oxford 1644.

36 Ein Beispiel dafür wäre Sir Edmund Verney, der 1642 bei Edgehill fiel, als er die königliche Standarte verteidigte, siehe Charles Carlton, Going to the Wars. The Experience of the British Civil Wars, London 1992, S. 50, S. 52; vgl. Susan E. Whyman, Art. Verney, Sir Edmund (1590-1642), in: Oxford Ditionary of National Biography, 2004, DOI 10.1093/ref:odnb/ 28228. 
von preisgünstigen panegyrischen Druckwerken und biographischen Abhandlungen es auch zweitrangigen Kommandeuren während des Bürgerkrieges erlaubte, sich als heroische Krieger darstellen zu lassen, verstärkte die agonale Konkurrenz zwischen den royalistischen Offizieren noch und führte zu zusätzlichen Spannungen. Die Konflikte hatten also auch eine spezifisch mediale Dimension. ${ }^{37}$

Auf der Seite des Parlaments spielte die individuelle Ehre des einzelnen Offiziers, sein Anspruch darauf, durch seine heroischen Taten Ruhm für sich und sein Geschlecht zu ernten, eine insgesamt geringere Rolle, was der Kohärenz der Armeen des Parlaments zugutekam. Zumindest in der Anfangsphase des Bürgerkrieges sahen sich die Kommandeure der Armee des Parlaments allerdings durchaus noch in der Tradition des ritterlichen Kriegers, der in diesem Fall für ständische Freiheiten und den wahren Glauben kämpfte. ${ }^{38}$ Auch militante Theologen wie Jeremiah Burroughs, der während des Bürgerkrieges die Armee des Parlaments durch Predigten zu motivieren suchte, die einen Heiligen Krieg heraufbeschworen, sahen zum Beispiel im dritten Earl of Essex, dem Oberkommandierenden auf parlamentarischer Seite, einen neuen Josua und ermunterten ihn mit den Worten: „Wherefore most noble Lord of our Hosts, Yea of the Hosts of God, goe on with true Heroicke magnanimity, and prosper, in the name of this glorious Lord of hosts" ${ }^{39}$ Erst in dem Maße, wie die zunächst hochadligen Stabsoffiziere und Generäle durch Offiziere ersetzt wurden, die aus der einfachen gentry stammten (die Self-Denying Ordinance von 3. April 1645 markierte hier einen wichtigen Einschnitt), trat diese Selbstdarstellung zurück.

Allerdings auch Regimentskommandeure, die streng puritanisch gesinnt waren, wie jener Oberst John Hutchinson, der später von seiner Frau Lucy in einer Biographie verherrlicht wurde, blieben in ihrem Habitus von den ständischen Verhaltensmustern der Renaissance geprägt, oder wie Gabriele Rippl es jüngst formuliert hat: „Although a Puritan and Anti-Royalist, Lucy Hutchinson, [...] presents her husband as a perfect Renaissance hero à la Castiglione ". ${ }^{40}$ Auf der Seite des Parla-

37 Vgl. Andrew Hopper, Turncoats and Renegadoes. Changing Sides during the English Civil Wars, Oxford 2012, S. 160, S. 177, siehe auch S. 149.

38 Zum Fortleben ritterlicher Traditionen in den Jahren vor 1640 und im Bürgerkrieg, auch auf parlamentarischer Seite siehe John S. A. Adamson, Chivalry and Political Culture in Caroline England, in: Kevin Sharpe / Peter Lake (Hrsg.), Culture and Politics in Early Stuart England (Problems in Focus), Basingstoke 1994, S. 161-198, hier S. 183-193, mit Verweis unter anderem auf das Begräbnis des Earl of Essex (zeitweiliger Oberbefehlshaber auf parlamentarischer Seite) 1646, bei dem die Herolde eine entscheidende Rolle spielten. Vgl. auch John S. A. Adamson, The Noble Revolt. The Overthrow of Charles I, London 2007. Jeremiah Burroughs, The Glorious Name of God, the Lord of Hosts. Opened in Two Sermons [Teil 4], London 1643, Epistle dedicatory, sign. A 3 recto.

40 Gabriele Rippl, "Merit, Justice, Gratitude, Duty, Fidelity”. Images of Masculinity in Autobiographies of Early Modern English Gentlewomen and Aristocrats, in: Stefan Horlacher (Hrsg.), Constructions of Masculinity in British Literature from the Middle Ages to the Present, Basingstoke 2011, S. 69-87, hier S. 82; vgl. Lucy Hutchinson, Memoirs of the Life of Colonel Hutchinson, hrsg. von Neil H. Keeble, London 1995, S. 45. 
ments stand dem individuellen Heldentum des einzelnen Offiziers aber immer der Gedanke gegenüber, dass die Truppen, die gegen den König kämpften, insgesamt eine Schar heroischer Gottesstreiter seien. So wie aus der Sicht puritanischer Theologen nicht mehr der König der Gesalbte des Herrn war, sondern die Gläubigen insgesamt oder auch eine gläubige Nation als von Gott gesalbt gedacht werden konnte, ${ }^{41}$ so war nun nicht mehr ein einzelner Heros das auserwählte Werkzeug der göttlichen Vorsehung, sondern eine ganze Armee. In diesem Sinne schrieb Joshua Sprigge in seiner „Anglia Reviva“, einer Geschichte der Feldzüge der New Model Army, dass man in den Taten dieser Armee leicht Werke Gottes erkennen könne: „I make no question, but you will easily discern a thread of divinity running through the whole proceeding of this army ". ${ }^{42}$ Schon Henry Burton hatte 1641 der ganzen Nation und nicht mehr einem gottesfürchtigen König die Aufgabe übertragen, in dieser Welt die Hure Babylon zu besiegen ${ }^{43}$ andere folgten ihm auf diesem Weg wie der schon erwähnte Jeremiah Burroughs. ${ }^{44}$ Eine besondere Rolle kam in diesem Kontext auch dem Parlament zu. Robert Zaller hat die Tendenz zur Sakralisierung dieser Institution mit den Worten beschrieben: „Parliament, representing the people, or the people themselves, in arms for their just liberties, and in God's cause, were the hosts of the Lord, the chosen of an elect nation" ${ }^{45}$ Mit dieser Sakralisierung des Kampfes gegen den König, die gleichzeitig einer kollektiven Heroisierung der Streiter für die Sache des Herrn gleichkam, wurde freilich auch jeder Kompromiss mit Karl. I. deutlich erschwert, oder, um noch einmal Zaller zu zitieren: „In sacralizing the parliamentary host, the London preachers demonized the royal party and ultimately the king himself. One could not settle differences with the Antichrist". ${ }^{46}$ Von daher war die Hinrichtung des besiegten Königs im Januar 1649 nur konsequent.

Die Royalisten hatten ihrerseits schon während des Krieges das mögliche Scheitern ihres Kampfes gegen die ,Rebellen' antizipiert. Schon lange vor 1649 war Karl I. als leidender König, als Opfer eines Angriffs auf seine von Gott gehei-

41 Vgl. Burroughs, The Glorious Name of God, S. 36-37.

42 Joshua Sprigge, Anglia Rediviva, London 1647, sign. A3 verso; vgl. dazu Raymond Waddington, Looking into Providences. Designs and Trials in Paradise Lost, Toronto 2012, S. 75-76 und generell zur New Model Army, in der das Gefühl, gemeinsam für die Sache Gottes zu streiten, besonders ausgeprägt war, auch Ian Gentles, The New Model Army in England, Ireland and Scotland, 1645-1653, Oxford 1992, S. 87-119.

43 Siehe S. 51, Anm. 21.

44 Vgl. Burroughs, The Glorious Name of God, S. 36-37; vgl. Thomas Goodwin, A Glimpse of Sion's Glory, or the Churches Beautie Specified. (Published for the Good and Benefit of all Those whose Hearts are Raised up in the Expectation of the Glorious Liberties of the Saints), London ${ }^{2} 1641$, besonders S. 1, S. 4.

45 Robert Zaller, The Discourse of Legitimacy in Early Modern England, Stanford, CA 2007, S. 704.

46 Robert Zaller, Breaking the Vessels. The Desacralization of Monarchy in Early Modern England, in: The Sixteenth Century Journal 29, Heft 3, 1998, S. 757-778, besonders S. 764, S. 767. 
ligte Autorität präsentiert worden.$^{47}$ Es war deshalb nicht schwierig, die Hinrichtung des Königs als Vollendung dieses Martyriums darzustellen. Der entscheidende Text, der die Transformation des Monarchen vom Heerführer zum Märtyrer vollzog, war „Eikon Basilike“ (1649), eine Sammlung von apologetischen Reflexionen über Ursachen und Verlauf des Bürgerkrieges, die durch Gebete des Königs und Passagen, die ihn vor allem als frommen Christen zeigten, ergänzt wurde. ${ }^{48}$ Es ist bis heute umstritten, in welchem Umfang „Eikon Basilike“, als dessen Autor in der Tat der König selbst firmierte, wirklich vom König verfasst wurde oder nur auf eigenhändigen Manuskripten basierte, die in den Monaten und Jahren vor seiner Hinrichtung entstanden waren. Die vom Kaplan des Königs, John Gauden, vorgenommene Endredaktion dürfte jedenfalls „Eikon Basilike" erst seine wirkliche Schlagkraft gegeben haben. ${ }^{49}$ Karl I. erschien hier als Märtyrer in der Nachfolge Christi, der willig sein Schicksal annimmt und vor Gericht ebenso wie bei seiner Hinrichtung heroischen Mut und Standhaftigkeit zeigt. ${ }^{50}$ Eine Fülle von anderen royalistischen Traktaten und Gedichten auf den toten König verstärkten diesen Eindruck; sie hoben die stoische Selbstbeherrschung des Königs hervor und unterstrichen, dass er durch seinen Tod alle Helden der Vergangenheit überstrahle. ${ }^{51}$

Dennoch blieb die Frage, ob ein gescheiterter König, der sich im Übrigen in „Eikon Basilike" vor allem als individueller Christ, der um sein Seelenheil besorgt war, und nicht als Staatsmann oder gar als Krieger präsentierte, wirklich ein Held sein konnte. Es gab durchaus Royalisten, die daran Zweifel hatten und Karls Aussage, er habe lieber ein guter als - auf Kosten seines Gewissens - ein machtvoller König sein wollen, als Zeichen von Schwäche sahen. ${ }^{52}$ Die Idee eines leidenden Königtums fand sich zwar in dieser Epoche keineswegs nur in England und konnte

47 Vgl. Andrew Lacey, The Cult of King Charles the Martyr (Studies in Modern British Religious History; 7), Woodbridge 2003, S. 18-48.

48 Vgl. Jim Daems / Holly F. Nelson (Hrsg.), Eikon Basilike. The Portraiture of his Sacred Majesty in his Solitudes and Sufferings with Selections from Eikonoklastes, John Milton, Plymouth 2006; vgl. Asch, Sacral Kingship, S. 91-93.

49 Vgl. Sean Kelsey, The King's Book. Eikon Basilike and the English Revolution of 1649, in: Nicholas Tyacke (Hrsg.), The English Revolution, c. 1540-1720. Politics, Religion and Communities (UCL/Neale Series on British History), Manchester 2007, S. 150-169.

50 Andrew Lacey, 'Charles the First, and Christ the Second': The Creation of a Political Martyr, in: Thomas S. Freeman / Thomas F. Mayer (Hrsg.), Martyrs and Martyrdom in England, c. 1400-1700 (Studies in Modern British Religious History; 15), Woodbridge 2007, S. 203-220, besonders S. 204-206.

51 Lacey, The Cult of King Charles the Martyr, S. 107-108, mit Bezug unter anderem auf John Quarles, Regale Lectum Miseriae, London 1649.

52 So richtete Karl an seinen Nachfolger die Ermahnung: „I had rather you should be Charles le Bon than le Grand, good than great", Daems / Nelson (Hrsg.), Eikon Basilike, S. 185. Zur Kritik an dieser Haltung: Anthony Milton, "Vailing his Crown": Royalist Criticism of Charles I's Kingship in the 1650s, in: Jason McElligott / David L. Smith (Hrsg.), Royalists and Royalism during the Interregnum (Politics, Culture and Society in Early Modern Britain), Manchester 2010, S. 88-105. 
sich durchaus mit dem Gedanken verbinden, dass das Leiden des Herrschers selbst heroische Züge trage - das zeigt ja das Beispiel Ludwigs XIII. in Frankreich ${ }^{53}$-, aber „Eikon Basilike“ erweckte den Eindruck, dass Karl I. den harten Entscheidungen und unangenehmen Kompromissen der Realpolitik anders als sein Schwager in Frankreich allzu lange ausgewichen war. ${ }^{54}$ Auch diese Prinzipientreue mochte heroisch sein, aber sie war eine Form des Heroismus, die einen gewissermaßen unpolitischen Charakter trug und für den Royalismus auf Dauer eher zur Belastung werden konnte, auch wenn das Überleben der Monarchie über die elf Jahre des Interregnums sich ohne Zweifel ganz wesentlich auch der ungeheuren Wirkung von „Eikon Basilike“ und der Verehrung des königlichen Märtyrers verdankte.

Der neu begründeten Republik gelang es nicht, die Verbreitung von „Eikon Basilike“ zu unterbinden, stattdessen wurde der Dichter Milton beauftragt, eine Gegenschrift, „Eikonoklastes“, zu verfassen. Für Milton, der jede Form von Monarchie wenn schon nicht offen ablehnte, so doch mit großer Skepsis betrachtete, war Karl I. ein Tyrann, der zu Recht wegen seiner Vergehen verurteilt worden war. ${ }^{55}$ Aber „Eikonoklastes“ blieb nicht bei diesem politischen Urteil stehen, sondern warf dem König vor allem vor, in seinem Werk sich selbst so zu heroisieren, als sei er ein Schauspieler auf einer Bühne. Das, so Milton, werde unter anderem daran deutlich, dass er in beliebiger Weise Worte und ganze Textpassagen anderer Autoren verwende und diese Formulierungen als seine eigenen ausgebe, bis hin zu eigentlich heidnischen Gebeten, die sich plötzlich in einem christlichen Kontext wiederfänden. Milton bezog sich dabei auf ein Gebet aus Sidneys „Arcardia“, das sich eigentlich an heidnische Götter richtete, aber nun unvermittelt in „Eikon Basilike" in ganz anderer Funktion wieder verwendet wurde:

„A prayer stolen word for word from the mouth of a Heathen Woman praying to a Heathen God: and that in no serious Book, but in the vain amatorious Poem of Sir Philip Sidney's Arcadia . [...] It hardly can be thought upon without some laughter, that he who had acted over us so stately and so Tragically, should leave the World at last with such a ridiculous exit". .6

Milton warf Karl vor, dass er am Ende doch ein bloßer Schauspieler blieb, der noch dazu aus der selbst gewählten Rolle fiel, weil er den falschen Text aufsagte. ${ }^{57}$

53 Siehe S. 72-73.

54 Vgl. Lacey, The Cult of King Charles the Martyr, S. 83-84; vgl. Kevin Sharpe, Private Conscience and Public Duty in the Writings of Charles I, in: Kevin Sharpe (Hrsg.), Remapping Early Modern England. The Culture of Seventeenth-Century Politics, Cambridge 2000, S. 172-198.

55 Siehe etwa David Armitage [et al.] (Hrsg.), Milton and Republicanism (Ideas in Context; 35), Cambridge 1998.

56 John Milton, Eikonoklastes, in: Jim Daems / Holly F. Nelson (Hrsg.), Eikon Basilike. The Portraiture of his Sacred Majesty in his Solitudes and Sufferings with Selections from Eikonoklastes, John Milton, Plymouth 2006, S. 217-283, hier S. 236.

57 Vgl. Steven N. Zwicker, Lines of Authority. Politics and English Literary Culture, 16491689, Ithaca, NY 1993, S. 55-56; vgl. Sharon Achinstein, Milton and King Charles, in: 
Miltons Angriff richtete sich letztlich über solche Einzelheiten hinaus gegen den Heroenkult an sich, der so eng mit der Selbstdarstellung von Monarchen im 17. Jahrhundert verbunden war. Dieser Heroenkult mochte sich bei Karl I. mit einer Inszenierung als Märtyrer verbinden, die seinem politischen Scheitern geschuldet war, war aber ansonsten für die höfische Kultur an sich schon typisch. Seine sorgsam berechneten Effekte konnten allzu leicht als dissimulatio, als Täuschung im Namen der Staatsräson, erscheinen, als ein Versuch, die Glaubwürdigkeitsdefizite, die sich mit der Darstellung des Herrschers als Heros verbanden, durch eine besonders effiziente Inszenierung zu überstrahlen. ${ }^{58}$ Zugleich verband sich für Milton mit dieser Form von Heroisierung unvermeidlich die Gefahr der Idolatrie, die für ihn letztlich ein Wesensbestandteil jeder monarchischen Herrschaft war. Über Karl I. schrieb er: „by the shrine he dresses out for him [he] certainly, would have the people come and worship him“. All dies werde zu einer „civil kind of Idolatry“ führen, zu der das Volk, von seinen Geistlichen verführt, ohnehin neige. Denn während es früher seine Freiheitshelden wie Simon de Montfort verehrt habe, die gegen Tyrannen gekämpft hätten, huldige es nun seinen Königen wie irdischen Götzen „with a besotted and degenerate baseness of spirit“. 59

Milton formulierte damit einen Vorwurf, der sich später insbesondere, aber keineswegs nur von protestantischer Seite auch gegen andere Herrscher des 17. Jahrhunderts, wie etwa gegen Ludwig XIV., richten sollte ${ }^{60}$ und thematisierte ein wesentliches Defizit der Heroisierung des Herrschers, unabhängig davon, ob er als siegreicher Feldherr oder, im Ausnahmefall, als Märtyrer verherrlicht wurde: ihre Theatralik, die immer auch als Täuschung und als Provokation zur Idolatrie verstanden werden konnte. Zugleich warf er den Anhängern des Königs Servilität und Feigheit vor und setzte dieser Haltung den heroischen Mut der Kämpfer für die Freiheit entgegen.

Allerdings fiel es der englischen Republik der 1650er Jahre nicht leicht, den traditionellen Formen der Herrscherheroisierung eine eigene politische Kultur entgegenzustellen, die ohne die traditionellen Pathosformeln der monarchischen Panegyrik auskam. ${ }^{61}$ Die politische Lage war ohnehin angespannt, denn gegen die

Thomas N. Corns (Hrsg.), The Royal Image. Representations of Charles I, Cambridge 1999, S. 141-161.

58 Vgl. Disselkamp, Barockheroismus, S. 219-221.

59 Milton, Eikonoklastes, S. 224-225; Lacey, The Cult of King Charles the Martyr, S. 88.

60 Siehe S. 86.

61 Sharpe, Image Wars, S. 391-403; vgl. Kevin Sharpe, "An image doting rabble”: The Failure of Republican Culture in Seventeenth-Century England, in: Kevin Sharpe / Steven N. Zwicker (Hrsg.), Refiguring Revolutions. Aesthetics and Politics from the English Revolution to the Romantic Revolution, Berkeley 1998, S. 25-56; vgl. allerdings auch Sean Kelsey, Inventing a Republic. The Political Culture of the English Commonwealth, 16491653 (Politics, Culture and Society in Early Modern Britain), Manchester 1997, der ein positiveres Bild zeichnet. 
immer noch bestehende Möglichkeit eines royalistischen Umsturzes konnte die Republik sich nur mit Hilfe der Armee behaupten, die sich jedoch keineswegs nur als willenloses Werkzeug der Parlamentarier sah, zumal es die Soldaten gewesen waren, die beim Sturz der Monarchie und bei der Entscheidung, den König hinzurichten, die entscheidende Rolle gespielt hatten. ${ }^{62}$ Die beherrschende Figur unter den Kommandeuren der Armee war Oliver Cromwell, Sieger in den Schlachten von Preston, Dunbar und Worcester, die er gegen die Schotten gewann und ebenso verantwortlich für die erfolgreiche und blutige Niederwerfung der irischen Rebellen in den Jahren 1649 bis 1651. Cromwell sah sich während seiner Feldzüge zunehmend als auserwähltes Werkzeug der Vorsehung ${ }^{63}$ und als er im Dezember 1653 zum Lord Protektor ausgerufen wurde, beruhte seine Legitimation in erheblichem Maße auf dem heroischen Charisma, das ihm aufgrund seiner militärischen Erfolge zugeschrieben werden konnte. Cromwell stammte aus einer Familie, die sozial eher am Rande der gentry stand, auch wenn sie in Huntingdonshire im späten 16. Jahrhundert durchaus einmal eine dominante Rolle gespielt hatte. Cromwells Gegner sahen seinen plötzlichen Aufstieg zu höchsten Würden daher auch recht kritisch. Ein Royalist des späten 17. Jahrhunderts sollte später über ihn schreiben:

„And who that had beheld such a bankcrupt beggarly fellow as Cromwell, first entring the parliament-house with a threadbare, torn cloak, and a great hat, and perhaps neither of them paid for, could have suspected that in the space of so few years, he should by the murder of one King and the Banishment of another ascend the Throne be invested in royal robes and want nothinge of the state of a king but the changeing of his hat into a crown". .64

Robert South, der diese Zeilen im späten 17. Jahrhundert schrieb, übertrieb stark. Ein armer Adliger im engeren Sinne des Wortes war Cromwell eigentlich nicht, denn ihm war es gelungen, nach dem Tode eines Onkels, der der Familie seiner Mutter entstammte, eine soziale Position, die zeitweilig prekär gewesen war, wieder zu festigen. Dennoch bleibt die Gestalt Cromwells auch deshalb bemerkenswert, weil hier ein Mann heroisiert wurde, der keiner der großen Adelsfamilien angehörte. Seine eigene Herrschaft konnte Cromwell nur dadurch rechtfertigen, dass er sich als Instrument der Vorsehung stilisierte. Im Falle Cromwells stand das militärische Heldentum, das sich in den gegen alle Wahrscheinlichkeit mit Gottes Hilfe errungenen Siegen zeigte, stark im Vordergrund der öffentlichen Darstellung. Aber dieses Heldentum war letztlich eingeordnet in einen heilsge-

62 Austin Woolrych, Britain in Revolution 1625-1600, Oxford 2002, S. 424-433, S. 461-500.

63 Colin Davis, Cromwell's Religion, in: David Lee Smith (Hrsg.), Cromwell and the Interregnum. The Essential Readings (Blackwell Essential Readings in History), Oxford 2003, S. $139-166$.

64 Robert South, Twelve Sermons Preached upon Several Occasions, London 1692, S. 395-396, zitiert nach Andrew Barclay, Electing Cromwell. The Making of a Politician (Political and Popular Culture in the Early Modern Period; 3), London 2011, S. 4-5. 
schichtlichen, ja eschatologischen Kontext, auch wenn Cromwell selbst dies immer nur andeutungsweise thematisierte. Cromwell hatte seine Siege errungen gegen den Antichristen, nicht einfach nur gegen politische Gegner. ${ }^{65}$

Was hingegen bei Cromwell trotz der vielen nicht zu übersehenden Anklänge an die monarchische Selbstdarstellung der Jahre vor 1640 doch weitgehend fehlte, waren die Bezüge zur Welt der Ritterromane oder der antiken Mythologie, die bei Philip Sidney, dem elisabethanischen Höfling, noch eine so große Rolle gespielt hatten. Cromwells Welt war die der Bibel und vor allem auch die des Alten Testamtens und seiner Gottesstreiter. Cromwell war das auserwählte Werkzeug Gottes, aber auch einer Republik der Heiligen, die freilich nie wahrhaft Realität wurde. Sein Heldentum bestand gerade darin, dass er für eine Sache kämpfte und sich in ihren Dienst stellte. ${ }^{66}$ Cromwell ließ sich oft - wenn auch, wie man zugeben muss, keineswegs durchgehend, denn es setzte sich in seiner Darstellung zwischen 1650 und 1658 niemals ein einheitlicher Bildtypus durch -67 auf eigenen Wunsch in schmuckloser, eben wahrhaft puritanischer und zugleich römisch-republikanischer Einfachheit, warts and all, darstellen - als einfacher Landedelmann, der seinem Lande zwar in höchsten Ämtern in Krieg und Frieden diente, aber ein country gentleman blieb. ${ }^{68}$ Diese Einfachheit war ein Zeichen seiner Aufrichtigkeit und Frömmigkeit und vielleicht auch seines republikanischen Bürgergeistes; klassische Porträts römischer Magistrate waren ähnlich gestaltet worden. Bezeichnenderweise pries ihn auch Milton in seiner „Defensio Secunda pro populo Anglicano“ als einen Mann, der bereit sei, nach vollbrachter Rettung des Vaterlandes wieder zum Bürger zu werden, um so in die Reihen zurückzutreten: „You suffered and allowed yourself, not indeed to be borne aloft, but to come down so many degrees from the heights and be forced into a definite rank" ${ }^{69}$ Würde Cromwell den Königstitel annehmen, dann würde er Göttern opfern, die er selbst noch eben besiegt habe. Gerade weil Cromwell der Befreier des Vaterlandes und sein Bewahrer sei und weil er mit seinen Taten nicht nur die der Könige, sondern auch die der Helden des Epos und der Legende übertroffen habe („By your deeds you have out-

65 Dazu Laura L. Knoppers, Constructing Cromwell. Ceremony, Portrait, and Print, 1645-1661, Cambridge 2000, S. 31-68. Zur Zurückhaltung Cromwells beim Bezug auf eschatologische Themen siehe allerdings Coffey, The Impact of Apocalyptism, S. 133-138.

66 Knoppers, Constructing Cromwell, S. 61.

67 Ebd., S. 88.

68 Sharpe, Image Wars, S. 493-511, besonders S. 498-501; zu Edward Mascalls Porträt des Herrschers von 1657 vgl. Knoppers, Constructing Cromwell, S. 130-131.

69 John Milton, A Second Defense of the English People, in: John Milton, Complete Prose Works, Bd. 4, 1650-1655, hrsg. von Don M. Wolfe, New Haven, CT 1966, S. 538-686, hier S. 672; vgl. die ursprüngliche lateinische Fassung der „Defensio Secunda pro populo Anglicano" in John Milton, The Works of John Milton, Historical, Political, and Miscellaneous, Bd. 2, London 1753, S. 398: „velut in ordinem cogi, publico commodo et sensisti et sutinuisti“. 
stripped not only the achievement of our kings, but even the legends of our heroes"), stehe er über weltlichem Tand wie dem Titel eines Königs. ${ }^{70}$ Mit diesem Appell an Cromwell in der „Defensio Secunda“ (Mai 1654) wollte Milton, indem er den Lord Protektor auf die nicht institutionalisierbare Rolle des nationalen Befreiers und Heros festlegte, gerade verhindern, dass dieser am Ende doch noch nach der angebotenen Krone griff. ${ }^{71}$

Während Milton in Cromwell mehr einen Brutus als einen Cäsar sehen wollte und vor allem versuchte, Cromwell davon zu überzeugen, dass er sich selbst so sehen solle, gab es auch Formen der Heroisierung des englischen Regenten, die bewusster und eindeutiger Bezug nahmen auf die römischen Imperatoren. Schon 1650 ließ Andrew Marvell in seiner „Horatian Ode“ Cromwell als einen neuen Cäsar erscheinen, der eine freiheitliche Verfassungsordnung begründete und ein Gemeinwesen, das sich wehrhaft gegen seine Nachbarn wie namentlich gegen die Schotten zu behaupten vermochte:

„As Cæsar he, ere long, to Gaul,

To Italy an Hannibal,

And to all States not free

Shall climacteric be.

The Pict no shelter now shall find

Within his particolour'd mind,

But, from this valour, sad

Shrink underneath the plaid."72

Spätere Lobeshymnen auf den parlamentarischen Feldherren betonten, dass er Cäsar durch seine Mäßigung und seine republikanischen Tugenden moralisch eigentlich überlegen sei, oder maßen ihm die Rolle des Augustus zu, der die republikanische Ordnung wiederhergestellt habe und gleichzeitig durch seine Autorität Frieden und Stabilität verbürge. ${ }^{73}$ Dass ein Feldherr faktisch zum Monarchen aufsteigen könne, dafür bot jedenfalls die römische Geschichte genug Beispiele. In manchen Darstellungen wurde Cromwell gleichzeitig als Gottesstreiter mit providenzieller Mission und als römischer Held mit imperialem Auftrag dargestellt wie in dem berühmten Stich „Cromwell between two pillars“, auch wenn

70 Milton, A Second Defense, S. 672; und Ders., Defensio Secunda, S. 399: „Heroum quoque nostrorum fabulas factis exuperasti."

71 Siehe auch Paul Stevens, Milton and National Identity, in: Nicholas McDowell / Nigel Smith (Hrsg.), The Oxford Handbook of Milton, Oxford 2009, S. 342-363, hier S. 360.

72 Andrew Marvell, An Horation Ode upon Cromwell's Return from Ireland, in: Andrew Marvell, The Poems of Andrew Marvell, hrsg. von Nigel Smith, Edinburgh 2007, S. 278, S. 101-108; vgl. Blair Worden, Andrew Marvell, Oliver Cromwell, and the Horatian Ode, in: Kevin M. Sharpe / Steven N. Zwicker (Hrsg.), Politics of Discourse. The Literature and History of Seventeenth-Century England (New York University Ottendorfer Series; 39), London [u.a.] 1987, S. 147-180.

73 Knoppers, Constructing Cromwell, S. 104-105. Siehe zu anderen Vergleichen Cromwells mit den antiken Imperatoren ebd., S. 63-64. 
hier die biblische Bildersprache dominiert.74 Das Bild Cromwells als republikanischer Heros und zugleich potenzieller Monarch blieb jedenfalls ein eigenartig schwankendes, oder wie Laura Lunger Knoppers es formuliert hat, „Cromwell both embodies and transforms heroic precedent" ${ }^{\text {“ }}{ }^{75}$

In Gestalt Cromwells trat in England ein durchaus neuer Typus des kriegerischen Heros auf, zum Teil verankert in den Wertvorstellungen eines politischen Republikanismus und eines radikalen Protestantismus, aber doch mit einer klaren Tendenz, sich von diesen Fundamenten zu lösen, denn Cromwell stand nicht nur für den Sieg über eine autoritäre monarchische Herrschaft und über Rom, sondern potenziell auch für eine neue Gestalt der Monarchie, die sich wesentlich nicht mehr sakral oder gar dynastisch, sondern über den permanenten heroischen Kampf gegen die Feinde der Freiheit und der Nation legitimierte. Indem Cromwell sich 1654 für einen Krieg gegen Spanien entschied, den er als Kampf gegen einen nationalen Erbfeind und zwischen Licht und Finsternis darstellte, ${ }^{76}$ versuchte er, das Legitimitätskapital, das ihm seine Siege gegen Royalisten, Schotten und Iren verschafft hatten, zur dauerhaften Grundlage seiner Herrschaft zu machen. Das war allerdings im Frieden kaum möglich. Eine heroische Selbstinszenierung, die so stark wie bei Cromwell zum zentralen Bestandteil der eigenen politischen Legitimation wurde, verband sich daher schon fast notwendigerweise mit einer bellizistischen Außenpolitik. Im Übrigen warf der republikanische Heros Cromwell einen langen Schatten über die 1660 wiederhergestellte StuartMonarchie. Einerseits gab es nach der Restauration durchaus gewisse Elemente der Selbstdarstellung des Monarchen, die sich an das sonst natürlich abgelehnte Bild des Lord Protektors anlehnten, ${ }^{77}$ andererseits hatte Cromwell die heroische Pose so stark für sich okkupiert und so stark mit der Idee eines militanten Protestantismus verbunden, dass es für die Stuarts vor 1688 kaum noch möglich war, sich ähnlich zu inszenieren. Zu groß war die Gefahr, dass ein Monarch, der sich selbst vor allem als Held darstellte, aber kaum Heldentaten aufzuweisen hatte, gerade im Vergleich zu Cromwell als defizitärer Nachfolger eines wirklichen Helden erscheinen konnte. Erst Wilhelm III. wurde wieder, wenn auch nicht durchgehend und nicht ohne gewisse Kautelen, als heroischer Streiter für den wahren Glauben und die Freiheit Englands inszeniert. Seine antikatholische Außenpolitik und die Siege in Irland ließen es erneut als möglich erscheinen, seine Position als König, die freilich ohnehin nicht primär auf eindeutigen dynastischen An-

74 Zum Bild Cromwells in den 1650er Jahren siehe auch Sharpe, Image Wars, S. 493-507, besonders S. 504-505 zu dem Stich „The Embleme of Englands Distractions“ nach Francis Barlow, der Cromwell zwischen zwei Säulen in imperialer Pose darstellt.

Knoppers, Constructing Cromwell, S. 64.

76 Barry Coward, Oliver Cromwell (Profiles in Power), London 1991, S. 133, S. 170; vgl. Ronald G. Asch, Die britische Republik und die Friedensordnung von Münster und Osnabrück, in: Heinz Duchhardt (Hrsg.), Der Westfälische Friede, München 1998, S. 421-443.

77 Siehe S. 95-96. 
sprüchen beruhte, auf diese Weise zu legitimieren, obwohl dies selbst um 1700 nie ganz unproblematisch war. ${ }^{78}$

Was als Erbe der 1640er und 1650er Jahre blieb, war in England in jedem Fall eine dauerhafte Pluralisierung der Modelle des Heroischen. Während in Frankreich nach dem Ende der Religionskriege und namentlich nach der Ermordung Heinrichs IV. die offizielle Heroisierung des Herrschers kaum noch offen infrage gestellt werden konnte - auch während der Fronde richtete sich die Kritik ja primär gegen den Kardinalminister Mazarin, nicht gegen den König -, standen sich in England spätestens seit Ausbruch des Bürgerkrieges stark konkurrierende Modelle des Heroischen gegenüber. Es fehlte hier auch über das Ende der Republik hinaus an einer königlichen Kunst- und Literaturpatronage, die mit ausreichender Wirksamkeit verbindliche Leitbilder des Heroischen hätte propagieren können, wie dies in Frankreich ja spätestens seit den 1630er Jahren durchaus geschah. ${ }^{79}$

78 Siehe S. 95-100.

79 Siehe dazu Christian Jouhaud, Les pouvoirs de la littérature. Histoire d'un paradoxe (NRF Essais), Paris 2000; Ders., La main de Richelieu ou Le pouvoir cardinal, Paris 1991. 


\section{Der Heroismus der Heiligkeit, der leidende König und die Geste der Revolte: Frankreich $1610-1660$}

In England scheiterte die Herrschaft der Stuarts in den 1640er Jahren nicht zuletzt daran, dass Jakob I. und Karl I. nicht bereit waren, sich der Herausforderung eines heroischen Kampfes gegen die Kräfte der Gegenreformation zu stellen; das zumindest war der Eindruck den ihre Politik bei ihren Untertanen hervorrief. Der englische Bürgerkrieg trug Züge eines Religionskrieges und die Soldaten und Offiziere des Parlaments sahen sich als heroische Gottesstreiter. So wurde auch Cromwell inszeniert, nachdem er zum Regenten Englands, Schottlands und Irlands geworden war. Frankreich hatte zu Beginn des 17. Jahrhunderts Jahrzehnte des religiösen Bürgerkriegs eben erst hinter sich gelassen, aber ein Neuausbruch der erbitterten Kämpfe schien lange Zeit durchaus eine reale Gefahr zu sein. Gebannt werden konnte sie nur, wenn es einerseits gelang, dem Königtum die Aura einer unantastbaren, sakral legitimierten Autorität zu verleihen, und wenn andererseits die konfessionelle Militanz der leidenschaftlichen Verfechter der Sache Roms und der Gegenreformation in andere, friedlichere Bahnen als die des Kampfes gegen den konfessionellen Gegner gelenkt werden konnte. Der heroische Eifer der leidenschaftlichen Katholiken musste sublimiert und internalisiert werden, wenn der 1598 gewonnene Frieden dauerhaft sein sollte. Beides gelang bis zu einem gewissen Grade, allerdings erst, nachdem der Herrscher, der die Bürgerkriege beendet hatte, Heinrich IV., dem Dolch eines Attentäters zum Opfer gefallen war.

Während Heinrich IV. zu Lebzeiten als Herrscher nicht unumstritten gewesen war, setzte nach seinem Tode eine umso umfassendere Heroisierung des ersten Bourbonen ein. Sein Ende erschien nun als ein Opfertod für das Wohl des Landes, das er nach Jahrzehnten des Bürgerkrieges geeint hatte, und die Prediger, die seiner gedachten, hoben hervor, dass seine Konversion die größte Heldentat seines Lebens gewesen sei („l'acte le plus héroïque“). ${ }^{1} \mathrm{Zu}$ Lebzeiten war Heinrich IV. ein am Ende doch primär kriegerischer Held geblieben, auch wenn immer wieder hervorgehoben worden war, dass er Frankreich den Frieden gebracht und eine Herrschaft

1 François Vrevin S. J., Oraison funèbre prononcée en l'eglise de Rouen aux funerailles [...], Rouen 1610, S. 17; vgl. Jacques Hennequin, Henri IV dans ses Oraisons funèbres ou la naissance d'une légende (Bibliothèque française et romane, C; 62), Paris 1977; ferner Dominique Thibaut, Oraison funebre faite et pronounce à Paris en l'eglise de Saint Germain l'Auxerrois, Paris 1610, S. 10-14. Sowie Matthieu d'Abbeville, Discours funebre en l'honneur de Roy Henry le Grand, Paris 1610, S. 43-44; Charles de Saint-Sixt, Sermon funèbre prononcée en l'église cathédrale de Riez, au service du grand et auguste Henri IIII, Paris 1610, S. 23, wo der Opfertod des Herrschers explizit mit dem Tod Christi am Kreuz verglichen wird. 
der Vernunft über die Leidenschaften heraufgeführt habe. Erst nach seinem Tode wurde die recharge sacrale der Monarchie vollendet und aus dem Heerführer der Hugenotten nun wirklich ein christlicher Heilsbringer, der als Erretter seines Landes heroische und christliche Tugenden miteinander verband. ${ }^{2}$

Dennoch hatte der Anschlag gezeigt, dass die konfessionelle Militanz, die namentlich in Kreisen der Liga gepflegt worden war, unter der Oberfläche virulent geblieben war. Es galt nun, diese Militanz so zu kanalisieren, dass sie für die Monarchie nicht mehr zu einer Gefahr zu werden vermochte. Die Voraussetzungen waren dafür nach dem Tode Heinrichs IV. deutlich günstiger als unmittelbar nach dem Ende der Religionskriege. Heinrich IV. hatte zwar nach seiner Konversion die katholische Reform energisch unterstützt und auch die den Hugenotten gewährte Toleranz nur als ein vorübergehendes Zugeständnis dargestellt, aber aus katholischer Sicht galt er dennoch nicht als wirklich vertrauenswürdig. Seine Witwe hingegen, eine geborene Italienerin, und der gemeinsame Sohn, Ludwig XIII., ließen an ihrem persönlichen religiösen Eifer keinen Zweifel aufkommen, auch wenn die Außenpolitik des Königs nicht unbedingt dem Programm der dévots, der katholischen Eiferer, entsprach.

Stabilisiert wurde die Lage in Frankreich ohne Zweifel dadurch, dass die religiösen Energien, die vor 1589 den Hass auf den konfessionellen Gegner genährt hatten, nun sehr viel stärker verinnerlicht und spiritualisiert wurden. An die Stelle einer heroischen Frömmigkeit, die sich im aktiven und auch gewaltsamen Kampf gegen den konfessionellen Gegner manifestierte, traten nun deutlich anders akzentuierte Frömmigkeitsideale. Es war bereits bezeichnend, dass keiner der Märtyrer der Liga von der Kurie nach 1600 heiliggesprochen wurde, obwohl das Papsttum sich zeitweilig offen gegen Heinrich III. und seinen prospektiven Nachfolger Heinrich von Navarra gewandt hatte. Aber unter den Vorzeichen der tridentinischen Reform hatte sich das traditionelle Ideal von Heiligkeit wesentlich gewandelt. Im Vordergrund stand nun nicht mehr so sehr die öffentliche Bezeugung des wahren Glaubens, die womöglich zum Martyrium führte, sondern eher, wie Robert Descimon es genannt hat, die Verinnerlichung eines religiösen Gefühls von besonderer Intensität: „La Contre-Réforme n’a plus tant besoin de héros qui témoignent que de dévots qui ont su lier avec Dieu un lien personnel, exemplaire et communicatif“ („Die Gegenreformation braucht keine Helden mehr, die Zeugnis ablegen, sondern Fromme, denen es gelungen ist, zu Gott eine beispielhafte persönliche Verbindung herzustellen und mit ihm in Kommunikation zu treten".) $)^{3}$ In der Tat veränderten sich auch die Kriterien für die Heiligsprechung zu Beginn des 17. Jahrhunderts, als nach einer langen Pause (zwischen 1528 und 1588 hatte es

2 Vgl. Asch, Sacral Kingship, S. 33-34

3 Robert Descimon / José J. Ruiz Ibáñez, Les Ligueurs de l'exil. Le refuge Catholique Français après 1594 (Époques), Seyssel 2005, S. 22. 
keine Heiligsprechungen gegeben) die Kanonisationen wieder aufgenommen wurden. Im Vordergrund stand nun die „heroische Tugend“ der Kandidaten, ${ }^{4}$ das Martyrium trat außer bei Glaubenszeugen, die außerhalb Europas für die Kirche gestorben waren, eher in den Hintergrund und gerade an die Märtyrer, die in den französischen Religionskriegen im Kampf gegen die Protestanten den Tod erlitten hatten oder von der königlichen Justiz wegen ihrer Verbindung zu Akten des Widerstandes gegen die Krone hingerichtet worden waren, konnte nicht oder nur recht vorsichtig erinnert werden. ${ }^{5}$ Während die Idee des Kreuzzuges gegen die Türken zu Beginn des 17. Jahrhunderts in Frankreich eine letzte Blüte erlebte - Adlige wie der Herzog von Mercoeur oder der Herzog von Nevers engagierten sich nachhaltig an dieser Front -, konnte der Kreuzzug gegen die Häresie nun nicht mehr offen propagiert werden. Erst nach 1660 begann sich das schrittweise wieder zu ändern und Ludwig XIV. konnte in den 1680er Jahren seine Unterdrückung der Protestanten sogar als Äquivalent zu den Türkensiegen des Kaisers darstellen. ${ }^{6}$ An die Stelle des heroischen Kampfes gegen die Hugenotten und andere Ketzer traten nun innere Kreuzzüge gegen die eigenen Leidenschaften und den eigenen Körper im Sinne einer strengen Askese, aber auch im Sinne eines Ringens um die Gnade in der mystischen Versenkung. Der Heilige - oder die Heilige - zeichneten sich jetzt nicht mehr so stark wie früher durch ihre Wundertaten oder ihren Tod als Glaubenszeugen aus, sondern durch ihre mystischen Visionen, oder wie Robert Descimon es formuliert hat: „Le saint désormais se signale plutôt par ses 'états' que par ses actes. Il se reconnaît par ses écrits plus que par ses miracles“. („Der Heilige zeichnet sich als solcher stärker durch seine Befindlichkeiten und seinen seelischen Zustand als durch seine Taten aus. Man erkennt ihn eher an seinen Schriften als an seinen Wundern"). ${ }^{7}$

Dabei konnte sich die mystische Frömmigkeit mit der Vorstellung eines heroischen Leidens verbinden, ein Leiden an der Liebe zu Gott, aber vielleicht auch ein Leiden im beständigen Kampf gegen die Dämonen, denn Besessenheit und Mystik konnten in der Blütezeit der französischen Mystik durchaus ineinander übergehen, ${ }^{8}$

4 Éric Suire, La Sainteté française de la Réforme catholique (XVI ${ }^{\mathrm{e}}$-XVIII ${ }^{\mathrm{e}}$ siècles) d'après les textes hagiographiques et les procès de canonisation (Identités religieuses), Pessac 2001, S. 209-213.

5 Vgl. Ebd., S. 27-28, und Descimon / Ruiz Ibáñez, Les Ligueurs de l'exil, S. 25.

6 Vgl. Descimon / Ruiz Ibáñez, Les Ligueurs de l'exil, S. 26; zum Kreuzzugsgedanken vgl. Géraud Poumarède, Pour en finir avec la Croisade. Mythes et réalités de la lutte contre les Turcs aux XVI ${ }^{\mathrm{e}}$ et XVII ${ }^{\mathrm{e}}$ siècle, Paris 2004. Zu den inneren „Kreuzzügen“ Ludwigs XIV.: Jean Orcibal, Les « supercroisades » de Louis XIV (1683-1689), in: Janet van Bavel (Hrsg.), Jansénius et le Jansénisme dans les Pays-Bas (Ephemerides theologicae Lovanienses; 56), Löwen 1982, S. 138-147.

7 Robert Descimon, Préface, in: Stéphane-Marie Morgain (Hrsg.), La Théologie politique de Pierre de Bérulle 1598-1629 (La France au fil des siècles), Paris 2001, S. 11-24, hier S. 15-16.

8 Hierzu Sophie Houdard, Les Invasions Mystiques. Spiritualités, hétérodoxies et censures au début de l'époque moderne (Histoire; 91), Paris 2008; vgl. auch Michel de Certeau, La fable mystique [1982], Paris 2013. 
und nicht zuletzt Michel de Certeau hat auf die enge Verwandtschaft der religiösen Mystikerin mit der Figur der Besessenen hingewiesen. ${ }^{9}$ Besonders diejenigen französischen Mystiker - und vielleicht noch mehr die Mystikerinnen -, die in der Nachfolge Theresas von Avila standen, betonten die Nähe von Gottesversenkung und Leiden..$^{10}$ Daneben trat auch, namentlich bei Frauen, der Einsatz für die Kranken und Armen in der Vordergrund, der ebenfalls Züge eines heroischen Selbstopfers annehmen konnte. Man kann in diesem Kontext wohl sogar von einer Feminisierung der Idee heroischer Heiligkeit sprechen. Weibliche Leitfiguren, wie Madame Acarie (Barbe Acarie / Marie de l'Incarnation, 1566-1618), die Witwe eines der Führer der Liga in Paris, traten jedenfalls stärker in den Vordergrund und auch in der späteren Frömmigkeitsbewegung von Port Royal, die im Jansenismus aufging, spielten die Äbtissinnen und Nonnen dieses Klosters, die sich bewusst einem heroischen Ideal der Heiligkeit verschrieben, eine entscheidende Rolle. ${ }^{11}$

Im Prozess dieser Internalisierung und Spiritualisierung einer heroischen Heiligkeit wurde auch das Leiden der potenziellen Heiligen neu bewertet. Wie Antoinette Gimaret gezeigt hat, traten in den Heiligenviten des frühen 17. Jahrhunderts die Schilderungen des körperlichen Leidens eher zurück. Die Liga hatte in ihrem politischen Kampf den „corps spectacle“, wie Gimaret es formuliert, noch zum Argument gemacht. Leidensmystik und konfessionelle Militanz waren während der Religionskriege eng miteinander verbunden. ${ }^{12}$ Diese Verbindung löste sich jetzt schrittweise auf, der fromme Körper konnte nun nicht mehr öffentlich leiden, weil dies den Frieden zwischen den Untertanen des Königs und namentlich den Frieden zwischen den Konfessionen gestört hätte. Das Leiden wurde damit in den Bereich des Intimen oder des Privaten verwiesen, nahm dort als Zeichen der Frömmigkeit oder gar der Heiligkeit aber eine umso wichtigere Position ein. ${ }^{13}$ Betont wurde es vor allem in weiblichen Heiligenviten, da Ordensschwestern und selbst Äbtissinnen ein aktives Apostolat verwehrt war. Aber auch Ordenskonstitutionen

9 Vgl. Michel de Certeau, Le Lieu de l'autre. Histoire religieuse et mystique, Paris 2005, S. 195-215, hier S. 205. Zu den Fällen von Besessenheit in religiösen Orden siehe auch Daniel Vidal, Critique de la raison mystique. Benoît de Canfield, possession et dépossession au XVII siècle, Grenoble 1990, S. 309-380.

$10 \mathrm{Vgl}$. Jacques Gélis, Le corps, l'Église et le sacré, in: Alain Corbin [et al.] (Hrsg.), Histoire du Corps, Bd. 1, De Renaissanc aux Lumières, Paris 2005, S. 17-108, hier S. 60-64; Houdard, Les invasions mystiques, S. 83-85 zu den Karmeliterinnen in Frankreich.

11 Vgl. Barbara B. Diefendorf, From Penitence to Charity. Pious Women and the Catholic Reformation in Paris, Oxford 2004, besonders S. 77-100; vgl. Vidal, Critique de la raison mystique, S. 71-86. Zu Port Royal siehe René Taveneaux, Jansénisme et réforme catholique, Nancy 1992, S. 35-44. Vgl. Gimaret, Extraordinaire et ordinaire des croix, S. 69, S. 144-179.

13 Vgl. ebd., S. 25-26; vgl. zum Kontext auch Jacques Le Brun, Mutations de la Notion de Martyre au XVII ${ }^{e}$ siècle d'après les biographies spirituelles féminines, in: Jacques MarX (Hrsg.), Saintété et martyre dans les religions du livre (Problèmes d'histoire du christianisme; 19), Brüssel 1989, S. 77-90; vgl. Ders., Les discours de la stigmatisation au XVII siècle, in: Les Cahiers de l'Herne 75, 2001, S. 103-118. 
hoben den Wert der leidenden Selbstaufopferung hervor. ${ }^{14}$ So hieß es in den Konstitutionen der Filles Hospitalières (1636 begründet), wer Kranke mit abstoßenden Symptomen behandle, ohne davor zurückzuschrecken, würde einen heroischen Sieg über sich selbst erringen, würdig der religiösen Berufung der Nonnen („remportant héroiquement sur elles-mêmes des victoires dignes de leur vocation"). ${ }^{15}$ Die heroische Tugend, die nun auch offiziell zum entscheidenden Kriterium für eine von der Kirche anerkannte Heiligkeit wurde, zeigte sich eben ganz besonders im Ertragen des Leidens und das Leiden beglaubigte diese Tugend; man kann sogar davon sprechen, dass in der religiösen Leidensrhetorik ein allmählicher Übergang vom Mystizismus zum Moralismus vollzogen wurde. ${ }^{16}$ Anders als der Märtyrerkult des 16. Jahrhunderts stellte dieser Moralismus keine Gefahr mehr für die Monarchie dar, sondern konnte sogar in ihren Dienst gestellt werden. In vielen Orden war die Tendenz nicht zu übersehen, wahre Frömmigkeit nun auch explizit über die Bereitschaft zum Gehorsam gegenüber dem Monarchen zu definieren. ${ }^{17}$

Allerdings hatten Anhänger des neuen Frömmigkeitsideals, die außerhalb des Klosters lebten und keine Geistlichen waren, unter Umständen größere Probleme, ihre Religiosität und ihre Loyalität gegenüber dem König immer gänzlich zur Deckung zu bringen. Zum Teil kam es hier zu einer noch stärkeren Verinnerlichung der Frömmigkeit. Während man sich in politischen Fragen von Gesichtspunkten der Zweckmäßigkeit leiten ließ, wurde das Ideal einer heroischen Überwindung der Welt nur im Privaten, in der Meditation und der theologischen Reflexion gelebt, wie bei jenem Armeeintendanten René d'Argenson, mit dem sich Michel de Certeau auseinandergesetzt hat und in dem dieser ein frühes Beispiel für die Trennung der weltlichen Sphäre vom Religiösen sieht. ${ }^{18}$

Die Figur des heroischen Märtyrers ließ sich freilich nicht ganz aus dem kulturellen politischen imaginaire verbannen, sie fand jedoch jetzt ihren Platz eher in einer zumindest partiell säkularisierten Form im Bereich der Politik und nicht mehr in der Religion. Nicht zuletzt der Neustoizismus des späten 16. und frühen 17. Jahrhunderts leistete einen wesentlichen Beitrag dazu, den heroischen Tod für die patrie, das Vaterland, an die Stelle des spektakulären Selbstopfers der religiösen Märtyrer zu setzen. ${ }^{19}$ Es war auch und gerade der Kardinal Richelieu, ein Mann von durchaus labiler Gesundheit, der sein Leben im Dienste des Staates auch als

14 Gimaret, Extraordinaire et ordinaire des croix, S. 155-158.

15 Ebd., S. 567, S. 155-158.

16 Vgl. ebd., S. 205.

17 Vgl. Pierre Benoist, La bure et le sceptre. La congrégation des Feuillants dans l'affirmation des États et des pouvoirs princiers vers 1560-vers 1660 (Publications de la Sorbonne / Série histoire moderne; 47), Paris 2006, S. 358: „À la sainteté héroique, à la sainteté mystique en substituait désormais la sainteté civile, celle que consistait à sacrifier sa personne pour défendre L'autorité du prince“. Vgl. S. 296 zur Zeit vor 1630, hier tritt die „sainteté mystique“ an die Stelle des „héroisme pénitentiel“.

18 Vgl. de Certeau, Le Lieu de l'autre, S. 265-299.

19 Vgl. Gimaret, Extraordinaire et ordinaire des croix, S. 85-89, S. 800 . 
heroisches Leiden inszenierte. Namentlich in den 1630er Jahren wurden seine häufigen Krankheiten durchaus ein Gegenstand der zeitgenössischen Publizistik und dienten als Beweise für seine Selbstaufopferung für das Wohl Frankreichs. Die Krankheit ist nicht nur Ausdruck einer Bereitschaft zum politischen Martyrium, sie unterstreicht den heroischen Charakters eines Lebens, das ganz durch den Eifer für den Staat aufgezehrt wurde. ${ }^{20}$ Natürlich war das nur ein Teilaspekt der Heroisierung des großen Staatsmannes, der auch eine Galerie der Helden und Heroinen der französischen Geschichte, eine Art heroischer Ahnengalerie, für seine Pariser Residenz konstruieren ließ und sich auch dezidiert mit Herkules identifizierte, eine Form der Heroisierung, die sonst eher regierenden Monarchen vorbehalten war, auch wenn sie sich in vergleichbarer Form auch bei Richelieus Gegenspieler, dem Conde Duque Olivares in Spanien, findet. ${ }^{21}$

Aber es entwickelte sich auch der Gedanke eines wirklichen Martyriums, das der Monarch selbst als Herrscher und in gewisser Weise als Ebenbild Christi erlitt. Ludwig XIII. war nach seinen Regierungsantritt natürlich unter Rückgriff auf alle traditionellen Metaphern und Bilder heroisiert worden. Anspielungen auf die römischen Imperatoren durften hier ebenso wenig fehlen wie auf Ludwig den Heiligen, den Ahnherren der Bourbonen, die wohl auch deshalb so prominent in den Vordergrund traten, weil sie den Gallikanismus und das faktisch ausgeübte königliche Kirchenregiment rechtfertigen konnten. ${ }^{22}$ Ebenso traten die Gestalten der Mythologie von Perseus bis zu Herkules hinzu. ${ }^{23}$ Nach dem Triumph über die Protestanten Ende der 1620er Jahre verstärkten sich diese Tendenzen zur Heroisierung des Herrschers, ${ }^{24}$ die sich zum Teil aber auch mit der Verherrlichung seines treuesten Dieners, des Kardinalministers, verbanden. In einer Grafik, die den König

20 Vgl. ebd., S. 124-131, hier besonders S. 126: „La maladie [...] met en relief un héroisme de l'abandon volontaire de soi au profit du public".

$21 \mathrm{Vgl}$. Thomas Kirchner, Richelieu et son usage programmatique de l'art. L'image du cardinal dans le décor de ses résidences, in: Jean-Claude Boyer [et al.] (Hrsg.), Richelieu patron des arts (Passagen; 17), Paris 2009, S. 251-272; Hanno-Walter Kruft, Richelieu, un projet à l'image de la raison d'État, in: Jean-Claude Boyer [et al.] (Hrsg.), Richelieu patron des arts (Passagen; 17), Paris 2009, S. 19-54, besonders S. 32; vgl. John H. Elliott, The Count-Duke of Olivares. The Statesman in an Age of Decline, New Haven, CT 1986, S. 46-47, S. 251; vgl. Hillard von Thiessen, Der entkleidete Favorit. Legitimation von Günstlings-Herrschaft und politische Dynamik im Spanien des Conde-Duque de Olivares, in: Ronald G. Asch [et al.] (Hrsg.), Integration - Legitimation - Korruption. Politische Patronage in Früher Neuzeit und Moderne, Frankfurt am Main [u.a.] 2011, S. 131-147.

22 Vgl. Alain Boureau, Les enseignements absolutistes de Saint Louis, 1610-1630, in: Centre de Recherches sur l'Occident moderne (Hrsg.), La Monarchie absolutiste et l'histoire en France. Théories du pouvoir, propagandes monarchiques et mythologies nationales (Mythes, critique et histoire; 1), Paris 1987, S. 79-87.

23 Hélène Duccini, Faire Voir, Faire Croire. L'opinion publique sous Louis XIII (Époques), Seyssel 2003, S. 205-208, S. 384.

24 Jan-Friedrich Mißfelder, Das Andere der Monarchie. La Rochelle und die Idee der „monarchie absolue" in Frankreich 1568-1630 (Pariser historische Studien; 97), München 2012, S. 288-304. 
1632 als siegreichen römischen Krieger zeigte, prangte auf dessen Schutzschild ein Porträt des Kardinals Richelieu. ${ }^{25}$ Bemerkenswerterweise wurde Ludwig XIII. auch als ein Herrscher dargestellt, aus dem ein neuer Alexander werden könne - wenn schon nicht als unmittelbare Reinkarnation des makedonischen Helden -, ein Vergleich, der in der Heroisierung französischer Herrscher bis dahin keine maßgebliche Rolle gespielt hatte und der auch im Falle des zweiten Bourbonen als unangemessen erscheinen konnte, denn ein großer Eroberer war er, vom Sieg über La Rochelle abgesehen, eigentlich nicht. ${ }^{26}$ Doch mit dem Bild Alexanders verband sich eben auch die Hoffnung auf einen neuen Kreuzzug zur Befreiung Konstantinopels, denn Alexander der Große war für die Zeitgenossen, jedenfalls in Frankreich, vor allem der Eroberer des Ostens, aus dem man nachträglich auch einen katholischen Helden machen konnte. ${ }^{27}$ Im Übrigen stand auch die Identifikation des Herrschers mit dem Bild des Heiligen Ludwig im Kontext eines neu erwachten Kreuzzugsgedankens, denn Ludwig war ja auf einem Kreuzzug gestorben. ${ }^{28}$

Trotz der von offizieller Seite betriebenen vollmundigen Heroisierung des Königs blieb seine Politik jedoch umstritten. Namentlich das Bündnis mit protestantischen Mächten und der Kampf gegen Spanien an allen Fronten, der 1635 zur offiziellen Politik wurde, stießen auf heftigen Widerstand bei den dévots, den Frommen, darunter auch jenen ,religiösen Virtuosen', die einem heroischen Ideal von Heiligkeit anhingen. ${ }^{29}$ Soweit die dévots sich nach den 1640er Jahren unter dem Banner des Jansenismus versammelten, war ihnen die Idee weltlichen Ruhmes, auf welche die königliche Politik ausgerichtet war, ohnehin suspekt. Ihr von Augustinus inspirierter moralischer Rigorismus lehnte jedenfalls die von den Jesuiten propagierte These ab, christliche Vollkommenheit könne sich aus den natürlichen Anlagen des Menschen entwickeln, sei einfach nur ihre Vollendung. ${ }^{30} \mathrm{Ob}$

25 Duccini, Faire voire, Faire Croire, S. 438, vgl. S. 205-208, S. 348. Siehe ferner die Grafik von Abraham Bosse, die Ludwig XIII. als Herkules zeigt (1635): Abraham Bosse, Louis XIII en Hercule, v. 1635, Eau-forte, 261 x 331 au coup de planche, avec le placard, 567 x 395 (feuille), BNF Est., coll. Hennin, 2516, épr. du 2e état sur 4.

26 Chantal Grell / Christian Michel, L'École des princes ou Alexandre disgracié. Essai sur la mythologie monarchique de la France absolutiste (Nouveaux confluents), Paris 1988, S. 56.

27 Ebd., S. 58.

28 Pierre Benoist, Le Père Joseph. L'Éminence grise de Richelieu, Paris 2007, S. 205-208.

29 Zu den Dévots und zu den Konflikten mit Richelieu siehe Joseph Bergin, The Politics of Religion in Early Modern France, New Haven, CT 2014, S. 86-132; Caroline Maillet-Rao, La théologie politique des dévots Mathieu de Morgues et Michel de Marilllac, opposant au Cardinal de Richelieu, in: Renaissance and Reformation 32, Heft 3, 2009, S. 51-77; Seung-Hwi Lim, Mathieu de Morgues. Bon Français ou bon catholique?, in: Dix-septième siècle 213, 2001, S. 655-672.

30 Zum Jansenismus Bergin, The Politics of Religion, S. 181-205; vgl. Jean-Louis Quantin, Le rêve de la communauté pure, in: Bernard Cottret [et al.] (Hrsg.), Jansénisme et puritanisme, Paris 2002, S. 166-194; Anthony D. Wright, The Divisions of French Catholicism, 1629-1645. The Parting of the Ways (Catholic Christendom 1300-1700), Farnham 2011. $\mathrm{Zu}$ den ethischen Vorstellungen der Jansenisten und ihren Rückwirkungen auf das Bild des Heros siehe immer noch Paul Bénichou, Morales du Grand Siècle, Paris 1948, S. 77-138, besonders S. 97-111. 
deshalb jedes heroische Lebensideal an sich schon unmöglich wurde, ist eine andere Frage, denn in ihrem Widerstand gegen eine korrupte Welt demonstrierten die Rigoristen und Jansenisten in der Kirche selbst, wenn man so will, eine bewusst heroische Haltung. ${ }^{31}$ Aber einen Herrscher wegen seiner Siege zu verherrlichen, der einen ungerechten Krieg führte, das war eine andere Angelegenheit, zumal Cornelis Jansen selbst, der in den spanischen Niederlanden lebte und lehrte, die französische Kriegslegitimation ausdrücklich verworfen hatte. ${ }^{32}$ Richelieu versuchte zwar mit rigorosen Methoden, alle kirchlichen Kritiker der königlichen Politik zum Schweigen zu bringen, aber letztlich blieb der Zwiespalt zwischen den Maximen der Staatsräson, denen der König, beraten von Richelieu, folgte, und seiner demonstrativen Frömmigkeit bestehen. ${ }^{33}$

Erst gegen Ende seines Lebens vermochte Ludwig XIII., durch seinen Tod diese Kluft zu schließen. Sein Leiden an seiner letzten Krankheit wurde geradezu zelebriert und als Martyrium dargestellt. Nach seinem Tode hoben die Prediger hervor, wie sehr der König durch seine Gottergebenheit seinen Glauben unter Beweis gestellt habe. In einer der zahlreichen Leichenpredigten, die auf Ludwig XIII. gehalten wurden, in diesem Fall in der Kirche der Sorbonne, hieß es 1643, Gott habe, indem er so viele Leiden über den König verhängt habe, dessen Leben bewusst dem Leben und Sterben Christi angleichen wollen. So wie Christus niemals als König auf Erden geherrscht habe ohne zu leiden - denn eigentlich sei seine Königsherrschaft auf den Augenblick der Passion begrenzt gewesen -, so habe Ludwig XIII. keinen Tag seiner Herrschaft ohne körperliches Leiden erlebt. Um zu sehen, wie die "Chemie des Leidens" aus einem Menschen einen Engel mache und aus einem irdischen Herrscher einen himmlischen Monarchen, müsse man nur einen Blick werfen auf das Sterbezimmer des Königs, des neuen Hiob, im Schloss von Saint Germain. ${ }^{34}$

Auch andere Predigten betonten die Frömmigkeit des Verstorbenen und wie geduldig er die Schmerzen in seiner letzten Krankheit ertragen haben. So verkündete ein Prediger in Orléans der Gemeinde:

„sa mort fut sa gloire, sa sortie de la terre fut son entrée dans le ciel, cet astre ne fut iamais plus brillant que quand il volut s'esteindre, et ce roy ne parut iamais plus sainct, que quand il fut sur le point d'aller accroistre le nombre des bien-heureux. Le ciel permist que sa mort fust lente afine qu'elle en fust plus belle, et que ceux que n'avaient pû s’instruire par ses actions Royalles, se peussent convertir par ses actions Chretiennes" ${ }^{35}$

31 Olivier Chaline, Port Royal et la gloire, in: Histoire, économie, societé 20, 2001, S. 163-175. Cornelis Jansen, Alexandri Patricii Armancani. Mars Gallicus, editio novissima, o.O. 1639 (1. Aufl. 1635).

33 Asch, Sacral Kingship, S. 75-83.

34 Pierre Bertier, Evesque coadjuteur de Montauban, Docteur de Sorbonne. Oraison funèbre du roy Louis le Juste, prononcée en l'eglise de Sorbonne 1643, Paris 1644, S. 49-52, S. 58 zum König als einem Athleten des Glaubens.

35 „Sein Tod war sein Ruhm, sein Abschied von der Erde war sein Eintritt in den Himmel. Dieser Stern leuchtete nie heller als in dem Moment, als er erlöschen wollte, und dieser 
Das fromme Sterben des Königs sollte beweisen, dass er fälschlich dafür kritisiert worden war, seine Mutter allzu hart behandelt zu haben - entgegen seinen Pflichten als Sohn (Marie de' Medici war tatsächlich genötigt gewesen, ins Exil zu gehen). ${ }^{36}$ In dieser Perspektive erschien der sterbende König, der tatsächlich während der letzten Wochen seines Lebens in aller Öffentlichkeit gelitten hatte, als heroischer Märtyrer und so wollte der zweite Bourbone gegen Ende seine Lebens wohl auch selbst gesehen werden. ${ }^{37}$

Nach dem Ende der Religionskriege wandelte sich der Blick auf die Figur des heroischen Märtyrers tiefgreifend. An die Stelle eines Kämpfers gegen die Häresie und die Ungläubigen traten nun der Asket oder der Mystiker oder eben in weiblicher Gestalt die Mystikerin oder Asketin, während umgekehrt der Monarch selbst und der leitende Staatsmann als Märtyrer dargestellt wurden, sei es im Sinne einer Aufopferung für das eigene Land oder im Sinne einer Nachfolge Christi. Dies waren jedoch Modelle, die sich für den Schwertadel kaum zur Nachahmung anboten. Wenn er sich nach dem Ende der Religionskriege weiter dem heroischen Kampf für den wahren Glauben verschrieb, dann fand dieser Kampf am ehesten in Gestalt des Krieges gegen die Türken statt. Der letzte Führer der Liga etwa, der Herzog von Mercoeur, trat nach 1598 bewusst in die Dienste der Habsburger - zu Spanien hatte das Haus Lothringen von jeher enge Verbindungen unterhalten -, um gegen die Osmanen zu kämpfen. Nach einem siegreichen Feldzug im Jahre 1601 wurde er in Wien und Prag als Triumphator empfangen, starb aber schon auf der Heimreise in Nürnberg. Bei seiner Beerdigung hielt François de Sales die Leichenpredigt. De Sales sparte sorgfältig die politisch problematischeren Aspekte von Mercoeurs Unternehmen aus und erweckte den Eindruck, er sei mit dem ausdrücklichen Einverständnis des Königs von Frankreich in die Dienste des Kaisers getreten. Mercoeur war hier nicht der enttäuschte Adlige, der im Kampf gegen die neue Dynastie der Bourbonen unterlegen war, sondern der perfekte Kreuzrit-

König erschien niemals heiliger als in dem Moment, als er sich anschickte, die Zahl der Seligen zu vermehren. Der Himmel ließ es zu, dass sein Tod sich langsam vollzog, so dass er schöner war und die, die nichts von seinen Taten als König zu lernen vermochten, sich durch sein Handeln als Christ bekehren ließen.", Jean-François Senault, Harangues funèbres de Louis le Iuste Roy de France et de Nauarre, et de la Royne sa mère Marie de Medicis. Prononcées dans l'Eglise Cathedrale de Sainte Croix d'Orléans, par le père JeanFrançois Senault, Prestre de l'Oratoire, Paris 1643, S. 38.

36 Ebd., S. 40; vgl. Charles François Abra de Raconis, Discours funebre, panegyrique et histoire sur la vie et vertus, la maladie et la mort du Roy tres-chretien. Prononcé le 19 et 20 Juin [...], Paris 1643, S. 82-83.

37 Cédric Coraillon, Les deux morts de Louis XIII, in: Revue d'histoire moderne et contemporaine 55, 2008, S. 50-73; Alexandre Y. Haran, Louis Le Juste à travers les oraisons funèbres: roi-sauveur et monarque providentiel, in: Bernard Barbiche [et al.] (Hrsg.), Pouvoirs, contestations et comportements dans l'Europe moderne. Mélanges en l'honneur du professeur Yves-Marie Bercé (Collection Roland Mousnier; 23), Paris 2005, S. 247-262, besonders S. 252-258; vgl. Jacques Hennequin, L'image du prince dans les oraisons funèbres de Louis XIII, in: Travaux de Linguistique et de Littérature 22, Heft 2, 1984 (Colloque sur l'Image du Roi), S. 41-55. 
ter, ein wirklicher miles christianus, dessen Leben und Tod für alle Adlige, die ein Feld suchten, auf dem sich ihre „fureur guerrière“ 38 in legitimer Weise manifestieren konnte, als Vorbild fungieren konnte. Zugleich ließ de Sales Mercoeur als den würdigen Erben der beiden Dynastien, denen er entstammte, erscheinen, der Häuser Lothringen und Savoyen. Auf der anderen Seite betonte de Sales stark, dass Mercoeur eben nicht im Kampf als Krieger gefallen, sondern an einer Krankheit als gläubiger Christ nach hinreichender Vorbereitung auf den Tod gestorben war; der gute christliche Tod trat hier an die Stelle des heroischen Todes auf dem Schlachtfeld, der bis dahin für den Schwertadel das maßgebliche Modell gewesen war. ${ }^{39}$

Als Gottesstreiter sollte Mercoeur im frühen 17. Jahrhundert noch viele Nachfolger finden. Der Herzog von Nevers, wie Mercoeur ein prince étranger, also ein Adliger, dessen Dynastie außerhalb Frankreichs Titel und Herrschaften besaß (in seinem Fall das Herzogtum Mantua in Italien), versuchte vor Ausbruch des Dreißigjährigen Krieges sogar, einen eigenen neuen Ritterorden, die milice Chrétienne, zu begründen, um Konstantinopel zu befreien. ${ }^{40}$ Auch wenn dieser Plan schon im Anfangsstadium scheiterte, so gab sich doch auch der enge Berater Richelieus, der Kapuzinerpater Joseph (François-Joseph Le Clerc du Tremblay de Maffliers), der ebenfalls aus dem Schwertadel stammte, der Idee eines neuen Kreuzzuges hin, die ihre Attraktivität für den Adel also keineswegs verloren hatte, auch wenn sie bei Père Joseph zunehmend nationale Züge annahm. ${ }^{41}$

Während bei Mercoeur und Nevers der heroische Gewalthabitus des Adels in den Dienst einer höheren Sache gestellt wurde, stellte das 17. Jahrhundert doch zugleich eine Blütezeit des Duells dar. ${ }^{42}$ Auch schon scheinbar geringfügige Anlässe reichten, um Adlige zum Zweikampf zu provozieren. Das Leitbild heroischer Männlichkeit, dem sich so viele Adlige verschrieben hatten, schien nur auf diese Weise realisierbar zu sein. Die Adelserziehung, welche die jungen Männer auf den Krieg vorbereitete, war jedenfalls darauf angelegt, auch den Regelbruch als legitim erscheinen zu lassen. Diese Erziehung und die Erfahrung des Krieges selbst prägten das Selbstverständnis von Adligen. Für Gewalt und zerstörerische

38 Poumarède, Pour en finir avec la Croisade, S. 397-406, hier S. 406; vgl. François de Sales, Oraison funèbre de Philippe-Emmanuel de Lorraine, duc de Mercœur et de Penthièvre, in: François de Sales, Les Epistres spirituelles du bien-heureux François de Sales, [...] avec l'oraison funèbre de M. le duc de Mercoeur, recueillies par Messire Louys de Sales, Lyon 1628, S. 1020-1051.

39 Hélène Germa-Romann, Du «Bel Mourir » au «Bien Mourir » (Travaux d'humanisme et renaissance; 347), Genf 2001, S. 292-295.

40 Martin Wrede, Ohne Furcht und Tadel - Für König und Vaterland. Frühneuzeitlicher Hochadel zwischen Familienehre, Ritterideal und Fürstendienst (Francia, Beihefte; 75), Ostfildern 2012, S. 301-311.

41 Benoist, Le Père Joseph, S. 129-160, S. 208-215.

42 François Billacois, Le duel dans la société française des XVIe-XVII ${ }^{e}$ siècles. Essai de psychosociologie historique (Civilisations et Sociétés; 73), Paris 1986; Stuart Carroll, Blood and Violence in Early Modern France, Oxford 2006, S. 147-159. 
Leidenschaft, wenn sie sich im Kampf in Form von Wut und Aggression äußerte, blieb hier ein relativ großer Raum, oder wie Jonathan Dewald es formuliert hat:

„Contemporaries were impressed by the special psychological impact of the experience of warfare and by the ways this experience separated nobles from other social groups. In combat as in other aspects of his life, the military nobleman was expected to regulate his passions in ways quite unlike other men. Passion was not to be entirely repressed “.${ }^{43}$

Die Bereitschaft des Adels, im Duell und im Krieg, oder auch im zivilen Leben, die Regeln, die für andere Menschen galten, zu ignorieren oder zu überschreiten, hingen also eng mit seinen heroischen Idealen zusammen.

An keinem individuellen Adligen wird das vielleicht so deutlich wie an der Person des Prinzen von Condé (1621-1686). Condé gilt oft als der letzte große aristokratische Heros, dessen Ruhm einst den der Hauptlinie der Bourbonen selbst überstrahlt hatte und dessen Leben und Taten zeitgenössische Dichter, darunter auch Corneille, dazu inspiriert hatten, in ihren Werken ein Porträt des klassischen Helden, seiner Seelengröße, seines Mutes, aber auch seines unstillbaren Hungers nach Ruhm zu zeichnen. ${ }^{44}$ Condé gehörte einer Nebenlinie der Königsdynastie an, war also ein Prinz von Geblüt. 1621 in Paris geboren, hatte er schon in jungen Jahren mit 22 die Truppen des Erzfeindes der Bourbonen, der spanischen Habsburger, an der Grenze zu den spanischen Niederlanden bei Rocroi entscheidend geschlagen. Der französischen Armee war es bis dahin kaum je gelungen, die spanischen Truppen in offener Feldschlacht zu besiegen, umso größer war die Wirkung, die von Rocroi ausging, das galt auch deshalb, weil in der Schlacht die Kavallerie, die unter anderem von dem Protestanten Jean de Gassion kommandiert wurde, eine entscheidende Rolle spielte. Wie namentlich Hervé Drévillon hervorgehoben hat, verband sich mit der Schlacht die Hoffnung auf eine stärkere Position des französischen Schwertadels nicht nur auf dem Schlachtfeld, sondern auch in Staat und Gesellschaft. Die französischen Religionskriege waren noch weitgehend von Reiterarmeen ausgefochten worden, unter deren Offizieren und Soldaten sich zu einem großen Teil Angehörige des Adels befanden. Nach ihrem Ende war die Kavallerie in ihren militärischen Funktionen jedoch zunächst stark reduziert worden. Man konnte auf sie für das Fouragieren und den kleinen Krieg nicht verzichten, in den großen Feldschlachten spielte sie im französischen Heer aber eine eher untergeordnete Rolle. Mit Rocroi änderte sich dies, so schien es zumindest. Der Sieger von Rocroi wurde weithin als ein strahlender Held und als ein neuer Alexander gepriesen. ${ }^{45}$ Der Vergleich mit Alexander stand im Vordergrund,

43 Jonathan Dewald, Aristocratic Experience and the Origins of Modern Culture. France 1570-1715 (A Centennial Book), Berkeley, CA 1993, S. 65.

44 Vgl. Michel Prigent, Le héros et l'État dans la tragédie de Pierre Corneille, Paris 1986; zu Condé siehe auch Simone Bertière, Condé. Le héros fourvoyé, Paris 2011.

$45 \mathrm{Zu}$ Rocroi und den damit verbundenen Hoffnungen des französischen Schwertadels siehe Hervé Drévillon, Batailles, scènes de guerre de la table ronde aux Tranchées (L'Univers historique), Paris 2007, S. 119-140. 
orientierte sich freilich weniger an der historischen Alexanderfigur, sondern an dem Mythos, der sich im Laufe der Jahrhunderte herausgebildet hatte, und an den Helden zahlreicher barocker Romane, die von dieser Figur inspiriert worden waren. Condé hatte sich mit dem Leben Alexanders schon als Schüler bei den Jesuiten auseinandergesetzt, wie Zeitgenossen bezeugten. Sein Alexander war anders als bei Ludwig XIII. nicht die Präfiguration eines Herrschers, der einen Kreuzzug anführte, sondern ein durch und durch aristokratischer Held, der unbegrenztes Selbstvertrauen mit dem ebenso unbegrenzten Streben nach Ruhm verband. ${ }^{46}$

Wichtig war für Condé aber auch der Roman „Polexandre“ von Marin le Roy de Gomberville, der in den 1630er Jahren erschienen war und der von seinem Autor immer wieder in neuen Auflagen fortgeschrieben und modifiziert wurde. Der Roman, den Condé, damals noch Herzog von Enghien, offenbar verschlang, konzentrierte sich in seiner Ursprungsfassung vor allem auf die erotischen Abenteuer der Hauptfigur. In späteren Auflagen traten aber auch militärische Heldentaten in den Vordergrund, offenbar durchaus unter dem Einfluss des Krieges gegen Spanien, in dem Condé eine so erhebliche Rolle spielte.

Condé hatte sich als junger Mann am Vorbild heroischer Romangestalten inspiriert, es war in seinem Freundeskreis nicht ungewöhnlich, Liebesbriefe, die sich an eine mögliche Mätresse richteten, aus solchen Romanen abzuschreiben. Nach seinen ersten großen Erfolgen wurde er selbst beinahe zu einer Romanfigur. Fakten und Fiktion waren hier kaum noch zu unterscheiden. ${ }^{47}$

Die Tatsache, dass Ludwig XIII., der König, einige Tage vor der Schlacht von Rocroi, dem ersten spektakulären Sieg Condés, gestorben und sein Sohn ein minderjähriges Kind war, erleichterte es Condé sicherlich, sich in den Mittelpunkt eines neuen Heldenkultes zu stellen. Er besaß zwar in dieser Rolle durchaus auch seine Rivalen, wie etwa den Comte de Harcourt, der 1645 zum französischen Vizekönig in Katalonien ernannt worden war und von manchen Panegyrikern schon als das alter ego des Königs - gewissermaßen als Gegenstück zu den validos (Favoritenministern), die den spanischen Königen zur Seite standen - gefeiert wurde, ${ }^{48}$ aber Condé wurde doch zur beherrschenden Figur im Pantheon militärischer Helden in den 1640er Jahren. Die transgressiven Züge einer heroischen Selbstinszenierung, die Jonathan Dewald mit Blick auf den Schwertadel insgesamt hervorhebt, waren ihm dabei keineswegs fremd, im Gegenteil, wie Simone Bertière in ihrer Biographie des Prinzen feststellt:

46 Grell / Michel, L’École des princes, S. 63-64.

47 Dies nach Bertière, Condé, S. 198-200; zum Roman Gombervilles siehe auch Edward B. Turk, Baroque Fiction-Making. A Study of Gomberville's Polexandre (North Carolina Studies in the Romance Languages and Literatures; 196), Chapel Hill, NC 1978.

René de Ceriziers, Le Héros français ou l'idée du grand capitaine, Paris 1645. 
„Pour caractériser le duc d'Enghien soudain propulsé au faîte de la gloire, le terme que vient à l'esprit est la démesure - en bien comme en mal. Tout est chez lui porté au paroxysme: l'orgueil, la violence, le mépris, tournés contre les autres, le rend haïssable“. ${ }^{49}$

Es waren nicht zuletzt die erotischen Eskapaden Condés und seine demonstrative Verachtung für die Sexualmoral und die Verhaltensnormen der Kirche, in denen das transgressive Element seines Heldentums zum Ausdruck kam. Er trat bewusst als Libertin auf, wohl auch um zu zeigen, dass er vor den Strafen der Kirche weder im Diesseits noch im Jenseits Angst hatte, denn, „la morale héroïque est fondée sur la négation de la peur“ („die heroische Moral hat als Fundament die Verneinung der Furcht"). Allerdings, ein solches Heldentum, das die Autorität keiner irdischen oder jenseitigen Macht anerkannte, war schwer vereinbar mit der Selbstdisziplin, die das französische Königtum nun doch zunehmend von seinen Heerführern und Offizieren verlangte. Das Heldentum Condés, um noch einmal einen Gedanken Simon Bertières aufzugreifen, hatte sein Ziel am Ende nur in sich selbst, im Vordergrund stand der persönliche Ruhm..$^{50} \mathrm{Dem}$ König und dem eigenen Land zu dienen, war dafür nur ein Mittel zum Zweck, so mochte es zumindest erscheinen.

Selbst im militärischen Bereich war in den 1640er Jahren allerdings die Zeit nicht mehr fern, in der sich der Adel einer strikteren Disziplin unterwerfen musste. ${ }^{51}$ Feste Regeln über eine nach den Prinzipien der Anciennität verlaufende Laufbahn stellten nach 1660 den Vorrang des ererbten Ranges zumindest tendenziell infrage, obwohl der Hof- und Hochadel auch weiterhin die wichtigsten Stabsoffiziersstellen im Heer besetzte. Aber ganze Regimenter oder noch größere Einheit so zu behandeln, als seien sie gewissermaßen Teil einer Privatarmee, wie das in der Fronde noch geschehen war, war nach 1660, als der Kriegsminister Le Tellier und nach ihm sein Sohn Louvois die Streitkräfte einem umfassenden Disziplinierungsprozess unterwarfen, kaum noch möglich.

Noch Ende der 1640er Jahre war es freilich mit der Fronde zu einer letzten großen Adelsrevolte gekommen, in der die neue Ordnung, deren Fundamente bereits Richelieu vor seinem Tode (1642) gelegt hatte, noch einmal fundamental infrage gestellt wurde und in der Condé und andere Hochadlige zeitweilig eine zentrale Rolle spielten. Eine wesentliche Voraussetzung dieser Revolte lag auch in dem Umstand, dass Frankreich in diesen Jahren von einer weiblichen Regentin regiert wurde, von Anna von Österreich, der Witwe Ludwigs XIII. Die letzte weibliche Regentschaft lag 1643 gut 25 Jahre zurück, denn nach dem Tode Heinrichs IV. hatte

49 Bertière, Condé, S. 227, „Um den Herzog von Enghien, der sich plötzlich auf dem Gipfel des Ruhmes befand, zu charakterisieren, bietet sich der Begriff des Maßlosen an, im Guten wie im Bösen. Alles ist bei ihm auf das Äußerste gesteigert, der Stolz, die Gewalt, die Verachtung, die sich gegen andere richten, machen ihn verhasst“.

50 Vgl. ebd.

51 Guy Rowlands, The Dynastic State and the Army under Louis XIV. Royal Service and Private Interest in France 1661-1701 (Cambridge Studies in Early Modern History), Cambridge 2002 . 
Maria de' Medici 1610 ebenfalls die Rolle der Regentin übernommen. Erst 1617 konnte sich ihr Sohn von ihrer Vormundschaft befreien. Maria de' Medici hatte sich sowohl während ihrer Regentschaft als auch in den 1620er Jahren, als sie ihren politischen Einfluss wiedergewinnen wollte, als machtvolle Matriarchin, aber auch - in bestimmten Kontexten - als erotisch attraktive Amazonin, die selbst heldenhaft ihre Armeen in den Kampf führte, inszeniert oder inszenieren lassen, so etwa in dem großen Zyklus, in dem Rubens ihr Leben und ihre Regentschaft verherrlichte. Maria de' Medicis Versuch, ein traditionell eher männlich konnotiertes heroisches Charisma für sich zu beanspruchen und doch gleichzeitig als vorbildliche Mutter zu erscheinen, wirkte jedoch allzu widersprüchlich und war nicht wirklich dazu angetan, ihren Anspruch auf Autorität und Macht zu legitimieren. ${ }^{52}$ Auch Anna von Österreich ließ sich bis zu einem gewissen Grade eine heroische Rolle als Regentin zuschreiben. Sie konnte sich dabei auf eine mittlerweile relativ umfangreiche Literatur über die femme forte und ihre Rolle in der Geschichte stützen. Die Frau als Heldin wirkte also nicht mehr so exotisch, wie das vielleicht in den Jahren nach dem Tode Heinrichs IV. noch der Fall gewesen war, obwohl die einschlägige Literatur die heroische Frau meist nur als weibliches Gegenstück zu einem Heldentum gelten ließ, das im Kern doch männlich geprägt blieb. „Männliches Heldentum setzt den Maßstab und eine übergeschlechtliche Norm, der allenfalls Frauen vom Rang einer Jeanne d'Arc, Grande Mademoiselle [Anne Marie Louise d'Orléans, Duchesse de Montpensier, die während der Fronde selbst Truppen kommandierte; R. G. A.] und Duchesse de Longueville entsprechen ". ${ }^{53}$ Wenn weibliches Heldentum dann am Ende aber doch eher in „Herzensgüte" und seelischer Stärke und nicht in kriegerischem Mut bestand, ${ }^{54}$ dann hatte sich Anna von Österreich dieser Vorstellung von weiblicher heroischer Größe in ihrer Selbstdarstellung sehr viel besser angepasst als Maria de' Medici. Sie vermied es zum Beispiel sorgfältig, sich als Heerführerin oder Kriegerin darstellen zu lassen. Sie betonte stets, dass sie nur im Namen ihres Sohnes, nicht im eigenen Namen regierte. Ebenso wenig stellte sie ihre erotische Attraktivität in den Vordergrund, sondern eher ihre tiefe Frömmigkeit. ${ }^{55}$

52 Katherine B. Crawford, Perilous Performances. Gender and Regency in Early Modern France (Harvard Historical Studies; 145), Cambridge, MA 2004, S. 85-89. Vgl. zum Medici-Zyklus von Rubens Fanny Cosandey, La Reine de France. Symbole et pouvoir. XV ${ }_{-}$ XVIII ${ }^{\mathrm{e}}$ siècle (Bibliothèque des histoires), Paris 2000, S. 333-360.

53 Renate Kroll, Von der Heerführerin zur Leidensheldin. Zur Domestizierung der Femme Forte, in: Bettina Baumgärtel / Silvia Neysters (Hrsg.), Die Galerie der Starken Frauen. Regentinnen, Amazonen und Salondamen, München 1995, S. 51-63, hier S. 58. Zur Selbstinszenierung von Anna von Österreich siehe demnächst auch die in Beiheften der Zeitschrift „Francia“ erscheinende Studie von Oliver Mallick.

54 Vgl. ebd.

55 Vgl. Crawford, Perilous Performances, S. 98-136, besonders S. 103-104; vgl. auch Sylvie Steinberg, Le mythe des amazones et son utilisation politique de la Renaissance à la Fronde, in: Kathleen Wilson-Chevalier / Eliane Viennot (Hrsg.), Royaume de Fémynie. Pouvoirs, contraintes, espaces de liberté des femmes de la Renaissance à la Fronde (Colloques, congrès 
Allerdings sahen die Prinzen von Geblüt es dennoch als Demütigung an, von der Regentschaft ausgeschlossen zu sein und einer Frau und ihrem Favoriten, dem Kardinalminister Mazarin, noch dazu einem Italiener, gehorchen zu müssen. Und diese Unzufriedenheit des hohen Adels war ein wesentlicher Faktor für die innere Krise Frankreichs in den Jahren 1648 bis 1653. Die Fronde selbst ging zwar im Sommer 1648 vor allem von der noblesse de robe aus, die sowohl ihre Privilegien und Einkünfte als auch die Herrschaft des Rechtes an sich in dem permanenten Ausnahmezustand bedroht sahen, den die Kardinalminister Richelieu und Mazarin seit den 1630er Jahren geschaffen hatten. Aber schon bald, Anfang 1650, inszenierten hohe Adlige, darunter auch der Prince de Condé sowie - zumindest zeitweilig - Henri de la Tour d'Auvergne, Vicomte de Turenne, die Herzogin von Longueville und deren Gemahl sowie der Prinz Conti (die drei zuletzt genannten entstammten Nebenlinien der Königsdynastie), ihren eigenen Aufstand gegen die Regentin und den verhassten Premierminister Mazarin. Diese Fronde des Princes war durch heftige innere Konflikte gekennzeichnet und mag auf den ersten Blick den Eindruck einer bloßen Farce erwecken. Sie war in der Tat weit davon entfernt, eine wirkliche Revolution zu sein, an der die Beteiligten, die letztlich ein Mehr an Einfluss innerhalb des monarchischen Systems und nicht dessen Zerstörung anstrebten, auch kein Interesse haben konnten. ${ }^{56}$ Gerade Condé ging es eher darum, in der schwierigen Situation der Regentschaft selbst als Protektor des jungen Königs auftreten zu können, um damit Macht und Einfluss seines Hauses gegen die Ambitionen eines Favoriten abzusichern, der durchaus danach strebte, auch seine Familie unter den führenden Adelshäusern dauerhaft zu etablieren. ${ }^{57}$

et conférences sur la Renaissance européenne; 16), Paris 1999, S. 261-273; Marlies Mueller, The Taming of the Amazon. The Changing Image of the Woman Warrior in Ancien Régime Fiction, in: Papers on French Seventeenth-Century Literature 22, Heft 42, 1995, S. 199-232; Renée-Claude Breitenstein, Représentation de l'histoire et parole féminine dans Les Femmes illustres ou les Harangues héroïques des Scudéry, in: Jean-Claude Arnould / Sylvie Steinberg (Hrsg.), Les Femmes et l'écriture de l'histoire (1400-1800), Mont-Saint-Aignan 2008, S. 341353. Zeitgenössische Werke, die die Regentschaft von Anna von Österreich zu rechtfertigen suchten, indem sie die heroische Frau priesen, waren unter anderem Pierre Le Moyne, Gallerie des femmes fortes, Paris 1647 und Jacques du Bosc, La femme héroïque, Paris 1645.

56 Zur Fronde unter anderem Alexander Rubel, Eine Frage der Ehre. Die Fronde im Spannungsfeld von Adelsethos und Literatur, in: Francia. Forschungen zur westeuropäischen Geschichte 32, Heft 2, 2005, S. 31-57; Gerrit Walther, Protest als schöne Pose, Gehorsam als Event. Zur Formation des ludovizianischen Absolutismus aus dem Geiste der Fronde, in: Lothar Schilling (Hrsg.), Absolutismus, ein unersetzliches Forschungskonzept? Eine deutsch-französische Bilanz / L'absolutisme, un concept irremplaçable? Une mise au point franco-allemande (Pariser Historische Studien; 79), München 2008, S. 173-189. Siehe auch Michel Pernot, La Fronde, Paris 1994. Zum Hintergrund der Fronde und zum Werthorizont der beteiligten Adligen auch Jean-Marie Constant, La folle liberté des baroques 16001661, Paris 2007.

57 Katia Béguin, Les princes de Condé. Rebelles, courtisans et mécènes dans la France du grand siècle (Époques), Seyssel 2003, S. 110. 
Trotz ihrer begrenzten Ziele konnte die Fronde des Princes der Monarchie in einer Situation, in der sowohl die Regentin (Anna von Österreich, eine Spanierin) als auch der leitende Minister (Mazarin, ein Italiener) Ausländer waren, durchaus gefährlich werden. Sie scheiterte letztlich daran, dass die Führer des Aufstandes sich von einem Verständnis von Ehre leiten ließen, das Kompromisse auch innerhalb des eigenen Lagers sehr erschwerte, weil man durch jedes Zugeständnis den eigenen Status und Rang gefährdet sah. Gerade die heroische Selbstinszenierung führte ähnlich wie bei den royalistischen Kommandeuren des Bürgerkrieges in England zu einem übersteigerten Individualismus; ein durch heroischen Stolz geprägtes Beharren auf dem eigenen Prestige und dem Anspruch auf den eigenen Rang war keine gute Grundlage für die Zusammenarbeit zwischen einer Schar malkontenter Adliger, die keinen natürlichen Anführer besaßen. ${ }^{58}$

Schon Zeitgenossen hatten den Eindruck, dass die Adligen, die an der Spitze der Fronde standen, ihre Revolte so inszenierten, als handele es sich um eine Episode aus einem Ritterroman, in dem sie selbst die heroischen Hauptfiguren waren. In der Tat schrieben zeitgenössische Pamphlete, Biographien und panegyrische Schriften den führenden Adligen ganz ähnliche Charaktereigenschaften zu wie den Protagonisten solcher Romane, die sich ja ihrerseits zum Teil an lebenden Vorbildern wie Condé orientierten. ${ }^{59}$ Es liegt nahe anzunehmen, dass einige der Akteure ihr Handeln jenseits jedes machtpolitischen Kalküls selbst mithilfe jener Kategorien und jener Sprache begriffen, die ihnen die entsprechenden literarischen Werke an die Hand gaben. Zwar war das Prestige der traditionellen Ritterromane zu diesem Zeitpunkt bereits im Niedergang begriffen, nicht zuletzt aufgrund des Umstandes, dass popularisierte Versionen der Romanstoffe für ein breiteres, nichtadliges Publikum im Rahmen der sogenannten Bibliothèque bleue weithin vertrieben und damit, wie es schien, vulgarisiert wurden. Andererseits entfalteten historische Biographien der großen Gestalten der Spätphase des Rittertums, wie etwa des Chevalier Bayard (Pierre du Terrail, 1476-1524) gerade um die Mitte des 17. Jahrhunderts eine erhebliche Wirkung im Milieu des Adels, so wie entsprechende Lebensbeschreibungen schon im späten Mittelalter vom niederen Adel intensiv rezipiert worden waren. ${ }^{60}$ Das Vorbild eines Bayard ließ zusammen mit den Schlachtensiegen eines Herzogs von Enghien eine Wiederbelebung ritterlicher Werte möglich erscheinen. Nicht wenige Adlige hofften, sie könnten mit derselben Selbstverständlichkeit wie ein Bayard zugleich für ihre ganz persönliche Ehre und den König kämpfen. ${ }^{61}$ Solche Vorstellungen eines

58 Hopper, Turncoats and Renegadoes, S. 160, S. 177.

59 Mark Bannister, Privileged Mortals. The French Heroic Novel 1630-1660 (Oxford Modern Languages and Literature Monographs), Oxford 1983, S. 26.

60 Siehe dazu demnächst die Dissertation von Gero Schreier (SFB 948) zum Heroismus in adligen Lebenszeugnissen des späten Mittelalters. Schreier setzt sich hier auch mit dem Chevalier Bayard auseinander.

61 Pascal Brioist [et al.], Croiser le fer. Violence et culture de l'épée dans la France moderne (XVI ${ }^{\mathrm{e}}-\mathrm{XVIII}$ siècle) (Époques), Seyssel 2002, S. 271-273, vgl. S. 264-268. Zum Ritterro- 
sehr individualistisch verstandenen heroischen Lebensentwurfes erwiesen sich freilich bald als utopisch und in dieser Perspektive wäre das Scheitern der Fronde dann nur die notwendige Folge eines allgemeinen Niedergangs der traditionellen Adelskultur und der damit verbundenen Ordnungsvorstellungen gewesen. Und so ist die Fronde auch oft interpretiert worden. Kein Zweifel kann daran bestehen, dass der Adel nach dem Ende der Fronde und erst recht nach Beginn der selbstständigen Regierung Ludwigs XIV. (1661) genötigt war, sein Verhältnis zur Monarchie grundsätzlich zu überdenken. Die flamboyante heroische Selbstinszenierung der Vergangenheit mit ihrer Tendenz zur beständigen Revolte gegen Disziplin und Ordnung wurde nun deutlich zur Ausnahme, zu einem marginalen Phänomen. Sie lebte bis zu einem gewissen Grade fort in der Praxis des Duells, die freilich von der Monarchie im 18. Jahrhundert weitgehend stillschweigend geduldet wurde. Aber das Duell war eben nur noch soziale Praxis, einen öffentlichen Diskurs, der diese Praxis hätte legitimieren können, gab es nicht. ${ }^{62}$ Ob dieser Wandel mit dem endgültigen Verblassen der Figur des adligen Helden gleichzusetzen ist, ist jedoch weniger klar, als es auf den ersten Blick erscheinen mag. Das wird ein Blick auf die Epoche Ludwigs XIV. zeigen.

man auch Günter Berger, Aspekte der Rezeption des mittelalterlichen Romans im 17. Jahrhundert, in: Reinhold R. Grimm (Hrsg.), Mittelalter-Rezeption. Zur Rezeptionsgeschichte der romanischen Literaturen des Mittelalters in der Neuzeit (Begleitreihe zum Grundriß der romanischen Literaturen des Mittelalters; 2), Heidelberg 1991, S. 89-109; Geneviève Bollème (Hrsg.), Les contes bleus (Bibliothèque bleue), Paris 1983; Giovanni Dotoli, Letteratura per il popolo in Francia (1600-1750). Proposte di lettura della "Bibliothèque bleue " (Biblioteca della ricerca; 8,4), Fasanao 1991.

62 Hervé Drévillon, Le dire et le fer: le duel et sa publicité au XVII e siècle, in: Pascal Brioist [et al.], Croiser le fer. Violence et culture de l'épée dans la France Moderne (XVI ${ }^{\mathrm{e}}-\mathrm{XVIII}{ }^{\mathrm{e}}$ siècle) (Époques), Seyssel 2002, S. 239-304. 


\section{Die Transformation des Helden in Frankreich in der zweiten Hälfte des 17. Jahrhunderts}

Mit dem Scheitern der Fronde kam in Frankreich eine Form aristokratischer heroischer Selbstinszenierung zu einem Ende, für welche die Traditionen einer immer wieder neu erfundenen und neu artikulierten ritterlichen Kultur der Ehre ebenso entscheidend waren wie das Streben der Protagonisten nach persönlichem Ruhm. In den 1660er Jahren schickte sich der junge König Ludwig XIV. an, das, was von den Traditionen eines adligen Rittertums noch übrig war, vollends in die Selbstdarstellung des Königtums zu integrieren und zu absorbieren, wie etwa an dem großen Rossballett (carrousel) von 1662 deutlich wurde. Während die Turniere des 16. Jahrhunderts, die außerhalb Frankreichs, wo die Turniere nach dem Tode Heinrichs II. 1559 eingestellt worden waren, auch noch bis zum Beginn des 17. Jahrhunderts ihre Fortsetzung fanden, immer auch dem Adel eine Bühne für seine Selbstdarstellung geboten hatten, nicht nur dem Fürsten selbst, war das Rossballett von 1662 ganz auf den jungen Herrscher zugeschnitten. Die hohen Adligen, die an dem Fest teilnahmen, konnten hoffen, dass ein Strahl vom Glanz der königlichen Sonne auf sie fallen würde, aber aus eigenem Recht für sich Ruhm und Glanz zu beanspruchen, war im Umfeld des Hofes deutlich schwieriger geworden - und der Hof als Zentrum der Adelskultur war nun sehr viel wichtiger geworden als in der Vergangenheit. ${ }^{1}$ Der König hatte erfolgreich seinen Anspruch geltend gemacht, dass er der einzig wahre ritterliche Held war. Allerdings spielte die Kultur des Rittertums am Hof selbst in späteren Jahren kaum noch eine maßgebliche Rolle. Der König trat, wie noch jüngst Martin Wrede betont hat, als roi connétable auf, aber nicht mehr als roi-chevalier; die Sprache des Rittertums hatte im Wesentlichen ausgedient, wenn es galt, dem Monarchen ein heroisches Charisma zuzuschreiben.2 Das Heldentum Ludwigs XIV. war ohnehin von anderer Art als das seines Großvaters Heinrich IV., der seine Truppen noch selbst in die Schlacht geführt hatte. Für Ludwig XIV. genügte es, sich an der Spitze seiner Truppen zu zeigen, um seinen Anspruch zu unterstreichen, diese Truppen würden ihre Siege am Ende vor allem seinem Genie, seiner Tatkraft und seiner charismatischen Aura verdanken. Er musste nicht mehr selbst am Kampfe teilnehmen. ${ }^{3}$ Diese Zuschreibung heroischer Ei-

1 Zur Herrschaft Ludwigs XIV. und zu seiner Selbstdarstellung: Oliver Chaline, Le Règne de Louis XIV, Paris 2005; Gérard Sabatier, Versailles ou la figure du roi (Bibliothèque Albin Michel histoire), Paris 1999; Peter Burke, The Fabrication of Louis XIV, New Haven, CT 1992.

2 Wrede, Ohne Furcht und Tadel, S. 351, vgl. S. 344-350.

3 Mark Bannister, Condé in Context. Ideological Change in Seventeenth-Century France (Legenda), Oxford 2000, S. 178-180. Vgl. zu ähnlichen Entwicklungen außerhalb Frankreichs auch Disselkamp, Barockheroismus, S. 21, der konstatiert, dass sich im Rahmen der Fürstenpanegyrik das allgegenwärtige „Heroismusetikett“ immer mehr von einem konkreten Anlass löste und nun weniger ein „bestimmtes Handeln“ kennzeichnete und mehr für 
genschaften an den König ohne einen allzu engen Realitätsbezug wurde in den 1660er und 1670er Jahren sicherlich dadurch erleichtert, dass der Herrscher sich weitgehend in Darstellungen mit einem historischen Bezug inszenieren ließ, in antiker Pose gewissermaßen, im Kostüm der Heroen und großen Herrscher des Altertums, begleitet von den Gestalten der Mythologie. ${ }^{4}$ Eine zentrale Bedeutung kam hier anfänglich der Gestalt Alexanders des Großen zu, dem der Hofmaler Le Brun Anfang der 1660er Jahren einen großen Zyklus widmete, in dem er allerdings die militärischen Heldentaten, die Ludwig XIV. vor 1667 noch nicht vorzuweisen hatte, gegenüber den Liebesabenteuern des Makedoniers und anderen signifikanten Episoden aus seinem Leben eher in den Hintergrund treten ließ. Es galt, die Tugend des Herrschers zu zeigen, nicht primär seine Triumphe als Krieger. ${ }^{5}$ Auch so blieb Alexander der Große allerdings eine kontroverse Figur. Allzu sehr schien sein hervorstechendster Charakterzug die Hybris zu sein und namentlich Geistliche, die in der Tradition des Augustinismus standen, was etwa für die Jansenisten galt, sahen in ihm ein Beispiel für eine maß- und gottlose Ruhmsucht. ${ }^{6}$ Eine vorsichtige Distanzierung des Königs von diesem antiken Heros wurde daher schon im Laufe der 1670er Jahre deutlich, allerdings war es nicht nur die Figur Alexanders, die zunehmend ins Zwielicht geriet, so dass der König ihre Identifikationsoptionen in den 1680er Jahren auch wieder an den Grand Condé abtrat, sondern der Held überhaupt. ${ }^{7}$ Philosophie und Essayistik der Epoche betonten zunehmend die transgressiven Elemente des Heroischen. Für Helden schien in der literarischen und politischen Imagination kein Platz mehr zu sein und wenn für sie doch noch Raum war, dann war doch jede konkrete Heroisierung einer einzelnen Figur der Geschichte oder Gegenwart immer sofort kontrovers. Indes, wie Thomas Kirchner zu Recht betont, „Ludwig XIV. pochte [...] auf seine Heldenrolle“. ${ }^{8}$ Darstellbar schien sie jetzt aber nur noch zu sein, wenn man auf die Sprache der antiken Geschichte und Mythologie weitgehend verzichtete, da damit zu viele Assoziationen verbunden waren, welche die transgressiven Elemente der Heldenfigur in den Vordergrund treten ließen - von weiteren Vorbehalten gegen diese Sprache des Heroischen, etwa ihre Verwendbarkeit auch durch hohe Adlige, einmal abgesehen. ${ }^{9}$

ein „verdecktes Darstellungsinteresse“ stand; vgl. auch ebd. S. 181. Zur Darstellung des Königs als Kriegsheld vgl. auch Joël Cornette, Le roi de guerre. Essai sur la souveraineté dans la France du Grand Siècle (Bibliothèque historique Payot), Paris 2000.

Siehe dazu Sabatier, Versailles; vgl. auch Nicolas Milanovic, Du Louvre à Versailles. Lecture des grands décors monarchiques, Paris 2005.

5 Thomas Kirchner, Der epische Held. Historienmalerei und Kunstpolitik im Frankreich des 17. Jahrhunderts, München 2001, S. 113-115; vgl. Joël Cornette, La tente de Darius, in: Joël Cornette / Henry Méchoulan (Hrsg.), L'État classique 1652-1715. Regards sur la pensée politique dans la France dans la seconde moitié du XVII siècle, Paris 1996, S. 9-42. Grell / Michel, L’École des princes, S. 68-80.

Ebd., S. 76-78.

Kirchner, Der epische Held, S. 346-355, S. 357.

Ebd., S. 431. 
Die Querelle des anciens et des modernes ließ dann in den späten 1680er Jahren die Mythologie in den offiziellen Repräsentationsräumen in Versailles als Mittel der Verherrlichung des Königs endgültig in den Hintergrund treten. Sie überlebte am ehesten noch in den eher privaten Nebenresidenzen wie Marly oder in den Privatgemächern des Königs in der Hauptresidenz. ${ }^{10}$ Die sogenannten Modernen beharrten in diesem literarischen und ästhetischen Streit darauf, dass die Kultur Frankreichs unter dem Sonnenkönig derjenigen der Blütezeit der Antike, der augusteischen Epoche, überlegen sei. Alexander der Große wurde mehr denn je in der Geschichtsschreibung wegen seiner Zügellosigkeit und seines Jähzorns kritisch gesehen, aber auch Augustus warf man nun zumindest die Proskriptionen als Akt ungeheurer Grausamkeit vor. ${ }^{11}$ Vor allem aber wollte man betonen, dass Ludwig XIV. alle möglichen Rivalen übertroffen habe. So schrieb Guyonnet de Vertron 1685 in seiner Abhandlung „Parallèle de Louis le Grand avec les princes qui ont été surnommez Grands", dass alle Großen Männer Ludwig ähnelten, er aber nur sich selbst gleiche, warum also solle man in mythologischen Fabeln oder in der Geschichte eines Alexanders des Großen nach exempla suchen, wenn doch der Bourbone selbst ein Exempel für alle Tugenden gebe. Deshalb sei es auch unsinnig, den Monarchen als zweiten Cäsar oder Augustus oder auch als Alexander oder Herkules zu feiern, er solle vielmehr als moderner Held erscheinen, nicht als Wiedergänger der römischen oder griechischen Halbgötter, Heroen und Imperatoren, die ihm in Wirklichkeit unterlegen seien. ${ }^{12}$

Der Sieg der Modernes über die Anciens, der sich auch im Wandel der Bildprogramme in Versailles ab etwa 1680 manifestierte, führte dazu, dass in Frankreich die Darstellung des Monarchen als römischer oder griechischer Heros oder im Gewande der antiken Mythologie zumindest entwertet wurde, auch wenn sie nicht ganz verschwand; ${ }^{13}$ sie drohte aber doch im politischen Kontext zur bloßen Staffage oder Kostümierung zu werden. Der König war nun im Bild vor allem er selbst. Das Königtum als Amt, als Idee und der konkrete Leib des Königs, seine menschliche Person gingen ineinander auf, viel stärker als das in der Ver-

10 Sabatier, Versailles, S. 436-544.

11 Christian Michel, Les enjeux historiographiques de la Querelle des Anciens et des Modernes, in: Centre de Recherches sur l'Occident Moderne (Hrsg.), La monarchie absolutiste et l'histoire en France. Théories du pouvoir, propagandes monarchiques et mythologies nationales (Mythes, critique et histoire; 1), Paris 1987, S. 139-155, hier besonders S. 146; Catherine Volpilhac-Auger, Auguste et Louis XIV. Les contradictions de Voltaire devant le pouvoir absolu, in: Centre de Recherches sur l'Occident Moderne (Hrsg.), La monarchie absolutiste et l'histoire en France. Théories du pouvoir, propagandes monarchiques et mythologies nationales (Mythes, critique et histoire; 1), Paris 1987, S. 197-215. Siehe auch Kirchner, Der epische Held, S. 367-369; Heinz Thoma, Art. Querelle des Anciens et des Modernes, in: Heinz Thoma (Hrsg.), Handbuch Europäische Aufklärung. Begriffe, Konzepte, Wirkung, Stuttgart/Weimar 2015, S. 407-418.

12 Nach Cornette, Le roi de guerre, S. 242.

13 Zur Problematisierung der Heroisierung sowohl antiker wie moderner Figuren siehe Kirchner, Der epische Held, S. 346-370. 
gangenheit der Fall gewesen war. Entscheidendes Medium für die Darstellung der Idee des Königtums war nun nicht mehr etwa die bildende Kunst oder gar ein politisches Ritual, sondern der Leib des Königs selbst, dem unmittelbar jene Schönheit und jener Glanz, jener éclat, zugeschrieben wurde, der sonst antiken Heroen vorbehalten war. ${ }^{14}$ Letztlich konnte der König nur noch sich selbst und damit auch die Idee eines vollkommenen heroischen Herrschers darstellen, kein Abbild wurde ihm ganz gerecht und vor allem kein Porträt, das seine Größe nur in allegorischer Form zur Anschauung brachte. ${ }^{15}$

Dies brachte Ludwig XIV. als konkreter Person einen enormen Legitimitätszuwachs, machte seine Verherrlichung als Herrscher allerdings auch angreifbarer. Eine Herkules-Skulptur oder ein Bild des Apoll, das die Stärke und die Überlegenheit des Königs, seine virtus, zur Anschauung brachten, konnten weniger leicht als Ausdruck der Eitelkeit angegriffen werden als eine Statue, die unverkennbar ihn selbst darstellte wie im Falle des Monuments, das 1686 auf der Place des Victoires in Paris errichtet wurde. Es zeigte den König bekrönt von der Siegesgöttin wie er einen Cerberus, Symbol der Tripelallianz seiner Gegner, in den Staub trat. Zu Füßen des Denkmals kauerten vier Sklaven, die die Feinde Frankreichs darstellten, das Reich, Spanien, die Niederlande und Brandenburg. Namentlich dieser politische Affront führte zur Intervention ausländischer Diplomaten. Aber auch in Frankreich selbst war die grenzenlose Verherrlichung eines lebenden Herrschers, der sich auf dem Denkmal selbst als „vir immortalis“ bezeichnen ließ, umstritten. Es gab katholische Geistliche, die das offen als Idolatrie brandmarkten und meinten, ein Herrscher der sich wie einst Nebukadnezer in dieser Weise göttliche Eigenschaften zuschreiben lasse, werde den Zorn Gottes heraufbeschwören, der dann sein Land treffen werde. ${ }^{16}$

Seit den 1690er Jahren wurde die Selbstdarstellung des Königs tatsächlich zurückhaltender. Denkmäler wurden für ihn auch jetzt noch errichtet, betonten aber weniger stark das Siegreich-Heroische und zeigten den König stärker mit imperialer Geste als einen Herrscher, der ohne aufzutrumpfen durch seine anstrengungslose Autorität Ordnung und Frieden garantierte. ${ }^{17}$ Im höfischen Kon-

14 Vgl. André Félibien, Le portrait du roi, in: André Félibien, Description des divers ouvrages de peinture faits pour le roi, Paris 1671, S. 83-112, besonders S. 104-106.

Édouard Pommier, Le portrait du pouvoir. De la norme à la réalité, in: Olivier Bonfait / Brigitte Marin (Hrsg.), Les portraits du pouvoir (Collection d'histoire de l'art de l'Académie de France à Rome, Académie de France; 3), Rom 2003, S. 3-17, hier S. 13-15.

16 Hendrik Ziegler, Der Sonnenkönig und seine Feinde. Die Bildpropaganda Ludwigs XIV. in der Kritik (Studien zur internationalen Architektur- und Kunstgeschichte; 79), Petersberg 2010, S. 76-111, besonders S. 95, S. 271.

17 Zur Reiterstatue auf der Place Vendôme, die 1699 errichtet wurde, siehe Ziegler, Der Sonnenkönig und seine Feinde, S. 120-124 und Michel Martin, Les monuments équestres de Louis XIV. Une grande entreprise de propagande monarchique, Paris 1986, S. 92-117. 
text, in den Bildprogrammen der Residenzen, besonders in Versailles, trat die Figur des Königs zeitweilig sogar ganz in den Hintergrund. ${ }^{18}$

Mit dem relativen Zurücktreten älterer Modelle der Heroisierung des Monarchen wurde die Idee des Königtums, die nun ganz im Bild der individuellen Person des Monarchen aufging, allerdings generell angreifbarer. Dieser Wandel in der Repräsentation des Königs drohte die Aura der Monarchie selbst zu schwächen, wenn nicht zu zerstören, wenn eines Tages ein Nachfolger herrschte, dem diese Verkörperung der Würde der Krone nicht mehr in so überzeugender Weise gelang. Es stand jetzt keine mythologische, historisierende oder allegorische Formensprache mehr zur Verfügung, um solche Schwächen überzeugend zu überdecken. Aus der Gleichsetzung des Herrschers mit Herkules oder Alexander war eine bloße Metapher geworden, die keine Metamorphose seiner Person mehr bewirkte, wie Gerard Sabatier es in seiner großen Studie über Versailles, „Versailles ou la figure du roi“", konstatiert hat. ${ }^{19}$

Die guerre spectacle, die die höfische Kunst in den ersten Regierungsjahrzehnten verherrlicht hatte - wobei im Spiegelsaal in Versailles in den 1680er Jahren schon die politischen und diplomatischen Siege gegenüber den rein militärischen Erfolgen dominierten,$-{ }^{20}$ fand freilich in den 1690er Jahren ohnehin ein Ende, da der alternde König Versailles nicht mehr verließ, um sich als Feldherr zu inszenieren. ${ }^{21}$ Damit wurde ein Stück weit die Bühne doch wieder frei für adlige Offiziere und Kommandeure, die als kriegerische Helden in Szene gesetzt wurden, vielleicht nicht mehr im Stil der 1640er Jahre, aber doch in einer Form, die dem adligen Streben nach Prestige und Ehre Raum ließ, solange es sich den Notwendigkeiten einer effizienten und rationalisierten Kriegführung unterordnete. Selbst eine so flamboyante Erscheinung wie Charles de Batz de Castelmore d'Artagnan, der berühmte Musketier des Königs, der später durch Alexandre Dumas unsterblich werden sollte, konnte seinen Platz im Pantheon der Monarchie finden. D’Artagnan wurde um 1610 in der Gascogne geboren. ${ }^{22}$ In den legendenhaften Pseudomemoiren d'Artagnans, die etwa 30 Jahre nach seinem Tod von Gatien de Courtilz de Sandras publiziert wurden, wird d'Artagnan entsprechend als typischer Adliger aus dem Südwesten Frankreichs dargestellt, wobei bei Courtilz allerdings das Béarn an die Stelle der Gascogne tritt. ${ }^{23}$ Seinen Aufstieg verdankte

18 Dazu Milanovic, Du Louvre à Versailles, S. 229: „il ya dans le même temps une disparition ou plutôt une dissolution du portrait du roi, qui peut être également interprétée dans le context de l'impossibilité d'une véritable sacralité du roi dans les monarchies occidentales“.

21 Zur „guerre spectacle“ siehe ebd., S. 249-264.

22 Dies und das Folgende nach Hervé Drévillon, L'impôt du sang. Le métier des armes sous Louis XIV, Paris 2005, S. 63-68; Ders., Batailles, S. 149-170; vgl. Odile Bordaz, D’Artagnan. Capitaine-lieutenant des Grands Mousquetaires du Roi, Montréal/Baixas 2001.

23 Gatien de Courtilz de Sandras, Mémoires de M. d'Artagnan, capitaine-lieutentant de la première Compagnie des Mousquetaires du Roi, 3 Bde., Köln 1701-1702. 
d'Artagnan jedoch vor allem der Protektion Mazarins, als dessen treue Kreatur er galt und dem er auch während der Fronde ins Exil nach Deutschland folgte. 1667 wurde d'Artagnan nach einer militärischen Karriere im Umkreis des Hofes Kapitänleutnant der Musketiere des Königs, einer Einheit, die in der Theorie vom Monarchen selbst kommandiert wurde und deren Offiziere und Soldaten nahezu beständigen Zugang zum Monarchen besaßen. In diesem Sinne war d'Artagnan mindestens ebenso sehr Höfling wie Soldat, was ihn nicht hinderte, sich bei unterschiedlichen militärischen Einsätzen auszuzeichnen. Den letzten dieser Einsätze erlebte er bei der Belagerung der Festung Maastricht 1673. Bei einem Angriff auf eine feindliche Schanze, den er mit gewohnter Tollkühnheit führte, ohne Deckung vor dem feindlichen Beschuss zu suchen, traf ihn eine Kugel tödlich. Sein Angriff, bei dem er die Belagerungsgräben verlassen hatte, war eigentlich ein Verstoß gegen die Regeln der geltenden Kriegskunst und der Festungsingenieur Vauban äußerte sich auch in seinen Aufzeichnungen entsprechend kritisch. Andererseits leistete der Angriff d'Artagnans doch einen wesentlichen Beitrag zum Fall der Festung, war also nicht nur eine glorreiche Geste, mit der sich d'Artagnan einen ruhmreichen Tod sichern wollte.

Hervé Drévillon bemerkt in diesem Kontext, der Tod des Musketiers zeige, wie sich der Kult des heroischen Mutes, der den Armeen Ludwigs XIV. keineswegs fremd war, gerade in der Konfrontation mit der technischen Rationalität der Belagerungen - eine Vorwegnahme der noch intensiveren Technisierung des Krieges im 20. Jahrhundert - habe beweisen müssen, aber auch seinen Sinn erhielt. Der Tod des großen Musketiers war nicht mehr der ,schöne Tod' des ritterlichen Kriegers, der sich selbst genügte, sondern war, so spektakulär er auch erscheinen mochte, doch den Gesetzen der militärischen ratio unterworfen. ${ }^{24}$

Jedenfalls war für heroische adlige Krieger wie d'Artagnan in den Armeen Ludwigs XIV. durchaus noch Platz, ja die Monarchie war geradezu darauf angewiesen, mehr denn je an die Bereitschaft des Adels zum Selbstopfer zu appellieren. Zwar lag der Akzent nun stärker als in der Vergangenheit auf dem sparsamen Umgang mit den militärischen Ressourcen - und dazu gehörten eben auch Menschenleben - und militärische Karrieren verdankten sich stärker als früher den rein administrativen Fähigkeiten der jeweiligen Offiziere, ihrer strategischen Kompetenz, nicht nur dem offen zur Schau getragenen Mut und der Angriffslust. Aber die persönliche Reputation blieb dennoch abhängig von der Fähigkeit, in einer Ausnahmesituation Taten zu vollbringen, die als Heldentaten angesehen und dargestellt werden konnten, wie d'Artagnan es bei Maastricht getan hatte. ${ }^{25}$

Die Monarchie war weiter auf Adlige angewiesen, die sich plausibel heroisieren ließen, wie es der Autor Courtilz des Sandras für d'Artagnan besorgte, selbst

24 Drévillon, Batailles, S. 164; vgl. ebd., S. 167 mit der Feststellung „Le sacrifice de d'Artagnan abandonnait ainsi le registre de la 'belle mort' où le fait d'armes s'insérait dans un système de valeur autoréférencé, où l'action héroique se suffisait à elle-même“.

25

Drévillon, L'impôt du sang, S. 405-407, vgl. S. 324-327, S. 338. 
wenn deren Heroismus dann stark transgressive Elemente zeigte. Von einer allgemeinen Domestizierung des Adels, einem Verschwinden des adligen Helden, konnte also selbst im Frankreich Ludwigs XIV. nicht die Rede sein. Dann hätte man aus d'Artagnan keinen Helden machen können oder wollen und Gleiches gilt für andere Offiziere, die durch panegyrische Schriften und durch offiziöse Biographien nach 1660 heroisiert wurden, wie den 1647 verstorbenen Marschall Jean de Gassion.

Gassion war ein Reitergeneral, der zusammen mit dem Prinzen Condé 1643 die Schlacht von Rocroi gewonnen hatte. Über Gassion, der überdies noch Protestant war und im Heer Gustav Adolfs gekämpft hatte, schreibt Drévillon: „Dans sa radicalité cette figure de l'homme de guerre incarnait la démesure, la déraison et la violence des combats“ („In seiner Radikalität verkörperte diese Gestalt des Kriegers die Maßlosigkeit, die Irrationalität und die Gewalt des Kampfes"). Schon zu Lebzeiten sei eine solche figure hérö̈que als ein Außenseiter erschienen, was dem Ruhm Gassions aber keinen Abbruch tat. ${ }^{26}$ Gassion hatte all das getan, was ein adliger Offizier in den Armeen Ludwigs XIV. eigentlich nicht tun sollte: Er hatte sich ständig in Duellen mit persönlichen Gegnern geschlagen, er war unnötige Risiken eingegangen nur wegen des sensationellen Effektes und hatte stets auch den persönlichen Kampf mit dem Gegner oder feindlichen Kommandeuren gesucht und siegreich bestanden. Vor allem war er Spezialist in einer Art der Kriegführung, die sich bis dahin in Frankreich keines großen Ansehens erfreut hatte, des kleinen Krieges, bei dem es um das Beutemachen und die Unterbrechung des feindlichen Nachschubes ging. Diesen Krieg führte er mit Leidenschaft und mit erheblicher Brutalität und Rücksichtslosigkeit, aber, wenn man seinen Biographen glauben darf, auch im Vertrauen auf eine göttliche Vorsehung, der er sich als gläubiger Calvinist blind anvertraute. Drévillon spricht davon, Gassion sei eine Art Gotteskrieger, ein „guerrier de dieu“, gewesen, der zugleich die radikale Inhumanität des Krieges demonstriert habe. Aber weil ihm ein heroischer Status zugeschrieben wurde, fand diese Brutalität in seiner Biographie ebenso wie seine zahlreichen Verletzungen der üblichen militärischen Regeln eine gewisse Rechtfertigung. ${ }^{27}$

Allerdings stellten weder Gassion noch d'Artagnan als militärische Helden eine Gefahr für die Monarchie dar. Wenn man davon absieht, dass Gassion zum Zeitpunkt, als Ludwig XIV. seine selbstständige Regierung begann, schon 14 Jahre tot war und seine Präsenz im Bewusstsein der Zeitgenossen nach 1660 primär eine mediale war, die es ohnehin erschwerte, den historischen Gassion von dem Bild zu unterscheiden, das seine Biographen von ihm schufen, und dass d'Artagnan 1673 starb, waren eben beide auch keine Angehörigen der hohen Aristokratie gewesen. Gassion stammte sogar aus dem Amtsadel und d'Artagnans Vater war

26 Hervé Drévillon, L’héroïsme à l'épreuve de l'absolutisme. L'exemple du maréchal de Gassion (1609-1647), in: Politix 15, 2002, S. 15-38, hier S. 16.

27 Ebd., S 36. 
ein armer Provinzadliger gewesen, lediglich seine Mutter hatte der Familie ein Plus an Geld und Prestige verschafft. ${ }^{28}$

Ein Mann wie der Grand Condé, jener klassische Heros, von dem im Kontext der Neudefinition heroischer Leitbilder in der ersten Hälfte des 17. Jahrhunderts bereits die Rede war, war hier freilich ein ganz anderer Fall. Als Prinz von Geblüt gehörte er dem eigenen Selbstverständnis nach zu den natürlichen Ratgebern des Herrschers und er besaß in wichtigen Provinzen wie namentlich in Burgund ein dichtes Netzwerk von Klienten. In der Fronde hatte er zeitweilig eine ganze Armee hinter sich versammelt. War auch für eine solche Figur in der militärischen Kultur der Zeit Ludwigs XIV. noch ein Platz vorgesehen? Condé war in der Tat nach seiner Rückkehr nach Frankreich aus dem Exil (1659) genötigt gewesen, mit jeder seiner Gesten seine Ergebenheit gegenüber dem König zu demonstrieren. Er hatte sogar eine Eheschließung zwischen seinem Enkel und einer unehelichen Tochter des Königs, die aus der Verbindung mit Madame de Montespan stammte, selbst mit in die Wege geleitet, ${ }^{29}$ womit er den unbedingten Vorrang der Hauptlinie der Bourbonen vor seinem eigenen Hause anerkannte.

Als er 1686 starb - er hatte sich schon 1675 auf sein Landgut in Chantilly zurückgezogen, nachdem er in den Jahren zuvor noch einmal die königlichen Armeen in den Krieg gegen die Feinde Frankreichs geführt hatte -, hoben die panegyrischen Schriften und Leichenpredigten, die zu diesem Anlass erschienen, in der Tat seine unbedingte Ergebenheit gegenüber dem Monarchen hervor. Am Hofe war es der berühmte Bossuet, der die Leichenpredigt auf ihn hielt, die ein Meisterstück der sakralen Rhetorik darstellte. ${ }^{30}$ Im Pariser Jesuitenkolleg war es hingegen der Pater Jacques La Baune, dem diese Aufgabe zukam. Ähnlich wie für Bossuet war Condé hier der vollkommene Held, groß im Frieden ebenso wie im Krieg. Keine der klassischen Tugenden des heroischen Kriegers und Edelmannes fehlte ihm, von Mut und Schönheit bis hin zu Großzügigkeit und Scharfsinn. Aber so wie Bossuet nachdrücklich hervorhob, dass alle menschlichen Tugenden ohne die Gnade Gottes und die Frömmigkeit wertlos seien, so unterstrich La Baune, dass Condé nicht nur ein ruhmreicher Feldherr gewesen sei, sondern seine eigene Person stets der des Königs untergeordnet habe. La Baune betonte immer wieder, wie sehr der deutlich ältere Condé den König bewundert habe. Wenn er mit dem König Kriegsrat gehalten habe, soll er anschließend immer ausgerufen haben: „Quantus est, Superi, Ludovicus! Quam nobis omnibus major“? („Wie groß, oh ihr Götter, ist Ludwig, wie sehr ist er uns allen überlegen“). ${ }^{31}$

28 Drévillon, L'impôt du sang, S. 64.

Bannister, Condé in Context, S. 171; vgl. Bertière, Condé, S. 702.

Jacques Bénigne Bossuet, Oraison funèbre de tres-haut et tres-puissant prince Louis de Bourbon, prince de Condé, premier prince du sang. Prononcée dans l'église de NostreDame de Paris, le 10. jour de mars 1687, Paris 1687. Vgl. Béguin, Les Princes de Condé, S. 341-342.

31 Jacques de La Baune, Laudatio funebris Ludovici Borbonii, principis Condaei, [...] dicta die 17 Kal. Maii an. 1687 in regio Ludovici Magni collegio, Paris 1687, S. 35. 
La Baune betonte freilich auch, dass Condé am Ende seine Furchtlosigkeit vor dem Tode so weit überwunden habe, dass er das göttliche Gericht doch gefürchtet und seinen Frieden mit Gott gemacht habe. ${ }^{32}$

Dass ein Kriegsheld und Frondeur wie Condé wenn schon nicht als serviler, so doch zumindest als blind gehorsamer Diener des Königs dargestellt wurde, scheint - und so ist es auch oft gedeutet worden - in der Tat den Niedergang eines bestimmten Ideals adliger Existenz anzudeuten: der adlige Krieger, dem sein Ruhm und seine Ehre letztlich wichtiger waren als die Unterordnung unter den König und seine Minister, der trotzig seine Unabhängigkeit auch noch in der Niederlage verteidigte und dessen Loyalität seinem Stande mindestens ebenso sehr wie der regierenden Dynastie galt. ${ }^{33}$ Ein näherer Blick zwingt aber doch dazu, dieses Urteil zu differenzieren.

Kurz vor dem Tode des großen Condé hatte ein Geistlicher namens Rapin eine Abhandlung über das Erhabene erscheinen lassen, in der auch Condé selbst eine nicht unerhebliche Rolle spielte. Rapin sah gerade im Rückzug Condés auf seine Güter nach 1675 die Legitimation seines Anspruches auf Größe, eine Größe, die freilich nicht unbedingt dem traditionellen Leitbild des militärischen Heros entsprach. Diese Form heroischer Selbstdarstellung kam nämlich nun in erster Linie dem König zu. ${ }^{34}$ In Rapins Schrift erschien zwar auch noch Turenne, der Waffengefährte und Rivale Condés, in diesem Gewand, aber doch primär als ergebener Diener seines Herrschers, der in seinem Auftrag Krieg führte. Diese Darstellung stieß freilich auf die Kritik der Familie des Prinzen Condé. ${ }^{35}$ Rapin suchte kurz vor seinem eigenen Tod und nach dem Tod Condés selbst seinen Fehler auszugleichen, indem er eine aufwendige Eloge auf den Herzog verfasste. Auch hier wurde zwar hervorgehoben, wie würdevoll der Herzog sich nach der Beendigung seiner militärischen Karriere auf seine Güter zurückgezogen habe, aber es waren nun auch andere Argumente, die den Anspruch des Helden auf Größe untermauerten. Vor allem wurde hervorgehoben, dass er eben nicht nur grand capitaine, sondern auch grand homme gewesen sei, ein großer Geist mit weitgespannten intellektuellen Interessen und mit einem persönlichen Charisma, das ihn auch im Ruhestand nicht verlassen habe. ${ }^{36}$ Damit wurden Argumente der früheren Schrift noch einmal aufgenommen, aber in einem anderen Kontext. Dennoch kann man diese Eloge Rapins so lesen, dass er durch den Akzent, den er auf die Rolle Condés als grand homme legte, eben doch eine Art Gleichwertigkeit zwischen dem

32 Ebd., S. 46.

33 So argumentiert auch Bannister, Condé in Context, S. 181-188.

34 René Rapin, Du grand ou du sublime dans les moeurs et dans les différentes conditions des hommes, Paris 1686.

35 Béguin, Les Princes de Condé, S. 342; Bannister, Condé in Context, S. 192.

36 René Rapin, Le Magnanime, ou l'Éloge du Prince de Condé, premier prince du sang, Paris 21690, S. 59. 
Prinzen und dem König herstellen wollte. Ludwig XIV. erschien zwar in der „Abhandlung über das Sublime“ als Vertreter des Erhabenen im öffentlichen Leben, Condé in der privaten Sphäre, aber die Eigenschaften, die Rapin dem König zusprach, sprach er in etwas anderer Form auch Condé zu, obwohl dieser seine Größe nun jenseits von Politik und Krieg zur Wirkung kommen lassen musste. ${ }^{37}$

Für eine Aufwertung des Grand Condé sprach auch ein zweiter Umstand: Rapin setzte sich in seiner panegyrischen Schrift auch mit dem dunkelsten Kapitel in der Biographie des Herzogs auseinander, seiner Teilnahme an der Fronde. Dass Rapin den Aufstand Condés gegen die Regentin als Betriebsunfall erscheinen ließ und auch als politischen Fehler, verwundert nicht, aber so ganz kehrte er die Ereignisse der späten 1640er und frühen 1650er Jahre doch nicht unter den Tisch, denn er hob hervor, dass Condé auch deshalb in die Fronde hineingezogen worden sei, weil er ein so treuer Patron und Freund gewesen sei, ja er sprach von seiner Fähigkeit zur „amitié héroïque“ und von seinem Stolz auf seinen Rang als Mitglied der französischen Königsdynastie, den er auch im Exil nicht abgelegt habe. ${ }^{38}$

Trotz des Anpassungsdrucks, unter dem ein Mann wie Condé gegen Ende seines Lebens stand, war es also doch möglich, 1687 eine Eloge auf ihn erscheinen zu lassen, die ihm nicht nur den Heldenstatus bescheinigte, sondern auch als eine - allerdings sehr vorsichtige - Apologie für seinen unbeugsamen Stolz erscheinen konnte, der seine Haltung während der Fronde mit motiviert hatte. Im Übrigen entsprach dem auch bis zu einem gewissen Grade die Selbstdarstellung der Bourbon-Condé in ihrem Schloss in Chantilly. Nach dem Tode des Grand Condé gab sein Erbe eine Serie von Gemälden in Auftrag, die dort in einer eigenen Galerie den Ruhm des großen Feldherren preisen sollten. Es handelt sich, wie Katia Béguin es genannt hat, um ein "programme pictural hérö̈que“. ${ }^{39}$ Das Bildprogramm mochte in vielem konventionell wirken, bemerkenswert war jedoch, dass eine Darstellung den Titel „Le repentir du Grand Condé“ trug, es handelte sich um ein Bild des Malers Michel Corneille, das Henri-Jules de Bourbon in Auftrag gegeben hatte. In allegorischer Form wurde hier dargestellt, wie der Sieger von Rocroi es ablehnte, sich jene Siege zu seinem Ruhme zurechnen zu lassen, die er in den 1650er Jahren im Dienste Spaniens erfochten hatte. Handelt es sich also um ein Zeichen adliger

37 Bannister, Condé in Context, S. 191-192, vgl. besonders die Feststellung „In danger of losing his heroic status behind the king's apotheosis as a conqueror, Condé had been recuperated as an icon of the redefined ideal noble, a hero of civilized living, a sublime vesion of the honnête homme“.

Rapin, Le Magnanime, S. 72, S. 90-91.

39

Katia Béguin, La trahison glorieuse. Une transfiguration de la mémoire de la Fronde condéenne à la fin du XVII ${ }^{\mathrm{e}}$ siècle, in: Martin Wrede / Horst Carl (Hrsg.), Zwischen Schande und Ehre. Erinnerungsbrüche und die Kontinuität des Hauses. Legitimationsmuster und Traditionsverständnis des frühneuzeitlichen Adels in Umbruch und Krise (Veröffentlichungen des Instituts für Europäische Geschichte Mainz, Abt. Universalgeschichte; 73), Mainz 2007, S. 53-64, hier S. 55. 
Demut? Dies war nur oberflächlich betrachtet der Fall, denn der Maler hatte Wert darauf gelegt, alle Siege des Feldherren im Dienste Spaniens durch Anspielungen im Bild präsent werden zu lassen, ja sogar seine eine große Niederlage, in der sogenannten Dünenschlacht (Juni 1658) fand Erwähnung, aber nur, um durch einen als Text in das Bild eingeblendeten Dialog zwischen Condé und Don Juan d'Austria, dem spanischen Oberbefehlshaber, klar zu machen, dass letzterer die Verantwortung für diese Niederlage trug. In Form einer rhetorischen Praeteritio wurde also gerade auf jene Lebensepoche des Prinzen von Condé verwiesen, die man direkt nicht ansprechen konnte. Die Botschaft blieb aber doch, dass er ein unvergleichlicher Feldherr, ein wahrer Heros gewesen sei, selbst in seinem Kampf für Philipp IV. von Spanien, nur dass dieser Kriegsherr eben leider der falsche gewesen sei. Katia Béguin betont zu Recht, dass große Aristokraten auch noch Ende des 17. Jahrhunderts den Ruhm ihrer eigenen Familie pflegen und ihre Vorfahren als Heroen feiern konnten. Ihre Hofhaltungen, die auch Zentren künstlerischer Patronage waren, waren in dieser Hinsicht eben doch mehr als nur kleine Planeten, die um die Sonne Versailles kreisten. ${ }^{40}$

Wer freilich die Siege seiner Vorfahren in der Fronde oder in anderen Konflikten so thematisierte, dass dies als ein direkter Angriff auf den König verstanden werden konnte, nicht in der subtilen Form, wie es in Chantilly geschah, der musste nun mit Konsequenzen rechnen, wie es der Fall des Kardinals von Bouillon, Emmanuel Théodose de la Tour d'Auvergne, zeigte, der in Cluny, dessen Abt er war, 1698 ein gewaltiges Grabmal für seine Familie errichten ließ, dessen Reliefs auch den Sieg seines Vaters Frédéric Maurice de La Tour-d'Auvergne, Herzog von Bouillon, über die Truppen des Königs in der Schlacht von La Marfée (1641) zeigten. Bouillon hatte damals sein Fürstentum Sedan gegen den Versuch Ludwigs XIII. und Richelieus verteidigt, die wichtige Festung Frankreich einzuverleiben. Mit diesem Grabmal und seinem taktlosen Beharren auf einem Status seines Hauses, der es den Bourbonen genealogisch nahezu gleichstellte, zog Bouillon den Zorn des Königs auf sich und musste den Rest seines Lebens im Exil in Rom verbringen. ${ }^{41}$

Auch in anderen Fällen waren Demutsgesten unvermeidlich, wenn man keine Zweifel an der eigenen Loyalität aufkommen lassen wollte. Das zeigen auch die Elogen auf Turenne, auch er ein de la Tour-d'Auvergne und ein Onkel des Kardinals von Bouillon. Er war in den 1670er Jahren der Rivale Condés als aristokratischer Heerführer. Der Mut des Helden habe, so wurde argumentiert, für den König und den Staat nur dann einen Wert, wenn er durch Klugheit und Vorsicht gebän-

40 Ebd., S. 59-62.

41 Martin Wrede, Zwischen Mythen, Genealogen und der Krone. Rivalisierende Familiengedächtnisse im französischen Hochadel des 17. Jahrhunderts: die Häuser Bouillon, Noailles und Bourbon, in: Zeitschrift für Historische Forschung 32, Heft 1, 2005, S. 17-43. 
digt sei. Oder wie es in seiner Leichenpredigt hieß: „le Capitaine n'est pas accompli, s'il ne renferme en soy l'homme de bien, et l'homme sage". ${ }^{42}$ Mit der Forderung, dass der adlige Heros zugleich ein Weiser und ein Mann mit verdienter gesellschaftlicher Reputation auch außerhalb der Sphäre des Krieges sein müsse, wurden fast schon die Forderungen der Aufklärung vorweggenommen, die freilich aus dem Helden einen grand homme, einen Wohltäter der Menschheit und zugleich einen vorbildlichen Bürger des eigenen Vaterlandes zu machen versuchte. ${ }^{43}$

42 Esprit Flechier, Abbé de Saint-Séverin, Oraison funèbre de tres haust et tres-puissant Prince Henri de la Tour d'Auvergne, Vicomte de Turenne, Paris 1676, S. 21. Zu Turenne auch Laurent Jalabert (Hrsg.), Nouveaux regards sur Turenne. $400^{\mathrm{e}}$ anniversaire de la naissance d'Henri De La Tour d'Auvergne 1611-1675. Actes du colloque tenu les 17 et 18 septembre 2011 à Sedan, Nancy 2013.

43 Vgl. Lilti, Figures publiques, S. 124-131; Jean-Claude Bonnet, Naissance du Panthéon. Essais sur le culte des grands hommes (L'esprit de la cité), Paris 1998; Thomas W. Gaehtgens, Du Parnasse au Panthéon. La représentation des hommes illustres et des grands hommes dans la France du XVIII e siècle, in: Thomas W. Gaehtgens / Gregor Wedekind (Hrsg.), Le culte des grands hommes 1750-1850 (Passagen; 16), Paris 2009, S. 135-172. Siehe S. 119. 


\section{Die Restauration und die Krise des Heroischen in England nach 1660}

In England war, wie wir gesehen haben, in der Zeit des Bürgerkrieges und vor allem in den 1650er Jahren Oliver Cromwell die eine große charismatische Figur gewesen, die zumindest von den Anhängern des Parlaments heroisiert wurde. Er war der Held des Kampfes gegen Unfreiheit und Papsttum und sogar Dichter wie Dryden, die später ganz auf der Seite der Tories standen, widmeten ihm panegyrische Gedichte. ${ }^{1}$ Vergleichbares hatte die royalistische Seite nicht zu bieten, obwohl für sie Cromwell natürlich ein Anti-Held, keine positive Identifikationsfigur war. Karl II., der 1660 inthronisierte Erbe des Märtyrerkönigs Karl I., eignete sich jedenfalls nicht für die Heldenrolle, zu sehr und zu sichtbar überwogen in seiner Persönlichkeit die Neigung zu Zynismus und Indolenz, aber auch der bloße Hedonismus. ${ }^{2}$ Spannungen in seiner Selbstdarstellung waren schon anlässlich seiner Krönung deutlich geworden. Als Karl II. 1661. zu seiner Krönung durch die Straßen Londons zog, war sein Weg mit Triumphbögen geschmückt, die recht deutlich auf den Sieg des Augustus über die Mörder Cäsars anspielten und zum Teil auch mit direkten Zitaten aus der „Aeneis“ operierten. So wie Augustus den Tod Cäsars gerächt habe, so trete Karl II. als Rächer des Königsmordes auf, so hieß es in offiziellen Festbeschreibungen. Er sei „extinctor tyrannidis, restitutor libertatis und fundator quietis“ („Überwinder der Tyrannis, Wiederhersteller der Freiheit und Begründer des Friedens") und führe ein neues Goldenes Zeitalter herauf. Auf einem der Triumphbögen war tatsächlich der Vers „redeunt saturnia regna“ („die Zeiten des Saturn kehren zurück“) zu lesen, ein Zitat aus der berühmten vierten Ekloge des Vergil, die später in anderer Form auch die Vereinigten Staaten für sich in Anspruch nehmen sollten. ${ }^{3}$ Die sakrale Legitimation des Königtums, die Karl I. gegen Ende seines Lebens so stark betont hatte, trat demgegenüber zurück. Mit dem Hinweis auf Augustus konnte man die gemäßigten Anhänger der gestürzten Republik vielleicht noch integrieren, während der Kult eines Märtyrerkönigs, dessen Gegner in einer ähnlichen Rolle erschienen wie diejenigen, die einst Christus gekreuzigt hatten, eine Aussöhnung kaum denkbar erscheinen ließ. Das Bild des im

1 Annabel Patterson, Dryden and Political Allegiance, in: Steven N. Zwicker (Hrsg.), The Cambridge Companion to John Dryden (Cambridge Companions to Literature), Cambridge 2004, S. 221-236, hier S. 224; vgl. Blair Worden, The Politics of Marvell's Horatian Ode, in: Historical Journal 27, Heft 3, 1984, S. 525-547.

2 Asch, Sacral Kingship, S. 133-135.

3 John Ogilby, The Entertainment of His Most Excellent Majestie Charles II in His Passage through the City of London to His Coronation [London 1662], hrsg. von Ronald Knowles, New York 1988, S. 31-33, S. 37, S. 25. Vgl. Knoppers, Constructing Cromwell, S. 169; Kevin Sharpe, Rebranding Rule. The Restoration and Revolution Monarchy, 16601714. New Haven, CT 2013, S. 154-160. 
Bürgerkrieg gescheiterten Monarchen stellte für die Herrschaft seines Sohnes in der Tat eine starke Belastung dar, denn es schien ihn auf ein bedingungsloses Bündnis mit jenen Prälaten der anglikanischen Kirche festzulegen, welche die Erben des Puritanismus kompromisslos marginalisieren und ausgrenzen wollten. ${ }^{4}$ Augustus, mit dem sich Karl II. bei seiner Krönung zu identifizieren schien, war immerhin noch ein heroischer Herrscher gewesen. In späteren Jahren schien der König aber eher bestrebt zu sein, das Ideal heroischer Männlichkeit, das auf der republikanischen Seite mit der Erinnerung an den Bürgerkrieg verbunden war, subversiv zu unterlaufen, da er es nicht auslöschen oder gänzlich beiseite drängen konnte. Sein prononcierter Hedonismus und seine geringe Bereitschaft zur konventionellen Inszenierung seiner eigenen Autorität und Würde bei Hof - hier setzte in den späteren Regierungsjahren freilich ein klarer Wandel ein - mochten auch dem Ziel dienen, seine sittenstrengen Gegner einfach lächerlich zu machen. ${ }^{5}$ Zum Teil war all dies auch Ausdruck einer zumindest unter der sozialen Elite verbreiteten Einstellung, der alles Heroische nach den Jahren des Bürgerkrieges verdächtig geworden war. Diese antiheroische Haltung stellte allerdings für die Aristokratie und die Oberschicht auch ein Problem dar, denn wie konnte man den Anspruch auf soziale Überlegenheit aufrechterhalten, wenn man sich nicht glaubwürdig als Erbe einer langen Tradition des ritterlichen Kampfes und der heroischen Tugend präsentieren konnte? ${ }^{3}$ Wenn all dies obsolet geworden, reines Theater war, wie unterschied man sich dann noch von einem einfachen Londoner Bürger? Die Antwort auf diese Krise war der restoration rake, ein vor allem für das eigene Vergnügen lebender Adliger, der höfische Manieren mit Grobianismus und Zügellosigkeit im nicht-höfischen Alltag verband. Einer der prominentesten Vertreter dieser Gattung war der Earl of Rochester, John Wilmot. Geboren 1647 war er der Sohn eines relativ prominenten royalistischen Offiziers und Kommandeurs, dessen eigener Vater zu Anfang des 17. Jahrhunderts wie manch ein anderer englischer Amtsträger und Landspekulant in Irland zu Geld gekommen und in das irische House of Lords aufgestiegen war, und dessen Frau Anne St. John, die ihn in zweiter Ehe geheiratet hatte. ${ }^{7}$ Er war nicht nur ein durchaus begabter Dichter, sondern fiel auch durch seine beißenden

4 Kelsey, The King's Book, S. 150-169.

5 Paul Hammond, The King's Two Bodies. Representations of Charles II, in: Jeremy Black / Jeremy Gregory (Hrsg.), Culture, Politics and Society in Britain, 1660-1800, Manchester 1991, S. 13-48; vgl. Matthew Jenkinson, Culture and Politics at the Court of Charles II, 1660-1685 (Studies in Early Modern Cultural, Political and Social History; 9), Woodbridge 2010.

6 Zur Krise des Heroischen in dieser Epoche auch John Spurr, England in the 1670s. The Masquerading Age (A History of Early Modern England), Malden, MA 2000, S. 84-117; Ronald G. Asch, Die Kunst des Regelbruchs. Adlige Libertins in der Epoche der Restauration in England, ca. 1660-1688, in: Christian Wieland / Claudius Sittig (Hrsg.), Die Kunst des Adels in der Frühen Neuzeit, im Druck. Die folgenden Ausführungen zu den restoration rakes beruhen weitgehend auf diesem Aufsatz.

7 James W. Johnson, A Profane Wit. The Life of John Wilmot, Earl of Rochester, Rochester, NY 2004. 
Satiren auf, die auch den Hof, dem er selbst angehörte, nicht verschonten. Rochester war nur eines der prominentesten Mitglieder einer Gruppe von Adligen, die oft als court wits bezeichnet wurden. ${ }^{8}$ Was die court wits miteinander verband, war ein Lebensstil, der ebenso sehr von sexueller Freizügigkeit wie durch eine Neigung zu Raufhändeln, Duellen und zu wüsten Trinkgelagen gekennzeichnet war. Man wollte die braven Bürger Londons durch sexuelle Eskapaden, durch Obszönitäten, aber auch durch Gewalt, die von nächtlicher Ruhestörung bis zum Totschlag gehen konnte, provozieren und praktizierte gewissermaßen eine systematische anticivility. ${ }^{9}$ Die Begabteren unter diesen restoration rakes, wie sie rückblickend genannt wurden, versuchten überdies, ihrer Existenz durch die Publikation pornografischer Gedichte oder von Gesellschaftskomödien einen zusätzlichen Glanz zu geben. Im geistigen Haushalt der rakes verbanden sich Libertinismus und Antiklerikalismus oft mit einem zynischen Blick auf die Welt des Hofes und der Politik. Eine solche Lebenshaltung findet man in der Aristokratie sicherlich auch in anderen Epochen. Dass sie nach 1660 in so zugespitzter Form auftrat, war sicherlich auch durch den Sieg des Parlamentes im Bürgerkrieg mitbedingt. Er hatte zwar keineswegs einen wirklichen sozialen Umsturz mit sich gebracht, aber in der Armee des Parlamentes hatten doch nicht wenige Offiziere Karriere gemacht, die allenfalls den unteren Rängen der gentry angehörten, wenn sie nicht sogar Söhne von Handwerkern oder kleinen Kaufleuten waren. Ihnen hatte sich die altetablierte Elite in den 1650er Jahren unterordnen müssen, ganz abgesehen davon, dass viele auch einen Teil ihres Besitzes verloren hatten. Schon im Bürgerkrieg selbst hatten sich die Cavaliers im Übrigen den Ruf verschafft, sich von der Sittenstrenge ihrer puritanischen Gegner durch Fluchen, Saufen, Streithändel und Huren zu unterscheiden. ${ }^{10}$

Diese Konfrontation setzte sich gewissermaßen über die Restauration hinaus fort, verschärft sicherlich auch dadurch, dass die eher schwache und in ihrer Autorität stark gefährdete Monarchie es nicht verstand, als Schiedsrichter zwischen rivalisierenden Ansprüchen auf sozialen Rang aufzutreten, wie dies Ludwig XIV. in Frankreich zur gleichen Zeit durchaus gelang. ${ }^{11}$ Auch dies mag manche Höflinge und Aristokraten veranlasst haben, ihren Vorrang durch ein bewusstes épater le bourgeois zu demonstrieren. Dieses Verhalten stieß außerhalb des Hofes freilich auf harsche Kritik. So erschien 1673 ein polemischer Angriff auf die Umgangsformen der towen gallants unter dem Titel „Remarques upon the Humours and Conversation of the Town". Diese Schrift hob hervor, dass es den town and courts wits durchaus um einen heroischen Lebensentwurf gehe, aber, ,if you cannot mock at Vertue and prudence with a mene [!] of scorn and contempt, you will not be able to keep company with those heroes". Die in diesen Kreisen beliebten heroischen

8 Jenkinson, Culture and Politics, S. 134-166.

9 Zur anti-civility siehe Anna Bryson, From Courtesy to Civility. Changing Codes of Conduct in Early Modern England (Oxford Studies in Social History), Oxford 1998, S. 243-275.

10 Roy, Royalist Reputations, S. 99.

11 Bryson, From Courtesy to Civility, S. 262. 
Dramen „have made the three grand characters of a Hero to be love, honour and friendship", aber Liebe, Ehre und Freundschaft seien von den Dichtern dieser Kreise lächerlich gemacht worden. ${ }^{12}$ Liebe sei nur eine flüchtige Leidenschaft und nicht besser stehe es mit der Ehre, die in der Verachtung für die Vernunft und alle Regeln bestehe. Überdies seien die von den court wits gepredigten Ideale kaum für ein Lebensalter jenseits der Jugend geeignet. Am Ende bleibe nur der Schluss: ,instead of teaching them to burn like Heroes they have made them love like beasts, and all the industry of the stage, has helpt them to nothing more refin'd in that passion, than what is common to the goat, and the bull". ${ }^{13}$

Auf diese Polemik antwortete jedoch eine Gegenschrift, die „Remarks upon Remarques or a Vindication of the Conversations of the Town". Der unbekannte Autor dieser Schrift argumentierte, es sei ja durchaus diskutabel, sich auf die eigenen Landgüter zurückzuziehen und vor allem ein treuer Ehemann und Familienvater zu sein - das Lebensideal der town wits war offenbar das der Jugend und mit Ehe und Familie nur schwer zu vereinen -, aber der Ruhm des Helden sei bei einer solchen Lebensweise schlechterdings unerreichbar. Der Kritiker der Sitten von Hof und Stadt argumentiere: „Walking, sleeping and dreaming in the country, will make you a Hero, and going to London make you a Rogue“. Aber da stelle sich doch die Frage, „what sort of hero will the other author make you?", am Ende bleibe nur der Schluss, „but you must be a hero, ay that you must, you must live in ignorance and become like an useless country vermin and King Oberon at a lucky chance, shall ipso facto Metamorphose you into a Hero". Das sei wenig überzeugend, ebenso wenig wie der Gedanke, dass man durch eine Eheschließung in jungen Jahren ein Held werde. Selbst wenn man die Witwe Ciceros heirate, sei man deshalb noch kein Held. ${ }^{14}$ Zumindest implizit war damit gesagt, dass das ausschweifende Leben in den westlichen Vorstädten Londons dann doch immer noch eher mit den Idealen aristokratischer Männlichkeit und einer heroischen Selbstinszenierung vereinbar war, als das Leben eines Krautjunkers und Stoppelhopsers, und ein Mann wie Rochester betonte dann auch in der Tat, dass die Wunden, die man sich in Wirtshausschlägereien und in Form von Geschlechtskrankheiten im Bett diverser Mätressen zuzog, nicht weniger ehrenhaft seien, als die Narben eines alten Veteranen, der als Soldat auf dem Schlachtfeld gekämpft habe. ${ }^{15}$

Entscheidend für die anarchische Haltung der restoration rakes, die in solchen Äußerungen ihren Ausdruck fand, war sicherlich auch, dass der Hof selbst der Aristokratie wenig Orientierung geben konnte oder wollte. Am Hofe Karls II. herrschte noch mehr als an anderen zeitgenössischen Höfen ein Klima der Täu-

12 Remarques on the Humours and Conversations of the Town, London 1673 (Nachdr., Drydeniana II, NY 1974), S. 39-40, S. 52.

13 Ebd., S. 58.

14 Remarks upon Remarques or a Vindication of the Conversations of the Town, in Another Letter Directed to the Same Sir T. L., London 1673, S. 43, S. 97, S. 49.

15 Jenkinson, Culture and Politics, S. 220-221. 
schung und Verstellung und des offenen Zynismus. ${ }^{16}$ Dass der König selbst hinter dem Rücken seiner Minister einen Geheimvertrag mit Frankreich, den Vertrag von Dover, schloss, in dem er seine Konversion zum Katholizismus in Aussicht stellte, sprach für sich, wie überhaupt die konfessionelle Situation verworren war. Letztlich konnten der König und seine Berater sich nie einigen, welche die richtige Antwort auf die anhaltende Bedrohung durch Republikanismus und protestantischen Radikalismus war. Eine Rückkehr vielleicht zu den moralischen Werten und der religiösen Ausrichtung der 1630er Jahre, zur Kirchenpolitik eines William Laud? Oder ließen sich der heroische Republikanismus und der religiöse Enthusiasmus der 1630er Jahre nur bekämpfen, indem man diesen Idealismus lächerlich machte und ihm eine rationalistische, wenn nicht gar materialistische Philosophie entgegensetzte? Das war ja letztlich die Antwort des „Leviathan“, die Antwort von Thomas Hobbes gewesen, mit der er sich freilich beim royalistischen Klerus extrem unbeliebt gemacht hatte. Ein Mann wie Rochester, deutlich insbesondere in seiner berüchtigten „Satyr against Reason and Mankind“, die den Menschen komplett auf seine animalischen Bedürfnisse reduzierte, ging noch weiter und vertrat einen uneingeschränkten Materialismus, der auch die Herrschaft der Vernunft selbst infrage stellte. Das war gewissermaßen ein radikalisierter Hobbes, aber ebenso wie der Rationalismus konservativer Theologen auch inspiriert von der Feindschaft gegen den Enthusiasmus der Puritaner und ihrer Erben mit seinen potenziell egalitären Tendenzen. ${ }^{17} \mathrm{Wie}$ ernst man Rochesters Verse als Ausdruck einer philosophischen Lebenshaltung wirklich nehmen muss, darüber mag man sich streiten. An der Verbindung von Libertinismus im Sinne einer Ablehnung aller traditionellen Autoritäten und eines misanthropischen Menschenbildes kann aber wenig Zweifel bestehen. In Rochesters Gedichten ist der Feind des Mannes, der zu sich selbst ehrlich ist, freilich nicht so sehr der religiöse Fanatiker, sondern der Fop, eine Figur, die einer der court wits, George Etherege, in seinem „Man of Mode“ in Gestalt von Sir Fopling Flutter als Gegenbild zu Dorimant, der wohl ein Porträt Rochesters ist, verewigte. ${ }^{18}$

Der Fop ist ein Mitglied der Elite, im Normalfall eher ein Parvenü, der seinen Anspruch auf sozialen Status durch Luxus, eine allzu gesuchte Eleganz und ein übertriebenes Geschmäcklertum in Fragen der Kleidung und des Auftretens untermauern will, aber anders als der Gallant oder Hector, wie die gewalttätigen aris-

16 Ebd., S. 113-117, S. 225-227.

17 John Wilmot, The Complete Poems of John Wilmot, Earl of Rochester, hrsg. von David M. Vieth, New Haven, CT 1968, S. 94-95; Sarah Ellenzweig, The Fringes of Belief. English Literature, Ancient Heresy and the Politics of Freethinking, 1660-1760, Stanford, CA 2008, S. 51.

18 George Etherege. The Man of Mode, hrsg. von John Barnard, London 1979; vgl. zur Gestalt des Fop Laura S. Rosenthal, Masculinity in Restoration Drama, in: Susan J. Owen (Hrsg.), A Companion to Restoration Drama (Blackwell Companions to Literature and Culture; 12), Oxford 2008, S. 92-108. 
tokratischen Jugendlichen auch genannte wurden, nicht bereit ist, sich den Gefahren eines Lebens auszusetzen, das wirklich konsequent dem Vergnügen und dem Sich-Ausleben ohne Grenzen gewidmet ist. ${ }^{19}$ Oder wie ein Freund Rochesters an diesen 1676 mit Bezug auf die Fops schrieb: „fellowes that would make the world believe they are not afraid of dying and yet are out of heart if the wind disorders their hairs or ruffles their cravats". .20

Rochesters Ambitionen waren größer als die der durch und durch anti-heroischen Figur des Fop. Eigentlich konnte es in einer Welt, in welcher der Mensch durch seine animalischen Bedürfnisse beherrscht wurde, weder Helden noch Aristokraten geben, weil es keine Ehre und keinen Raum für magnanimitas gab, aber für Rochester gab es dennoch ein Heldentum des Lasters. Der Wagemut der sexuellen Exzesse und des Angriffs auf alles, was der Masse, aber auch der Generation der eigenen Väter heilig war, verbunden mit der Bereitschaft, dafür auch eine ruinierte Gesundheit und einen frühen Tod in Kauf zu nehmen, unterschied den wahren Aristokraten vom normalen Menschen, aber auch vom gekünstelten Parvenü, dem Fop.

Es gab zum Zynismus der restoration rakes und zu ihrem heroischen Anarchismus nach 1660 natürlich auch Gegenentwürfe und dies nicht nur von den Anhängern der Good Old Cause, also der politischen Ordnung der Republik, sondern auch von royalistischer Seite. Der Dichter John Dryden, der dem Thronfolger, dem späteren Jakob II., nahestand, setzte sich in seinen Dramen immer wieder mit der Idee eines heroischen Lebensentwurfes auseinander. Er bemühte sich, Stoffe auf die Bühne zu bringen, die den hohen Anforderungen an ein wahrhaft heroisches Drama entsprachen. ${ }^{21}$ Aber ganz gelang ihm das nie, selbst wenn er den Ort der Handlungen nach Indien, nach Mexiko oder ins spätmittelalterliche Granada verlegte. Es gab ein starkes Spannungsverhältnis zwischen der Vorstellung, ein Held oder auch eine Heldin müsse eine Figur sein, die allen normalen Menschen so weit überlegen sei, dass für sie keine Regeln mehr galten - Heldentum sei also immer auch transgressiv -, und einer gegenteiligen Konzeption, die in der heroischen Tugend eher eine letzte Steigerung allgemeiner menschlicher Tugenden sah - der Regelbruch war hier nicht vorgesehen. Solche Tugend-Helden wirkten als Bühnenfiguren freilich leicht eindimensional, ihnen fehlte jedenfalls das notwendige

19 Harold Love, Dryden, Rochester and the Invention of the "Town", in: Claude Rawson / Aaron Santesso (Hrsg.), John Dryden (1631-1700). His Politics, his Plays and his Poets, Newark, NJ 2004, S. 36-51, hier S. 46. John Wilmot, The Letters of John Wilmot, Earl of Rochester, hrsg. von Jeremy Treglown, Oxford 1980, S. 125, H. Bulkeley to Rochester, Mai / Juni 1676.

21 Patterson, Dryden and Political Allegiance; vgl. Philip Harth, Pen for a Party. Dryden's Tory Propaganda in its Context, Princeton, NJ 1993. - Zu Dryden vgl. auch Christiane Hansen, Staging Admiration in John Dryden's Indian Emperour, or the Conquest of Mexico by the Spaniards (1667), in: helden. heroes. héros. Special Issue 1, 2014, S. 47-53, DOI 10.6094/helden.heroes.heros./2014/QM/06. 
Charisma. Am Ende wurde aus dem Heldentum eine „private and sentimental virtue not incompatible with childishness and political incompetence", so jedenfalls in den Dramen von Dryden, wie in der Forschung konstatiert wurde, und das war natürlich kein sehr aristokratisches Heldentum.22 Die court wits machten sich über seine Werke daher auch lustig. Dryden wurde zum Beispiel im Bühnenstück „The Rehearsal", das von George Villiers, dem zweiten Herzog von Buckingham, stammte, dem Spott preisgegeben. ${ }^{23}$ Buckingham, der auch politische Gründe hatte, Dryden, der dem Herzog von York nahestand, anzugreifen, warf dem damaligen Poet Laureate vor, Stücke zu schreiben, die durch ihren Kult des Heroischen lächerlich und schwülstig wirkten. Das Projekt eines Tory-heroism war daher nach 1660 am Ende kein sehr erfolgreiches, es war durch zu viele innere Widersprüche belastet.

Die Whigs besaßen im Gegensatz zu den Royalisten den Vorteil, das Erbe der Sieger des Bürgerkrieges, nicht der Verlierer, verteidigen zu können. Cromwell selbst war allerdings schon vor der Restauration unter den Anhängern der Republik umstritten gewesen. Sein Griff nach der Alleinherrschaft konnte als Usurpation erscheinen und allzu nahe war seine Position am Ende der eines Königs gekommen. Sehr viel eher eignete sich aus der Perspektive der Anhänger der Good Old Cause Sir Henry Vane der Jüngere als heroisches Vorbild. Er hatte im Bürgerkrieg und während des sogenannten Commonwealth zwischen 1649 und 1653 eine maßgebliche Rolle gespielt, hatte sich nach Errichtung des Protektorats unter Cromwells Führung dann jedoch gegen diesen gestellt. ${ }^{24}$ Nach der Restauration wurde er verhaftet und 1662 auf Drängen des Parlamentes als Königsmörder hingerichtet. Vane sah sein eigenes Leben ganz im Lichte der Apokalypse. Er war offenbar davon überzeugt, dass sein Tod mit dazu beitragen würde, Gottes Herrschaft über die Welt heraufzuführen, ja identifizierte sich möglicherweise sogar mit der Figur der beiden Zeugen, von denen im 11. Kapitel der Offenbarung die Rede war und von denen es dort hieß:

„Und ich will meinen zwei Zeugen geben, daß sie weissagen tausendzwei-hundertundsechzig Tage, angetan mit Säcken. [...] Und so jemand sie will schädigen, so geht Feuer aus ihrem Munde und verzehrt ihre Feinde; und so jemand sie will schädi-

22 Michael West, Dryden and the Disentegration of Renaissance Heroic Ideals, in: Costerus. Essays in English and American Literature 7, 1973, S. 193-222, hier besonders S. 218. Vgl. auch Susan J. Owen, Restoration Theatre and Crisis, Oxford 1996, S. 200, die mit Blick auf die von den Tories gepflegte Idee eines Heldentums der absoluten Loyalität gegenüber dem Herrscher konstatiert: „However much moral and political force the idea of absolute loyalty is feld to have, there is something unconvincing about the spectacle of 'quiet' heroes". George Villiers Duke of Buckingham, The Rehearsal, hrsg. von D. E. L. Crane, Durham 1976.

24 Zu Vane David Parnham, Sir Henry Vane, Theologian. A Study in Seventeenth-Century Religious and Political Discourse, Madison/London 1997; Violet A. Rowe, Sir Henry Vane the Younger. A Study in Political and Administrative History (University of London Historical Studies; 28), London 1970; David Cuckson, Too Dangerous to Let Live. A Biography of Sir Henry Vane the Younger, Raleigh, NC 2011. 
gen, der muß also getötet werden. [...] Und wenn sie ihr Zeugnis geendet haben, so wird das Tier, das aus dem Abgrund aufsteigt, mit ihnen einen Streit halten und wird sie überwinden und wird sie töten." 25

Seinem Tod sah Vane mit stoischem Gleichmut ins Gesicht, getragen vielleicht von der Hoffnung, er würde wie die Zeugen der Offenbarung bei dem für die unmittelbare Zukunft erwarteten Endgericht, etwa im Jahr 1666, von den Toten auferweckt werden, und dies schon in dieser Welt so wie Christus selbst. Kein Zweifel kann jedenfalls daran bestehen, dass Vane sich selbst bei seiner Hinrichtung als heroischer Märtyrer inszenierte, der in seinem Tode über seine Gegner siegte. ${ }^{26}$

Algernon Sidney (1623-1683), der ihn stets bewundert hatte und der selbst ein Anhänger der Republik der 1650er Jahre war, für die er im Bürgerkrieg im Range eines Obristen gekämpft hatte, sollte über ihn sagen, er sei ein Mann gewesen, „who by obeyeing reason, at once seem'd to renounce all kind of unbecoming passions and affections: nay such was his magnanimity, that if the frame of the whole world had been dissolv'ed and gon to rack about his ears, he would have remained undaunted in the midst of its ruin ". ${ }^{27}$ Sidney selbst verband einen ausgeprägten Adelsstolz mit einem tiefen Hass auf jede Willkürherrschaft. Und für ihn stellte die Herrschaft von Königen jedenfalls unter den Bedingungen seiner eigenen Epoche anders als im Mittelalter fast schon automatisch eine Willkürherrschaft dar. Der Herkunft nach war er ein Großneffe des 1586 verstorbenen Philip Sidney und ein Sohn des Earl of Leicester. Seine Mutter war eine Percy aus der Familie der Earls of Northumberland. Die Percies, die mit den Normannen nach England gekommen waren, hatten sich seit dem späten Mittelalter immer wieder an die Spitze von Adelsrevolten im Nordosten Englands gesetzt und waren auch am Sturz Richards II. 1399 beteiligt gewesen. Sie hatten mit der Krone zu Ausbruch des Bürgerkrieges noch eine Rechnung offen, denn seit dem Aufstieg der Tudors hatten die Träger des Titels „Northumberland“ bis ins frühe 17. Jahrhundert fast mehr Jahre im Tower als in Freiheit verbracht, soweit sie nicht dem Schwert des Henkers zum Opfer fielen. Eine kritische Haltung gegenüber einer autoritären monarchischen Herrschaft verband sich bei ihnen also eng mit der Verteidigung der eigenen ständischen Ehre. Und Ähnliches galt bis zu einem gewissen Grade auch für Sidney.

25 Joh 11, 3-8. Zu den zwei Zeugen siehe auch Petersen, Preaching in the Last Days und oben, S. 50.

26 John Coffey, The Martyrdom of Sir Henry Vane the Younger. From Apocalyptic Witness to Heroic Whig, in: Thomas S. Freeman / Thomas F. Mayer (Hrsg.), Martyrs and Martyrdom in England, c. 1400-1700 (Studies in Modern British Religious History; 15), Woodbridge 2007, S. 221-240.

27 Jonathan Scott, Algernon Sidney and the English Republic 1623-1677 (Cambridge Studies in Early Modern British History), Cambridge 1988, S. 95-96, nach Philip Sidney, The Character of Sir Henry Vane (Hertfordshire Record Office D/EP F 45). 
Sidney hatte sich im Bürgerkrieg auf die Seite des Parlamentes gestellt. Nach der Restauration wurde er nicht nur politisch zum Außenseiter, sondern verlor aufgrund von Familienstreitigkeiten und weil er nun genötigt war, mehrere Jahre im Exil zu verbringen, auch einen Teil seines Vermögens. Aus seinen Gesinnungen hatte er nie einen Hehl gemacht. Als ihn das englische Parlament 1659 als Gesandten nach Kopenhagen schickte, trug er sich in das Album amicorum der dortigen Universität mit dem Spruch ein: „Manus haec inimica tyrannis“ („diese Hand ist den Tyrannen ein Feind“), möglicherweise mit dem Zusatz „Ense petit placidam cum libertate quietem“ („mit dem Schwert sucht sie ungestörte Ruhe in der Freiheit"), was einen Skandal auslöste. Anscheinend fügte er dem Eintrag den Namen Philippus Sidney hinzu, berief sich also auf den seiner Familie angehörenden protestantischen Helden des späten 16. Jahrhunderts, in dessen Leben er eine Präfiguration seines eigenen sah. ${ }^{28}$ Sein Großonkel verkörperte für ihn ein aristokratisches Freiheitsideal, das in seiner eigenen Zeit durch machthungrige Monarchen unterminiert wurde, wie er meinte. Wird hier schon der Wunsch deutlich, sein eigenes Leben dem der heroischen Figuren der Vergangenheit anzugleichen, so wird dieses Streben auch an anderer Stelle greifbar, wie eben im Verhältnis zu dem 1662 hingerichteten Sir Henry Vane. Sidneys Heroenkult bestimmte seine eigene Haltung im Sinne einer prononcierten imitatio heroica. Einer seiner Biographen hat über ihn mit Blick auf seinen Tod als politischer Märtyrer im Jahre 1683 geschrieben: „After a career of almost uniform failure the man who had made heroes of others became a hero himself“ ${ }^{29}$

Jedenfalls wurde Sidney nach seiner Rückkehr aus dem Exil nach England 1677 rasch in die Streitigkeiten zwischen Whigs und Tories verwickelt. Nachdem der Versuch, den katholischen Herzog von York von der Thronfolge auszuschließen, der für manche radikale Whigs wie Sidney wohl nur der Auftakt zum Sturz oder zum radikalen Umbau der Monarchie sein sollte, gescheitert war, entstanden Pläne für ein Attentat auf Karl II. Ob Sidney sich wirklich an solchen Planungen beteiligte, bleibt unklar, aber er wurde im Auftrag des Königs als Verschwörer und Hochverräter verhaftet und trotz der zweideutigen Beweislage zum Tode verurteilt. Über seine Hinrichtung schrieb Gilbert Burnet, er sei seinem Tode entgegen gegangen, „with an unconcernedness that became one who had set up Marcus Brutus for his pattern". ${ }^{30}$ Zugleich mit Sidney waren noch zwei andere Verschwörer angeklagt, Lord William Russell und Arthur Capell, Earl of Essex. Capell beging im Tower Selbstmord, Russell wurde hingegen wie Sidney hingerichtet.

28 Worden, Roundhead Reputations, S. 126; John Carswell, The Porcupine - The Life of Algernon Sidney, London 1989, S. 110-111; Scott, Algernon Sidney and the English Republic, S. 53, S. 133.

29 Carswell, The Porcupine, S. 230.

30 Worden, Roundhead Reputations, S. 130, nach Gilbert Burnet, History of His Own Time, Bd. 1, London 1724, S. 573. 
So wie die Erinnerung an den als Märtyrer heroisierten Karl I. die Royalisten nach 1649 darin bestärkt hatte, an ihren politischen Zielen festzuhalten, so wurden auch Capell, Russell und Sidney rasch als heroische Märtyrer dargestellt und für die Whigs zu einer wichtigen Inspiration. Das Bild Sidneys, das nach seinem Tode konstruiert wurde, war freilich, wie Melinda Zook betont hat, eher durch den Versuch geprägt, aus ihm einen Propheten zu machen, der vor den Gefahren der Tyrannis ebenso wie vor denen des katholischen „Götzendienstes“ gewarnt und dafür sein Leben geopfert hatte. Wegen seines radikalen Republikanismus war er nicht leicht als unschuldiger Märtyrer und reines Opfer eines Justizmordes darstellbar. Das war mit Russel einfacher, da dieser zu Lebzeiten ähnlich wie Capell gemäßigter aufgetreten war. Seine Abschiedsrede, die seine politischen Freunde vorbereitet hatten und die er vor seinem Tod in schriftlicher Form als sein politisches Testament niederlegte - er sah davon ab, sie wirklich zu halten -, verwandelte jedenfalls das Bild, das die Öffentlichkeit sich von ihm machte. Aus dem Verschwörer und Agitator wurde nun ein „protestantischer Held und patriotischer Befreier“ ${ }^{31}$ Russells Abschied lehnte sich dabei offenbar an die Selbstinszenierung protestantischer Märtyrer seit den großen Protestantenverfolgungen der 1550er Jahre an.

So kamen in der Figur Russells aber auch der anderen Whig martyrs - so wie sie in der Öffentlichkeit inszeniert wurden - ganz unterschiedliche Elemente zusammen. Alle drei gehörten der Aristokratie an oder stammten aus ihr (Sidney war der jüngere Sohn eines peer) und ihr Republikanismus bzw. ihr Beharren auf ständischen Freiheitsrechten war und blieb aristokratisch gefärbt. Zugleich nahm ihre Heroisierung die Tradition der protestantischen Märtyrer auf, die in England ganz wesentlich von John Foxe geprägt worden war. Allerdings, dies wurde vor allem nach 1688 deutlich, setzte im späten 17. Jahrhundert auch schon eine zunehmende, wenn auch nie vollständige Säkularisierung des Politischen ein. Die Whigs des frühen 18. Jahrhunderts mochten immer noch leidenschaftliche Gegner des Katholizismus und der päpstlichen Suprematie sein, aber mit den theologischen Streitfragen, welche die Vorkämpfer der ,Puritan Revolution' des 17. Jahrhunderts bewegt hatten, vermochten sie meist nichts mehr anzufangen. Bezeichnenderweise wurde die Erinnerung sowohl an die Märtyrer der 1680er Jahre wie auch an die Helden der Good Old Cause aus der Zeit des Bürgerkrieges und der englischen Republik dann auch von Zügen gesäubert, die das konfessionelle Engagement dieser Ahnherren des modernen Whigismus allzu sehr in den Vordergrund treten ließen. Wo dies nicht möglich war, weil die Männer, um die es hier ging, ihr Leben und ihr politisches Engagement zu eindeutig an konfessionellen Leitvorstellungen ori-

31 Melinda S.Zook, Violence, Martyrdom and Radical Politics: Rethinking the Glorious Revolution, in: Howard Nenner (Hrsg.), Politics and the Political Imagination in Later Stuart Britain. Essays Presented to Lois Green Schwoerer, Rochester, NY 1997, S. 75-96, hier S. 82, S. 84; vgl. Dies., "The Bloody Assizes". Whig Martyrdom and Memory after the Glorious Revolution, in: Albion 27, Heft 3, 1995, S. 373-396; Dies., Radical Whigs and Conspiratorial Politics in Late Stuart England, University Park, PA 1999, S. 115-148. 
entiert hatten, gerieten diese Helden in Vergessenheit oder wurden deheroisiert, wie es seit dem Ende des 17. Jahrhunderts etwa mit Sir Henry Vane geschah, dessen eschatologische Visionen im 18. Jahrhundert einfach nicht mehr vermittelbar waren. ${ }^{32}$ Erst im 19. Jahrhundert wurde aus ihm in Amerika (er war in seiner Jugend Gouverneur von Massachusetts gewesen) ein Held der Freiheit und des Kampfes für eine libertäre Verfassung und den Fortschritt. ${ }^{33}$

Andere Heroen des Widerstandes gegen eine autoritäre Monarchie konnte der Aufklärer, Deist und Whig John Toland (1670-1722) hingegen schon nach 1688 erfolgreich in einem neuen Gewande präsentieren, das weitaus stärker das Kostüm des antiken Republikanismus als das des strengen Calvinismus oder gar des religiösen Enthusiasmus des späten 16. und frühen 17. Jahrhunderts war. ${ }^{34}$ Sidney selbst, der sich zwar öffentlich weniger stark als Vane als religiöser Enthusiast präsentierte, aber doch den strenggläubigen Congregationalisten nahegestanden hatte, und dem die Hoffnung auf ein apokalyptisches göttliches Strafgericht, das eine der Idolatrie verbundene Königsherrschaft zerstören würde, nicht fremd war, wurde nun als Vorkämpfer für rein bürgerliche Freiheitsrechte präsentiert, wobei freilich auch sein politischer Radikalismus zunehmend ausgeblendet wurde..$^{35}$ So wurden aus den Helden der Good Old Cause am Ende, im 19. Jahrhundert, nicht ohne gewaltsame Brüche, Ahnherren des modernen Liberalismus - dies übrigens im Falle Russells nicht nur im übertragenen Sinne, denn von ihm stammten die Herzöge von Bedford ab, die bis ins frühe 20. Jahrhundert hinein eine der Säulen der Whig aristocracy waren; noch der Parlamentsreformer John Russell (1 $1^{\text {st }}$ Earl Russell, gest. 1878) und der Philosoph Bertrand Russell (gest. 1970) wussten sich der Tradition verpflichtet, die mit dem Andenken an den Märtyrer von 1683, William Russell, verbunden war.

Auf je unterschiedliche Weise reagierten sowohl die restoration rakes als auch die Männer, die ihr Leben für den Kampf gegen den Katholizismus und eine, wie sie meinten, tyrannische Monarchie opferten, auf die politischen und kulturellen Umbrüche des späten 17. Jahrhunderts. Die rakes lebten ihr transgressives Heldentum des Lasters in den Wirtshäusern, Theatern und Bordellen des Londoner Westend aus, Männer wie Russell und Sidney hingegen ihr Streben nach Freiheit im Parlament und in den politischen Zirkeln der Hauptstadt. Sowohl der Libertinismus der court wits wie der Freiheitskampf der Whigs stellten Versuche dar, adlige Lebensentwürfe zu modernisieren, ohne dabei den Anspruch des Adligen aufzugeben, sich von der Masse der Bevölkerung als Elite abzusetzen. Der moralische Anarchismus der restoration rakes blieb Episode, obwohl er in den Hell

32 Worden, Roundhead Reputations, S. 197-198.

33 Coffey, The Martyrdom of Sir Henry Vane the Younger, S. 236-337.

34 Worden, Roundhead Reputations, S. 95-121, vgl. zu John Toland auch Justin A. I. Champion, Republican Learning. John Toland and the Crisis of Christian Culture 1696-1722 (Politics, Culture and Society in Early Modern Britain), Manchester 2003.

35 Worden, Roundhead Reputations, S. 142-46, S. 147-180. 
Fire Clubs des 18. Jahrhunderts seine Nachahmer fand; ${ }^{36}$ dem Kampf eines Sidney oder eines Russell gelang es hingegen, wirklich für adlige Lebensentwürfe neue Optionen zu eröffnen.

In Frankreich, auf das wir im vorherigen Abschnitt einen Blick geworfen haben, blieb ein revolutionärer Umbruch, wie ihn England in den 1640er Jahren erlebte, im 17. Jahrhundert aus. Der Anpassungsprozess, dem sich der Adel unterwerfen musste, verlief daher weniger dramatisch und deutlich subtiler, das galt auch für die Transformation überkommener Leitbilder des Heroischen. In Frankreich ging es vor allem darum, das adlige Streben nach Ruhm und Ehre mit dem Dienst für einen König zu verbinden, der sowohl im Krieg, in der Armee, als auch bei Hofe nun ein immer höheres Maß von Selbstdisziplin von seinen Offizieren ebenso wie von seinen Höflingen verlangte. Die spektakuläre heroische Tat musste sich nun einem Kalkül militärischer Rationalität unterordnen, das allzu große Verluste an Menschenleben und Ressourcen zu vermeiden strebte. Für die traditionelle gasconitude, eine theatralische heroische Selbstinszenierung um ihrer selbst willen, war nun deutlich weniger Platz als in der Vergangenheit. Aber auch Ludwig XIV. erwartete von seinen Offizieren die Bereitschaft, ihr Leben im Krieg zu opfern. Dieses Opfer musste freilich nun einem klar definierten militärischen Ziel dienen, durfte nicht einfach nur eine schöne Geste sein. Wie Hervé Drévillon jedoch zu Recht hervorgehoben hat, wäre es falsch, das späte 17. Jahrhundert in Frankreich auf den simplen Nenner einer Entwertung des Heroischen, einer démolition du héros zu bringen, denn sogar für ein transgressives Heldentum, wie es der Marschall und Reitergeneral Gassion verkörperte, blieb durchaus noch Raum, wie wir gesehen haben. ${ }^{37}$ Aber traditionelle adlige Verhaltensmuster wandelten sich in der Tat und wurden von neuen Leitbildern überlagert. Ein Hochadliger wie Condé, der weithin als kriegerischer Heros gefeiert wurde, musste deutlich vorsichtiger auftreten als vor 1660 und seine Loyalität gegenüber dem König und dem Land, dem er diente, stärker betonen als in der Vergangenheit; auch stellte er sich in seinen späteren Lebensjahren ebenso sehr als grand homme wie als traditioneller Held dar und nahm damit die Neudefinition von Größe und Ruhm, welche die Aufklärung vollziehen sollte, bis zu einem gewissen Grade vorweg. Aber selbst in Frankreich, wo die Verherrlichung des Monarchen zeitweilig alles Dagewesene überbot und auch deshalb von den Kritikern des Königs als Idolatrie scharf abgelehnt wurde, blieb neben dem Sonnenkönig einstweilen Raum für den Ruhm des adligen Heros, auch wenn dieser Ruhm nicht mehr ohne weiteres in der Sprache des Rittertums inszeniert werden konnte, sondern auf ein neues Vokabular angewiesen war.

36 Vgl. Geoffrey Ashe, The Hell-Fire Clubs. A History of Anti-Morality, Stroud 2005.

37 Drévillon, L'impôt du sang, S. 324-339, S. 407, S. 410; Ders., L'Individu et la Guerre. Du chevalier Bayard au Soldat inconnu, Paris 2013, S. 72-79 über den „héroïsme de la raison“. 


\section{Der Held im 18. Jahrhundert zwischen Kritik und Transformation}

Das 18. Jahrhundert gilt gemeinhin als eine Epoche der tiefen Krise des klassischen Helden. Gerade mit Blick auf Frankreich gibt es gute Argumente für eine solche Interpretation. Während Ludwig XV. zunächst im Österreichischen Erbfolgekrieg noch einige Erfolge erringen konnte, die es ihm erlaubten, sich als kriegerischen Heros darstellen zu lassen, verließ ihn und Frankreich im Siebenjährigen Krieg das Kriegsglück. Das heroische Charisma des Monarchen war dauerhaft geschwächt. Schon lange vorher hatte die Aufklärung jedoch die dominierende Position des adligen oder eben auch des monarchischen Heros ohnehin infrage gestellt. Der Abbé de Saint Pierre hatte bereits 1739 auf den Unterschied zwischen den bloßen hommes illustres und grands hommes hingewiesen; zu letzteren konnten nur diejenigen gehören, die nicht nur ihrem Ruhm, sondern der Menschheit oder zumindest ihrem eigenen Land gedient hatten. Eine solche Auffassung brach zwar nicht vollständig mit der Verehrung der kriegerischen Heroen der Vergangenheit, unterzog diese aber doch einer tiefgreifenden Kritik und ließ zugleich in Gestalt des Wissenschaftlers oder des Philosophen den Geistesheroen neben den traditionellen Helden treten. ${ }^{1}$

Auf diese Krise des Heroischen im Frankreich der Aufklärung wird zurückzukommen sein. Werfen wir jedoch zunächst einen Blick auf England. Hier war es spätestens mit dem Bürgerkrieg zu einer tiefgreifendenden Pluralisierung der heroischen Leitbilder und Modelle gekommen. Ein größerer Gegensatz als zwischen dem Gottesstreiter Cromwell und dem königlichen Märtyrer Karl I. ließ sich kaum denken. Diese Polarisierung heroischer Modelle setzte sich nach 1660 fort, wie wir gesehen haben. Auf der einen Seite stand die Erinnerung an die Helden der Good Old Cause, die allerdings Ende des 17. Jahrhunderts zunehmend im Sinne einer partiellen Säkularisierung des Politischen umgedeutet wurde, ebenso wie die Verehrung für die Whig martyrs des Jahres $1683 .^{2}$ Auf der Seite der Tories hatte man diesem Heldenkult lange Zeit eigentlich nur die Erinnerung an Karl I. entgegenzustellen, der als Märtyrer und Heiliger der anglikanischen Kirche (oder doch ihres konservativen Flügels) freilich auch kein klassischer Held war. Ein siegreicher roi connétable, dessen Triumphe man feiern konnte, war keiner der Stuartkönige gewesen, obwohl Jakob II. vor seiner Thronbesteigung durchaus eine militärische Karriere absolviert hatte. ${ }^{3}$ Als er freilich 1688 mit der Armee seines Schwiegersohnes, die in England gelandet war, konfrontiert war, hatte er, ohne zu zögern, die Flucht

\footnotetext{
Siehe S. 119, Anm. 51.

Siehe S. 105.

Vgl. John Callow, The Making of King James II. The Formative Years of a Fallen King, Stroud 2000, S. 214-237.
} 
ergriffen; er ließ sich im Exil durchaus noch als Märtyrer darstellen, der in seinem Leiden heroische Seelenstärke zeigte, aber wohl kaum als kriegerischer Heros. ${ }^{4}$ Diese Rolle blieb dem Mann vorbehalten, der ihn vertrieben hatte, Wilhelm III. Als Ausländer, der die Verbindung zu seinem Heimatland, den Niederlanden, nie abbrach, schlug ihm in England ein starkes Misstrauen entgegen. So war es umso wichtiger, seine Herrschaft durch ein Selbstbild zu legitimieren, das für möglichst viele seiner Untertanen akzeptabel war. Dabei stand der heroische Kampf gegen die französische Universalmonarchie, den Wilhelm III. auch selbst als Soldat und Feldherr führte, stark im Vordergrund; anknüpfen konnte man bei der Heroisierung des Königs als Kämpfer gegen die Tyrannis bei der Verehrung für Elisabeth I., die seinerzeit ihr Land siegreich gegen Spanien verteidigt hatte. ${ }^{5}$ Auch biblische Vorbilder gab es für den neuen Monarchen, wie den jüdischen König Josia, der im Königreich Judah den Götzendienst bekämpft hatte und der schon in der Vergangenheit als Präfiguration jener englischen Monarchen gesehen worden war, die im Kampf gegen Rom für den wahren protestantischen Glauben gestritten hatten, wie Eduard VI. oder Elisabeth I. ${ }^{6}$ Allerdings musste Wilhelm III. darauf achten, sich nicht zu sehr auf die Rolle des heroischen Streiters gegen Rom und das Papsttum festzulegen, denn außenpolitisch war er auf katholische Verbündete wie namentlich das Haus Habsburg angewiesen. Überdies verfolgte er in seinem Heimatland eine Politik der Toleranz gegenüber den zahlreichen Katholiken und auch seiner Armee gehörten viele Katholiken an. ${ }^{7}$ Predigten in England mochten betonen, dass der Oranier ein frommer Herrscher und ein geschworener Feind jeder Form von Idolatrie war, aber das offizielle Bild Wihelms III. wurde durch andere Modelle des Heroischen bestimmt. Herkules war hier eine wichtige Gestalt, auch wenn in den Niederlanden selbst diese Identifikationsoption nur mit einer gewissen Vorsicht verwandt wurde. Im Park des Schlosses von Het Loo befand sich zwar eine Herkules-Skulptur, aber sie zeigte den Helden als Kleinkind, wie er die Schlangen, die ihn töten sollten, erwürgte. ${ }^{8}$ Entscheidend war auch, dass die militärischen Heldentaten des Statthalters und Königs immer in einem Kontext dargestellt wur-

\footnotetext{
Vgl. Ders., King in Exile. James II, Warrior, King and Saint, Stroud 2004, S. 302-339.

Sharpe, Rebranding Rule, S. 416-417.

6 Tony Claydon, William III and the Godly Revolution (Cambridge Studies in Early Modern British History), Cambridge 1996, S. 37-39, S. 62.

7 Zur Politik des Königs siehe Wouter Troost, William III, the Stadholder-King. A Political Biography, übers. von J. C. Grayson, Aldershot 2005.

8 Olaf Mörke, Das Erbe des „Wilhelmus“. Ein Niederländisches Modell der heroischen Monarchie, in: Martin Wrede (Hrsg.), Die Inszenierung der heroischen Monarchie. Frühneuzeitliches Königtum zwischen ritterlichem Erbe und militärischer Herausforderung (Historische Zeitschrift, Beihefte N.F.; 62), S. 334-357, hier S. 355; Stephen B. Baxter, William III as Hercules: the Political Implications of Court Culture, in: Lois G. Schwoerer (Hrsg.), The Revolution of 1688-89. Changing Perspectives, Cambridge 1992, S. 95-106. Zum weiteren Kontext Ulrich Niggemann, Herrschermemoria als Norm und Symbol. Zum Umgang mit der Erinnerung an Wilhelm III. im England des frühen 18. Jahrhunderts, in: Zeitschrift für Historische Forschung 39, 2012, S. 1-36, hier besonders S. 6-8.
} 
den, der sie als Handlungen erschienen ließ, die einem höheren Ziel dienten und nicht primär den Sinn hatten, den Ruhm des Herrschers und seiner Dynastie zu mehren. In dieser Hinsicht knüpfte die Heroisierung des Oraniers doch stärker an die Panegyriken an, die in den 1650er Jahren Cromwell zu ihrem Gegenstand gemacht hatten, als an rein monarchische Traditionen, ${ }^{9}$ wobei natürlich die republikanischen Traditionen der Niederlande auch eine wesentliche Rolle spielten. Wilhelm III. war, wie vor ihm Wilhelm der Schweiger, ein Freiheitsheld und ein von Gott selbst auserwählter Streiter für das Evangelium, auch ein wahrer Patriot und Vater des Vaterlandes, aber eben anders als Ludwig XIV. kein Halbgott, der unendlich weit über allen anderen Menschen stand einschließlich der Adligen, die ihm dienten. ${ }^{10}$ Im Übrigen, diese Ansicht ist mit einer gewissen Plausibilität vertreten worden, fiel es den englischen und britischen Untertanen Wilhelms III. vermutlich leichter, ihn als heroischen Krieger zu akzeptieren denn als König, denn einen erblichen Anspruch auf die Krone besaß noch am ehesten seine Gattin, die Königin Maria, die eine Stuart war, nicht aber der Oranier selbst, der überdies Zeit seines Lebens als Ausländer wahrgenommen wurde. ${ }^{11}$

Wilhelms Nachfolgerin, Anna, war hingegen wie Maria eine Tochter Jakobs II. Ihre Herrschaft dynastisch zu legitimieren, war also deutlich einfacher. Umgekehrt konnte Anna ihre Heere als Frau nicht selbst in den Kampf führen, diese Rolle übernahm nun vor allem der Herzog von Marlborough, der als Feldherr gefeiert wurde wie kaum ein anderer Kommandeur vor ihm und als kriegerischer Heros schon fast selbst wie ein Monarch dargestellt wurde. Auch sein Schloss Blenheim Castle war ja mehr ein königlicher Palast als der Landsitz eines adligen Heerführers. ${ }^{12}$ Allerdings war Marlborough als kriegerischer Held nie unumstritten. Mochte er für seine Anhänger ein Cäsar oder Cato sein, war er für seine Gegner aus dem Lager der Tories eher ein Sulla, einer der Totengräber der römischen Republik. ${ }^{13} \mathrm{Im}$ Falle der Königin traten stattdessen die sakralen Züge ihrer Herrschaft in den Vordergrund, die bei Wilhelm III. kaum eine größere Rolle gespielt hatten.

9 Craig Rose, England in the 1690s. Revolution, Religion and War (History of Early Modern England), Oxford 1999, S. 22-24; vgl. Sharpe, Rebranding Rule, S. 420-421.

10 Mörke, Das Erbe des „Wilhelmus“, S. 352-357.

11 Baxter, William III as Hercules, S. 102. Zu den Schwächen der Selbstdarstellung des Königs und zur generell erodierenden Autorität der Monarchie gegenüber einer Öffentlichkeit, die nun selbst beansprucht, über die angemessene Darstellung des Monarchen zu urteilen, siehe Sharpe, Rebranding Rule, S. 502-506.

$12 \mathrm{Zu}$ Marlborough Hannah Smith, Last of all the Heavenly Birth. Queen Anne and Sacral Queenship, in: Parliamentary History Yearbook 28, Heft 1, 2009, S. 136-149, besonders S. 146-147; zu Marlborough als einer Art Ersatzmonarch vgl. auch Richard Johns, The British Caesar. John Churchill, $1^{\text {st }}$ Duke of Marlborough, and the Visual Arts, in: John B. Hattendorf [et al.] (Hrsg.), Marlborough. Soldier and Diplomat, Rotterdam 2012, S. 320-355.

$13 \mathrm{Zu}$ Marlborough als - umstrittener - Opernfigur respektive zu Figuren, die als Anspielung auf ihn gedeutet werden können, siehe Thomas McGeary, The Politics of Opera in Handel's Britain, Cambridge 2013, S. 35-36, S. 30. 
Während der Regierungszeit der Königin Anna wurde jedoch nicht nur Marlborough als soldatischer Heros verherrlicht. Der Offizier und der Soldat, die in England, das lange Zeit über kein größeres stehendes Herr verfügt hatte, nur geringes gesellschaftliches Ansehen besaßen, wurden generell aufgewertet. Eine ganze Reihe von Theaterstücken machte nun den patriotic gentleman-hero zur Hauptfigur, der zugleich eine durch Anstand und Selbstdisziplin gezügelte Männlichkeit verkörperte. Während nach 1660 Berufsoffiziere oft als sozial problematische Figuren mit einer Neigung zu sexuellen und anderen Exzessen dargestellt wurden - darin verwandt den restoration rakes - wuchs mit dem Engagement Englands in kontinentaleuropäischen militärischen Auseinandersetzungen auch das Ansehen des Militärs. ${ }^{14} \mathrm{Ri}-$ chard Steeles „Christian Hero“, ein Traktat von 1701, das im Laufe des 18. Jahrhunderts immer wieder nachgedruckt wurde, leistete im Übrigen einen eigenen bedeutenden Beitrag zur Moralisierung des kriegerischen Heros. ${ }^{15}$ Steele entwickelte später zusammen mit Joseph Addison als Herausgeber und Autor des „Tatler“ und anderer Zeitschriften das Projekt einer umfassenden ,reformation of manners'. Nicht zuletzt ging es hier darum, an die Stelle der höfischen Verhaltensnormen mit ihrer Tendenz zur Dissimulation und zur auftrumpfenden Betonung der eigenen Überlegenheit einen neuen Kanon von urbanen Umgangsformen zu setzen, die auf die sich herausbildende commercial society des 18. Jahrhunderts zugeschnitten waren, in der Standesunterschiede zwischen den städtischen Führungsschichten und der Aristokratie zumindest zum Teil relativiert wurden. ${ }^{16}$ Auch für den kriegerischen Helden war hier noch ein Platz, aber eben nur, wenn sich sein Streben nach Ruhm und Ehre mit der Fähigkeit zur Selbstbeherrschung und zu einem ungezwungenen natürlichen Umgang mit anderen Menschen verband. Auch vom Soldaten musste erwartet werden, dass er die Kunst der Konversation beherrschte und sich auf die Umgangsformen des Kaffeehauses und des Salons einließ. David Hume sollte später um die Mitte des 18. Jahrhunderts betonen, dass ein solcher Prozess der zivilisatorischen Verfeinerung keineswegs unvereinbar sei mit einem „martial spirit“, solange die Eliten sich einen ausgeprägten Sinn für Ehre bewahrten, wie dies in Frankreich und England der Fall sei, nicht aber in Italien, wo man

14 Hannah Smith, Politics, Patriotism and Gender. The Standing Army Debate on the English Stage, circa 1689-1720, in: Journal of British Studies 50, Heft 1, 2011, S. 48-75, besonders S. 73.

15 Richard Steele, The Christian Hero. An Argument Proving that no Principles but those of Religion are Sufficient to Make a Great Man, London ${ }^{7} 1722$.

$16 \mathrm{Zu}$ Steel und der „reformation of manners“ siehe Markku Peltonen, The Duel in Early Modern England. Civility, Politeness and Honour (Ideas in context; 65), Cambridge 2003, S. 228-229; Philip Carter, Men and the Emergence of Polite Society, Britain 1660-1800 (Women and Men in History), London 2001, S. 70-76; Nicholas Phillipson, Politics and Politeness in the Reigns of Anne and the Early Hanoverians, in: John G. A. Pocock [et al.] (Hrgs.), The Varieties of British Political Thought, 1500-1800, Cambridge 1993, S. 211-245, hier S. 225-227. 
den Krieg Söldnern und „soldiers of fortune“ überlasse. ${ }^{17}$ Die Debatten über politeness und eine neue Form der urbanen Männlichkeit veränderten in England die Einstellung zu heroischen Idealen tiefgreifend, oder wie Philip Carter es formuliert hat: „The net result was a superior form of courage which, though still partly configured in terms of industry, vigour and warriorship, now also required a generosity, eloquence and refinement only attainable by active participation in a modern environment of commercial exchange and polite sociability“. ${ }^{18}$

Es wäre falsch zu behaupten, dass ähnliche Debatten wie in England in Frankreich nicht geführt worden wären. Schon La Rochefoucauld hatte in seinen „Maximen" nach dem Scheitern der Fronde Abschied genommen von der ostentativen Suche nach Ruhm und nach dem éclat der allen sichtbaren Heldentat. Die Seelengröße des wahren honnête homme trug bei ihm zwar noch heroische Züge, genügte sich aber selber und war nicht mehr mit dem Versuch verbunden, ein großes Publikum zur Bewunderung zu nötigen, denn damit hätte sich der honnête homme von diesem Publikum ja auch abhängig gemacht. Andere Theoretiker der bonnêteté und der in den Salons entwickelten verfeinerten Umgangsformen wie der Chevalier de Méré (gest. 1684) gingen noch weiter und ästhetisierten das Ideal heroischer Größe, das zugleich ganz dem Ziel des Mannes von Stand untergeordnet wurde, durch die Gefälligkeit und den Anmut der Umgangsformen in der guten Gesellschaft Anerkennung zu finden. ${ }^{19}$ Hier gab es also durchaus Parallelen zu den Debatten, die in England im frühen 18. Jahrhundert geführt wurden und die ja im Übrigen auch von den Diskussionen in Frankreich beeinflußt waren. Überdies ließ in Frankreich die Neigung, persönliche oder gar politische Differenzen gewaltsam in Form eines öffentlichen Duells auszutragen, im späten 17. Jahrhundert deutlich nach. Dies hieß nicht, dass das Duell, das sich freilich zunächst auch in England noch hielt, verschwunden wäre, sondern nur, dass es diskreter ausgetragen wurde und meist kein Kampf mehr zwischen den Repräsentanten verfeindeter adliger Familienverbände, sondern nur noch zwischen zwei Individuen war, in dem es um oft eher banale Fragen wie erotische Rivalitäten ging. ${ }^{20} \mathrm{Aber}$ was Frankreich von England unterschied, war zum einen der Umstand, dass die honnêteté anders als politeness in England ihren Bezugspunkt entweder im Hof besaß oder in einer Pariser Gesellschaft der Salons, in denen die höfische Aristokratie mit anderen Adelsgruppierungen zusammentraf - ein Gegenstück zur commercial society des frühen 18. Jahrhun-

17 David Hume, Of Refinement in the Arts, in: David Hume, Essays, Moral, Political, and Literary, hrsg. von Eugene F. Miller, Indianapolis, IN 21987, S. 268-280, hier S. 274-275.

18

19

Isabelle Chariatte, Transfigurations du héros dans la culture mondaine du siècle classique. Madeleine de Scudéry, La Rochefoucauld, le chevalier de Méré, in: helden. heroes. héros. E-Journal zu Kulturen des Heroischen 2, Heft 2, 2014, S. 37-47, besonders S. 39-44, DOI 10.6094/helden.heroes.heros./2014/02/04; vgl. Dies., La Rochefoucauld et la culture mondaine. Portraits du coeur de l'homme (Lire le XVII e siècle; 7), Paris 2011, S. 152-158.

20 Carroll, Blood and Violence, S. 324-329; Brioist [et al.], Croiser le fer, S. 305-328, vgl. zum Nachleben des Duells auch unten, Epilog, S. 142. 
derts in London, die sich ganz vom Hof emanzipiert hatte, gab es in Paris nicht wirklich. ${ }^{21}$ Zum anderen bestand im gesellschaftlichen Umgang in Frankreich doch eine spürbare Rivalität zwischen einer militärischen Elite, der noblesse d'epée, und einem Adel, der sein Selbstgefühl aus dem Besitz von Ämtern und seiner juristischen Bildung ableitete, der noblesse de robe. Sicherlich waren die Grenzen zwischen den beiden Gruppen im 18. Jahrhundert unklarer geworden als hundert Jahre zuvor, aber verschwunden waren sie nicht, zumal die höfische Etikette mit ihrer Rangordnung diese Unterschiede auch immer wieder erneut hervortreten ließ.22 Was die Schwertadligen von den Juristen, die dem Staat dienten, unterschied, war gerade der Umstand, dass ihr Lebensentwurf ein potenziell heroischer war, unabhängig davon, ob man nun wirklich an Kampfhandlungen als Offizier teilgenommen hatte oder nicht. Genau dies machte es auch für Söhne von Amtsadligen attraktiv, in die militärische Laufbahn zu wechseln und sich in die noblesse d'epée zu integrieren. Das war nicht unmöglich, erforderte aber doch einen gewissen Bruch mit der Vergangenheit der eigenen Familie, eventuell auch ein dezidiertes Umschreiben der Familiengeschichte, vor allem aber die Bereitschaft, die bisherige soziale Identität zu verleugnen, ${ }^{23}$ eine Haltung, die unter den Söhnen der Magistrate der parlaments wohl nicht unbedingt selten war. Jedenfalls schrieb Louis-Sébastian Mercier, der Beobachter der Pariser Gesellschaft, um 1760 über den jungen Magistrat: „il parle chevaux, spectacles, histoires des filles, courses, batailles. Il rougit de connoître son métier“ („er spricht über Pferde, Schauspiele, Frauengeschichte, Pferderennen, Schlachten. Er errötet, wenn man ihm die Kenntnis seines Metiers nachweist"). ${ }^{24}$

Solche Probleme bestanden in dieser Form in England nicht. Zwar war auch die englische Gesellschaft des 18. Jahrhunderts eine aristokratische und es war schwer, in die obersten Ränge dieser Führungsschicht aus Großgrundbesitzern vorzustoßen, die im Parlament den Ton angab, die meisten Minister stellte und viele andere wichtige Ämter besetzte, aber die unteren Ränge der Elite waren doch deutlich offener für Aufsteiger, zumal die Zugehörigkeit zur Elite, wenn damit die gentry und nicht die peerage gemeint war, nicht juristisch definiert war. ${ }^{25}$ Überdies fehlte anders als in Frankreich ein Schwertadel, der sein Selbstbewusstsein aus der Ab-

21 Dazu Mathieu Marraud, La noblesse de Paris au XVIII e siècle (L'univers historique), Paris 2000.

22 Vgl. Leonhard Horowski, Die Belagerung des Thrones. Machtstrukturen und Karrieremechanismen am Hof von Frankreich 1661-1789 (Francia, Beihefte; 74), Ostfildern 2012, S. 62-73; zur Trennung der Lebensstile und der Karrieren bei Justiz- und Schwertadel vgl. François Bluche, Les magistrats du parlement de Paris au XVIII ${ }^{\mathrm{e}}$ siècle (Collection Histoire), Paris 1986.

23 Élie Haddad, La difficile intégration des noblesses. Les Mesgrigny ou le coût social et moral des prétentions à l'épée, in: Robert Descimon / Elie Haddad (Hrsg.), Épreuves de Noblesse. Les expériences nobiliaires de la haute robe parisienne (XVI ${ }^{\mathrm{e}}-\mathrm{XVIII}{ }^{\mathrm{e}}$ siècles), Paris 2010, S. 210-231.

24 Louis-Sébastian Mercier, Tableau de Paris, Bd. 1, Amsterdam 1782, S. 258.

25 Vgl. Ellis Wasson, Born to Rule. British Political Elites, Stroud 2000. 
grenzung gegen Kaufleute, Juristen und städtische Rentiers bezog. Leichter als in Frankreich ließ sich in England daher auch der militärische Held als Teil einer Gesellschaft vorstellen, in welcher der Soldat in der urbanen Geselligkeit der Stadt ebenso zu Hause war wie auf dem Schlachtfeld, während umgekehrt der Hof keine wirklich zentrale Rolle mehr für seine gesellschaftliche Verankerung spielte. Ein weiterer Umstand muss ebenfalls noch berücksichtigt werden: Die militärischen Helden Englands waren oft Seehelden, jedenfalls viel häufiger als in Frankreich. Noch im 17. Jahrhundert hatte es in England in der Kriegsmarine eine strikte Trennung zwischen gentlemen und bloßen Seeleuten gegeben. ${ }^{26}$ Selbst wenn die Letzteren in den Rang eines Kapitäns aufstiegen, so definierten sie ihren Anspruch auf Autorität doch vor allem durch seemännische Leistung und weniger durch die heroische Tapferkeit des adligen Offiziers. ${ }^{27}$ Die gentlemen hingegen waren eigentlich Landsoldaten, die auf das Deck eines Schiffes versetzt worden waren, und von der Seefahrt als solcher meist wenig verstanden. Seit der Mitte des 18. Jahrhunderts wuchs jedoch die Zahl junger Offiziersanwärter der Kriegsmarine, die ihr Handwerk als midshipman (Seekadett) von der Pike auf lernten, deutlich. So wurde die Seekriegführung im späten 18. Jahrhundert sogar sehr viel stärker als früher zur Domäne von gentlemen, aber eben von gentlemen, die sich offen zeigten gegenüber der Tendenz zur Professionalisierung der militärischen Karriere. Dass der aristokratische Held in Großbritannien, wenn auch in veränderter Form, sehr viel eher überlebte als in Frankreich, war auch diesem Umstand zu verdanken. ${ }^{28}$

Dass selbst der höhere Adel, die eigentliche Aristokratie, in England kein höfischer war, dürfte ihm die Anpassung an neue Herausforderungen, wie sie in der veränderten Karrierestruktur von Seeoffizieren deutlich wird, erleichtert haben. Der relative - keineswegs absolute - Bedeutungsverlust des Hofes in England nach 1714 implizierte freilich nicht, dass sich die Hannoveraner nicht um eine Selbstinszenierung bemüht hätten, die ihrer Herrschaft Legitimität verleihen konnte. Und dazu gehörte eben durchaus auch die Heroisierung des regierenden Monarchen. Ja, für die Monarchie gewann nach dem Tode Annas eine heroische Selbstdarstellung sogar wieder an Bedeutung. Während der Entfaltungsraum der Hannoveraner innenpolitisch deutlich geringer war, als der ihrer Vorgänger aus dem Hause Stuart, und auch die Ausstrahlungskraft des Hofes als kulturelles Zentrum im Vergleich zum späten 17. Jahrhundert stark nachgelassen hatte, ${ }^{29}$ blieben die Kriegführung und die Kontrolle über die Armee eine Prärogative der Krone. Die Landstreitkräfte

26 Siehe J. D. Davies, Gentlemen and Tarpaulins: The Officers and Men of the Restoration Navy, Oxford 1991.

27 Douglas A. B. Ronald, Youth, Heroism and War Propaganda. Britain and the Young Maritime Hero, 1745-1820, London 2015, S. 61.

28 Zu diesem Kontext ebd., besonders S. 55-77.

29 Dazu Timothy C. W. Blanning, Die Hannoveraner Monarchie und ihre Repräsentationskultur, in: Ronald G. Asch (Hrsg.), Hannover, Großbritannien und Europa. Erfahrungsraum Personalunion, 1714-1837 (Veröffentlichungen der Historischen Kommission für Niedersachsen und Bremen; 277), Göttingen 2014, S. 178-196. 
waren in England traditionell eher unpopulär, sie galten anders als die Flotte als mögliches Instrument einer monarchischen Willkürherrschaft. Überdies spielte hier auch noch die Erinnerung an die faktische Militärherrschaft der 1650er Jahre eine gewisse Rolle. ${ }^{30}$ Dennoch kultivierten sowohl Georg I. als auch Georg II. ein militärisch-heroisches Image. ${ }^{31}$ Georg II. konnte immerhin für sich beanspruchen, seine Truppen in der Schlacht von Dettingen 1743 in eigener Person zu einem großen Sieg geführt zu haben. Es war die letzte Schlacht, an der ein britischer Monarch selbst teilnahm. Sein Vater und Vorgänger Georg I. (Georg Ludwig von Hannover) hatte schon in jungen Jahren in den Feldzügen des Reiches gegen Frankreich gekämpft und in den 1680er Jahren auch gegen die Türken. Diesen Kampf für die ganze Christenheit konnte man auch in England durchaus propagandistisch verwerten, was für die Kaiser- und Reichstreue des Hauses Braunschweig-Lüneburg so nicht galt. ${ }^{32}$ Gerade Georg I. inszenierte sich aber auch bewusst als Nachfolger früherer englischer Monarchen, die als heroische Kämpfer gegen den Nachbarn und Rivalen Frankreich in die Geschichte eingegangen waren. Das galt für Wilhelm III. genauso wie für Eduard III., den großen Erobererkönig des Mittelalters. Ebenso nahm Georg I. in seiner Selbstdarstellung Bezug auf den Nationalheiligen St. George, den der Maler Thornhill ihm zum Beispiel in seinem großen Fresko in der Painted Hall in Greenwich, das die Sukzession der protestantischen Hannoveraner verherrlichte, an die Seite stellte. ${ }^{33}$ Man muss allerdings einräumen, dass Thornhill selbst Zweifel hatte, ob es wirklich noch angemessen war, eine zeitgenössische Persönlichkeit mit mythologischen Gestalten oder Figuren aus Heiligenlegenden zu umgeben, oder ob nicht ein stärker realistischer Stil vorzuziehen sei. Der spätere Streit um die angemessene Bildsprache für eine plausible Heroisierung deutete sich also schon im frühen 18. Jahrhundert an. ${ }^{34}$

Ohnehin standen Versuche zur Heroisierung der Könige aus dem Hause Hannover auch noch vor anderen Problemen. Während Ludwig XIV. in Frankreich über den Hof und die Akademien das öffentliche Bild der Monarchie und damit

30 Lois G. Schwoerer, "No Standing Armies!”. The Antiarmy Ideology in Seventeenth-Century England, Baltimore 1974; Andrew Lavoie, "Chaining Mars" - The Politics of the English Standing Army 1660-1716, Mai 2014, https://www.academia.edu/8467931/Chaining Mars-_The_politics_of_the_English_Standing_Army_1660-1716, 20. Juli 2015.

31 Zu Georg II. Hannah Smith, Georgian Monarchy. Politics and Culture, 1714-1760 (Cambridge Studies in Early Modern British History), Cambridge 2006, S. 108 zur Bemerkung seiner Tochter, die seine „affectation of heroism“ hervorhob.

32 Vgl. Martin Wrede, Die Welfen im Reich. Selbstverständnis und Selbstdarstellung einer mehr oder weniger - patriotischen Dynastie, 1648-1714, in: Ronald G. Asch (Hrsg.), Hannover, Großbritannien und Europa. Erfahrungsraum Personalunion, 1714-1837 (Veröffentlichungen der Historischen Kommission für Niedersachsen und Bremen; 277), Göttingen 2014, S. 149-177.

33 Smith, Georgian Monarchy, S. 23-28.

34 Werner Busch, Über Helden diskutiert man nicht. Zum Wandel des Historienbildes im englischen 18. Jahrhundert, in: Ekkehard Mai (Hrsg.), Historienmalerei in Europa. Paradigmen in Form, Funktion und Ideologie, Mainz 1990, S. 57-76, hier S. 59-60. 
auch sein eigenes erfolgreich kontrollieren konnte - was nicht ausschloss, dass im Ausland oder im Untergrund auch Franzosen ihre Kritik in Druckschriften und Pamphleten artikulierten, von den Propagandisten verfeindeter Mächte ganz abgesehen -, war es in England für den Monarchen schon im späten 17. Jahrhundert fast unmöglich geworden, seine Person der Kritik zu entziehen. Für die einen mochten Georg I. und Georg II. heroische Herrscher sein oder zumindest mochte dieser Kreis, allen voran die court Whigs, es als nützlich ansehen, ein solches Bild zu verbreiten und ihm Anerkennung zu verschaffen. Für andere wie den Dichter Swift, der nach 1714 den Tories zuneigte, blieb der erste Hannoveraner auf dem britischen Thron hingegen eine lächerliche Figur, der sich von seinem leitenden Minister nach Belieben manipulieren ließ. ${ }^{35}$ Aber auch die country Whigs, die ebenso wie die Minister des Königs die Thronansprüche des Hauses Stuart ablehnten, standen der offiziellen monarchischen Panegyrik mit Vorbehalten gegenüber und zelebrierten stattdessen ihre eigenen Helden.

Die Möglichkeit, dies in England auch abseits des Hofes mit entsprechender Öffentlichkeitswirkung zu tun, war deutlich größer als in den meisten kontinentaleuropäischen Monarchien und auch größer als in Frankreich. Westminster Abbey in der Hauptstadt mochte schon im frühen 18. Jahrhundert bis zu einem gewissen Grade die Funktion eines nationalen Pantheons erfüllen, aber kontrolliert wurde dieses Pantheon vom Kapitel der Stiftskirche, das Plätze für Grabmonumente vor allem auch nach finanziellen Kriterien vergab. ${ }^{36}$ Es gab vor 1750/60 vereinzelte Ausnahmen von dieser Regel. So ließ Königin Anna durch einen von ihr erwirkten Parlamentsbeschluss in der Abtei ein Monument für den Admiral Cloudesley Shovell errichten, der 1707 mit seiner Flotte bei den Scilly Inseln auf Grund gelaufen und dabei umgekommen war.$^{37}$ Aber diese Ausnahmen waren doch recht selten. Das erste nach 1714 durch Parlamentsbeschluss in Westminster errichtete Grabmonument war dem Andenken an einen anderen Seehelden, James Cornewall, gewidmet, der 1743 gefallen war. ${ }^{38}$ Seehelden spielten im Pantheon der kriegerischen Helden in England ohnehin eine besonders prominente Rolle, nicht nur deshalb, weil die Flotte lange Zeit als Waffengattung wichtiger war als das Heer, sondern auch, weil sie weniger stark mit der Person des Monarchen identifiziert

35 Paul Langford, Swift and Walpole, in: Claude Rawson (Hrsg.), Politics and Literature in the Age of Swift. English and Irish Perspectives, Cambridge 2010, S. 52-79; Edward Pearce, The Great Man. Sir Robert Walpole, Scoundrel, Genius and Britain's First Prime Minister, London 2007, S. 333-335; Jon T. Rowland, Faint Praise and Civil Leer. The "Decline” of Eighteenth-Century Panegyric, Newark, NJ 1994, S. 147-153 zu Swifts „Directions for a Birthday Song“, einer besonders beißenden Satire auf Georg II. Matthew Craske, Westminster Abbey 1720-70. A Public Pantheon Built upon Private Interest, in: Richard Wrigley / Matthew Craske (Hrsg.), Pantheons: Transformations of a Monumental Idea, Aldershot 2004, S. 57-79, hier besonders S. 58-59.

37 Joan Coutu, Persuasion and Propaganda. Monuments and the Eighteenth-Century British Empire, Montreal 2006, S. 9-10.

38 Craske, Westminster Abbey 1720-1770, S. 57; Coutu, Persuasion and Propaganda, S. 121122. 
wurden und sich die Verherrlichung von Seehelden und die Erinnerung an sie daher auch eher eignete, um Opposition gegen Hof und Regierung zu artikulieren. Überdies genoss die Flotte von jeher mehr Popularität als das Heer. Dass aristokratische ,Helden' hier, wie wir gesehen haben, ${ }^{39}$ im Laufe des 18. Jahrhunderts eher dazu bereit waren, das Los ihrer Untergebenen zumindest zu Beginn ihrer Karriere zu teilen, um zu wirklichen Seeleuten zu werden, dürfte die Popularität der Flotte noch einmal verstärkt haben.

Besonders beliebt war in oppositionellen Kreisen in den 1740er Jahren etwa Admiral Edward Vernon, der im Krieg gegen Spanien 1739 erste Erfolge errungen hatte und trotz späterer Rückschläge als patriot hero galt, ein Ansehen, das er nicht zuletzt seinem politischen Engagement als Kritiker des Ministeriums, aber auch der Führung der Admiralität verdankte. Diese Kritik veranlasste dann Georg II., ihm 1746 sein Kommando zu entziehen und ihn in den Ruhestand zu versetzen. Für die Kritiker des Hofes war er ein politischer Märtyrer und sein Neffe ließ ihm nach seinem Tode (1757) im Jahr 1763 ein großes Grabmal in Westminster Abbey errichten. ${ }^{40}$

Allerdings hatten Gegner der offiziellen Politik noch andere Möglichkeiten, ihre Helden durch Monumente zu feiern, als die Errichtung von Grabmälern in Westminster Abbey. Die ausgedehnten Parkanlagen der englischen country houses, die zwar vielleicht nicht jedermann, aber doch den Angehörigen der politisch-sozialen Elite zugänglich waren und auch häufig genug von ihnen besucht wurden, boten sich dafür an. Eines der bekanntesten Beispiele für ein heroisches Bildprogramm außerhalb des strikt öffentlichen Raumes stellt in England der Park des Landhauses von Stowe dar, der ursprünglich von Richard Temple Viscount Cobham in den 1730er und 1740er Jahren geschaffen wurde (Temple starb 1749). Cobham gehörte zusammen mit seinen Verwandten aus dem Hause Grenville zu einem Netzwerk von oppositionellen Whigs, die sich Anfang der 1730er Jahre mit dem allmächtigen Minister Walpole überworfen hatten und die politische Korruption des Walpole Regimes ebenso kritisierten wie den vermeintlich mangelnden Patriotismus der führenden Politiker. Die Temples und Grenvilles traten im Übrigen für eine aktive, konfliktfreudige Außenpolitik ein, die der Auseinandersetzung mit den bourbonischen Mächten Spanien und Frankreich nicht aus dem Weg ging und vor allem zur See die Konfrontation mit den außenpolitischen Rivalen Englands suchte. Es war bezeichnend, dass Cobham in Stowe zum Andenken an einen seiner Neffen, Thomas Grenville, der als Kapitän zur See 1747 im Kampf gegen die französische Flotte vor Kap Finisterre gefallen war, eine Gedenksäule errichten ließ, die in ihrer Inschrift den heroischen Mut Grenvilles, der im Übrigen mit dem Sir Philip Sidneys verglichen wurde, dem unheroischen Geist einer dekadenten Zeit entgegen-

39 Siehe S. 113.

40 Gerald Jordan / Nicholas Rogers, Admirals as Heroes. Patriotism and Liberty in Hanoverian England, in: Journal of British Studies 28, Heft 3, 1989, S. 201-224, besonders S. 208209; vgl., Coutu, Persuasion and Propaganda, S. 110. 
stellte. ${ }^{41}$ Der Heldenkult trug also auch hier deutliche Züge einer oppositionellen Kulturkritik, die sich gegen die angebliche Dekadenz der Gegenwart wandte. Das galt auch für das wohl berühmteste Monument im Park von Stowe House, den Temple of English Worthies. Zwar waren etliche der Helden, deren Büsten diesen Tempel schmückten, nicht eindeutig parteipolitisch konnotiert, wie etwa Alfred der Große oder der Dichter Shakespeare. Andere hingegen konnten als Symbolfiguren eines Freiheitskampfes gegen Tyrannis und Papismus gelten wie John Locke oder Edward Hampden (ein Abgeordneter des Langen Parlamentes) oder auf ihre Weise auch Drake und Raleigh. ${ }^{42}$ Der Park von Stowe mit seiner politischen Erinnerungspolitik war ein besonders ambitioniertes Projekt, aber auch andere Besitzer von Landhäusern schufen sich auf ihre Weise ihr eigenes kleines Pantheon mit Skulpturen der Großen Männer und gelegentlich auch Frauen (man denke an Elisabeth I.) der Vergangenheit. Was fehlte, waren freilich oft Mäzene, die große Historienbilder oder entsprechende bildhauerische Arbeiten von entsprechender Dimension in Auftrag gaben. Es dominierte vielfach das Porträt, auf das auch Maler wie Joshua Reynolds spezialisiert waren. ${ }^{43}$

Bezeichnend für die Entwicklung in England war jedoch seit den 1720er und 1730er Jahren der Umstand, dass unabhängig davon, ob man nun das heroisierende Porträt, die großen Grabmäler der Epoche oder andere Medien wie historische Werke, Biographien oder Theaterstücke betrachtet, der Held, soweit er eine politisch relevante Figur war, eher als Patriot und als Verteidiger seines Landes und der Freiheit, weniger jedoch als treuer Diener des Monarchen dargestellt wurde. ${ }^{44}$ Patriotismus, und zwar ein Patriotismus, der sich dezidiert auch gegen den Hof und den König richten konnte, und Heldentum gingen in England somit schon frühzeitig eine enge Verbindung ein. Das mag mit ein Grund dafür gewesen sein, dass es in England keine wirklich nachhaltige Abwertung militärischer Helden gab, denn diese ließen sich auch von der politischen Opposition für ihre Zwecke ins Feld führen und eben durchaus auch als Verteidiger der Freiheit darstellen. Überdies hatten sich weite Teile der Oberschicht, der Aristokratie und der gentry frühzeitig, nämlich spätestens nach der Revolution von 1688, einem Ethos des Patriotismus verschrieben, der seine Kraft auch republikanischen Traditionen verdankte. Für die Legitimation ihres Anspruches auf politische Macht war es für die Angehö-

41 Ebd., S. 154-158.

42 Ebd., S. 148-151, vorsichtiger in der Bewertung ist Matthew G. Sullivan, Les grands hommes, le panthéon domestique et la carrière du sculpteur dans l'Angleterre du XVIII ${ }^{\mathrm{e}}$ siècle, in: Thomas W. Gaehtgens / Gregor Wedekind (Hrsg.), Le culte des grands hommes 1750-1850 (Passagen; 16), Paris 2009, S. 39-69, hier S. 45-46.

43 Ebd., besonders S. 60-65. Zu Reynolds siehe etwa Martin Postle (Hrsg.), Joshua Reynolds. The Creation of Celebrity, London 2005.

44 Für Westminster konstatiert dies Craske, Westminster Abbey 1720-1770, S. 72-75. Das galt für den Temple in Stowe natürlich erst recht, aber auch für die zahlreichen heroisierenden Skulpturen Cromwells, die man seit den 1730er Jahre vermehrt in englischen Landhäusern und Stadtresidenzen fand, vgl. Sullivan, Les grands hommes, S. 48-59, wobei Cromwell in solchen Darstellungen oft ein ambivalenter Held blieb. 
rigen dieser Oberschicht sogar von zentraler Bedeutung, sich als heroische Patrioten zu inszenieren, wobei dies allerdings für die letzten Jahrzehnte des 18. Jahrhunderts und erst recht in den Kriegen gegen Frankreich ab 1792 noch deutlich emphatischer geschah als vor $1750 .{ }^{45}$ Das heißt nicht, dass es nicht auch in England eine Kritik an der Figur des militärischen oder allgemein aggressiv auftrumpfenden Helden gegeben hätte, sei es nun, dass diese ironisiert und ins Lächerliche gezogen wurde, wie Alexander Pope es in seinem Epos „The Rape of the Locke“ (1712) getan hatte, ${ }^{46}$ oder dass die transgressiven Elemente des Heroischen aus christlicher Perspektive kritisiert wurden. Evangelikale Christen neigten in besonders starker Weise zu einer solchen Distanzierung von traditionellen heroischen Verhaltensmustern. Aber gerade diese christliche Kritik am Soldatischen und Heroischen konnte in England am Ende doch in ein Ethos des heroischen Patriotismus integriert werden, der den Kampf für das eigene Land zugleich als einen Kampf für Zivilisation und Humanität erschienen ließ. Dies war eine Perspektive, die auch die Vorstellungen von heroischer Größe stark beeinflusste, wie jüngst noch einmal Holger Hoock betont hat. ${ }^{47}$ Ein weiterer Umstand trat hinzu: Englische militärische Helden errangen ihre Siege im Laufe des 18. Jahrhunderts immer häufiger auf außereuropäischen Schlachtfeldern, oft sogar im Kampf gegen nichteuropäische Gegner. Mochte man im europäischen Kontext noch zögern, das volle Arsenal einer triumphalistischen Rhetorik zu entfalten, wenn es galt, einen Sieg zu feiern, so entfiel die Zurückhaltung, wenn der Besiegte zum Beispiel ein indischer Fürst war. Dieser neue Triumphalismus, der sich etwa seit der Mitte des 18. Jahrhunderts auch in Grabmälern bemerkbar machte, fiel namentlich französischen Beobachtern auf, denn in Frankreich wirkte das abschreckende Beispiel der grenzenlosen Selbstheroisierung Ludwigs XIV. nach. ${ }^{48}$ Aber die englische Kultur des Heroischen war frei von solchen Hypotheken und konnte sich auch deshalb im späten 18. Jahrhundert besser entfalten als in Frankreich.

Allerdings, auch wenn ältere Modell des Heroischen in veränderter Form in eine sich wandelnde politische Kultur integriert werden konnten, so riskierte doch jede Heroisierung einer Gestalt der jüngeren Vergangenheit oder gar der Gegenwart, sofort in den Mahlstrom der politischen Auseinandersetzungen zu geraten. Überparteiliche Maßstäbe für heroische Leistung gab es zumindest dort, wo es um Figuren

200

47 eenth-Century Classical Learning, London 1993.

Linda Colley, Britons. Forging the Nation 1707-1837, New Haven, CT 1992, S. 155-193.

Zur Gattung des mock-beroic siehe Richard Terry, Mock-Heroic from Butler to Cowper. An English Genre and Discourse (Studies in Early Modern English Literature), Burlington

World, London 2010, S. 173-177.

48 Matthew Craske, Making National Heroes? A Survey of the Social and Political Functions and Meanings of Major British Funeral Monuments to Naval and Military Figures, 17301770, in: John Bonehill / Geoff Quilley (Hrsg.), Conflicting Visions: War and Visual Culture in Britain and France, c. 1700-1830, Aldershot 2005, S. 41-60, besonders S. 47-49. 
von möglicher politischer Relevanz ging, schlechterdings nicht mehr. Und das galt weitgehend auch für die meisten kriegerischen Helden, von denen manche wie Admiral Vernon ja ohnehin parallel zur militärischen eine politische Karriere verfolgten, zumal auch außenpolitische Grundsatzentscheidungen und damit die Kriege, die aus ihnen resultierten, in der Regel stark umstritten waren.

All dies war in Frankreich deutlich anders, wo der Hof und die vom Hof kontrollierten offiziellen Institutionen wie die Akademien in der zweiten Hälfte des 17. Jahrhunderts doch in erheblichem Umfang eine Definitionshoheit über das Heroische und eine Schiedsrichterposition in Debatten über einzelne historische Gestalten erlangt hatten, die gewissermaßen als Kandidaten für den Heldenstatus gelten konnten. Nicht zuletzt weil der traditionelle kriegerische Held so stark mit der Selbstverherrlichung einer machtbewussten Monarchie verbunden war, war die Kritik an dieser Figur in Frankreich insgesamt ausgeprägter als in England, wo freilich der traditionelle Held schon zu Beginn des 18. Jahrhunderts stärker moralisiert und von seinen transgressiven Zügen gesäubert worden war.

Gegen Ende der Regierungszeit Ludwigs XIV. hatte in Frankreich hingegen schon Fénelon einen Frontalangriff gegen die traditionellen heroischen Ideale geführt. In seinem „Telemach“ übte er auf diese Weise vor allem Kritik an der Ruhmsucht Ludwigs XIV. und der Bellizität seiner Politik. ${ }^{49}$ Der „Telemach“ sollte in Frankreich und darüber hinaus zu einem der einflussreichsten Werke des frühen 18. Jahrhunderts werden..$^{50}$ Die von Fénelon geübte Kritik am traditionellen Ethos heroischer Krieger wurde im frühen 18. Jahrhundert sowohl von Montesquieu aufgenommen als auch vom Abbé de Saint-Pierre, der, wie bereits erwähnt, in seinem „Discours sur les différences de Grand Homme de l'Homme Illustre“ von 1739 den Großen Mann, der etwas für das Glück der Menschen und seines Vaterlandes geleistet habe, den lediglich berühmten Persönlichkeiten gegenüberstellte - und hier bot sich einmal mehr die Figur Alexanders des Großen an -, die nur nach Ruhm gestrebt hätten und dieser Leidenschaft alles andere geopfert hätten. ${ }^{51}$ Saint Pierre verwarf das Streben nach Ruhm nicht grundsätzlich und er ließ auch Monarchen wie Heinrich IV. als Große Männer gelten, aber es musste sich mehr denn je einem höheren Zweck unterordnen. Ähnlich argumentierten auch Montesquieu und andere Aufklärer. ${ }^{52}$

49 François de Salignac de La Mothe-Fénelon, Les aventures de Télémaque, hrsg. von JeanneLydie Goré, Paris 1987.

50 Zu Fénelon Riley, Fénelon's 'Republican’ Monarchism in Telemachus.

51 Die Schrift von Charles Irénée Castel de Saint-Pierre erschien zuerst als Anhang zu Abbé Seran de la Tour, Histoire d'Épaminondas pour servir de suite aux hommes illustres de Plutarque, avec des remarques de M. le Chevalier de Folard sur les principales batailles d'Épaminondas, Paris 1739 und wird hier zitiert nach Abbé Seran de La Tour, Histoire de Scipion l'Africain, Paris ${ }^{2} 1752$, S. XXI-XLIV. Vgl. auch Pierre Briant, Alexandre des Lumières. Fragments d'histoire européenne (NRF Essais), Paris 2012, S. 222-226, vgl. S. 208-221.

52 Bonnet, Naissance du Panthéon, S. 39-40. 
Man darf die Differenz zwischen dem grand homme der Aufklärung und dem klassischen Helden sicherlich nicht zu stark betonen; die Übergänge blieben oft fließend und wie Antoine Lilti konstatiert hat, war der grand homme „plutôt une redéfinition, une reformulation, peut-être même une réhabilitation, après la ,démolition du héros' à laquelle s'étaient livrés les moralistes augustiniens et les Jansenistes dans la seconde moitié du XVIIe siècle “. ${ }^{53}$ Neu war allerdings wohl das Phänomen, dass nun auch dem scheinbaren Durchschnittsmenschen, dem sowohl die ständische Qualität einer vornehmen Geburt als auch der Glanz einer Existenz jenseits des Sphäre der Alltäglichkeit fehlten, heroische Qualitäten oder eben auch die Eigenschaften eines grand homme zugeschrieben werden konnten - hier gab es in der Praxis am Ende oft doch nur eine geringe Trennschärfe. Ein Beispiel dafür war der Geistliche und Parlamentsrat Henri-Philippe de Chauvelin (1716-1770), der sich im Kampf gegen die Jesuiten ebenso wie als Kritiker der Politik der Krone hervorgetan hatte. Manche seiner Bewunderer machten aus dem äußerlich wenig attraktiven Mann, den seine Feinde wegen seiner kleinen Statur mit einem Äffchen verglichen, geradezu einen David, der den Goliath des Jesuitenordens besiegt habe. Vor allem aber war Chauvelin eine Symbolfigur, der heroische Eigenschaften relativ willkürlich in einem politischen Propagandakrieg zugeschrieben wurden. Dass Chauvelin nach Abklingen dieses Kampfes rasch wieder in Vergessenheit geriet, verwundert daher nicht. ${ }^{54}$

Zum Wandel in der Beurteilung historischer Größe, die auch an solchen Beispielen sichtbar wird, trug aber auch der Umstand bei, dass sich nicht nur eine neue Öffentlichkeit für die Diskussion über solche Fragen herausbildete, ${ }^{55}$ sondern dass die sozialen und intellektuellen Trägerschichten der Aufklärung bewusst dem Hof und dem Klerus die Definitionshoheit zu entziehen versuchten, die es diesen erlaubt hatte zu bestimmen, was als heroisch und als historische Größe zu gelten hatte. Und das nicht ohne Erfolg. Während die traditionelle Leichenpredigt, ein klassisches Medium der Konstruktion von Helden, zu einer weitgehend obsoleten, altmodisch wirkenden Gattung wurde, beanspruchten nun die Literaten und Intellektuellen der Aufklärung für die neue Form der ,philosophischen Eloge' fast ein Monopol, wenn es darum ging, historische Größe und heroische Tugend für ein gebildetes Publikum darzustellen. ${ }^{56}$

53 Lilti, Figures publiques, S. 125, „der grand homme [ist] eher eine Neudefinition eine NeuArtikulation, vielleicht sogar eine Rehabilitierung [des Helden] nach der ,Zerstörung des Heros', die die augustinischen Moralisten und die Jansenisten in der zweiten Hälfte des 17. Jahrhunderts unternommen hatten“.

54 Pierre Wachenheim, Un héros éphémère sous le règne de Louis XV. L’abbé Chauvelin, ou le portrait du sapajou en Grand Homme, in: Thomas W. Gaethgens [et al.] (Hrsg.), L'art et les normes sociales au XVIII siècle (Passagen; 2), Paris 2001; S. 213-239, hier besonders S. 237.

55 Thomas E. Keiser, The Public Sphere, in: William Doyle (Hrsg.), The Oxford Handbook of the Ancien Régime, Oxford 2012, S. 409-430; Colin Jones, The Great Nation. France from Louis XV to Napoleon, New York 2002, S. 212-225.

56 Bonnet, Naissance du Panthéon, S. 54-56. 
Dass die ,Philosophen' die Debatte über Größe und das Heroische seit etwa dem zweiten Drittel des 18. Jahrhunderts so stark zu bestimmen vermochten, lag freilich auch daran, dass der König dem heroischen Rollenfach weniger denn je gerecht wurde. Ludwig XV. versuchte zwar, im Österreichischen Erbfolgekrieg noch einmal als Schlachtenlenker aufzutreten und bei Fontenoy gelang ihm das auch mit einem gewissen Erfolg, mochte auch das wirkliche Kommando beim Marschall Moritz von Sachsen gelegen haben, aber der politisch eher unrühmliche Ausgang des Krieges - im Frieden von Aachen vermochte Frankreich weder in Europa noch in Übersee seinen militärischen Erfolg in territoriale Eroberungen umzusetzen diskreditierte seinen Anspruch auf militärischen Ruhm bereits zu einem gewissen Grade. Vollends unglaubwürdig wurde dieser Anspruch mit dem desaströs verlaufenden Siebenjährigen Krieg ab 1756, zumal der König diesmal dem Kriegsgeschehen gänzlich fernblieb. Sicherlich, auch sein Vorgänger hatte nicht wirklich an der Front gekämpft, aber bis 1693 hatte er doch immer wieder an Belagerungen oder anderen militärischen Aktionen wie etwa dem Überschreiten von Flüssen teilgenommen. ${ }^{57}$ All das fehlte jetzt. Umso stärker waren die Zweifel, welche die Kritiker des Königs an der Plausibilität der Heroisierung eines Monarchen äußerten, dem anscheinend seine Mätressen sehr viel wichtiger waren als das Wohl des Landes, das er regierte. Entsprechend fielen die Reaktionen auf die öffentliche Verherrlichung des Herrschers als siegreicher Feldherr aus. 1763, nach dem Ende des Siebenjährigen Krieges, wurde in Paris ein großes Reiterdenkmal des Königs feierlich eingeweiht, das die Stadt Paris 1748 in Auftrag gegeben hatte. Es zeigte den König in der Kleidung eines römischen Imperators als roi connétable. 1748 mochte diese Inszenierung noch plausibel gewesen sein, denn der Österreichische Erbfolgekrieg 1740 bis 1748 war militärisch noch ein Erfolg gewesen, auch wenn dieser Erfolg schon keine politischen Dividenden mehr abwarf. 1756 bis 1763 war dies anders gewesen, denn Frankreich hatte auf fast allen Kriegstheatern katastrophale Niederlagen erlitten. Jetzt ein Denkmal für den König aufzustellen, das ihn als siegreichen Imperator darstellte, wirkte daher grotesk. Die Folgen waren entsprechend. Das Denkmal wurde durch Graffiti entstellt oder man heftete Zettel an seinen Sockel mit Texten, die sich über den König lustig machten oder ihn gar als Feind seines eigenen Volkes erscheinen ließen. Um das Schlimmste zu verhindern, musste das Denkmal permanent bewacht werden. ${ }^{58}$

57 Martin Wrede, Des Königs Rock und der Rock des Königs. Monarch, Hof und Militär in Frankreich von Ludwig XIV. zu Ludwig XVI., in: Martin Wrede (Hrsg.), Die Inszenierung der heroischen Monarchie. Frühneuzeitliches Königtum zwischen ritterlichem Erbe und militärischer Herausforderung (Historische Zeitschrift, Beihefte N.F.; 62), München 2014, S. 382-408, hier besonders S. 388-399. Zu Ludwig XV. auch Bernard Hours, Louis XV. Un Portrait, Toulouse 2009.

58 Richard Clay, Bouchardon's Statue of Louis XV. Iconoclasm and the Transformation of Signs, in: Stacy Boldrick / Richard Clay (Hrsg.), Iconoclasm. Contested Objects, Contested Terms, Aldershot 2007, S. 93-122; Andrew McClellan, The Life and Death of a Royal Monument. Bouchardon's Louis XV, in: Oxford Art Journal 23, Heft 2, 2000, S. 3-27. 
Das sich spätestens seit den späten 1750er Jahren abzeichnende Scheitern der traditionellen Strategien zur Heroisierung des Monarchen erleichterte es den Aufklärern sicherlich, ihr neues Ideal von heroischer Größe der monarchischen und aristokratisch geprägten Tradition entgegenzusetzen. Manche Philosophen stilisierten sich dabei auch selbst als Helden oder gar als heroische Märtyrer wie etwa Rousseau der in seiner „Nouvelle Héloïse“ (1761) einen „héroïsme de la valeur" predigte, der sich vom aristokratischen Streben nach ständischer Ehre scharf absetzte, aber die Idee keineswegs grundsätzlich ablehnte, dass die heroische Tugend des Großen Mannes sich auch mit der Sehnsucht nach Ruhm verband sowie mit der Bereitschaft, die Grenzen zu überschreiten, die menschlichem Handeln im Alltag gesetzt waren. ${ }^{59}$

Zu dem Zeitpunkt, als die „Nouvelle Hélö̈se“ erschien, hatte sich in Frankreich die Diskussion über die Rolle der grands hommes in Geschichte und Politik und ihre Beziehung zur traditionellen Idee des Heroischen bereits zugespitzt. Gerade die sich abzeichnende Niederlage im Siebenjährigen Krieg warf die Frage auf, ob Frankreich nicht wie sein Gegner England - oder auf andere Weise auch Preußen - wirkliche Helden als Vorbilder benötige, die alle Franzosen und nicht nur die adlige Elite zu einem heroischen Einsatz für das Vaterland zu motivieren vermochten. In Preußen wurde der Monarch selbst, Friedrich der Große, als dieser Held inszeniert bzw. inszenierte sich selbst in dieser Weise. ${ }^{60}$ Thomas Abbts „Vom Tode für das Vaterland“ (1761) war eine der Schriften, in denen dieser neue heroische Patriotismus seinen Ausdruck fand. ${ }^{61}$

In England gab es, wie wir gesehen haben, eine gewisse Tradition des Heroenkults, aber kaum öffentliche Institutionen, die versuchten, einen kohärenten Kanon von Nationalhelden zu schaffen. Der Hof war als kulturelles Zentrum nicht mehr bedeutend genug und andere Institutionen, die seine Rolle hätten übernehmen können, gab es nicht. Auch in England wurden im Laufe des Siebenjährigen Krieges aber die Stimmen lauter, die nach einem Pantheon für die nationalen Helden riefen. Es war der Tod von General Wolfe in Kanada (1759) anlässlich der Eroberung von Quebec und die bald darauf auf Vorschlag des Premierministers Pitt getroffene Entscheidung, ihm in der Westminster Abtei auf Staatskosten ein Grabmal zu errichten, die der Krönungs- und Grabeskirche der englischen Krone

59 Bonnet, Naissance du Panthéon, S. 30-31, S. 201-202, S. 207.

60 Siehe etwa Eckhart Hellmuth, Die „Wiedergeburt Friedrichs des Großen“ und der „Tod für das Vaterland“. Zum patriotischen Selbstverständnis in Preußen in der zweiten Hälfte des 18. Jahrhunderts, in: Eckhart Hellmuth / Reinhard Stauber (Hrsg.), Nationalismus vor dem Nationalismus? (Aufklärung. Interdisziplinäre Halbjahresschrift zur Erforschung des 18. Jahrhunderts; 10/2), Hamburg 1998, S. 23-54; Marian Füssel, Der „roi connétable“ und die Öffentlichkeit, in: Bernd Sösemann / Gregor Vogt-Spira (Hrsg.), Friedrich der Große in Europa. Geschichte einer wechselvollen Beziehung, Bd. 2, Stuttgart 2012, S. 199-215.

61 Vgl. Thomas Abbt, Vom Tode für das Vaterland. Neue vermehrte und verbesserte Auflage, in: Thomas Abbt, Vermischte Werke, Bd. 2, Berlin 1770, S. 1-103; vgl. Jörn Leonhard, Bellizismus und Nation. Kriegsdeutung und Nationsbestimmung in Europa und den Vereinigten Staaten 1750-1914 (Ordnungssysteme; 25), München 2008, S. 181-214. 
dann auch offiziell die Rolle eines solchen nationalen Pantheons zuwiesen, dem später die St. Paul's Kathedrale in London zur Seite trat. ${ }^{62}$ In Saint-Denis, der Grablege der französischen Könige vor den Toren von Paris, fanden hingegen nur höchst selten hohe Adlige, die nicht der Königsfamilie angehörten, ihre letzte Ruhe. Eine der wenigen Ausnahmen war der Marschall Turenne, den Ludwig XIV. 1675 wegen seiner vertus herö̈ques ehren wollte. Weitere Ehrungen dieser Art blieben jedoch aus. Hier mag eine Rolle gespielt haben, dass Turennes Angehörige in den Jahren nach dem Tode des großen Feldherren versucht hatten, für ihre Familie einen Status zu beanspruchen, der dem der Königsfamilie gefährlich nahekam. ${ }^{63}$ Das darüber hinausgehende, von Joël Cornette vorgetragene Argumente, die bürokratisierte absolute Monarchie habe keinen Bedarf an Helden mehr gehabt ${ }^{64}$ und diese bewusst marginalisiert, ist hingegen, wie wir bereits gesehen haben, wenig überzeugend, zumal dem Marschall von Sachsen, der Protestant war, nach seinem Tode (1750) auf Geheiß des Königs in einer lutherischen Kirche in Straßburg ein aufwendiges, 1776 vollendetes Grabmal errichtet wurde. ${ }^{65}$ Jean-Baptiste Pigalle, der das Grabmal schuf, stellte den Marschall durchaus traditionell im eigentlich einer längst vergangenen Epoche angehörenden, aber als Attribut des Heros immer noch unentbehrlichen Harnisch des Ritters (oder zumindest des ritterlichen Kavalleristen des 17. Jahrhunderts) dar, wie er, vor einer Pyramide stehend, hoheitsvoll und nicht ohne Verachtung dem personifizierten Tod, der den Sarg für ihn öffnete, entgegenschreitet, betrauert von einem durch Erschütterung gezeichneten Herkules, während die weibliche Personifikation Frankreichs den Tod zurückzuhalten sucht. So eindrucksvoll dieses Denkmal heute erscheinen mag, so hatte es im 18. Jahrhundert doch durchaus seine Kritiker, die namentlich daran Anstoß nahmen, dass die mythologische Figur des Herkules, der wohl auch die um ihren Feldherren trauernden französischen Soldaten verkörpern sollte, neben eine ansatzweise realistisch gestaltete Statue des Verstorbenen gesetzt wurde, die eben nicht römisch oder griechisch gewandet war, sondern einen Harnisch trug. Auch dass Herkules, das Sinnbild der Stärke schlechthin, trauerte, wurde beanstandet. ${ }^{66}$

Wie schwierig es war, im späten 18. Jahrhundert noch eine verbindliche Bildsprache für ein heroisierendes Monument zu finden, zeigt auch das Grabmal für General Wolfe in London. In England wählte der Bildhauer Joseph Wilton, der

62 Craske, Westminster Abbey 1720-1770, S. 76-77; Hoock, Empires of the Imagination, S. $40-45$, S. 132-161.

63 Jean-Marie Le Gall, Le Mythe de Saint Denis entre Renaissance et Révolution (Époques), Seyssel 2007, S. 467-470; siehe auch Wrede, Zwischen Mythen, Genealogen und der Krone, S. 17-43.

64 Cornette, Le roi de guerre, S. 202, S. 314.

65 Thomas Steinruck, Jean-Baptiste Pigalle. Das Grabmal für Moritz von Sachsen, Studien zum Mausolée du Maréchal de Saxe in St. Thomas in Straßburg, Saarbrücken 2009. Ludwig XV. hatte offenbar zunächst daran gedacht, den Marschall in Saint Denis beerdigen zu lassen, sah aber dann davon ab, weil dieser kein Katholik und überdies nur der BastardSohn eines deutschen Fürsten war.

66 Vgl. ebd., S. 64-69. 
nach einer öffentlichen Ausschreibung den Auftrag erhielt, das 1773 vollendete Grabmal zu errichten, allerdings einen ganz anderen Stil der Heroisierung als Pigalle. Wolfes Grabmonument sollte in England für den Heldenkult des späten 18. Jahrhunderts ähnlich wie auf andere Weise das 1771 vollendete Bild des Künstlers Benjamin West, das ebenfalls den Tod des britischen Generals bei der Erstürmung der französischen Stellungen vor Quebec darstellte, wegweisend werden. ${ }^{67}$ Wolfe erschien in Wiltons Werk - anders als der aristokratische Marschall von Sachsen bei Pigalle - ganz als ,moderner ${ }^{6}$ Held, eigentlich ein Mann wie jeder andere, ein everyman, der aber in einer Ausnahmesituation sein Leben für sein Land geopfert hatte. Dabei war das Denkmal in Westminster Abbey, das bezeichnenderweise ganz darauf verzichtete, Wolfes in der Realität eher kränklichen und schwachen Körper zu heroisieren, nicht frei von einer gewissen „unctuous sentimentality“, wie eine neuere Studie konstatiert. ${ }^{68}$ Holger Hoock hat dem Denkmal bescheinigt, dass es einen Punkt in einem Transformationsprozess markiert, in dessen Verlauf ikonographische Ausdrucksformen und Rituale, die bis dahin der Verehrung von Märtyrern oder auch - im katholischen Bereich - Heiligen vorbehalten waren, auf die neuen nationalen Helden übertragen wurden. ${ }^{69}$

Ähnliches kann man vielleicht auch für Wests Gemälde sagen, das sich stark auf die emotionale Anteilnahme der Begleiter und Offiziere Wolfes an dessen Tod konzentrierte und sich ikonographisch an christlichen Motiven wie der Pietà oder Kreuzabnahme orientierte. Yuval Harari hat darauf hingewiesen, dass West, indem er den Soldaten und Begleitern des Generals, die dessen Sterben und Tod mitansahen, eine so prominente Rolle in seinem Bild zuwies, sich einer Tendenz anschloss, die im späten 18. Jahrhundert generell spürbar wurde: „Death in battle is no longer just heroism. It has also became 'an experience'". Indem Soldaten den Tod eines Kameraden oder ihres Kommandeurs in der Schlacht bewusst erleben, finden sie, so deuteten Selbstzeugnisse der Epoche, aber eben auch Kunstwerke wie das von West, dieses Phänomen, zu einer besonderen Form von Selbsterfahrung, und dieser Selbsterfahrung wurde selbst eine heroische Qualität zugeschrieben. Auf diesem Wege entdeckten sie, so wurde es postuliert, ihr wirkliches Selbst. ${ }^{70}$

Wests Gemälde war zum Zeitpunkt seiner Fertigstellung freilich recht umstritten, weil es Wolfe ganz in zeitgenössischer Kleidung darstellte und eben nicht im Kostüm eines römischen Generals - von der Rüstung eines Maréchal de Saxe einmal ganz abgesehen -, wie es in solchen Fällen bis dahin weithin üblich gewesen war. Kritiker wie der Maler Reynolds hoben hervor, dass ein Held nur dann als eine Ge-

67 Siehe generell dazu Alan McNairn, Behold the Hero. General Wolfe and the Arts in the Eighteenth Century, Liverpool 1997.

Coutu, Persuasion and Propaganda, S. 122, dort auch S. 103-146 zu dem Denkmal und seiner Entstehung und S. $135 \mathrm{zu}$ Wolfe als everyman und zur Gestaltung seines Körpers. Zum historischen Kontext der Verehrung für Wolfe siehe auch Leonhard, Bellizismus und Nation, S. 285-292.

69 Hoock, Empires of the Imagination, S. 164.

70 Harari, The Ultimate Experience, S. 224-225. 
stalt präsentiert werden könne, der ewiger, überzeitlicher Ruhm zukomme, wenn ihre Darstellung das ästhetische Vokabular der griechisch-römischen Antike und nicht das banalere der Gegenwart verwende. Der Bildhauer Wilton war dieser Entscheidung zwischen Moderne und Antike partiell ausgewichen, indem er Wolfe halbnackt dargestellt hatte, umhüllt nur von einem Stück Tuch, das man statt als Toga auch als Decke deuten konnte. Allerdings trugen die Figuren, die Wolfe umgaben, durchaus zeitgenössische Uniformen, was schon Zeitgenossen als eine auffällige ästhetische Inkonsequenz kritisierten. ${ }^{71}$ Parallelen zu den Diskussionen um das Grabmal für den Maréchal de Saxe springen hier ins Auge. Diese Debatten zeigen, dass es im letzten Drittel des 18. Jahrhunderts auch in England schon außerordentlich schwierig geworden war, eine verbindliche und für alle akzeptable Bildsprache für das Heroische und die historische Größe zu finden.

Frankreich fehlte im Siebenjährigen Krieg ein siegreicher General Wolfe, dem man ein großes Denkmal hätte widmen können, aber das Bedürfnis, den englischen und anderen ausländischen Helden eigene Heroen entgegenzustellen, war umso größer, auch wenn man diese Helden nach 1750, zumindest soweit sie Kriegshelden sein sollten, eher in der Geschichte, nicht in der Gegenwart, suchen musste. Bezeichnenderweise wurden in diesem Kontext in den 1770er Jahren Planungen für ein nationales Pantheon entwickelt. ${ }^{72}$ Aber es waren zunächst andere Medien als die bildenden Künste, nämlich Literatur und Drama, die sich des Themas annahmen. Schon der Österreichische Erbfolgekrieg 1740 bis 1748, in dem Frankreich militärisch eigentlich noch einmal siegreich gewesen war, auch wenn dieser Sieg sich nicht in politische Erfolge umsetzen ließ, hatte hier wie ein Katalysator gewirkt. Der Mut, den die einfachen Soldaten des Elite-Regiments der Gardes Françaises 1745 bei Fontenoy bewiesen hatten, wo sie aus taktischen Gründen stoisch das englische Gewehrfeuer über sich hatten ergehen lassen, ohne als Erste zu schießen, war hier ein entscheidender Wendepunkt gewesen. ${ }^{73}$ Mehr als früher wurde nun auch der Heroismus des einfachen Soldaten und nicht nur der des adligen Offiziers gewürdigt, Claude Godard d'Aucourt de Saint-Just zum Beispiel hatte 1749 einen Roman veröffentlicht, der den Titel „L'académie Militaire ou Les Héros subalternes" trug. Dieser Roman wurde ein großer Erfolg und lieferte später auch den Stoff für ein Theaterstück. ${ }^{74}$

Auch das Thema des Patriotismus war dem politischem Diskurs schon vor dem Ausbruch des Siebenjährigen Krieges nicht ganz fremd gewesen, aber meist lag der Akzent darauf, dass es sich hier doch in erster Linie um eine Empfindung handele, die typisch sei für die Bürger einer Republik, nicht für die Untertanen eines Mon-

71 Coutu, Persuasion and Propaganda, S. 140-141, S. 144; McNairn, Behold the Hero, S. 6468, S. 127-133.

72 Siehe S. 129.

73 Drévillon, L'individu et la Guerre, S. 133; zu Fontenoy siehe S. 131.

74 Smith, Nobility Reimagined, S. 147-148; vgl. Drévillon, Secondary Heroes. 
archen. Wenn von Patrioten die Rede war, dann waren damit oft die Angehörigen anderer Staaten gemeint. Wie jedoch Edmond Dziembowski demonstriert hat, finden wir seit der zweiten Hälfte der 1750er Jahre eine deutliche semantische Verschiebung. ${ }^{75}$ Der Siebenjährige Krieg war vielleicht der erste Krieg, den die französische Krone führte, der nicht mehr als der Krieg eines Monarchen gegen andere Dynastien, sondern vor allem als der Krieg der französischen Nation gegen andere Nationen, allen voran natürlich gegen England, erschien und so offiziell auch dargestellt wurde. Auch die Begriffe, patrie ${ }^{\varsigma}$, ,patriotisme $e^{\varsigma}$ und ,nation ${ }^{6}$ tauchten nun in Publikationen deutlich häufiger auf als vor 1756 und das galt auch für den Begriff des Staatsbürgers, ,citoyen'. Bezeichnenderweise förderte der Hof den neuen patriotischen Diskurs. Das galt besonders für den Leiter der französischen Außenpolitik und zeitweiligen Kriegsminister, den Herzog von Choiseul, der in den Jahren 1760/61, als sich bereits eine französische Niederlage im Siebenjährigen Krieg abzeichnete, eine ganze Reihe von Publikationen auf den Weg brachte, um an die Bereitschaft der Franzosen zu appellieren, für ihr Land zumindest finanzielle Opfer zu bringen und dies keineswegs ohne Erfolg. ${ }^{76}$ Schon 1757 war im Übrigen in Paris ein Stück aufgeführt worden, das den Kampf des Karthagers Hasdrubal für sein Vaterland gegen die perfiden Römer und sein Selbstopfer thematisierte. ${ }^{77}$ An diese älteren Ansätze knüpfte nach dem unrühmlichen Ende des Siebenjährigen Krieges, das in Frankreich eine allgemeine Krisenstimmung ausgelöst hatte, ein Schauspieler und Dramatiker von ansonsten eher mittelmäßiger Begabung an, Pierre-Laurent Buirette de Belloy. Sein Drama „Die Belagerung von Calais“ wurde 1765 in Paris aufgeführt und wurde ein spektakulärer Erfolg. ${ }^{78}$

Calais war im Hundertjährigen Krieg 1347 erst nach 11 Monaten Belagerung von Eduard III. von England erobert worden. Der siegreiche englische König tat zwar nicht das, was nach damaligem Kriegsrecht durchaus möglich gewesen wäre, er brachte also nicht alle erwachsenen Bewohner der Stadt um, aber er vertrieb doch einen Großteil - auch wenn faktisch viele der Vertriebenen mehr oder weniger zügig zurückkehren konnten. Die Vornehmsten der Bürger mussten für ihren Widerstand Buße tun, indem sie im bloßen Hemd und mit einem Strick um den Hals zu Fuß die Stadt verließen und den König um Gnade baten, die auch gewährt wurde. Schon die mittelalterliche Chronistik deutete diese symbolische Bestrafung jedoch zum Teil um. Sie stellte es so dar, als hätten sich sechs Bürger unter Führung des Kaufmanns Eustache de Saint-Pierre als Geiseln gestellt, um

75 Edmond Dziembowski, Un nouveau patriotisme français 1750-1770. La France face à la puissance anglaise à l'époque de la guerre de Sept Ans (SVEC; 365), Oxford 1998, S. 385.

Ebd., S. 411-412.

78 Zu dem Drama siehe Jean-Marie Moeglin, Les bourgeois de Calais. Essai sur un mythe historique (L'évolution de l'humanité), Paris 2002, S. 177-202; Pierre-Laurent Buirette de Belloy, Le siège de Calais, in: Jacques Truchet (Hrsg.), Théâtre du XVIII siècle, Bd. 2, Paris 1974, S. 447-516. 
mit ihrem Leben das der übrigen Bürger freizukaufen. Erst auf Bitten der englischen Königin seien sie vom rachelustigen König begnadigt worden. ${ }^{79}$

Diesen Mythos griff de Belloy auf. Er hatte vorher allerdings schon Eingang gefunden in die Schuldramen der großen Collèges, die meist von Jesuiten geleitet wurden - ganz neu war das Thema als dramatisches Sujet also nicht. ${ }^{80}$ Das Drama „Die Belagerung von Calais“ ist heute weitgehend vergessen, wohl auch zu Recht, große Literatur ist es nicht. In den 1760er Jahren war es jedoch ein großer Erfolg und schuf ein neues Bild des nationalen Helden, hierin durchaus vergleichbar der Heroisierung von General Wolfe in England.

De Belloy erklärte in der Vorrede zu seinem Drama, ihm sei es darum gegangen, eine nationale Tragödie nach dem Vorbild der Geschichtsdramen Shakespeares zu schaffen. Wer dieses Stück gesehen habe, solle sagen können, er habe einen französischen Helden gesehen und wie dieser könne auch er ein Held sein. ${ }^{81}$ Die Aufforderung zur patriotischen imitatio heroica war also in das Stück gewissermaßen eingebaut und vor allem die Helden, die das Stück präsentierte, sollten normale Bürger sein - keine Aristokraten mit einer Ahnenreihe von vielen Generationen oder vollständige Ausnahmefiguren wie die Gestalten der Mythologie oder der antiken Geschichte, sondern eher Menschen wie Du und Ich, nur eben mit der Kraft, in einer Ausnahmesituation über sich selbst hinauszuwachsen. Es war bezeichnend, dass einer der Antihelden im Stück ein Adliger war, der Graf de Harcourt, der sich erst in letzter Minute bekehrte und dann doch für seinen König und seine Nation eintrat und nicht für die Engländer.

Das Drama gehörte damit dezidiert in den Kontext einer Verbürgerlichung des Helden, wandte sich aber zugleich gegen die starke Kritik der traditionellen Vorstellungen des Heroischen, die für diese Phase der Aufklärung nicht untypisch war. Schon seit Fénelon und seinem „Telemach“ war der aristokratische militärische Held in Verruf geraten, oder zumindest stieß dieses Ideal nun auf eine starke Skepsis. ${ }^{82}$ Aristokratische Helden präsentierte de Belloy daher auch nicht, aber sehr wohl Bürger, die bereit waren, für das Vaterland zu sterben, und nicht einfach nur für die gesamte Menschheit, wie es den Idealen der Aufklärung eigentlich entsprochen hätte. Das Stück von de Belloy wurde von Diderot und anderen aufgeklärten Philosophen daher auch scharf abgelehnt - eine Kritik, die de Belloy im Drama antizipiert hatte, denn im vierten Akt verkündete ein englischer Edelmann den Bürgern von Calais, in seinem eigenen Lande sei die Vaterlandsliebe ganz selbstverständlich: „L'Anglais est citoyen; et sa raison suprême / veut qu'une nation se chérisse elle-même“ (,der Engländer ist ein Staatsbürger, und seine überlegene Ver-

79 Moeglin, Les bourgeois de Calais, S. 79-89.

80 Ebd., S. 175-176.

81 Vgl. De Belloy, Le siège de Calais, S. 449. De Belloy kritisierte damit Dramen, deren Helden Gestalten der Antike waren, weil sich mit diesen der Zuschauer nicht identifizieren könne, sondern sage ,je ne suis pas né dans un pays où je puisse leur ressembler“.

82 Siehe S. 22. 
nunft bejaht es, dass eine Nation sich selbst schätzt"). Es sei nur natürlich, dass man sich seinen Landsleuten enger verbunden fühle als Menschen aus anderen Nationen: „Je hais les coeurs glacés et morts pour leur pays, / qui, voyant ses malheurs dans une paix profonde, / s'honorent du grand nom de citoyen du monde, / feignent dans tout climat d'aimer l'humanité / pour ne la point servir dans leur propre cité. ${ }^{83}$

Indem Belloy den Patriotismus der Bürger von Calais feierte - gemessen an den wirklichen Ereignissen von 1347 in natürlich recht anachronistischer Weise, denn die patrie dieser Bürger war damals vor allem ihre Stadt, nicht Frankreich, gewesen -, stellte er sich gegen eine einflussreiche Strömung einer eher kosmopolitisch gesinnten Aufklärung. Im Übrigen war sein Bild der Helden von Calais gar so weit von den Idealen der Aufklärung dann aber doch nicht entfernt, denn seine Heroen waren eben keine ungezähmten Krieger auf der Suche nach Ruhm und getrieben von persönlichem Ehrgeiz und Geltungsstreben. Ihr Heldentum ist ein eher passives, gekennzeichnet durch die Bereitschaft zum Opfer. Und es ist ein kollektives, sie gehen nicht als Einzelne in den Tod, sondern als Gruppe und verkörpern damit den sens civique, den Gemeinsinn, den die Aufklärung von ihren grands hommes forderte. ${ }^{84}$

Zugleich stellt „Die Belagerung von Calais“ den Versuch dar, einen neuen, auf die Nation bezogenen Patriotismus mit der Loyalität gegenüber der Dynastie und dem König als Person zur Deckung zu bringen. Der Patriotismus der Bürger von Calais bei de Belloy ist durchgehend königstreu. Nationalstolz und Loyalität gegenüber der Dynastie, die aufgrund der Lex Salica ihre Herrschaft ausübt, lassen sich nicht trennen, aber der König selbst ist weniger der zentrale Orientierungspunkt der Loyalität, das nämlich ist die Nation, sondern der erste unter einer Heerschar von Patrioten. Er verkörpert den Patriotismus der Franzosen, er steht nicht notwendigerweise im Mittelpunkt dieses Patriotismus'. ${ }^{85}$ In der Auseinandersetzung des Dichters mit der historischen Quellenkritik an seinem Drama trat der König sogar noch weiter in den Hintergrund und de Belloy ließ nun eine Interpretation zu, die aus den sechs Bürgern Helden machte, die ein Vaterland verteidigten,

83 De Belloy, Le siège de Calais, Akt 4, Szene 2, S. 493-494, der Engländer Mauni zu den „six bourgeois“, „Ich hasse die vereisten Herzen, die abgestorben sind für ihr Vaterland und sich sein Unglück unerschüttert mit der größten Seelenruhe ansehen und sich dabei des Namens eines Weltbürgers rühmen und vorgeben, in jeder Lage die Menschheit zu lieben, um dieser Menschheit nicht in ihrem eigenen Gemeinwesen zu dienen." Vgl. Jacques Truchet (Hrsg.), Théâtre du XVIII e siècle, Bd. 2, Paris 1974, S. 1437 (Erläuterungen des Herausgebers) und zur Kritik Voltaires und anderer Philosophen am Stück auch Moeglin, Les bourgeois de Calais, S. 191-193. Siehe ferner Dziembowski, Un nouveau patriotisme français 1750-1770, S. 481-484.

84 Vgl. Moeglin, Les bourgeois de Calais, S. 187-188, „Man sieht einen Eduard, der zur Infamie rät, und um einen Untertanen zu korrumpieren, dessen Geist bis zur Erschöpfung ermüdet, aber welcher Sterbliche wäre nicht eifersüchtig, wenn er mein Los sieht? Ihr zwingt mich, Herr, größer zu sein als Ihr.“

85 Vgl. ebd., S. 182. 
das der eigene König schon fast aufgegeben hatte. Die Anklage, die der Anführer der Bürger, Eustache de Saint-Pierre, dem englischen Herrscher entgegenschleuderte, als dieser ihn zum Verrat bewegen wollte, konnte im Übrigen sehr wohl als Kritik an der Monarchie an sich gelesen werden: „On regarde Édouard conseillant l'infamie / pour corrompre un sujet épuisant son génie / quel mortel de mon sort ne serait point jaloux? / Vous me forcez, Seigneur, d'être plus grand que vous.“ "86 Der Untertan oder Bürger als Held, dessen moralische Größe die des Herrschers übertraf, war eine Figur, die durchaus subversives Potenzial besaß.

De Belloys Drama erlebte einen enormen Erfolg auf der Bühne, trotz seiner eher begrenzten literarischen Qualität. Allein in Paris wurde es 1765 fünfzehn Mal aufgeführt und zusätzlich ein Mal vor dem König in Versailles; überdies ordnete der König eine Gratisvorstellung in Paris durch de Comédie Française an, was im 18. Jahrhundert eher selten vorkam. Auch diese Gratisvorstellung war ein großer Publikumserfolg. De Belloy erschien am Ende auf der Bühne und wurde mit den Rufen „Vive le roy et Monsieur de Belloy“ gefeiert. Den Aufführungen in Paris schlossen sich Präsentationen in der Provinz an, die ebenso gut besucht waren. ${ }^{87}$

Aber es blieb nicht bei dem Versuch de Belloys, eine Synthese zwischen dem neuen Ideal eines heroischen Bürgerpatriotismus und den alten Traditionen des Dienstes für Krone und König herzustellen. Je mehr sich die Krise des Ancien Régimes nach 1763 vertiefte, desto attraktiver wurde ein solches Programm aus der Sicht des Hofes und der Minister, zumal die Rivalität zum alten Gegner England auch noch in den 1770er Jahren ein bestimmender Faktor der französischen Politik blieb. Nach 1774 versuchte ein Minister Ludwigs XVI., den patriotischen Impuls von „Die Belagerung von Calais“, aber auch anderer Werke aufzunehmen. Der in diesem Jahr von Ludwigs XVI. zum Directeur Général des Bâtiments, Arts, Jardins et Manufactures de France ernannte Charles Claude Flahaut de La Billarderie, Comte d'Angiviller, entwarf nicht nur Pläne für ein Nationalmuseum im Louvre eine Art Pantheon der großen Gestalten der französischen Geschichte -, sondern ließ auch von bedeutenden Bildhauern eine Serie von Statuen der grands hommes, oder vielleicht sollte man besser sagen, der hommes illustres Frankreichs schaffen. Zu diesen bommes illustres - und bezeichnenderweise fehlten die Frauen hier ganz, denn das neue Ideal von Größe war ein fast exklusiv männliches, was für die heroischen Figuren der Vergangenheit in dieser Schärfe nicht gegolten hatte - gehörten Dichter und Denker ebenso wie Maler, etwa Poussin, große Juristen wie der Kanzler d'Aguesseau oder der Parlamentspräsident de Molé aus der Zeit der Fronde. Aber selbst noch zu diesem Zeitpunkt, auf dem Höhepunkt der Aufklärung, behaupteten sich auch bedeutende Feldherren auf ihrem Platz, wie etwa Turenne oder Condé, oder ritterliche Krieger wie der Chevalier Bayard, auch wenn sie nun

86 Vgl. de Belloy, Le siège de Calais, S. 507, Akt 5, Szene 2 und Moeglin, Les bourgeois de Calais, S. 196-202; zur späteren Umdeutung des Dramas durch den Autor; vgl. Dziembowski, Un nouveau patriotisme français 1750-1770, S. 484-486.

87 Vgl. Moeglin, Les bourgeois de Calais, S. 183-184. 
den Kanon der Nationalhelden nicht mehr dominierten. ${ }^{88}$ Die heroisierten Feldherren hatten sich nicht zuletzt durch ihre Loyalität gegenüber der Monarchie ausgezeichnet, die so weit gehen konnte, dass sie Befehlen gefolgt waren, die sie eigentlich für falsch hielten, wie es der Admiral Tourville bei La Hougue (1692) getan hatte. Und die Denker und Künstler, die Angivillier verherrlichen ließ, verdankten ihren Ruhm oft auch der Förderung durch den König, oder zumindest konnte man es so erscheinen lassen. ${ }^{89}$

$\mathrm{Zu}$ den nationalen Identifikationsfiguren des Angivillierschen Statuenprogramms gehörte unter anderem auch der Marschall de Catinat, dessen von Claude Dejoux geschaffene Statue (1781) heute in Versailles steht. Angivillier hatte über ihn gesagt, er sei „un général de terre non moins recommandable par ses talents militaires que par son désintéressement, son humanité et son esprit philosophique “. ${ }^{90}$ Schon in dieser Würdigung wird deutlich, dass die Heroisierung Catinats als die Verherrlichung eines modernen Helden angelegt war, der von den Fehlern eines ungestümen Bellizismus oder eines überbordenden persönlichen Ehrgeizes frei war. Catinat war im Übrigen einige Jahre bevor Dejoux seine Skulptur vollendete Gegenstand eines rhetorischen Wettbewerbs in der Académie française gewesen, der recht deutlich zeigt, wie sehr sich das Bild des militärischen Helden im Zeitalter der Aufklärung zumindest in Frankreich verändert hatte.

Rhetorische Wettbewerbe, bei denen es darum ging, eine möglichst überzeugende panegyrische Rede auf einen grand homme zu entwerfen, waren seit 1758 in der Académie üblich und entsprachen einem Anliegen der Aufklärung, die Verwaltung des Ruhmes und seine Konstruktion nicht länger dem Hof und den Klienten der Aristokratie zu überlassen. Auch wenn in Frankreich die Philosophen den aristokratischen und kriegerischen Helden der Vergangenheit durch neue Symbolfiguren zu ersetzen suchten, dominierten unter den historischen Persönlichkeiten, die von den Mitgliedern der Académie verherrlicht wurden, doch weiterhin die Krieger und hohen Amtsträger der Monarchie. Sicherlich, auch Descartes oder Molière kamen zu Ehren, aber im Vordergrund standen doch Figuren wie der Maréchal de Saxe (1759), Colbert (1773), Vauban (1787) oder eben Catinat. Dennoch hatte sich 1758 ein wichtiger Wandel vollzogen, denn bis dahin hatten die Prunkreden der Académie sich über hundert Jahre lang mit religiösen Themen beschäftigt. Jetzt hingegen ging es um die Helden und Großen Männer der Nation. ${ }^{91}$

88 Zum Statuenprogramm siehe Bonnet, Naissance du Panthéon, S. 126-129; David Bell, The Cult of the Nation in France. Inventing Nationalism, 1680-1800, Cambridge, MA 2001, S. 111; sowie Gaehtgens, Du Parnasse au Panthéon, S. 135-172, hier S. 154-161.

89 Vgl. ebd., S. 158-159.

90 Bonnet, Naissance du Panthéon, S. 129, „ein General des Heeres, der wegen seiner Uneigennützigkeit, seiner Menschlichkeit und seines philosophischen Geistes genauso zu preisen ist wie wegen seiner militärischen Begabung".

91 Bell, The Cult of the Nation in France, S. 111-112; siehe dazu auch: Henning Ritter, Die Krise des Helden. Der Ruhm und die großen Männer im Ancien Régime, in: Martin 
Der Mann, dem 1775 der Redewettbewerb galt, Nicolas de Catinat, war 1637 als Sohn eines Amtsadligen geboren worden und war ursprünglich selbst als Jurist tätig gewesen. 1681 zum Generalmajor (maréchal de camp) befördert, krönte er seine Karriere durch eine Reihe von Siegen im Pfälzischen Erbfolgekrieg. 1693 zum Marschall von Frankreich ernannt, zog er sich 1703 auf seine Güter zurück, wo er 1712 starb. Preisgekrönt wurde im Wettbewerb am Ende die Eloge von Jean-François de la Harpe. Er hob in seiner Rede eingangs hervor, dass Catinat in einem Zeitalter, in dem die ganze Kultur auf die Verehrung des Monarchen ausgerichtet gewesen sei, sich allein am Vaterland, an der patrie, als höchstem Wert orientiert habe. ${ }^{92}$ Im Übrigen habe Catinat in einer Epoche gelebt, in der die Bedingungen für kriegerischen Mut sich tiefgreifend geändert hätten. In der Gegenwart sehe man bei Belagerungen und auf dem Schlachtfeld eine Tötungsindustrie am Werk, eine „industrie meurtière“, die das Altertum so nicht gekannt habe. Auch der einfache Soldat könne unter diesen Bedingungen ein Held sein. Das war ein Thema, das in Frankreich spätestens seit der Schlacht von Fontenoy 1745 aktuell war, wie bereits betont wurde. Der Heldenmut der einfachen Soldaten jener machines hérö̈ques bestehe oft einfach nur darin, auf den Tod bewegungslos zu warten, „attendre la mort sans la repousser, de la voir sans la fuir, de la recevoir sans le venger". ${ }^{93}$

Schon durch diese Aussagen wurde die Heroisierung von Catinat ein Stück weit relativiert, denn der moderne militärische Heros war jetzt eben keine absolute Ausnahmeerscheinung mehr, Mitglied einer Elite von Aristokraten, die allein die Möglichkeit hatten, sich als Helden zu inszenieren, sondern eher der Erste unter Gleichen, ein Vorbild zwar, aber kein unerreichbares. So betonte de la Harpe denn auch, dass Catinat, gerade weil er anders als Condé oder Turenne kein großer Aristokrat gewesen sei, als Soldat die Vernunft eines Philosophen und die Gesinnung eines Bürgers demonstriert habe. Er habe im Krieg nichts anderes gesehen als ein öffentliches Verbrechen, ein Unglück für die Völker. Den Sieg anzustreben, sei für ihn nur deshalb gerechtfertigt gewesen, weil dieser Sieg auch ein Ende des Krieges herbeiführen sollte. ${ }^{94}$ Für ihn sei jede unnötige Schlacht ein Unglück gewesen. Während die militärischen Helden der Vergangenheit ihrem Ruhm sinnlos Opfer gebracht hätten, sei Catinat stets sparsam mit allen Ressourcen und eben auch mit dem Leben der ihm anvertrauten Soldaten umgegangen..$^{95}$ Was man sich wünschen müsse, im Kriege wie im Frieden, das seien nicht die „génies brillants“ und die „âmes naturellement prédominantes“, sondern die „esprits justes“ und „les coeurs

Warnke (Hrsg.), Politische Kunst. Gebärden und Gebaren (Hamburger Forschungen zur Kunstgeschichte; 3), Berlin 2004, S. 1-16, hier S. 7.

92 Jean-François de La Harpe, Éloge de Nicolas de Catinat, Maréchal de France, Paris 1775, S. 6.

93 Ebd., S. 19, „auf den Tod zu warten ohne ihn zurückzuweisen, ihm ins Auge zu sehen, ohne zu fliehen, ihn zu erleiden, ohne sich zu rächen“. Zur Schlacht von Fontenoy und der von ihr ausgelösten Debatte über den Heldenstatus einfacher Soldaten und Unteroffiziere siehe S. 121.

94 Ebd., S. 26, S. 65.

95 Ebd., S. 27-28. 
vertueux“. Es gelte, die Vernunft und die Tugend zu verherrlichen, die zu lange durch die Wörter ,Größe' und ,Genie`, die so viele geblendet hätten, in den Hintergrund gedrängt worden seien. Und diesem Ideal habe Catinat, der von seine Soldaten „Le Père Pensée“ genannt worden sei, entsprochen. ${ }^{96}$

Die Preisrede von de La Harpe demonstriert somit einerseits durchaus die Kritik der Aufklärung am traditionellen Bild des kriegerischen Helden, wie sie bereits in der Schrift des Abbé de Saint Pierre über den Unterschied zwischen dem grand homme und dem homme illustre deutlich geworden war. ${ }^{97}$ Andererseits blieb Catinat am Ende eben doch Soldat, mochte er auch noch so sehr Philosoph und Weiser sein, und natürlich ging die Lobrede auch auf seine Siege und Erfolge ein. In La Harpes Eloge auf Catinat wird noch einmal deutlich, dass es zwischen den Großen Männern der Aufklärung und den aristokratischen Helden des âge classique fließende Übergänge gab. Allerdings, die grands hommes des 18. Jahrhunderts waren selbst dann, wenn der Krieg ihr Beruf war, gezähmte Helden, die ihre transgressiven Züge weitgehend verloren hatten. Überdies traten nun einfache Soldaten oder Bürger neben die Offiziere adliger Herkunft, während die Dichter, Denker und Wissenschaftler einen neuen Typus historischer Größe verkörperten. Auch ihnen war der Anspruch auf eine heroische Inszenierung nicht fremd, die bei Philosophen wie Rousseau auch bewusste Selbstinszenierung war, aber das Heroische definierte sich nun eher über Seelenstärke und Tugend als über die Bereitschaft, sich in einem gewaltsamen Kampfe aufzuopfern.

Noch schärfer als bei La Harpe trat die Kritik an traditionellen Modellen des Heroischen in einer zweiten Eloge auf Catinat hervor, die der Militärreformer Graf Guibert verfasst hatte. Guibert, der auch der Verfasser eines Theaterstückes über den connétable Charles de Bourbon war, in dem er dem Chevalier Bayard die eigentliche Heldenrolle zuwies, sah in Catinat ein Vorbild, dem er selbst nachzueifern versuchte, wie auch Voltaire bemerkte. ${ }^{98}$ In seiner Eloge ließ Guibert die Niederländer und Engländer als die eigentlichen Verteidiger höherer Werte erscheinen, weil sie gegen Ludwig XIV. für die Freiheit gekämpft hätten. Zum anderen bestand er vehement darauf, dass es auch dem einfachen Bürger möglich sein müsse, zu den höchsten Gipfeln des militärischen Ruhmes aufzusteigen. ${ }^{99}$ Überdies betonte er, dass es Frankreich - und damit war die Nation gemeint, nicht der König oder sein Hof - besser verstünde als andere Nationen, seine Helden zu ehren, eine Verehrung, die der Monarch nicht befehlen und auch nicht wirklich lenken könne, sondern die spontan sein müsse. ${ }^{100}$

96 Ebd., S. 65.

97 Siehe S. 107.

98 Éthel Groffier, Le stratège des Lumières. Le comte de Guibert (1743-1790), Paris 2005, S. 134-138.

99 Jacques Antoine Hippolyte, Comte de Guibert, Éloge du Maréchal Catinat (Exemplar BN, Arsenal 8to BL 3068, nr. 3), Edinburgh 1775, S. 9, S. 16.

100 Vgl. ebd., S. 1-2, S. 56-57. 
Guibert gehörte im späten 18. Jahrhundert zu einer Reihe von Offizieren und Militärtheoretikern, die sich um eine Reform der Armee bemühten, diese aber zugleich als Teil einer Erneuerung der französischen Gesellschaft sahen. Zentral für seine Reformpläne war dabei auch der Gedanke, dass nun die ganze Nation teilhaben müsse am Ehrgefühl des Adels und dass nur ein heroischer Patriotismus den Niedergang Frankreichs aufhalten oder rückgängig machen könne. Alle Bürger sollten Soldaten werden und alle Soldaten Bürger. ${ }^{101}$ Guibert und andere Reformer wollten den Adel nicht notwendigerweise abschaffen, aber seine spezifische Rolle als Erbe eines besonderen Ethos wurde doch in der Reformdebatte vor 1789 zunehmend zweifelhaft. Vielfach übernahm die Armee - jedenfalls in der militärischen Theorie - als solche vom Adel die neue Rolle, Träger eines heroischen Patriotismus zu sein. ${ }^{102}$

In England war die Reaktion gegen den Typus des traditionellen Helden, der in der Regel der landbesitzenden Elite angehörte, weniger ausgeprägt als in Frankreich, auch wenn hier von kirchlicher Seite gelegentlich Kritik an der zu starken Präsenz von heroischen Kriegern im öffentlichen Bewusstsein geübt wurde. ${ }^{103}$ Aber in einem Land, in dem hohe Militärs oft zugleich Politiker waren - das galt für Marlborough zu Beginn des Jahrhunderts genauso wie später für Admiral Vernon - und in dem der Übergang zwischen militärischer Karriere und zivilem Leben ein gleitender war, fehlte die Zuspitzung, welche die Debatte über den grand bomme in Frankreich zeitweilig erfuhr. Es gab auch kein geschlossenes Milieu wie das der Philosophen in Frankreich, das sein Konzept heroischer Größe gegen konkurrierende Ideen, die vom Hof und etablierten Eliten favorisiert wurden, durchzusetzen versuchte. Allerdings war auch in England eine Tendenz erkennbar, Personen zu heroisieren, die ein einziges Ereignis, wie etwa der Tod in einer siegreichen Schlacht, aus der Masse anderer Menschen hervorhob. Ein Beispiel dafür wäre General Wolfe, der als Feldherr nicht immer überdurchschnittliches Talent gezeigt, aber durch günstige Umstände einen großen Sieg errungen hatte und im richtigen Moment gestorben war. An die Stelle überzeitlicher Größe trat zumindest im Einzelfall eher die an konkrete Kontexte gebundene, unter Umständen sogar ephemere Berühmtheit. ${ }^{104}$

Generell zeigte aber die englische Elite ein bemerkenswertes Talent, sich an die sich wandelnden Modelle des Heroischen im 18. Jahrhundert anzupassen. Die Rückbesinnung auf die Traditionen des mittelalterlichen Rittertums, die im späten 18. Jahrhundert einsetzte und in der Romantik ihre Vollendung fand, erleichterte diese Neuformulierung eines Ideals des aristokratischen Heros in England sicher-

101 Smith, Nobility Reimagined, S. 195, vgl. Rafe Blaufarb, The French Army 1750-1820. Careers, Talent, Merit, Manchester 2002, S. 12-45.

102 Smith, Nobility Reimagined, S. 204.

103 Craske, Westminster Abbey 1720-1770, S. 66.

$104 \mathrm{Zu}$ den medialen Dimensionen der Verehrung für celebrities im späten 18. Jahrhundert, die keine klassischen Helden mehr waren, siehe Lilti, Figures publiques, S. 84-98. 
lich. ${ }^{105}$ Zwar mochte nicht jeder Land- oder Seeoffizier, wie es Nelson 1776 nach seiner eigenen - späteren - Aussage angeblich tat, sagen: „I will be a hero and confiding in Providence I will brave every danger" ", ${ }^{106}$ aber kein Zweifel kann daran bestehen, dass der „new cult of elite heroism“ in England auch das Verhalten des Einzelnen prägte, ${ }^{107}$ das von einer glorifizierten antiken Überlieferung ebenso wie von den heroischen Gemälden eines Benjamin West oder anderer Maler beeinflusst wurde. Eine Elite, die sich an den Idealen von „patrician valour and self sacrifice" (Linda Colley) orientierte, oder ihr Leben doch zumindest in Übereinstimmung mit diesen Idealen inszenierte, zeigte in den Jahrzehnten nach 1790 eine bemerkenswerte Überlebensfähigkeit, während es dem französischen Adel schon vor der Revolution zunehmend schwer fiel, ein Selbstbild zu formulieren, das mit den neuen Idealen der Aufklärung ohne größere Konflikte zur Deckung gebracht werden konnte. $\mathrm{Zu}$ sehr war das Ideal des grand homme als Gegenentwurf zum traditionellen adligen Heros konzipiert und zu laut waren die Stimmen, die verlangten, der ganzen Nation und ihren Bürgern einen Anteil an jenem Anspruch auf Ehre und Ruhm und damit an der diesem Anspruch entsprechenden heroischen Selbstinszenierung zu geben, der bislang dem Adel vorbehalten gewesen war.

105 Hoock, Empires of the Imagination, S. 181-182; zu vergleichbaren Phänomenen in Frankreich, die allerdings hier auch zu einer spezifischen Verehrung für bürgerliche Helden des Mittelalters, wie eben die Bürger von Calais, führen konnte, siehe Smith, Nobility Reimagined, S. 156-166.

106 Colley, Britons, S. 182. Nelson sprach diese Worte - nach eigenem Zeugnis - als er 1776 (er war damals 16 Jahre alt) von einer Malaria-Erkrankung genas. Allerdings ist dieser Ausspruch nur in einer späteren Biographie des frühen 19. Jahrhunderts überliefert, zu deren Autoren Nelson viel später, 1802, über diese Episode und seine Empfindungen sprach. Siehe dazu Edgar Vincent, Nelson. Love and Fame, New Haven, CT 2003, S. 27; James S. Clarke / John McArthur, The Life and Services of Horatio Viscount Nelson. Duke of Bronte, Vice-Admiral of the White, Bd. 1, London 1840, S. 24. Überliefert ist der Ausspruch in der Form „Well then, I exclaimed 'I will be a hero' and confiding in Providence I will brave every danger".

107 Colley, Britons, S. 182. 


\section{Epilog}

Als Carlyle im Frühjahr 1840 seine Vorlesungen über „Heroes, Hero-Worship and the Heroic in History“ hielt, eröffnete er seine Vorträge mit der Bemerkung: „I am well aware that in these days Hero-Worship, the thing I call Hero-Worship, professes to have gone out, and finally ceased" ${ }^{1}{ }^{1}$ Die Feststellung, die Gegenwart sei ein postheroisches Zeitalter und wahlweise die Klage darüber oder der Ausdruck der Genugtuung über die endgültige Erledigung eines Ideals und eines Lebensentwurfes, die als verstörend empfunden werden, ist also nichts grundsätzlich Neues, auch wenn diese Feststellung in der Vergangenheit oft nur der Ausgangspunkt dafür war, eine Rückkehr zu den heroischen Vorbildern der Vergangenheit zu fordern oder aber die Figur des Helden ganz neu zu definieren, um sie so zu erneuern. In der Tat blieb auch Carlyle bei dieser Aussage nicht stehen, sondern entwarf ein Szenario, das es als möglich erscheinen ließ, aus jedem einzelnen Menschen einen Helden werden zu lassen: „If Hero mean sincere man, why may not every one of us be a Hero?"“ Wenn man von einer solchen Definition des Helden ausgehe, dann sei es durchaus denkbar, dass eine ganze Nation eine "nation of heroes“ werden könne, nämlich ,a believing nation. There needs not a great soul to make a hero; there needs a god-created soul which will be true to its origin“. Eine solche "nation of heroes“ war nach Carlyles Ansicht sein eigenes Volk gewesen, die Schotten, als es in der Zeit der Reformation von John Knox geführt wurde. ${ }^{2}$

Carlyles Verortungen der Figur des Helden in seiner eigenen Epoche zeigen die widersprüchliche Haltung des 19. Jahrhunderts zur Gestalt des Helden, die sich in anderer Form auch noch bis zur Mitte des 20. Jahrhundert finden lässt und in den USA und in Großbritannien in stark abgeschwächter Form vielleicht sogar noch in der Gegenwart, da man sich hier nie vorbehaltlos auf ein postheroisches Selbstbild eingelassen hat. Einerseits kennzeichnet das 19. Jahrhundert eine Klage über den Verlust an heroischer Größe, über eine scheinbar unaufhaltsame Dekadenz, andererseits der Appell an die Nation, zu einem Volk von Helden zu werden. Ein solcher Appell wäre in der ständischen Gesellschaft das Ancien Régime kaum vorstellbar gewesen, denn die heroische Selbstinszenierung war letztlich einer Elite vorbehalten. Insbesondere der kriegerische Held war fast schon notwendigerweise ein Mann von Stand, allenfalls in genossenschaftlich organisierten oder republikanischen Staatswesen wie der Schweiz mochte das anders aussehen. Erst Mitte des 18. Jahrhunderts begann sich diese Einengung der Zuschreibung heroischer Eigenschaften nach ständischen Kriterien partiell aufzulösen, ein Prozess, der jedoch in Frankreich erst durch die Französische Revoluti-

1 Thomas Carlyle, On Heroes, Hero-Worship and the Heroic in History, in: David R. Sorensen / Brent E. Kinser (Hrsg.), Thomas Carlyle. On Heroes, Hero-Worship and the Heroic in History (Rethinking the Western Tradition), New Haven, CT 2013, S. 21-195, hier S. 29.

2 Ebd. S. 112, S. 113. 
on vollendet wurde. Vor der Revolution gab es zwar, um eine Formulierung Herfried Münklers zu verwenden, heroische Gemeinschaften, aber kaum heroische Gesellschaften und hierin lag ein wesentlicher Unterschied. ${ }^{3}$

Die Verbürgerlichung und Demokratisierung der Figur des Helden seit dem späten 18. Jahrhundert hatte und hat eine ambivalente Wirkung: Auf der einen Seite kann nun jeder für sich in Anspruch nehmen, ein potenzieller Held zu sein. Herkunft und das, was man im Englischen ,breeding' nennen würde, spielen dafür keine entscheidende Rolle mehr. Die Selbstvergewisserung mit Blick auf die eigene Heldenrolle erfolgt nun auch nicht mehr wirklich in der Kategorie des Ruhmes, sondern einerseits in der einer sehr viel kurzlebigeren Berühmtheit (célébrité) und andererseits im persönlichen Erleben einer bis zum äußersten gehenden Herausforderung, die im kriegerischen Kampf ebenso bestehen kann wie in anderen Formen der Gefahr, des Opfers oder überhaupt nur einer als extrem empfundenen Lebenssituation. Die Auseinandersetzung mit dieser Herausforderung wird an sich schon als heroische Leistung und zugleich als Prozess der Selbstfindung stilisiert, die heroische Tat als solche tritt im Verhältnis dazu zurück. Damit wird auch dem Umstand Rechnung getragen, dass in einer zunehmend technisierten und komplexer werdenden Welt der Einzelne nur noch eine begrenzte Möglichkeit hat, in entscheidender Weise in das Geschehen einzugreifen und eine rettende Tat von übergreifender Bedeutung zu vollbringen, im Krieg ebenso wie im Frieden. ${ }^{4}$

Diese Ambivalenz zwischen der Banalisierung des Heroischen - sichtbar zum Beispiel auch in den Verfallsformen des politischen Duells in Frankreich im späten 19. und frühen 20. Jahrhundert $-{ }^{5}$ und der omnipräsenten Faszination durch das Heroische, die sich zugleich mit dem Versuch verbindet, heroische Ideale für die Nation oder politische Bewegungen in Dienst zu nehmen, kennzeichnet die europäische Geschichte zwischen Französischer Revolution und dem Ende des Zweiten Weltkrieges fast durchgehend. Seit 1945 scheint hingegen der Gedanke eines heroischen Opfers für die Nation oder eine vergleichbare, mit missionarischem Eifer verfochtene Idee zunehmend diskreditiert zu sein. Das gilt zumindest für die Mehrzahl der europäischen Länder, mag auch Deutschland hier als Hochburg des Postheroischen noch einmal einen Sonderfall bilden. In der Populärkultur bleiben Versatzstücke älterer heroischer Traditionen dennoch oft präsent, auch wenn sie nicht notwendigerweise aus der eigenen Geschichte oder Kultur stammen. Der Umgang mit solchen kulturellen Reminiszenzen mag oft rein spielerisch oder halb-ironisch erscheinen, kann aber in bestimmten Situationen offenbar doch politisch relevant werden. Die Faszination, die von der heroischen Militanz des radikalen Islam ausgeht und die auch Nicht-Muslime in ihren Bann

3 Vgl. Münkler, Heroische und postheroische Gesellschaften.

4 Vgl. Harari, The Ultimate Experience.

5 Vgl. Stephan Geifes, Das Duell in Frankreich 1789-1830. Zum Wandel von Diskurs und Praxis in Revolution, Kaiserreich und Restauration (Pariser Historische Studien; 102), München 2013, S. 303-326. 
schlägt und zur Konversion bewegen kann, erklärt sich zum Teil auf diese Weise. Der radikale dschihadistische Islam bedient jedenfalls offenbar ein Bedürfnis seiner Anhänger zur theatralischen, heroischen Selbstinszenierung. Dass diese Selbstinszenierung in der islamischen Welt so oft in einer gewaltsamen Form erfolgt, mag auch daran liegen, dass die fehlende Demokratisierung der Politik den Heiligen Krieg als die einzig mögliche Bühne für denjenigen erscheinen lässt, der sich selbst als Held sehen will. ${ }^{6}$

Jenseits dieser sehr spezifischen Herausforderung der postheroischen Gesellschaften der Gegenwart durch einen radikalen Gegenentwurf, der ihnen aber vielleicht in seiner sehr modernen Kritik an der Moderne verwandter ist, als ihnen lieb sein kann, bleiben die heroischen Mythen der Vergangenheit in der Gegenwart aber auch noch in anderer Weise präsent. Auch jetzt noch können sie, wie in der Einleitung zu diesem Essay in Anlehnung an Hans Blumenberg betont wurde, als Präfiguration aktueller Entscheidungssituationen interpretiert werden. ${ }^{7}$ Die antiheroische Appeasement-Politik eines Chamberlain in den 1930er Jahren wird auch heute noch regelmäßig herangezogen, wenn es gilt, im Kontrast zu diesem Bild einer vermeintlich jämmerlichen Feigheit eine Haltung der kriegerischen Entschlossenheit zu begründen, gleichgültig, ob es nun um den Irak, die Ukraine oder vielleicht auch den radikalen Islamismus geht. Das leuchtende Gegenbeispiel, dem man folgen will, ist dann der heroische Kämpfer Churchill, der sich seinerseits an der Präfiguration orientiert haben mag, die ihm das Leben des ersten Herzogs von Marlborough, John Churchill, bot (immerhin war er Autor einer Biographie seines Urahnen). ${ }^{8}$ Auf Winston Churchills Beispiel als Präfiguration der Gegenwart zu verweisen, kann noch heute leicht jedes politische Argument ersetzen, obwohl Churchill sich vor 1939/40 eher als archaischer Imperialist ganz alter Schule und

6 Dazu Yassin al-Haj Saleh, Du djihadisme salafiste en tant que phénomène théâtral, http:// souriahouria.com/du-djihadisme-salafiste-en-tant-que-phenomene-theatral-par-yassine-al-hajjsalih/, 20. Juli 2015. Der Autor ist ein früherer Kommunist und syrischer Oppositioneller, der lange Jahre in syrischen Gefängnissen zugebracht hat. Über die Sehnsucht nach dem Heroischen, die die Anhänger des sogennannten Islamischen Staates motiviert, sagt er „Je pense que la base générale de l'ensemble de cette giga-pièce de théâtre, c'est la quête de l'héroïsme ou de la gloire. C'est là une motivation humaine universelle, qui peut pousser à des hauts faits pleins de noblesse ou à des crimes épouvantables. La modernité a généralisé l'hérö̈sme, elle l'a démocratisé. La gloire est produite en masse et le héros peut être n'importe qui. Mais, chez la plupart des Arabes et des musulmans contemporains, la production d'hérö̈sme est de piètre qualité: les militaires héroïques se comptent sur les doigts d'une main, la littérature et l'art permettent rarement de gagner sa croûte. Les sportifs de haut niveau sont extrêmement peu nombreux, le sport professionnel étant aujourd'hui une question d'industrie et d'investissement. La lutte politique est universellement réprimée et coûte extrêmement cher".

7 Siehe S. 15.

8 Der englisch-amerikanische Film „The Gathering Storm“ von 2002 (Regie: Richard Loncraine), der Churchills Kampf gegen die Appeasement-Politik Chamberlains darstellt, beginnt im Übrigen mit einer Szene, in der Churchill in einer Art Vision oder Traum seinen Vorfahren, den Herzog vom Marlborough, auf einem Schlachtfeld (wohl dem von Höchstädt / Blenheim) sieht. Marlboroughs Kampf gegen Frankreich erscheint hier explizit als die Präfiguration von Churchills Kampf gegen das Deutschland Hitlers. 
als politisch-militärischer Vabanquespieler einen Namen gemacht hatte, aber diese Schattenseiten werden durch den Mythos des heroischen Siegers überstrahlt.

In Ländern mit politischen Kulturen, die stark durch den Rekurs auf heroische Gründungsväter, Gesetzgeber und Stifter einer neuen Ordnung, eines novus ordo saeclorum, konstituiert werden, wie das besonders für die USA gilt, kann in ähnlicher Weise die Beschwörung der großen Taten und des Lebens einer dieser Figuren, sei es nun Lincoln, der noch jüngst (2012) von Spielberg in einem Historiendrama ganz affirmativ verherrlicht wurde, oder seien es Washington und Jefferson, jeder Diskussion eine neue Wendung geben. Diese persuasive Kraft der heroischen Präfiguration ist also auch in einem Zeitalter, in dem sich kaum eine westliche Nation noch als explizit heroische Gesellschaft definiert, keineswegs ganz verschwunden. Allerdings gibt es Nationalstaaten, in denen es schwerfällt oder gänzlich unmöglich ist, auf solche Mythen zurückzugreifen - und Deutschland gehört sicherlich zu diesen Staaten -, aber in diesem Fall kann man durchaus Anleihen bei der Geschichte anderer Nationen machen, die scheinbar oder wirklich gradliniger verlaufen ist.

Der Carlylesche Appell an eine „nation of heroes“ erscheint uns heute dennoch befremdlich und ist durch die Exzesse des Nationalismus in der ersten Hälfte des 20. Jahrhunderts diskreditiert, obwohl Carlyle bei seiner "nation of heroes" nicht primär an den kriegerischen Heroismus gedacht hatte. Vorbild für das Carlylesche Volk von Helden waren ja nicht etwa die antiken Spartiaten oder die revolutionären Volksmassen Frankreichs in den 1790er Jahren, sondern das Schottland der 1560er Jahre. Das Heroische lag hier weniger in der Bereitschaft zum militärischen Kampf - was nicht heißt, dass das Schottland des 16. Jahrhunderts eine friedliche Gesellschaft gewesen wäre -, sondern im Bekenntnis zur eigenen religiösen Überzeugung und in der Entschlossenheit, das gesamte Leben an dieser Überzeugung auszurichten. Die religiöse Leidenschaft und das Religiöse an sich nahmen in Carlyles Vorträgen ohnehin einen großen Raum ein, denn er eröffnete sie mit langen Ausführungen über „The Hero as Divinity“, an die sich ein Abschnitt über „The Hero as Prophet“ anschloss, in dessen Mittelpunkt der Prophet Mohammed und der Islam standen. Carlyles Bemerkungen zum Islam waren genauso subjektiv gefärbt wie die anderen Abschnitte seiner Abhandlung über Helden, aber sie zeigten immerhin eine für die damalige Zeit eher ungewöhnliche Bereitschaft, den Islam als geistige Kraft ernst zu nehmen, und antizipieren zugleich bis zu einem gewissen Grade die Spannungen des späten 20. und frühen 21. Jahrhunderts, die sich, wie bereits betont, zum Teil auch durch den Gegensatz zwischen religiösen Bewegungen im Islam, welche die heroische Vergangenheit der eigenen Religion noch nicht ad acta gelegt haben, und den postheroischen Gesellschaften des Westen erklären. ${ }^{9}$

9 Vgl. David R. Sorensen, In Defence of "Religiosity": Carlyle, Mahomet and the Force of Faith in History, in: David R. Sorensen / Brent E. Kinser (Hrsg.), Thomas Carlyle. On Heroes, Hero-Worship and the Heroic in History (Rethinking the Western Tradition), New Haven, CT 2013, S. 209-221. 
In der Frühen Neuzeit Europas war der Versuch, über alle Standesunterschiede hinweg eine ganze Gesellschaft auf einen Lebensentwurf der heroischen Frömmigkeit auszurichten, wie es John Knox in Schottland ebenso versuchte wie die Prediger und Theologen der Katholischen Liga in Paris und zum Teil auch sonst in Frankreich in der Endphase der Religionskriege, freilich eher die Ausnahme als die Regel. Dort, wo er unternommen wurde, wohnte ihm eine erhebliche subversive Kraft inne, wie Maria Stuart ebenso wie Heinrich III. erfahren mussten, auch wenn die schottische Königin in Schottland noch mit dem Leben davon kam und erst im Exil 20 Jahre nach der Flucht aus ihrer Heimat hingerichtet wurde. Der religiöse Radikalismus der schottischen Presbyterianer ebenso wie der der Heiligen Liga in Frankreich stellte die Autorität der weltlichen Obrigkeit infrage. Ihn zu kanalisieren und zu sublimieren war - wie wir gesehen haben - die Herausforderung, vor der monarchische Herrschaft in der ersten Hälfte des 17. Jahrhundert stand. In Frankreich gelang das bis zu einem gewissen Grade, in England deutlich weniger gut. Eine subversive Kraft konnte aber nicht nur eine religiöse Gemeinschaft mit dem Anspruch entfalten, eine ganze Nation in eine heroische Gesellschaft zu verwandeln, sondern auch Einzelne, die für sich eine besondere Mission beanspruchten. Die Selbstmordattentäter, denen Heinrich III. und Heinrich IV. von Frankreich zum Opfer fielen, waren solche Helden des Widerstandes gegen einen häretischen Tyrannen, jedenfalls aus der Sicht ihrer Anhänger. Und weil sie heroische Figuren waren, „homines a deo excitati“", ${ }^{10}$ war ihnen das gestattet - so zumindest sahen es die Vertreter einer konfessionellen Militanz -, was normalen Sterblichen nicht erlaubt war, nämlich einen gesalbten Monarchen anzugreifen und zur Rechenschaft zu ziehen.

,Helden' des Widerstandes wie Jacques Clément oder Ravaillac oder andere heroische Figuren, denen das Recht zur "single rebellion“ - wie Milton es in einem protestantischen Kontext formulierte - zugeschrieben wurde, ${ }^{11}$ mochten absolute Ausnahmeerscheinungen sein, aber auch der adlige Held war nicht ohne Spannungen in das frühneuzeitliche System monarchischer Herrschaft integrierbar. Die Konflikte zwischen Elisabeth I. und ihren männlichen Höflingen, zu denen Philip Sidney ebenso wie der zweite Earl Essex gehörten, zeigen recht deutlich, dass das Charisma des heroischen Kriegers oder des Adligen, der sich erfolgreich als solcher stilisierte, für eine Herrscherin, die ihre Truppen nicht selbst in die Schlacht führen konnte, oder aber später für einen König wie Jakob I., der nicht dazu gewillt war und sich selbst lieber als rex pacificus darstellte, eine erhebliche Herausforderung war.

10 Zur Figur des vir heroicus als Tyrannenmörder siehe Robert von Friedeburg, Bausteine widerstandsrechtlicher Argumente in der frühen Neuzeit (1523-1668): Konfessionen, klassische Verfassungsvorbilder, Naturrecht, direkter Befehl Gottes, historische Rechte der Gemeinwesen, in: Christoph Strohm / Heinrich de Wall (Hrsg.), Konfessionalität und Jurisprudenz in der frühen Neuzeit (Historische Forschungen; 89), Berlin 2009, S. 115-166, hier S. 143-146.

11 R. W. Serjeantson, Samson Agonistes and 'Single Rebellion', in: Nicholas McDowell / Nigel Smith (Hrsg.), The Oxford Handbook of Milton, Oxford 2009, S. 613-631. 
Das Problem, vor dem die Herrscher Frankreichs ebenso wie Englands standen, war, den heroischen Adligen in die bestehende politische Ordnung zu integrieren, ohne ihm seine Aura ganz zu nehmen, denn dann wurde er für diese Ordnung als Symbolfigur wertlos. In Frankreich gelang dies nach der Fronde bis zu einem gewissen Grade. Männer wie Condé mochten auch noch unter Ludwig XIV. über subtile Methoden verfügen, um auch jene Heldentaten im Bewusstsein der Zeitgenossen präsent zu halten, die sie nicht im Dienst der Krone, sondern gewissermaßen auf eigene Faust, wenn nicht sogar im Konflikt mit der Krone vollbracht hatten. Aber offiziell galt nun der König als die alle anderen überragende heroische Figur - und dies in Zweifel zu ziehen, war riskant. Zwar bestand, wie wir gesehen haben, gerade im Krieg weiter ein Bedarf an adligen Helden, auch an solchen, die ihren Glanz gerade dem Umstand verdankten, dass sie sich in entscheidenden Momenten nicht an die Regeln der Disziplin hielten, sondern eher die Maßlosigkeit der heroischen Tat verkörperten. Aber es war dennoch deutlich schwieriger geworden, sich selbst öffentlich als Held zu inszenieren. Das galt grundsätzlich für England ebenso wie für Frankreich, aber in England trugen die neuen Vorstellungen von politeness und das gentleman-Ideal des frühen 18. Jahrhunderts doch dazu bei, den adligen Helden, der allzu leicht mit dem restoration rake assoziiert werden konnte - jedenfalls in seiner royalistischen Variante -, mit den Umgangsformen der urbanen commercial society zu versöhnen. Die Figur des gentleman war in ihrer sozialen Verortung unscharf genug, um die heroische Selbstinszenierung nicht als ausschließliches Privileg einer Kriegerkaste erscheinen zu lassen.

Im Kontext der verstärkten Suche nach Nationalhelden, in denen die Nation sich wiederzuerkennen vermochte, veränderten sich freilich auch in England die maßgeblichen Modelle des Heroischen. Die eine große Tat und der heroische Tod konnten jetzt wichtiger werden als eine in sich konsistente brillante Karriere oder die von Geburt an sichtbare und bei allen Gelegenheiten demonstrierte Überlegenheit. In der Zeit der Kriege gegen Frankreich brachte die eingeschränkte Monarchie England dann ihren eigenen Typus des Helden hervor, für den nicht zuletzt charakteristisch war, dass er nach vollbrachter Tat in das zivile Leben zurückkehrte, - dass er zwar nicht wie ein Washington zum bloßen Bürger wurde, aber doch zu einem Gleichen unter Gleichen innerhalb der Elite, die das Land regierte. ${ }^{12}$ Dafür war nicht zuletzt der Herzog von Wellington zu Beginn des 19. Jahrhunderts ein bezeichnendes Beispiel. Indem man seine Biographie entsprechend retuschierte, konnte aus dem anglo-irischen Adligen und aus einem Militär mit zum Teil eher rustikalen Umgangsformen eine nationale Symbolfigur werden, in der ein spezifisch englisches Ideal von Männlichkeit ebenso seine Verkörperung fand wie die viktorianische Vision einer neuen muscular Cbristianity. ${ }^{13}$

12 Vgl. Iain Pears, The Gentleman and the Hero: Wellington and Napoleon in the Nineteenth Century, in: Roy Sydney Porter (Hrsg.), Myths of the English, Cambridge 1992, S. 216-236.

13 Peter W. Sinnema, The Wake of Wellington: Englishness in 1852, Athens, OH 2006. Zur Verbindung von evangelikalem Christentum und Bellizismus siehe Leonhard, Bellizismus 
Wellington war ein Schlachtensieger, der sich nach 1815 in den Alltag der englischen Politik integriert hatte, sogar kurzfristig das Amt des Premierministers bekleidete und dabei immerhin das Gesetz zur Katholikenemanzipation durch das Parlament brachte. Diese Reintegration des Helden in den Alltag gelang dem revolutionären Frankreich hingegen mit Napoleon gerade nicht. Und die Spannungen zwischen heroisierten Führerfiguren mit cäsaristischen Ambitionen, von Napoleon Bonaparte über Napoleon III. bis hin zu General Boulanger (gest. 1891) oder, wenn man so will, auch bis zu Pétain und De Gaulle, und einem Verfassungsgefüge, das wahlweise von gänzlich unheroischen Monarchen wie Ludwig XVIII. und dem Bürgerkönig oder politischen Funktionären bzw. bourgeoisen Provinzhonoratioren dominiert wurde, blieben ein Charakteristikum der politischen Kultur Frankreichs von der napoleonischen Zeit bis in die 60er Jahre des vergangenen Jahrhunderts. Auch hier waren Helden nationale Symbolfiguren, aber aufgrund der inneren Spaltung des Landes seit den 1790er Jahren konnten sich fast nie alle Franzosen mit ihnen identifizieren. Oft spaltete der Heldenkult eher statt zu integrieren und noch heute hat jede politische Richtung ihre eigenen politischen Helden und Heldinnen von Jeanne d'Arc und Chlodwig - vielleicht auch Ludwig XIV. - auf der einen Seite bis hin zu Robespierre oder Jean Jaurés und Dreyfus auf der anderen Seite.

Ein Problem, das Frankreich und England im 18. Jahrhundert jedoch teilten, war, überhaupt eine angemessene Bild- und Stilsprache für den Ausdruck heroischer Größe zu finden. Sollte man weiter auf das Repertoire römischer und generell antiker Helden zurückgreifen oder den Heros eher im zeitgenössischen Gewand darstellen, das seine Tat freilich auch leicht relativieren und banalisieren konnte, oder doch Anleihen bei der Welt des Rittertums machen? Für dieses Problem fand das Ancien Régime keine angemessene Lösung mehr und es ist in der Gegenwart vielleicht aktueller denn je, da Antike und Mittelalter nun endgültig ihre Vorbildfunktionen verloren haben.

Auch diese allmähliche Selbstauflösung des traditionellen rhetorischen und bildlichen Vokabulars der Heroisierung gestattet es dann doch, für das 18. Jahrhundert, wenn schon nicht von einer Krise des Heroischen schlechthin - dem würde die prononcierte Konstruktion eines Kanons von Nationalhelden widersprechen, die seit der Mitte des 18. Jahrhunderts mit Nachdruck betrieben wurde -, so doch von der Abenddämmerung des traditionellen aristokratischen Heros zu sprechen, die daher auch ein Grundthema dieser Studie ist. Wie problematisch traditionelle Formen der heroischen Selbstinszenierung des Adels geworden waren, macht vor allem ein Blick auf das Duell deutlich. Dem Duell kam seit dem 16. Jahrhundert eine besondere Bedeutung als Praxis adliger Selbstbehauptung zu, in der heroische Entschlossenheit und Mut (valeur) demonstriert werden konnten. Am Ende, hier

und Nation, S. 469-472; vgl. ferner Donald E. Hall (Hrsg.), Muscular Christianity. Embodying the Victorian Age, Cambridge 1994. 
kann man Hervé Drévillon folgen, blieb vom Duell, zu dem man sich nicht mehr offen bekennen konnte, schon im späten 17. und noch mehr im 18. Jahrhundert allerdings nur noch die Gewalt als solche übrig. ${ }^{14}$ Nur noch durch die nackte Gewalt - die selbst praktizierte, aber auch die Bereitschaft, sich der Gefahr eines gewaltsamen Todes im Kampf Mann gegen Mann auszusetzen - ließ sich die Glaubwürdigkeit des heroischen Lebensentwurfes unter Beweis stellen. Ein Diskurs, der diese soziale Praxis öffentlich hätte rechtfertigen können, stand aber faktisch nicht mehr zur Verfügung, denn Duelle, die in aller Öffentlichkeit stattfanden und explizit als Manifestation adliger Autonomie gerechtfertigt wurden, waren ab der zweiten Hälfte des 17. Jahrhunderts in Frankreich kaum noch möglich: „La valeur illustrée par le duel ne fonctionne vraiment que lorsqu'elle échappe à toute forme de reconnaissance." ${ }^{15}$ Schon bevor die von der Aufklärung vorgenommene Neudefinition heroischer Größe in Gestalt des grand homme den aristokratischen Helden infrage stellte oder zumindest seine Zähmung einforderte, sahen sich die Vertreter traditioneller Vorstellungen von adliger valeur und générosité somit genötigt, sich und ihre Wertvorstellungen gewissermaßen schweigend durch die bloße Tat in der gewaltsamen persönlichen Auseinandersetzung zu artikulieren.

Diese Praxis des Duells im 18. Jahrhundert lässt auf ihre Weise deutlich werden, vor welchen Problemen Gesellschaften stehen können, die für die heroische Selbstinszenierung von Eliten oder auch von anderen gesellschaftlichen Gruppen oder gar von Individuen nur einen eng begrenzten und reglementierten oder gar keinen Raum mehr bieten und auf diese Weise den Helden bzw. diejenigen, die sich dem Ideal einer imitatio heroica verpflichtet fühlen, letztlich sozial und kulturell marginalisieren. Sie geraten in Gefahr, eine Subkultur hervorzubringen, und unter Umständen eben auch eine Subkultur der Gewalt. Nun stellte das Duell des 18. Jahrhunderts die staatliche Ordnung nicht mehr wirklich infrage und wurde sogar stillschweigend geduldet. $\mathrm{Ob}$ dies - die relative Harmlosigkeit eines sich eher im Verborgenen in spezifischen sozialen Praktiken manifestierenden Gegenentwurfes zu den offiziellen Regeln - freilich für die Subkulturen heroischer Gewalt und einer aggressiven Männlichkeit, die es in den Gesellschaften der Gegenwart durchaus gibt, auch gilt, muss man dahingestellt sein lassen. ${ }^{16}$ Indem diese Gesellschaften vor allem in Kontinentaleuropa glauben, ganz ohne heroische Leitbilder jenseits der Sphäre der Unterhaltungsindustrie und der Populärkultur auskommen zu können, riskieren sie möglicherweise auch die Kontrolle über das über Jahrhunderte hinweg stets präsente subversive Potenzial heroischer Lebensmodelle zu verlie-

14 Drévillon, Le dire et le fer, S. 239-304, hier S. 303: „De cette pratique désormais inaccessible au discours, il ne reste plus que la violence. C'est-à-dire l'essentiel“".

15 Ebd., „Der Mut, der durch das Duell demonstriert wird, kann sich auf diese Weise nur zeigen, wenn er sich jeder öffentlichen Anerkennung entzieht.“

16 Vgl. Ahmet Toprak / Aladin El-Mafaalani, Eine Frage der Männlichkeit. Duelle bei muslimischen Jugendlichen in Deutschland, in: Ulrike Ludwig [et al.] (Hrsg.), Das Duell. Ehrenkämpfe vom Mittelalter bis zur Moderne, Konstanz 2012, S. 49-60. 
ren. Dass Helden Grenzgänger sind zwischen der Ordnung und den Werten, die sie verteidigen und verkörpern sollen, und der Revolte gegen eben diese Ordnung und diese Werte ist ja nichts grundsätzlich Neues und keine Entdeckung des 20. oder 21. Jahrhunderts, nur dass es der Gegenwart schwerer fällt als der Vergangenheit, mit diesem Grenzgängertum umzugehen. Damit werden jedoch auch jene Gruppen innerhalb der Gesellschaft zumindest in der eigenen Wahrnehmung marginalisiert, die gewissermaßen berufsbedingt darauf angewiesen sind, ihre gesellschaftliche Rolle durch den Bezug auf Modelle des Heroischen zu definieren, die ihr transgressives Potenzial nicht ganz verloren haben, wie es sich in der Affinität zu Gewalt und Gewalterfahrung, aber auch generell zum Tod zeigt. Das gilt etwa für das Militär, ganz besonders in einem Land wie Deutschland. Klagen darüber, in einer Gesellschaft zu leben, die dominiert sei vom „Misstrauen ,gegenüber jedem kriegerischem Altruismus“" und von der „Entzauberung des Helden an sich““, kennzeichnen die tiefe Entfremdung, die sich mittlerweile zum Beispiel zwischen Berufsoffizieren und der Gesellschaft, die sie theoretisch verteidigen sollen, ausgebreitet hat. ${ }^{17}$ Lapidar hat der Autor eines Beitrages in einem jüngst erschienenen einschlägigen Sammelband festgestellt: „Es findet [in der postheroischen Gesellschaft der Gegenwart, R. G. A.] eine Entzauberung des Helden an sich statt, welche auch eine fehlende Akzeptanz militärischer Verluste mit sich trägt. Diese werden nicht mehr als heroische Opfer, als Märtyrer sozusagen, betrachtet, sondern als tragische Opfer, als Victima.“ Und im selben Beitrag heißt es: „Die postheroische Gesellschaft ist nicht mehr in der Lage, sich mit dem Tod von Soldaten auseinanderzusetzen. Der Dienst am eigenen Land wird immer kritischer gesehen, gleichzeitig werden eigene Tote als Zeichen einer Niederlage gedeutet. [...] Der Tod wird vor allem mit der Gefahr einer Niederlage verbunden, weniger mit Solidarität." ${ }^{18}$

Nun ist die Klage der Vertreter militärischer Eliten über die mangelnde Anerkennung, die ihnen von einer Gesellschaft zuteilwird, die sich ihren Idealen nicht verpflichtet weiß, immer schon weit verbreitet gewesen, wie dies ja auch diese knappe Studie gezeigt hat. Sie findet sich bei Philip Sidney und dem zweiten Earl of Essex und den Protagonisten der Fronde ebenso wie später beim Herzog von Marlborough, dessen Karriere von seinen politischen Gegnern dem Ziel eines raschen Friedens mit Frankreich geopfert wurde. Das postheroische Selbstbild der europäischen oder zumindest kontinentaleuropäischen Gesellschaften der Gegenwart hat hier aber doch noch einmal eine neue Situation geschaffen. Bedeutsamer

17 Gerald Wagner, Keiner weiß, wie der Landser tickt, in: Frankfurter Allgemeine Zeitung, 25. Februar 2015, S. N 4. Es handelt sich um eine Auseinandersetzung mit dem Buch: Marcel Bohnert / Lukas J. Reitstetter (Hrsg.), Armee im Aufbruch: Zur Gedankenwelt junger Offiziere in den Kampftruppen der Bundeswehr, Berlin 2014. Einfache Anführungsstriche kennzeichnen Zitate aus dem Buch, doppelte aus dem Zeitungsartikel.

18 Jan-Philipp Birkhoff, Führen trotz Auftrag. Zur Rolle des militärischen Führers in der postheroischen Gesellschaft, in: Marcel Bohnert / Lukas J. Reitstetter (Hrsg.), Armee im Aufbruch. Zur Gedankenwelt junger Offiziere in den Kampftruppen der Bundeswehr, Berlin 2014, S. 105-128, hier S. 108, S. 125. 
vielleicht als die Klagen von Soldaten über die mangelnde Anerkennung ihrer Rolle ist dabei aber der Umstand, dass die Werteordnung dieser Gesellschaften langfristig durch einen Gegenentwurf, der seine persuasive Kraft aus ganz anderen kulturellen Traditionen als den westlichen bezieht, herausgefordert werden könnte. Ihre eigenen, so stark auf den Kult des leidenden Opfers fokussierten Ideale und die mit diesen Idealen verbundenen Ordnungsvorstellungen könnten sehr viel nachhaltiger infrage gestellt und destabilisiert werden, als uns dies heute noch möglich erscheint. Denn am Ende mag „la quête de l'héroïsme ou de la gloire“ (,die Suche nach Heroismus oder Ruhm") eben doch eine Konstante der menschlichen Verortung in dieser Welt sein, ebenso wie das Bemühen, die Welt zur Bühne dieser performativen, Realität und Theater zur Deckung bringenden Selbstinszenierung werden zu lassen, auch wenn dies keine in jeder Hinsicht beruhigende Erkenntnis für eine Gesellschaft ist, die bis vor kurzem glaubte, Begriffe wie Opferbereitschaft und Heldentum, soweit sie nicht von ihren transgressiven Elementen gänzlich gereinigt und den Erwartungen einer eigentlich postheroischen Kultur angepasst waren, für immer hinter sich gelassen zu haben. ${ }^{19}$

19 Vgl. al-Haj Saleh, Du djihadisme salafiste en tant que phénomène théâtral. 


\section{Quellen- und Literaturverzeichnis}

\section{Quellen}

Matthieu d'Abbeville, Discours funebre en l'honneur de Roy Henry le Grand, Paris 1610.

Thomas Abbt, Vom Tode für das Vaterland. Neue vermehrte und verbesserte Auflage, in: Thomas Abbt, Vermischte Werke, Bd. 2, Berlin 1770, S. 1-103.

Jacques Baron, Origine, généalogie et démonstration de ceste excellente, et héroïque maison de Lorraine, et Guyse en dependente. Avec les martyrs de Henry et Louys, Duc et Cardinal de Guise, Paris 1589.

Pierre Bertier, Evesque coadjuteur de Montauban, Docteur de Sorbonne. Oraison funèbre du roy Louis le Juste, prononcée en l'eglise de Sorbonne 1643, Paris 1644.

Jacques du Bosc, La femme hérö̈que, Paris 1645.

Jacques Bénigne Bossuet, Oraison funèbre de tres-haut et tres-puissant prince Louis de Bourbon, prince de Condé, premier prince du sang. Prononcée dans l'église de Nostre-Dame de Paris, le 10. jour de mars 1687, Paris 1687.

Jean Boucher, Apologie pour Iehan Chastel. Parisien, executé à mort, par François de Verone Constantin [Pseudonym für Jean Boucher], Teil II, [s. 1.] 1610.

Pierre-Laurent Buirette de Belloy, Le siège de Calais, in: Jacques Truchet (Hrsg.), Théâtre du XVIIIe siècle, Bd. 2, Paris 1974, S. 447-516.

Gilbert Burnet, History of His Own Time, Bd. 1, London 1724.

Jeremiah Burroughs, The Glorious Name of God, the Lord of Hosts. Opened in Two Sermons, London 1643.

Henry Burton, The Sounding of the Two Last Trumpets, the Sixth and Seventh or Meditations by Way of Paraphrase upon the $9^{\text {th }}, 10^{\text {th }}$ and $11^{\text {th }}$ Chapters of the Revelation, as Containing a Prophecie of these Last Times, London ${ }^{2} 1641$.

Cabala sive scrinia sacra: Mysteries of State and Government in Letters of [...] Great Ministers of State, London 1691.

Thomas Carlyle, On Heroes, Hero-Worship and the Heroic in History, in: David R. Sorensen / Brent E. Kinser (Hrsg.), Thomas Carlyle. On Heroes, HeroWorship and the Heroic in History (Rethinking the Western Tradition), New Haven, CT 2013, S. 21-195.

Charles Irénée Castel de Saint-Pierre, Discours sur les différences de Grand Homme de l'Homme Illustre, in: Abbé Seran de La Tour, Histoire de Scipion l'Africain, Paris ${ }^{21752}$, S. XXI-XLIV.

René de Ceriziers, Le Héros français ou l'idée du grand capitaine, Paris 1645.

Gatien de Courtilz de Sandras, Mémoires de M. d'Artagnan, capitaine-lieutenant de la première Compagnie des Mousquetaires du Roi, 3 Bde., Köln 1701-1702. 
Jim Daems / Holly F. Nelson (Hrsg.), Eikon Basilike. The Portraiture of his Sacred Majesty in his Solitudes and Sufferings with Selections from Eikonoklastes, John Milton, Plymouth 2006.

George Etherege, The Man of Mode, hrsg. von John Barnard, New York 1979.

André Félibien, Le portrait du roi, in: André Félibien, Description des divers ouvrages de peinture faits pour le roi, Paris 1671, S. 83-112.

Esprit Flechier, Abbé de Saint-Séverin, Oraison funèbre de tres haust et trespuissant Prince Henri de la Tour d'Auvergne, Vicomte de Turenne, Paris 1676.

Thomas Goodwin, A Glimpse of Sion's Glory, or the Churches Beautie Specified (Published for the Good and Benefit of all Those whose Hearts are Raised up in the Expectation of the Glorious Liberties of the Saints.), London ${ }^{2} 1641$.

Fulke Greville, Baron Brooke. The Life of the Renowned Sir Philip Sidney, o.O. 1652 (Nachdr. Delmar, NY 1984).

Georg Friedrich Wilhelm Hegel, Vorlesungen über die Ästhetik, Bd. 1, hrsg. von Eva Moldenhauer und Karl M. Michel, Frankfurt am Main 1970.

Jacques Antoine Hippolyte, Comte de Guibert, Éloge du Maréchal Catinat (Exemplar BN, Arsenal 8to BL 3068, nr. 3), Edinburgh 1775.

François Hotman, Franco-Gallia, in: Jürgen Dennert (Hrsg.), Beza, Brutus, Hotman. Calvinistische Monarchomachen (Klassiker der Politik; 8), Köln 1968, S. 203-327.

David Hume, Of Refinement in the Arts, in: David Hume, Essays, Moral, Political, and Literary, hrsg. von Eugene F. Miller, Indianapolis, IN 21987, S. 268-280.

Lucy Hutchinson, Memoirs of the Life of Colonel Hutchinson, hrsg. von Neil H. Keeble, London 1995.

Cornelis Jansen, Alexandri Patricii Armancani. Mars Gallicus, editio novissima, o.O. 1639 (1. Aufl. 1635).

Jacques de La Baune, Laudatio funebris Ludovici Borbonii, principis Condaei, [...] dicta die 17 Kal. Maii an. 1687 in regio Ludovici Magni collegio, Paris 1687.

Jean-François de La Harpe, Éloge de Nicolas de Catinat, Maréchal de France, Paris 1775.

François de Salignac de La Mothe-Fénelon, Les aventures de Télémaque, hrsg. von Jeanne-Lydie Goré, Paris 1987.

Pierre Le Moyne, Saint Louys ou la sainte couronne reconquise, Poème hérö̈que, Paris 1658.

Ders., Gallerie des femmes fortes, Paris 1647.

William Leigh, Queene Elizabeth Paralleld in her Princely Vertues with David, Iosua and Hezekia [...] in three Sermons, London 1612.

Louis-Sébastian Mercier, Tableau de Paris, 12 Bde., Amsterdam 1782-88.

John Milton, Eikonoklastes, in: Jim Daems / Holly F. Nelson (Hrsg.), Eikon Basilike. The Portraiture of his Sacred Majesty in his Solitudes and Sufferings with Selections from Eikonoklastes, John Milton, Plymouth 2006, S. 217-283. 
Ders., A Second Defense of the English People, in: John Milton, Complete Prose Works, Bd. 4, 1650-1655, hrsg. von Don M. Wolfe, New Haven, CT 1966, S. 538-686.

Ders., The Works of John Milton, Historical, Political, and Miscellaneous, Bd. 2, London 1753.

Juan Mariana, De Rege et eius institutione, Toledo 1599.

Andrew Marvell, The Poems of Andrew Marvell, hrsg. von Nigel Smith, Edinburgh 2007.

John Ogilby, The Entertainment of His Most Excellent Majestie Charles II in His Passage through the City of London to His Coronation [London 1662], hrsg. von Ronald Knowles, New York 1988.

Charles Pincelet, Le martyre de frère Jacques Clément de l'ordre S. Dominique, Troyes 1589.

John Quarles, Regale Lectum Miseriae, London 1649.

Charles François Abra de Raconis, Discours funèbre, panegyrique et histoire sur la vie et vertus, la maladie et la mort du Roy très-chretien. Prononcé le 19 et 20 Juin [...], Paris 1643.

René Rapin, Le Magnanime, ou l'Éloge du Prince de Condé, premier prince du sang, Paris ${ }^{2} 1690$.

Ders., Du grand ou du sublime dans les moeurs et dans les différentes conditions des hommes, Paris 1686.

Remarks upon Remarques or a Vindication of the Conversations of the Town, in Another Letter Directed to the Same Sir T. L., London 1673.

Remarques on the Humours and Conversations of the Town, London 1673, (Nachdr., Drydeniana II, NY 1974).

Charles de Saint-Sixt, Sermon funèbre prononcée en l'église cathédrale de Riez, au service du grand et auguste Henri IIII, Paris 1610.

François de Sales, Oraison funèbre de Philippe-Emmanuel de Lorraine, duc de Mercœur et de Penthièvre, in: François de Sales, Les Épistres spirituelles du bien-heureux François de Sales, [...] avec l'oraison funèbre de M. le duc de Mercoeur, recueillies par Messire Louys de Sales, Lyon 1628, S. 1020-1051.

Henry Savile, The End of Nero and Beginning of Galba. Foure Bookes of the Histories of Cornelius Tacitus, The Life of Agricola, London 1612.

Jean-François Senault, Harangues funèbres de Louis le Iuste Roy de France et de Nauarre, et de la Royne sa mère Marie de Medicis. Prononcées dans l'Eglise Cathedrale de Sainte Croix d'Orléans, par le père Jean-François Senault, Prestre de l'Oratoire, Paris 1643.

Abbé Seran de La Tour, Histoire de Scipion l'Africain, Paris ${ }^{2} 1752$.

Robert South, Twelve Sermons Preached upon Several Occasions, London 1692.

Joshua Sprigge, Anglia Rediviva, London 1647. 
Richard Steele, The Christian Hero. An Argument Proving that no Principles but those of Religion are Sufficient to Make a Great Man, London ${ }^{7} 1722$.

Dominique Thibaut, Oraison funebre faite et pronounce à Paris en l'eglise de Saint Germain l'Auxerrois, Paris 1610.

Jacques Auguste de Thou, Historia sui temporis, Bd. 4, London 1733.

George Villiers Duke of Buckingham, The Rehearsal, hrsg. von D. E. L. Crane, Durham 1976.

François Vrevin S. J., Oraison funèbre prononcée en l'eglise de Rouen aux funerailles [...], Rouen 1610.

Edward Walsingham, Alter Britanniae Heros, Oxford 1645.

Ders., Britannicae Virtutis Imago, Oxford 1644.

John Wilmot, The Letters of John Wilmot, Earl of Rochester, hrsg. von Jeremy Treglown, Oxford 1980.

Ders., The Complete Poems of John Wilmot, Earl of Rochester, hrsg. von David M. Vieth, New Haven, CT 1968.

\section{Literatur}

Sharon Achinstein, Milton and King Charles, in: Thomas N. Corns (Hrsg.), The Royal Image. Representations of Charles I, Cambridge 1999, S. 141-161.

John S. A. Adamson, The Noble Revolt. The Overthrow of Charles I, London 2007.

Ders., Chivalry and Political Culture in Caroline England, in: Kevin Sharpe / Peter Lake (Hrsg.), Culture and Politics in Early Stuart England (Problems in Focus), Basingstoke 1994, S. 161-198.

Geoffrey Aggeler, "Sparkes of Holy things". Neostoicism and the English Protestant Conscience, in: Renaissance and Reformation 14, Heft 3, 1990, S. 223-240.

Thomas P. Anderson / Ryan Netzley (Hrsg.), Acts of Reading. Interpretation, Reading Practices, and the Idea of the Book in John Foxe's Actes and Monuments, Newark, Del. 2010.

Jean-Marie Apostolidès, Héroïsme et victimisation. Une histoire de la sensibilité, Paris 2003.

Paul Arblaster, Antwerp and the World. Richard Verstegan and the International Culture of Catholic Reformation (Avisos de Flandes; 9), Löwen 2004.

David Armitage [et al.] (Hrsg.), Milton and Republicanism (Ideas in Context; 35), Cambridge 1998.

Ronald G. Asch, Die Kunst des Regelbruchs. Adlige Libertins in der Epoche der Restauration in England, ca. 1660-1688, in: Christian Wieland / Claudius Sittig (Hrsg.), Die Kunst des Adels in der Frühen Neuzeit, im Druck.

Ders., Sacral Kingship Between Disenchantment and Re-enchantment. The French and English Monarchies 1587-1688, New York 2014. 
Ders., The Hero in the Early Modern Period and Beyond. An Elusive Cultural Construct and an Indispensable Focus of Social Identity?, in: helden. heroes. héros. E-Journal on Cultures of the Heroic, Special Issue 1, 2014, S. 5-14, DOI 10.6094/helden.heroes.heros./2014/QM/02.

Ders., Märtyrer, Mörder und Monarchen. Das Königtum zwischen Heroismus und Heroismus-Defizit. Ein Vergleich zwischen England und Frankreich (1589-1628), in Achim Aurnhammer / Manfred Pfister (Hrsg.), Heroen und Heroisierungen in der Renaissance (Wolfenbütteler Abhandlungen zur Renaissanceforschung; 28), Wiesbaden 2013, S. 283-302.

Ders., Heros, Friedensstifter oder Märtyrer? Optionen und Grenzen heroischen Herrschertums in England ca. 1603-1660, in: Martin Wrede (Hrsg.), Die Inszenierung der Heroischen Monarchie. Frühneuzeitliches Königtum zwischen ritterlichem Erbe und militärischer Herausforderung (Historische Zeitschrift, Beihefte N.F.; 62), München 2014, S. 198-215.

Ders., Europäischer Adel in der frühen Neuzeit. Eine Einführung, Köln [u.a.] 2008.

Ders., The Revelation of the Revelation. Die Bedeutung der Offenbarung des Johannes für das politische Denken in England im späten 16. und frühen 17. Jahrhundert, in: Kai Trampedach / Andreas Pečar (Hrsg.), Die Bibel als politisches Argument. Voraussetzungen und Folgen biblizistischer Herrschaftslegitimation in der Vormoderne (Historische Zeitschrift, Beihefte N.F.; 43), München 2007, S. 315-331.

Ders., Jakob I. (1566-1625). König von England und Schottland, Stuttgart 2005.

Ders., Art. Elizabeth of Bohemia, in: Oxford Dictionary of National Biography, 2004, DOI 10.1093/ref:odnb/8638.

Ders., Die britische Republik und die Friedensordnung von Münster und Osnabrück, in: Heinz Duchhardt (Hrsg.), Der Westfälische Friede, München 1998, S. 421-443.

Geoffrey Ashe, The Hell-Fire Clubs. A History of Anti-Morality, Stroud 2005.

Achim Aurnhammer, Der intermediale Held. Heroisierungsstrategien in den Epicedien auf König Gustav II. Adolf von Paul Fleming, Johann Rist und Georg Rodolf Weckherlin, in: Achim Aurnhammer / Manfred Pfister (Hrsg.), Heroen und Heroisierungen in der Renaissance (Wolfenbütteler Abhandlungen zur Renaissanceforschung; 28), Wiesbaden 2013, S. 303-332.

Mark Bannister, Condé in Context. Ideological Change in Seventeenth-Century France (Legenda), Oxford 2000.

Ders., Privileged Mortals. The French Heroic Novel 1630-1660 (Oxford Modern Languages and Literature Monographs), Oxford 1983.

Andrew Barclay, Electing Cromwell. The Making of a Politician (Political and Popular Culture in the Early Modern Period; 3), London 2011. 
Stephen B. Baxter, William III as Hercules: the Political Implications of Court Culture, in: Lois G. Schwoerer (Hrsg.), The Revolution of 1688-89. Changing Perspectives, Cambridge 1992, S. 95-106.

Katia Béguin, La trahison glorieuse. Une transfiguration de la mémoire de la Fronde condéenne à la fin du XVII e siècle, in: Martin Wrede / Horst Carl (Hrsg.), Zwischen Schande und Ehre. Erinnerungsbrüche und die Kontinuität des Hauses. Legitimationsmuster und Traditionsverständnis des frühneuzeitlichen Adels in Umbruch und Krise (Veröffentlichungen des Instituts für Europäische Geschichte Mainz, Abt. Universalgeschichte; 73), Mainz 2007, S. 53-64.

Dies., Les princes de Condé. Rebelles, courtisans et mécènes dans la France du grand siècle (Époques), Seyssel 2003.

David Bell, The Cult of the Nation in France. Inventing Nationalism, 16801800, Cambridge, MA 2001.

Ilona Bell, "Souvereaigne Lord or Lordly Lady of this Land". Elizabeth, Stubbs and the Gaping Gulf, in: Julia M. Walker (Hrsg.), Dissing Elizabeth. Negative Representations of Gloriana, Durham, NC 1998, S. 99-116.

Alastair Bellany, 'Naught But Illusion'? Buckingham's Painted Selves, in: Kevin Sharpe / Steven N. Zwicker (Hrsg.), Writing Lives. Biography and Textuality, Identity and Representation in Early Modern England, Oxford 2008, S. $127-160$.

Ders., "The Enigma of the World". Memorializing and Remembering George Villiers, First Duke of Buckingham in the Aftermath of Assassination, c. 16281642, in: Martin Wrede / Horst Carl (Hrsg.), Zwischen Schande und Ehre. Erinnerungsbrüche und die Kontinuität des Hauses. Legitimationsmuster und Traditionsverständnis des frühneuzeitlichen Adels in Umbruch und Krise (Veröffentlichungen des Instituts für Europäische Geschichte Mainz, Abt. Universalgeschichte; 73), Mainz 2007, S. 27-52.

Paul Bénichou, Morales du grand siècle, Paris 1948.

Pierre Benoist, Le Père Joseph. L'Éminence grise de Richelieu, Paris 2007.

Ders., La bure et le sceptre. La congrégation des Feuillants dans l'affirmation des États et des pouvoirs princiers vers 1560-vers 1660 (Publications de la Sorbonne / Série histoire moderne; 47), Paris 2006.

Günter Berger, Aspekte der Rezeption des mittelalterlichen Romans im 17. Jahrhundert, in: Reinhold R. Grimm (Hrsg.), Mittelalter-Rezeption. Zur Rezeptionsgeschichte der romanischen Literaturen des Mittelalters in der Neuzeit (Begleitreihe zum Grundriß der romanischen Literaturen des Mittelalters; 2), Heidelberg 1991, S. 89-109.

Joseph Bergin, The Politics of Religion in Early Modern France, New Haven, CT 2014.

Mathilde Bernard, Écrire la peur à l'époque des guerres de Religion. Une étude des historiens et mémorialistes contemporains des guerres civiles en France 1562-1598 (Collection Savoir: Lettres), Paris 2010. 
Gilles Bertheau, Prince Henry as Chapman's 'Absolute Main', in: Timothy Wilks (Hrsg.), Prince Henry Revived. Image and Exemplarity in Early Modern England, Southampton 2007, S. 134-145.

Simone Bertière, Condé. Le héros fourvoyé, Paris 2011.

François Billacois, Le duel dans la société française des XVIe-XVII ${ }^{e}$ siècles. Essai de psychosociologie historique (Civilisations et Sociétés; 73), Paris 1986.

Jan-Philipp Birkhoff, Führen trotz Auftrag. Zur Rolle des militärischen Führers in der postheroischen Gesellschaft, in: Marcel Bohnert / Lukas J. Reitstetter (Hrsg.), Armee im Aufbruch. Zur Gedankenwelt junger Offiziere in den Kampftruppen der Bundeswehr, Berlin 2014, S. 105-128.

Timothy C. W. Blanning, Die Hannoveraner Monarchie und ihre Repräsentationskultur, in: Ronald G. Asch (Hrsg.), Hannover, Großbritannien und Europa. Erfahrungsraum Personalunion, 1714-1837 (Veröffentlichungen der Historischen Kommission für Niedersachsen und Bremen; 277), Göttingen 2014, S. 178-196.

Rafe Blaufarb, The French Army 1750-1820. Careers, Talent, Merit, Manchester 2002.

François Bluche, Les magistrats du parlement de Paris au XVIIIe siècle (Collection Histoire), Paris 1986.

Claudia Blümle, Souveränität im Bild. Anthonis van Dycks Reiterporträt Karls I., in: Horst Bredekamp / Pablo Schneider (Hrsg.), Visuelle Argumentationen. Die Mysterien der Repräsentation und die Berechenbarkeit der Welt (Kulturtechnik), München 2006, S. 79-102.

Hans Blumenberg, Präfiguration. Arbeit am politischen Mythos, Berlin 2014.

Ders., Arbeit am Mythos, Frankfurt am Main 1979.

Marcel Bohnert / Lukas J. Reitstetter (Hrsg.), Armee im Aufbruch: Zur Gedankenwelt junger Offiziere in den Kampftruppen der Bundeswehr, Berlin 2014.

Ann-Christin Bolay, Maximin und Cäsar. Adorationsmodelle im Stefan GeorgeKreis, in: Ronald G. Asch / Michael Butter (Hrsg.), Bewunderer, Verehrer, Zuschauer: Die Helden und ihr Publikum (Helden - Heroisierungen - Heroismen; 2), Würzburg 2015.

Geneviève Bollème (Hrsg.), Les contes bleus (Bibliothèque bleue), Paris 1983.

Jean-Claude Bonnet, Naissance du Panthéon. Essais sur le culte des grands hommes (L'esprit de la cité), Paris 1998.

Odile Bordaz, D’Artagnan. Capitaine-lieutenant des Grands Mousquetaires du Roi, Montréal/Baixas 2001.

Alain Boureau, Les enseignements absolutistes de Saint Louis, 1610-1630, in: Centre de Recherches sur l'Occident moderne (Hrsg.), La Monarchie absolutiste et l'histoire en France. Théories du pouvoir, propagandes monarchiques et mythologies nationales (Mythes, critique et histoire; 1), Paris 1987, S. 79-87. 
Theodore D. Bozeman, The Precisianist Strain. Disciplinary Religion and Antinomian Backlash in Puritanism to 1638, Chapel Hill, NC 2004.

Lucien Braun, Polysémie du concept de héros, in: Noémi Hepp / Georges Livet (Hrsg.), Héroïsme et création littéraire sous les règnes d'Henri IV et de Louis XIII (Actes et colloques; 16), Paris 1974, S. 19-28.

Renée-Claude Breitenstein, Représentation de l'histoire et parole féminine dans Les Femmes illustres ou les Harangues héroïques de Scudéry, in: Jean-Claude Arnould / Sylvie Steinberg (Hrsg.), Les Femmes et l'écriture de l'histoire (14001800), Mont-Saint-Aignan 2008, S. 341-353.

Pierre Briant, Alexandre des Lumières. Fragments d'histoire européenne (NRF Essais), Paris 2012.

Roberta F. Brinkley, Arthurian Legend in the $17^{\text {th }}$ Century [1932], Abingdon ${ }^{3} 2014$.

Pascal Brioist [et al.], Croiser le fer. Violence et culture de l'épée dans la France Moderne (XVIe-XVIII siècle) (Époques), Seyssel 2002.

Anna Bryson, From Courtesy to Civility. Changing Codes of Conduct in Early Modern England (Oxford Studies in Social History), Oxford 1998.

Peter Burke, The Fabrication of Louis XIV, New Haven, CT 1992.

Colin Burrow, "They make things happen", Rezension: Lucy Hughes-Hallett, Heroes. Saviours, Traitors and Supermen, London 2004, http://www.theguardian. com/books/2004/oct/09/highereducation.biography, 6. Dezember 2014.

Peter Burschel, Sterben und Unsterblichkeit. Zur Kultur des Martyriums in der Frühen Neuzeit (Ancien Régime. Aufklärung und Revolution; 35), München 2004.

Werner Busch, Über Helden diskutiert man nicht. Zum Wandel des Historienbildes im englischen 18. Jahrhundert, in: Ekkehard Mai (Hrsg.), Historienmalerei in Europa. Paradigmen in Form, Funktion und Ideologie, Mainz 1990, S. 57-76.

Martin Butler, The Stuart Court Masque and Political Culture, Cambridge 2008.

Michael Butter, Cincinnatus Popularized. The Heroization of William Henry Harrison during the Election Campaign of 1840, in: helden. heroes. héros. E-Journal zu Kulturen des Heroischen 2, Heft 1, 2014, S. 16-28, DOI 10.6094/helden.heroes.heros./2014/01/03.

John Callow, King in Exile. James II, Warrior, King and Saint, Stroud 2004.

Ders., The Making of King James II. The Formative Years of a Fallen King, Stroud 2000.

Denise Carabin, Les idées stoïciennes dans la littérature morale des XVIe et XVII ${ }^{e}$ siècles 1575-1642 (Études et essais sur la Renaissance; 51), Paris 2004.

Charles Carlton, Going to the Wars. The Experience of the British Civil Wars, London 1992.

Stuart Carroll, Martyrs and Murderers. The Guise Family and the Making of Europe, Oxford 2009. 
Ders., Blood and Violence in Early Modern France, Oxford 2006.

Philip Carter, Men and the Emergence of Polite Society, Britain 1660-1800 (Women and Men in History), London 2001.

John Carswell, The Porcupine - The Life of Algernon Sidney, London 1989.

Michel de Certeau, La fable mystique [1982], Paris 2013.

Ders., Le Lieu de l'autre. Histoire religieuse et mystique, Paris 2005.

Olivier Chaline, Le Règne de Louis XIV, Paris 2005.

Ders., Port Royal et la gloire, in: Histoire, économie, societé 20, 2001, S. 163-175.

Justin A. I. Champion, Republican Learning. John Toland and the Crisis of Christian Culture 1696-1722 (Politics, Culture and Society in Early Modern Britain), Manchester 2003.

Isabelle Chariatte, Transfigurations du héros dans la culture mondaine du siècle classique. Madeleine de Scudéry, La Rochefoucauld, le chevalier de Méré, in: helden. heroes. héros. E-Journal zu Kulturen des Heroischen 2, Heft 2, 2014, S. 37-47, DOI 10.6094/helden.heroes.heros./2014/02/04.

Dies., La Rochefoucauld et la culture mondaine. Portraits du coeur de l'homme (Lire le XVIIe siècle; 7), Paris 2011.

James S. Clarke / John McArthur, The Life and Services of Horatio Viscount Nelson. Duke of Bronte, Vice-Admiral of the White, Bd. 1, London 1840.

Richard Clay, Bouchardon's statue of Louis XV. Iconoclasm and the Transformation of Signs, in: Stacy Boldrick / Richard Clay (Hrsg.), Iconoclasm. Contested Objects, Contested Terms, Aldershot 2007, S. 93-122.

Tony Claydon, William III and the Godly Revolution (Cambridge Studies in Early Modern British History), Cambridge 1996.

John Coffey, The Martyrdom of Sir Henry Vane the Younger. From Apocalyptic Witness to Heroic Whig, in: Thomas S. Freeman / Thomas F. Mayer (Hrsg.), Martyrs and Martyrdom in England, c. 1400-1700 (Studies in Modern British Religious History; 15), Woodbridge 2007, S. 221-240.

Ders., The Impact of Apocalyptism during the Puritan Revolution, in: Perichoresis 4, Heft 2, 2006, S. 117-147.

Thomas Cogswell, John Felton, Popular Political Culture, and the Assassination of the Duke of Buckingham, in: Historical Journal 49, Heft 2, 2006, S. 357-385.

Ders., The People's Love. The Duke of Buckingham and Popularity, in: Thomas Cogswell [et al.] (Hrsg.), Politics, Religion and Popularity in Early Stuart Britain. Essays in Honour of Conrad Russell, Cambridge 2002, S. 211-234.

Ders. / Peter Lake, Buckingham Does the Globe. Henry VIII and the Politics of Popularity in the 1620s, in: Shakespeare Quarterly 60, Heft 3, 2009, S. 253-278.

Linda Colley, Britons. Forging the Nation 1707-1837, New Haven, CT 1992.

Patrick Collinson, The Birthpangs of Protestant England. Religious and Cultural Change in the Sixteenth and Seventeenth Centuries (The Anstey Memorial Lectures in the University of Kent at Canterbury; 3), Basingstoke 1988. 
Ders., The Religion of Protestants. The Church in English Society 1559-1625 (The Ford Lectures Delivered in the University of Oxford 1979), Oxford 1982. Jean-Marie Constant, La folle liberté des baroques 1600-1661, Paris 2007.

Ders., The Protestant Nobility in France during the Wars of Religions. A Leaven of Innovation in a Traditional World, in: Philip Benedict [et al.] (Hrsg.), Reformation, Revolt and Civil War in France and the Netherlands, 1555-1585, Amsterdam 1999, S. 69-82.

Ders., Les barons français pendant les guerres de religion, in: Association Henri IV (Hrsg.), Quatrième centenaire de la bataille de Coutras (Colloque de Coutras organisé par le GRAHC 1987), Pau 1989, S. 49-62.

Cédric Coraillon, Les deux morts de Louis XIII, in: Revue d'histoire moderne et contemporaine 55, 2008, S. 50-73.

Joël Cornette, Le roi de guerre. Essai sur la souveraineté dans la France du Grand Siècle (Bibliothèque historique Payot), Paris 2000.

Ders., La tente de Darius, in: Joël Cornette / Henry Méchoulan (Hrsg.), L'État classique 1652-1715. Regards sur la pensée politique dans la France dans la seconde moitié du XVIIe siècle, Paris 1996, S. 9-42.

Fanny Cosandey, La Reine de France. Symbole et pouvoir. XVe-XVIIIe siècle (Bibliothèque des histoires), Paris 2000.

Joan Coutu, Persuasion and Propaganda. Monuments and the EighteenthCentury British Empire, Montreal 2006.

Barry Coward, Oliver Cromwell (Profiles in Power), London 1991.

William Craft, Labyrinth of Desire. Invention and Culture in the Work of Sir Philip Sidney, Newark, NJ 1994.

Matthew Craske, Westminster Abbey 1720-70. A Public Pantheon Built upon Private Interest, in: Richard Wrigley / Matthew Craske (Hrsg.), Pantheons: Transformations of a Monumental Idea, Aldershot 2004, S. 57-79.

Ders., Making National Heroes? A Survey of the Social and Political Functions and Meanings of Major British Funeral Monuments to Naval and Military Figures, 1730-1770, in: John Bonehill / Geoff Quilley (Hrsg.), Conflicting Visions: War and Visual Culture in Britain and France, c. 1700-1830, Aldershot 2005, S. 41-60.

Katherine B. Crawford, Perilous Performances. Gender and Regency in Early Modern France (Harvard Historical Studies; 145), Cambridge, MA 2004.

Dies., The Politics of Promiscuity. Masculinity and Heroic Representation at the Court of Henry IV, in: French Historical Studies 26, Heft 2, 2003, S. 225-252.

Aurélie du Crest, Modèle familial et pouvoir monarchique. XVI ${ }^{\mathrm{e}-X V I I I}{ }^{e}$ siècles (Collection d'histoire des institutions et des idées politiques), Aix-en-Provence 2002.

Denis Crouzet, Dieu en ses royaumes. Une histoire des Guerres de Religion (Époques), Seyssel 2008. 
Ders., La genèse de la Réforme française, Paris 1999.

Ders., Capital identitaire et engagement religieux. Aux origines de l'engagement militant de la maison de Guise ou le tournant des années 1524-1525, in: Joël Fouilheron [et al.] (Hrsg.), Sociétés et idéologies des Temps modernes. Hommage à Arlette Jouanna, Bd. 2, Montpellier 1996, S. 573-589.

Ders., Un texte fondateur? Note sur "L'Histoire et recueil de la triomphante et glorieuse victoire ...», in: Brigitte Maillard (Hrsg.), Foi, fidélité, amitié en Europe à la période moderne. Mélanges offerts à Robert Sauzet, Bd. 2, Sensibilité et pratiques religieuses, Tours 1995, S. 311-331.

Ders., Les fondements idéologiques de la royauté d'Henri IV, in: Jacques Pérot / Pierre Tucoo-Chala (Hrsg.), Henri IV. Le Roi et la reconstruction du royaume, Pau 1990, S. 165-194.

Ders., Les Guerriers de Dieu. La violence au temps des troubles de religion (vers 1525-vers 1610), 2 Bde, Seyssel 1990.

David Cuckson, Too Dangerous to Let Live. A Biography of Sir Henry Vane the Younger, Raleigh, NC 2011.

Richard Cust, Charles I. A Political Life, Harlow 2005.

Alice Dailey, The English Martyr from Reformation to Revolution (Reformations), Notre Dame, IN 2012.

J. D. Davies, Gentlemen and Tarpaulins: The Officers and Men of the Restoration Navy, Oxford 1991.

Colin Davis, Cromwell's Religion, in: David Lee Smith (Hrsg.), Cromwell and the Interregnum. The Essential Readings (Blackwell Essential Readings in History), Oxford 2003, S. 139-166.

J. F. R. Day, Death be Very Proud. Sidney, Subversion and Elizabethan Heraldic Funerals, in: Dale Hoak (Hrsg.), Tudor Political Culture, Cambridge 1995, S. 179-203.

Robert Descimon / José J. Ruiz Ibáñez, Les Ligueurs de l'exil. Le refuge Catholique Français après 1594 (Époques), Seyssel 2005.

Ders., Preface, in: Stéphane-Marie Morgain (Hrsg.), La Théologie politique de Pierre de Bérulle 1598-1629 (La France au fil des siècles), Paris 2001, S. 11-24.

Jonathan Dewald, Aristocratic Experience and the Origins of Modern Culture. France 1570-1715 (A Centennial Book), Berkeley, CA 1993.

Barbara B. Diefendorf, From Penitence to Charity. Pious Women and the Catholic Reformation in Paris, Oxford 2004.

Martin Disselkamp, Barockheroismus. Konzeptionen „politischer“ Größe in Literatur und Traktatistik des 17. Jahrhunderts (Frühe Neuzeit; 65), Tübingen 2002.

Leif Dixon, Practical Predestinarians in England, c. 1590-1640, Farnham 2014.

Giovanni Dotoli, Letteratura per il popolo in Francia (1600-1750). Proposte di lettura della «Bibliothèque bleue» (Biblioteca della ricerca; 8,4), Fasano 1991. 
Hervé Drévillon, Secondary Heroes. War and the Making of the Individual in Eighteenth-Century France, erscheint in: Markus Menmann (Hrsg.),The Military in the Early Modern World. A Comparative Approach, Münster 2016.

Ders., L'Individu et la Guerre. Du chevalier Bayard au Soldat inconnu, Paris 2013.

Ders., Batailles, scènes de guerre de la table ronde aux Tranchées (L'Univers historique), Paris 2007.

Ders., L'impôt du sang. Le métier des armes sous Louis XIV, Paris 2005.

Ders., L'héroïsme à l'épreuve de l'absolutisme. L'exemple du maréchal de Gassion (1609-1647), in: Politix 15, 2002, S. 15-38.

Ders., Le dire et le fer: le duel et sa publicité au XVIIe siècle, in: Pascal Brioist [et al.], Croiser le fer. Violence et culture de l'epée dans la France Moderne (XVI'-XVIII siècle) (Époques), Seyssel 2002, S. 239-304.

Hélène Duccini, Faire Voir, Faire Croire. L'opinion publiques sous Louis XIII (Époques), Seyssel 2003.

Edmond Dziembowski, Un nouveau patriotisme français 1750-1770. La France face à la puissance anglaise à l'époque de la guerre de Sept Ans (SVEC; 365), Oxford 1998.

David El Kenz, Les usages subversifs du martyre dans la France des troubles de religion. De la parole au geste, in: Frank Lestringant (Hrsg.), Martyrs et martyrologes (Revue des Sciences Humaines; 269), Lille 2003, S. 33-51.

Ders., Les bûchers du roi. La culture Protestante des martyrs 1523-1572 (Époques), Seyssel 1997.

Sarah Ellenzweig, The Fringes of Belief. English Literature, Ancient Heresy and the Politics of Freethinking, 1660-1760, Stanford, CA 2008.

John H. Elliott, The Count-Duke of Olivares. The Statesman in an Age of Decline, New Haven, CT 1986.

Lori A. Ferrell, Government by Polemic. James I, the King's Preachers, and the Rhetoric of Conformity, 1603-1625, Stanford, CA 1998.

Kenneth Fincham / Nicholas Tyacke, Altars Restored. The Changing Face of English Religious Worship, 1547-c. 1700, Oxford 2007.

Kenneth Fincham / Peter Lake, The Ecclesiastical Policies of James I and Charles I, in: Kenneth Fincham (Hrsg.), The Early Stuart Church 1603-1642 (Problems in Focus), Basingstoke 1993, S. 23-50.

Andrew Foster, The Church of England 1570-1640 [1994], Abingdon 22013.

Thomas S. Freeman, 'Imitatio Christi with a Vengeance': The Politicisation of Martyrdom in Early-Modern England, in: Thomas S. Freeman / Thomas F. Mayer (Hrsg.), Martyrs and Martyrdom in England, c. 1400-1700 (Studies in Modern British Religious History; 15), Woodbridge 2007, S. 35-69. 
Ders., Providence and Prescription: The Account of Elizabeth in Foxe's 'Book of Martyrs', in: Susan Doran / Thomas S. Freeman (Hrsg.), The Myth of Elizabeth, Basingstoke 2003, S. 27-55.

Ute Frevert, Herren und Helden. Vom Aufstieg und Niedergang des Heroismus im 19. und 20. Jahrhundert, in: Richard van Dülmen (Hrsg.), Erfindung des Menschen. Schöpfungsträume und Körperbilder 1500-2000, Wien 1998, S. 323-346.

Ewald Frie, Adelsgeschichte des 19. Jahrhunderts? Eine Skizze, in: Geschichte und Gesellschaft 33, Heft 3, 2007, S. 398-415.

Robert von Friedeburg, Bausteine widerstandsrechtlicher Argumente in der frühen Neuzeit (1523-1668): Konfessionen, klassische Verfassungsvorbilder, Naturrecht, direkter Befehl Gottes, historische Rechte der Gemeinwesen, in: Christoph Strohm / Heinrich de Wall (Hrsg.), Konfessionalität und Jurisprudenz in der frühen Neuzeit (Historische Forschungen; 89), Berlin 2009, S. 115-166.

Marian Füssel, Der „roi connétable“ und die Öffentlichkeit, in: Bernd Sösemann / Gregor Vogt-Spira (Hrsg.), Friedrich der Große in Europa. Geschichte einer wechselvollen Beziehung, Bd. 2, Stuttgart 2012, S. 199-215.

Marc Fumaroli, L'héroïsme cornélien et l'éthique de la magnamité, in: Marc Fumaroli, Héros et orateurs. Rhétorique et dramaturgie cornéliennes (Histoire des idées et critique littéraire; 277), Genf 1996, S. 323-348.

Ders., Héros et orateurs. Rhétorique et dramaturgie cornéliennes (Histoire des idées et critique littéraire; 277), Genf 1996.

Thomas W. Gaehtgens, Du Parnasse au Panthéon. La représentation des hommes illustres et des grands hommes dans la France du XVIII ${ }^{e}$ siècle, in: Thomas W. Gaehtgens / Gregor Wedekind (Hrsg.), Le culte des grands hommes 17501850 (Passagen; 16), Paris 2009, S. 135-172.

Stephan Geifes, Das Duell in Frankreich 1789-1830. Zum Wandel von Diskurs und Praxis in Revolution, Kaiserreich und Restauration (Pariser Historische Studien; 102), München 2013.

Alexandra Gajda, The Earl of Essex and Late Elizabethan Political Culture (Oxford Historical Monographs), Oxford 2012.

Jacques Gélis, Le corps, l'Église et le sacré, in: Alain Corbin [et al.] (Hrsg.), Histoire du Corps, Bd. 1, De la Renaissanc aux Lumières, Paris 2005, S. 17-108.

Ian Gentles, The New Model Army in England, Ireland and Scotland, 16451653, Oxford 1992.

Hélène Germa-Romann, Du «Bel Mourir » au "Bien Mourir » (Travaux d'humanisme et renaissance; 347), Genf 2001.

Alexandra Gerstner, Neuer Adel. Aristokratische Elitenkonzeptionen zwischen Jahrhundertwende und Nationalsozialismus, Darmstadt 2008.

Andreas Gestrich, Absolutismus und Öffentlichkeit. Politische Kommunikation in Deutschland zu Beginn des 18. Jahrhunderts (Kritische Studien zur Geschichtswissenschaft; 103), Göttingen 1994. 
Jonathan Gibson, Civil War in 1614. Lucan, Gorges and Prince Henry, in: Stephen Clucas / Rosalind Davies (Hrsg.), The Crisis of 1614 and the Addled Parliament. Literary and Historical Perspectives, Aldershot 2003, S. 161-176.

Bernhard Giesen, Zwischenlagen. Das Außerordentliche als Grund der sozialen Wirklichkeit, Weilerswist 2010.

Ders., Triumph and Trauma (The Yale Cultural Sociology Series), Boulder, CO 2004.

Antoinette Gimaret, Extraordinaire et ordinaire des Croix. Les représentations du corps souffrant 1580-1650 (Bibliothèque littéraire de la Renaissance, Sér. 4; 82), Paris 2011.

Luigi Gonzaga di Castiglione, Le Pére Ange de Joyeuse, frère mineur capucin, maréchal de France (1563-1608), Paris 1928.

Brad S. Gregory, Salvation at Stake. Christian Martyrdom in Early Modern Europe (Harvard Historical Studies; 134), Cambridge, MA 1999.

Chantal Grell / Christian Michel, L'École des princes ou Alexandre disgracié. Essai sur la mythologie monarchique de la France absolutiste (Nouveaux confluents), Paris 1988.

Éthel Groffier, Le stratège des Lumières. Le comte de Guibert (1743-1790), Paris 2005.

Alexia Grosjean, General Alexander Leslie, The Scottish Covenanters and the Riksrad Debates, 1638-1640, in: Allan I. Macinnes [et al.] (Hrsg.), Ships, Guns and Bibles in the North Seas and Baltic States, c. 1350-1700, East Linton 2000, S. 115-138.

Élie Haddad, La difficile intégration des noblesses. Les Mesgrigny ou le coût social et moral des prétentions à l'épée, in: Robert Descimon / Élie Haddad (Hrsg.), Épreuves de Noblesse. Les expériences nobiliaires de la haute robe parisienne (XVIe-XVIII siècles), Paris 2010, S. 210-231.

Donald E. Hall (Hrsg.), Muscular Christianity: Embodying the Victorian Age, Cambridge 1994.

Paul E. J. Hammer, The Polarisation of Elizabethan Politics. The Political Career of Robert Devereux, 2nd Earl of Essex, 1585-1597 (Cambridge Studies in Early Modern British History), Cambridge 1999.

Ders., Upstaging the Queen. The Earl of Essex, Francis Bacon and the Accession Day Celebrations of 1595, in: David Bevington / Peter Holbrook (Hrsg.), The Politics of the Stuart Court Masque, Cambridge 1998, S. 41-66.

Paul Hammond, The King's Two Bodies. Representations of Charles II, in: Jeremy Black / Jeremy Gregory (Hrsg.), Culture, Politics and Society in Britain, 1660-1800, Manchester 1991, S. 13-48.

Christiane Hansen, Staging Admiration in John Dryden's Indian Emperour, or the Conquest of Mexico by the Spaniards (1667), in: helden. heroes. héros. Special Issue 1, 2014, S. 47-53, DOI 10.6094/helden.heroes.heros./2014/QM/06. 
Alexandre Y. Haran, Louis le Juste à travers les oraisons funèbres: roi-sauveur et monarque providentiel, in: Bernard Barbiche [et al.] (Hrsg.), Pouvoirs, contestations et comportements dans l'Europe moderne. Mélanges en l'honneur du professeur Yves-Marie Bercé (Collection Roland Mousnier; 23), Paris 2005, S. 247-262.

Yuval N. Harari, The Ultimate Experience. Battlefield Revelations and the Making of Modern War Culture 1450-2000, Basingstoke 2008.

Philip Harth, Pen for a Party. Dryden's Tory Propaganda in its Contexts, Princeton, NJ 1993.

Klaus Heinrich, Arbeiten mit Herakles. Zur Figur und zum Problem des Heros. Antike und moderne Formen seiner Interpretation und Instrumentalisierung (Dahlemer Vorlesungen; 9), Frankfurt am Main 2006.

Eckhart Hellmuth, Die „Wiedergeburt Friedrichs des Großen“ und der „Tod für das Vaterland“. Zum patriotischen Selbstverständnis in Preußen in der zweiten Hälfte des 18. Jahrhunderts, in: Eckhart Hellmuth / Reinhard Stauber (Hrsg.), Nationalismus vor dem Nationalismus? (Aufklärung. Interdisziplinäre Halbjahresschrift zur Erforschung des 18. Jahrhunderts; 10/2), Hamburg 1998, S. 23-54.

Jacques Hennequin, L'image du prince dans les oraisons funèbres de Louis XIII, in: Travaux de Linguistique et de Littérature 22, Heft 2, 1984 (Colloque sur l'Image du Roi), S. 41-55.

Ders., Henri IV dans ses Oraisons funèbres ou la naissance d'une légende (Bibliothèque française et romane, C; 62), Paris 1977.

Harro Höpfl, Jesuit Political Thought. The Society of Jesus and the State, c. 1540-1630 (Ideas in Context; 70), Cambridge 2004.

Holger Hoock, Empires of the Imagination. Politics, War and the Arts in the British World, London 2010.

Andrew Hopper, Turncoats and Renegadoes. Changing Sides during the English Civil Wars, Oxford 2012.

Leonhard Horowski, Die Belagerung des Thrones. Machtstrukturen und Karrieremechanismen am Hof von Frankreich 1661-1789 (Francia, Beihefte; 74), Ostfildern 2012.

Sophie Houdard, Les Invasions Mystiques. Spiritualités, hétérodoxies et censures au début de l'époque moderne (Histoire; 91), Paris 2008.

Bernard Hours, Lous XV. Un Portrait, Toulouse 2009.

David Howarth, Images of Rule. Art and Politics in the English Renaissance, 1485-1649, Basingstoke [u.a.] 1997.

Lucy Hughes-Hallett, Heroes. Saviours, Traitors and Supermen, London 2005. Volker Hunecke, Europäische Reitermonumente. Ein Ritt durch die Geschichte Europas von Dante bis Napoleon, Paderborn 2008.

Ronald Hutton, The Royalist War Effort, 1642-1646, London 1982. 
Laurent Jalabert (Hrsg.), Nouveaux regards sur Turenne. 400 anniversaire de la naissance d'Henri De La Tour d'Auvergne 1611-1675. Actes du colloque tenu les 17 et 18 septembre 2011 à Sedan, Nancy 2013.

Matthew Jenkinson, Culture and Politics at the Court of Charles II, 1660-1685 (Studies in Early Modern Cultural, Political and Social History; 9), Woodbridge 2010.

Richard Johns, The British Caesar. John Churchill, $1^{\text {st }}$ Duke of Marlborough, and the Visual Arts, in: John B. Hattendorf [et al.] (Hrsg.), Marlborough. Soldier and Diplomat, Rotterdam 2012, S. 320-355.

James W. Johnson, A Profane Wit. The Life of John Wilmot, Earl of Rochester, Rochester, NY 2004.

Colin Jones, The Great Nation. France from Louis XV to Napoleon, New York 2002.

Gerald Jordan / Nicholas Rogers, Admirals as Heroes. Patriotism and Liberty in Hanoverian England, in: Journal of British Studies 28, Heft 3, 1989, S. 201-224.

Christian Jouhaud, Les pouvoirs de la littérature. Histoire d'un paradoxe (NRF Essais), Paris 2000.

Ders., La main de Richelieu ou Le pouvoir cardinal, Paris 1991.

Jeffrey K. Jue, Heaven upon Earth. Joseph Mede (1586-1638) and the Legacy of Millenarianism (Archives internationals d'histoire des idées; 194), Dordrecht 2006.

Thomas E. Keiser, The Public Sphere, in: William Doyle (Hrsg.), The Oxford Handbook of the Ancien Régime, Oxford 2012, S. 409-430.

Sean Kelsey, The King's Book. Eikon Basilike and the English Revolution of 1649, in: Nicholas Tyacke (Hrsg.), The English Revolution, c. 1590-1720. Politics, Religion and Communities (UCL/Neale Series on British History), Manchester 2007, S. 150-169.

Ders., Inventing a Republic. The Political Culture of the English Commonwealth, 1649-1653 (Politics, Culture and Society in Early Modern Britain), Manchester 1997.

John N. King, James I and King David. Jacobean Iconography and its Legacy, in: Daniel Fischlin / Mark Fortier (Hrsg.), Royal Subjects. Essays on the Writings of James VI and I, Detroit, MI 2002, S. 421-453.

Thomas Kirchner, Richelieu et son usage programmatique de l'art. L'image du cardinal dans le décor de ses résidences, in: Jean-Claude Boyer [et al.] (Hrsg.), Richelieu patron des arts (Passagen; 17), Paris 2009, S. 251-272.

Ders., Der epische Held. Historienmalerei und Kunstpolitik im Frankreich des 17. Jahrhunderts, München 2001.

Robert J. Knecht, Hero or Tyrant? Henry III, King of France, 1574-89, Farnham 2014. 
Laura L. Knoppers, Constructing Cromwell. Ceremony, Portrait, and Print, 1645-1661, Cambridge 2000.

Renate Kroll, Von der Heerführerin zur Leidensheldin. Die Domestizierung der Femme Forte, in: Bettina Baumgärtel / Silvia Neysters (Hrsg.), Die Galerie der Starken Frauen. Regentinnen, Amazonen, Salondamen, München 1995, S. 51-63.

Hanno-Walter Kruft, Richelieu, un projet à l'image de la raison d'État, in: JeanClaude Boyer [et al.] (Hrsg.), Richelieu. patron des arts (Passagen; 17), Paris 2009, S. 19-54.

Andrew Lacey, 'Charles the First, and Christ the Second': The Creation of a Political Martyr, in: Thomas S. Freeman / Thomas F. Mayer (Hrsg.), Martyrs and Martyrdom in England, c. 1400-1700 (Studies in Modern British Religious History; 15), Woodbridge 2007, S. 203-220.

Ders., The Cult of King Charles the Martyr (Studies in Modern British Religious History; 7), Woodbridge 2003.

Jacqueline Lagrée, Just Lipse et la restauration du stoïcisme (Philologie et Mercure), Paris 1994.

Peter Lake, Lancelot Andrewes, John Buckeridge, and Avant-garde Conformity at the Court of James I, in: Linda L. Peck (Hrsg.), The Mental World of the Jacobean Court, Cambridge 1991, S. 113-133.

Joel B. Lande / Robert Suter, Einleitung, in: Joel B. Lande [et al.] (Hrsg.), Dynamische Figuren. Gestalten der Zeit im Barock (Rombach-Wissenschaften / Reihe Litterae; 192), Freiburg 2013, S. 9-25.

Calvin Lane, The Laudians and the Elizabethan Church. History, Conformity and Religious Identity in Post-Reformation England (Religious Cultures in the Early Modern World), London 2013.

Melissa S. Lane / Martin A. Ruehl (Hrsg.), A Poet's Reich. Politics and Culture in the George Circle (Studies in German Literature, Linguistics, and Culture), Rochester, NY 2011.

Paul Langford, Swift and Walpole, in: Claude Rawson (Hrsg.), Politics and Literature in the Age of Swift. English and Irish Perspectives, Cambridge 2010, S. 52-79.

Charles H. Larson, Fulke Greville, Boston 1980.

Andrew Lavoie, "Chaining Mars" - The Politics of the English Standing Army 1660-1716, Mai 2014, https://www.academia.edu/8467931/Chaining_Mars-_ The_politics_of_the_English_Standing_Army_1660-1716, 20. Januar 2015.

Jacques Le Brun, Les discours de la stigmatisation au XVII siècle, in: Les Cahiers de l'Herne 75, 2001, S. 103-118.

Ders., Mutations de la Notion de Martyre au XVII siècle d'après les biographies spirituelles féminines, in: Jacques Marx (Hrsg.), Saintété et martyre dans les re- 
ligions du livre (Problèmes d'histoire du christianisme; 19), Brüssel 1989, S. 77-90.

Jean-Marie Le Gall, Le Mythe de Saint Denis entre Renaissance et Révolution (Époques), Seyssel 2007.

Jörn Leonhard, Bellizismus und Nation. Kriegsdeutung und Nationsbestimmung in Europa und den Vereinigten Staaten 1750-1914 (Ordnungssysteme; 25), München 2008.

Nicolas Le Roux, L'héroïsme impossible des derniers Valois, in: Martin Wrede (Hrsg.), Die Inszenierung der heroischen Monarchie. Frühneuzeitliches Königtum zwischen ritterlichem Erbe und militärischer Herausforderung (Historische Zeitschrift, Beihefte N.F.; 62), München 2014, S. 152-169.

Ders., Le roi, la cour, l'état. De la Renaissance à l'absolutisme (Époques), Seyssel 2013.

Ders., La faveur du roi. Mignons et courtisans au temps des derniers Valois, vers 1547-vers 1589 (Époques), Seyssel 2001.

Antoine Lilti, Figures publiques. L'invention de la célébrité 1750-1850, Paris 2014.

Seung-Hwi Lim, Mathieu de Morgues. Bon Français ou bon catholique?, in: Dixseptième siècle 213, 2001, S. 655-672.

David Loades (Hrsg.), John Foxe at Home and Abroad, Aldershot 2004.

Harold Love, Dryden, Rochester and the Invention of the "Town", in: Claude Rawson / Aaron Santesso (Hrsg.), John Dryden (1631-1700). His Politics, his Plays and his Poets, Newark, NJ 2004, S. 36-51.

Michael Lynch, Court Ceremony and Ritual during the Personal Reign of James VI, in: Julian Goodare / Michael Lynch (Hrsg.), The Reign of James VI, East Linton 2000, S. 71-92.

Catherine MacLeod (Hrsg.), The Lost Prince. The Life and Death of Henry Stuart, London 2012.

Caroline Maillet-Rao, La théologie politique des dévots Mathieu de Morgues et Michel de Marilllac, opposants au Cardinal de Richelieu, in: Renaissance and Reformation 32, Heft 3, 2009, S. 51-77.

Andrew McClellan, The Life and Death of a Royal Monument. Bouchardon's Louis XV, in: Oxford Art Journal 23, Heft 2, 2000, S. 3-27.

Adriana McCrea, Constant Minds. Political Virtue and the Lipsian Paradigm in England, 1584-1650 (The Mental and Cultural World of Tudor and Stuart England), Toronto 1997.

Peter E. McCullough, Out of Egypt. Richard Fletcher's Sermon before Elizabeth I after the Execution of Mary Queen of Scots, in: Julia M. Walker (Hrsg.), Dissing Elizabeth. Negative Representations of Gloriana (British Literature \& History: Women's Studies), Durham, NC 1998, S. 118-148.

Thomas McGeary, The Politics of Opera in Handel's Britain, Cambridge 2013. 
John McKenzie, Heroic Myths of Empire, in: John McKenzie (Hrsg.), Popular Imperialism and the Military 1850-1950 (Studies in Imperialism), Manchester 1992, S. 109-138.

Ders. (Hrsg.), Popular Imperialism and the Military 1850-1950 (Studies in Imperialism), Manchester 1992.

Alan McNairn, Behold the Hero. General Wolfe and the Arts in the Eighteenth Century, Liverpool 1997.

Mathieu Marraud, La noblesse de Paris au XVIII siècle (L'univers historique), Paris 2000.

Michel Martin, Les monuments équestres de Louis XIV. Une grande entreprise de propagande monarchique, Paris 1986.

Paul-Alexis Mellet, L'ange et l'assassin. Les vocations extraordinaires et le regicide jusq'au 1610, in: Marie-Luce Demonet (Hrsg.), Hasard et providence XIVeXVII e siècles. Actes du cinquantenaire de la fondation du CESR et XLIX ${ }^{e}$ Colloque International d'études Humanistes, Tours, 3-9 juillet 2006, 2007, http:// umr6576.cesr.univ-tours.fr/Publications/HasardetProvidence/, 20. Juli 2015.

James Mervyn, Society, Politics and Culture. Studies in Early Modern England (Past and Present Publications), Cambridge 1986.

Christian Michel, Les enjeux historiographiques de la Querelle des Anciens et des Modernes, in: Centre de Recherches sur l'Occident Moderne (Hrsg.), La monarchie absolutiste et l'histoire en France. Théories du pouvoir, propagandes monarchiques et mythologies nationales (Mythes, critique et histoire; 1), Paris 1987, S. 139-155.

Nicolas Milanovic, Du Louvre à Versailles. Lecture des grands décors monarchiques, Paris 2005.

Anthony Milton, "Vailing his Crown": Royalist Criticism of Charles I's Kingship in the 1650s, in: Jason McElligott / David L. Smith (Hrsg.), Royalists and Royalism during the Interregnum (Politics, Culture and Society in Early Modern Britain), Manchester 2010, S. 88-105.

Ders., Catholic and Reformed. The Roman and Protestant Churches in English Protestant Thought, 1600-1640 (Cambridge Studies in Early Modern British History), Cambridge 1995.

Jan-Friedrich Mißfelder, Das Andere der Monarchie, La Rochelle und die Idee der „monarchie absolue“ in Frankreich 1568-1630 (Pariser historische Studien; 97), München 2012.

Jean-Marie Moeglin, Les bourgeois de Calais. Essai sur un mythe historique (L'évolution de l'humanité), Paris 2002.

Olaf Mörke, Das Erbe des „Wilhelmus“. Ein Niederländisches Modell der heroischen Monarchie, in: Martin Wrede (Hrsg.), Die Inszenierung der heroischen Monarchie. Frühneuzeitliches Königtum zwischen ritterlichem Erbe und militärischer Herausforderung (Historische Zeitschrift, Beihefte N.F.; 62), München 2014, S. 334-357. 
Louis Montrose, The Subject of Elizabeth. Authority, Gender, and Representation, Chicago 2006.

Marlies Mueller, The Taming of the Amazon. The Changing Image of the Woman Warrior in Ancien Régime Fiction, in: Papers on French SeventeenthCentury Literature 22, Heft 42, 1995, S. 199-232.

Herfried Münkler, Heroische und postheroische Gesellschaften, in: Merkur 61, Heft 8/9, 2007, S. 742-752.

Steve Murdoch (Hrsg.), Scotland and the Thirty Years' War 1618-1648 (History of Warfare; 6), Leiden 2001.

Nick Myers, Hercule Gaulois, Great Britain's Solomon. Myths of Persuasion, Styles of Authority, in: Eveline Cruickshanks (Hrsg.), The Stuart Courts, Stroud [u.a.] 2000, S. 29-42.

Ulrich Niggemann, Herrschermemoria als Norm und Symbol. Zum Umgang mit der Erinnerung an Wilhelm III. im England des frühen 18. Jahrhunderts, in: Zeitschrift für Historische Forschung 39, 2012, S. 1-36.

Robert A. Nye, Western Masculinities in War and Peace, in: The American Historical Review 112, Heft 2, 2007, S. 417-438.

Jean Orcibal, Les «supercroisades » de Louis XIV (1683-1689), in: Janet van Bavel (Hrsg.), Jansénius et le Jansénisme dans les Pays-Bas (Ephemerides theologicae Lovanienses; 56), Löwen 1982, S. 138-147.

Susan J. Owen, Restoration Theatre and Crisis, Oxford 1996.

David Parnham, Sir Henry Vane, Theologian. A Study in Seventeenth-Century Religious and Political Discourse, Madison/London 1997.

Annabel Patterson, Dryden and Political Allegiance, in: Steven N. Zwicker (Hrsg.), The Cambridge Companion to John Dryden (Cambridge Companions to Literature), Cambridge 2004, S. 221-236.

John Peacock, The Image of Charles I as a Roman Emperor, in: Ian Atherton / Julie Sanders (Hrsg.), The 1630s. Interdisciplinary Essays on Culture and Politics in the Caroline Era (Politics, Culture and Society in Early Modern Britain), Manchester 2006, S. 50-73.

Edward Pearce, The Great Man. Sir Robert Walpole, Scoundrel, Genius and Britain's First Prime Minister, London 2007.

Iain Pears, The Gentleman and the Hero: Wellington and Napoleon in the Nineteenth Century, in: Roy Sydney Porter (Hrsg.), Myths of the English, Cambridge 1992, S. 216-236.

Markku Peltonen, The Duel in Early Modern England. Civility, Politeness and Honour (Ideas in Context; 65), Cambridge 2003.

Michel Pernot, La Fronde, Paris 1994.

Rodney L. Petersen, Preaching in the Last Days. The Theme of "Two Witnesses" in the $16^{\text {th }}$ and $17^{\text {th }}$ Centuries, Oxford 1993. 
Nicholas Phillipson, Politics and Politeness in the Reigns of Anne and the Early Hanoverians, in: John G. A. Pocock [et al.] (Hrsg.), The Varieties of British Political Thought, 1500-1800, Cambridge 1993, S. 211-245.

Vincent J. Pitts, Henri IV of France. His Reign and Age, Baltimore 2009.

Friedrich Polleroß, From the "exemplum virtutis" to the Apotheosis. Hercules as an Identification Figure in Portraiture. An Example of the Adoption of Classical Forms of Representation, in: Allan Ellenius (Hrsg.), Iconography, Propaganda, and Legitimation (The Origins of the Modern State in Europe; G), Oxford 1998, S. 37-62.

Édouard Pommier, Le portrait du pouvoir. De la norme à la réalité, in: Olivier Bonfait / Brigitte Marin (Hrsg.), Les portraits du pouvoir (Collection d'histoire de l'art de l'Académie de France à Rome; 3), Paris 2003, S. 3-17.

Christina Posselt-Kuhli, Der ,Kunstheld' im Spannungsfeld zwischen Krieg und Frieden. Ein herrscherliches Tugendexempel im Deutschland des 17. Jahrhunderts, in: helden. heroes. héros. E-Journal zu Kulturen des Heroischen 2, Heft 2, 2014, S. 17-35, DOI 10.6094/helden.heroes.heros./2014/02/03.

Martin Postle (Hrsg.), Joshua Reynolds. The Creation of Celebrity, London 2005.

Géraud Poumarède, Pour en finir avec la Croisade. Mythes et réalités de la lutte contre les Turcs aux XVI et XVII e siècle, Paris 2004.

Michel Prigent, Le héros et l'État dans la tragédie de Pierre Corneille, Paris 1986.

Charles W. A. Prior, Defining the Jacobean Church. The Politics of Religious Controversy, 1603-1625 (Cambridge Studies in Early Modern British History), Cambridge 2005.

Jean-Louis Quantin, Le rêve de la communauté pure, in: Bernard Cottret, [et al.] (Hrsg.), Jansénisme et puritanisme, Paris 2002, S. 169-194.

Rory Rapple, Martial Power and Elizabethan Political Culture. Military Men in England and Ireland, 1558-1594 (Cambridge Studies in Early Modern British History), Cambridge 2009.

Jan Philipp Reemtsma, Der Held, das Ich und das Wir, in: Mittelweg 36, Heft 4, 2009, S. 41-64, http://www.his-online.de//fileadmin/verlag/leseproben/978-393609-645-3_01.pdf, 16. Februar 2015.

Joan Rees, Fulke Greville, Lord Brooke, 1554-1628. A Critical Biography, London 1971.

Sven Reichardt, Faschistische Kampfbünde. Gewalt und Gemeinschaft im italienischen Squadrismus und in der deutschen SA (Industrielle Welt; 63), Köln 2002.

Heinz Reif, Der Adel im „langen 19. Jahrhundert“. Alte und neue Wege der Adelsforschung, in: Gabriele B. Clemens [et al.] (Hrsg.), Hochkultur als Herrschaftselement. Italienischer und deutscher Adel im langen 19. Jahrhundert (Villa Vigoni; 25), Berlin 2011, S. 19-37. 
Jane Rickard, Authorship and Authority. The Writings of James VI and I, Manchester 2007.

Patrick Riley, Fénelon's 'Republican' Monarchism in Telemachus, in: Hans Blom [et al.] (Hrsg.), Monarchisms in the Age of Enlightenment. Liberty, Patriotism and the Common Good (UCLA Clark Memorial Library Series; 6), Toronto 2007, S. 78-100.

Gabriele Rippl, "Merit, Justice, Gratitude, Duty, Fidelity”. Images of Masculinity in Autobiographies of Early Modern English Gentlewomen and Aristocrats, in: Stefan Horlacher (Hrsg.), Constructions of Masculinity in British Literature from the Middle Ages to the Present, Basingstoke 2011, S. 69-87.

Henning Ritter, Die Krise des Helden. Der Ruhm und die großen Männer im Ancien Régime, in: Martin Warnke (Hrsg.), Politische Kunst. Gebärden und Gebaren (Hamburger Forschungen zur Kunstgeschichte; 3), Berlin 2004, S. 1-16.

Douglas A. B. Ronald, Youth, Heroism and War Propaganda. Britain and the Young Maritime Hero, 1745-1820, London 2015.

Craig Rose, England in the 1690s. Revolution, Religion and War (History of Early Modern England), Oxford 1999.

Laura J. Rosenthal, Masculinity in Restoration Drama, in: Susan J. Owen (Hrsg.), A Companion to Restoration Drama (Blackwell Companions to Literature and Culture; 12), Oxford 2008, S. 92-108.

Violet A. Rowe, Sir Henry Vane the Younger. A Study in Political and Administrative History (University of London Historical Studies; 28), London 1970.

Jon T. Rowland, Faint Praise and Civil Leer. The "Decline" of EighteenthCentury Panegyric, Newark, NJ 1994.

Guy Rowlands, The Dynastic State and the Army under Louis XIV. Royal Service and Private Interest in France 1661-1701 (Cambridge Studies in Early Modern History), Cambridge 2002.

Ian Roy, Royalist Reputations: the Cavalier Ideal and the Reality, in: Jason McElligott / David L. Smith (Hrsg.), Royalists and Royalism during the English Civil Wars, Cambridge 2007, S. 89-111.

Alexander Rubel, Eine Frage der Ehre. Die Fronde im Spannungsfeld von Adelsethos und Literatur, in: Francia. Forschungen zur westeuropäischen Geschichte 32, Heft 2, 2005, S. 31-57.

Gérard Sabatier, Le cavalier de bronze, in: Gérard Sabatier, Le Prince et les arts. Stratégies figuratives de la monarchie française de la Renaissances aux Lumières (Epoques), Seyssel 2010, S. 281-302.

Ders., Versailles ou la figure du roi (Bibliothèque Albin Michel histoire), Paris 1999. 
Yassin al-Haj Saleh, Du djihadisme salafiste en tant que phénomène théâtral, http://souriahouria.com/du-djihadisme-salafiste-en-tant-que-phenomenetheatral-par-yassine-al-hajj-salih/, 23. Februar 2015.

Thomas Scheffler, Helden, Märtyrer, Selbstmordattentäter. Zur religiösen Semantik des Heldentods, in: Amr Hamzawy / Ferhad Ibrahim (Hrsg.), Religion, Staat und Politik im Vorderen Orient. Festschrift für Friedemann Büttner, Münster 2003, S. 88-109.

Lois G. Schwoerer, "No Standing Armies!". The Antiarmy Ideology in Seventeenth-Century England, Baltimore 1974.

Joshua Scodel, Excess and the Mean in Early Modern English Literature (Literature in History), Princeton, NJ 2002.

Jonathan Scott, Algernon Sidney and the English Republic 1623-1677 (Cambridge Studies in Early Modern British History), Cambridge 1988.

R. W. Serjeantson, Samson Agonistes and 'Single Rebellion', in: Nicholas McDowell / Nigel Smith (Hrsg.), The Oxford Handbook of Milton, Oxford 2009, S. 613-631.

Kevin Sharpe, Rebranding Rule. The Restoration and Revolution Monarchy, 1660-1714, New Haven, CT 2013.

Ders., Image Wars. Promoting Kings and Commonwealths in England, 1603-1660, New Haven, CT 2010.

Ders., Selling the Tudor Monarchy. Authority and Image in Sixteenth-Century England, New Haven, CT 2009.

Ders., Private Conscience and Public Duty in the Writings of Charles I, in: Kevin Sharpe, Remapping Early Modern England. The Culture of SeventeenthCentury Politics, Cambridge 2000, S. 172-198.

Ders., "An image doting rabble": The Failure of Republican Culture in Seventeenth-Century England, in: Kevin Sharpe / Steven N. Zwicker (Hrsg.), Refiguring Revolutions. Aesthetics and Politics from the English Revolution to the Romantic Revolution, Berkeley 1998, S. 25-56.

Linda Shenk, Learned Queen. The Image of Elizabeth I in Politics and Poetry (Queenship and Power), Basingstoke 2010.

Andrew Shifflett, Stoicism, Politics and Literature in the Age of Milton. War and Peace Reconciled, Cambridge 1998.

Peter W. Sinnema, The Wake of Wellington: Englishness in 1852, Athens, OH 2006.

Sara Smart / Mara R. Wade (Hrsg.), The Palatine Wedding of 1613. Protestant Alliance and Court Festival (Wolfenbütteler Abhandlungen zur Renaissanceforschung; 29), Wiesbaden 2013.

Hannah Smith, Politics, Patriotism, and Gender. The Standing Army Debate on the English Stage, circa 1689-1720, in: Journal of British Studies 50, Heft 1, 2011, S. 48-75. 
Dies., Last of all the Heavenly Birth. Queen Anne and Sacral Queenship, in: Parliamentary History Yearbook 28, Heft 1, 2009, S. 136-149.

Dies., Georgian Monarchy. Politics and Culture, 1714-1760 (Cambridge Studies in Early Modern British History), Cambridge 2006.

Jay M. Smith, Nobility Reimagined. The Patriotic Nation in Eighteenth-Century France, Ithaca, NY 2005.

Malcolm Smuts, The Making of Rex Pacificus: James VI and I and the Problem of Peace in an Age of Religious War, in: Daniel Fischlin / Mark Fortier (Hrsg.), Royal Subjects. Essays on the Writings of James VI and I, Detroit, MI 2002, S. 371-387.

Ders., Court-Centred Politics and the Uses of Roman Historians c. 1590-1630, in: Kevin Sharpe / Peter Lake (Hrsg.), Culture and Politics in Early Stuart England, Basingstoke 1994, S. 21-43.

David R. Sorensen, Introduction, in: David R. Sorensen / Brent E. Kinser (Hrsg.), Thomas Carlyle. On Heroes, Hero-Worship, and the Heroic in History (Rethinking the Western Tradition), New Haven, CT 2013, S. 1-16.

Ders., In Defense of "Religiosity": Carlyle, Mahomet, and the Force of Faith in History, in: David R. Sorensen / Brent E. Kinser (Hrsg.), Thomas Carlyle. On Heroes, Hero-Worship, and the Heroic in History (Rethinking the Western Tradition), New Haven, CT 2013, S. 209-221.

John Spurr, England in the 1670s. The Masquerading Age (A History of Early Modern England), Malden, MA 2000.

John D. Staines, The Tragic Histories of Mary Queen of Scots, 1560-1690. Rhetoric, Passions and Political Literature, Farnham 2009.

André Stegmann, L’ambiguïté du concept hérö̈que dans la littérature morale en France sous Louis XIII, in: Noémi Hepp / Georges Livet (Hrsg.), Héroïsme et création littéraire sous les règnes d'Henri IV et de Louis XIII (Actes et colloques; 16), Paris 1974, S. 29-59.

Sylvie Steinberg, Le mythe des Amazones et son utilisation politique de la Renaissance à la Fronde, in: Kathleen Wilson-Chevalier / Eliane Viennot (Hrsg.), Royaume de Fémynie. Pouvoirs, contraintes, espaces de liberté des femmes de la Renaissance à la Fronde (Colloques, congrès et conférences sur la Renaissance européenne; 16), Paris 1999, S. 261-273.

Jan Steinhaußen, ,Aristokraten aus Not' und ihre ,Philosophie der zu hoch hängenden Trauben'. Nietzsche-Rezeption und literarische Produktion von Homosexuellen in den ersten Jahrzehnten des 20. Jahrhunderts: Thomas Mann, Stefan George, Ernst Bertram, Hugo von Hofmannsthal u.a. (Epistemata; 326), Würzburg 2001.

Thomas Steinruck, Jean-Baptiste Pigalle. Das Grabmal für Moritz von Sachsen. Studien zum Mausolée du Maréchal de Saxe in St. Thomas in Straßburg, Saarbrücken 2009. 
Paul Stevens, Milton and National Identity, in: Nicholas McDowell / Nigel Smith (Hrsg.), The Oxford Handbook of Milton, Oxford 2009, S. 342-363.

Roy C. Strong, Henry, Prince of Wales and England's Lost Renaissance, London 1986.

Donald Stump, Abandoning the Old Testament: Protestant Dissent and the Shift in Court Paradigms for Elizabeth, in: Donald Stump [et al.] (Hrsg.), Elizabeth I and the "Sovereign Arts". Essays in Literature, History and Culture (Medieval and Renaissance Texts and Studies; 407), Tempe, AZ 2011, S. 281-299.

Éric Suire, La Sainteté française de la Réforme catholique (XVIe-XVIII ${ }^{e}$ siècles) d'après les textes hagiographiques et les procès de canonisation (Identités religieuses), Pessac 2001.

Christine Sukic, The Earl of Essex. From one Reign to the Next, in: Jean-Christophe Mayer (Hrsg), The Struggle for the Succession in Late Elizabethan England. Politics, Polemics and Cultural Representations (Collection Astraea; 11), Montpellier 2004, S. 417-432.

Matthew G. Sullivan, Les grands hommes, le panthéon domestique et la carrière du sculpteur dans l'Angleterre du XVIII' siècle, in: Thomas W. Gaehtgens / Gregor Wedekind (Hrsg.), Le culte des grands hommes 1750-1850 (Passagen; 16), Paris 2009, S. 39-69.

Nicola M. Sutherland, Henry IV of France and the Politics of Religion, Bd. 1, Henry of Navarre, Bristol 2002.

Alain Tallon, Conscience nationale et sentiment religieux en France au XVIe siècle (Le noeud gordien), Paris 2002.

René Taveneaux, Jansénisme et réforme catholique, Nancy 1992.

Richard Terry, Mock-Heroic from Butler to Cowper. An English Genre and Discourse (Studies in Early Modern English Literature), Burlington 2005.

Hillard von Thiessen, Der entkleidete Favorit. Legitimation von GünstlingsHerrschaft und politische Dynamik im Spanien des Conde-Duque de Olivares, in: Ronald G. Asch [et al.] (Hrsg.), Integration - Legitimation - Korruption. Politische Patronage in Früher Neuzeit und Moderne, Frankfurt am Main [u.a.] 2011, S. 131-147.

Heinz Thoma, Art. Querelle des Anciens et des Modernes, in: Heinz Thoma (Hrsg.), Handbuch Europäische Aufklärung. Begriffe, Konzepte, Wirkung, Stuttgart/Weimar 2015, S. 407-418.

Ahmet Toprak / Aladin El-Mafaalani, Eine Frage der Männlichkeit. Duelle bei muslimischen Jugendlichen in Deutschland, in: Ulrike Ludwig [et al.] (Hrsg.), Das Duell. Ehrenkämpfe vom Mittelalter bis zur Moderne, Konstanz 2012, S. 49-60.

Wouter Troost, William III, the Stadholder-King. A Political Biography, übers. von J. C. Grayson, Aldershot 2005.

Jacques Truchet (Hrsg.), Théâtre du XVIII siècle, Bd. 2, Paris 1974. 
Edward B. Turk, Baroque Fiction-Making. A Study of Gomberville's Polexandre (North Carolina Studies in the Romance Languages and Literatures; 196), Chapel Hill, NC 1978.

Nicholas Tyacke, Anti-Calvinists. The Rise of English Arminianism, c. 1590-1640 (Oxford Historical Monographs), Oxford 1987.

Daniel Vidal, Critique de la raison mystique. Benoît de Canfield, possession et dépossession au XVIIe siècle, Grenoble 1990.

Edgar Vincent, Nelson. Love and Fame, New Haven, CT 2003.

Catherine Volpilhac-Auger, Auguste et Louis XIV. Les contradictions de Voltaire devant le pouvoir absolu, in: Centre de Recherches sur l'Occident Moderne (Hrsg.), La monarchie absolutiste et l'histoire en France. Théories du pouvoir, propagandes monarchiques et mythologies nationales (Mythes, critique et histoire; 1), Paris 1987, S. 197-215.

Pierre Wachenheim, Un héros éphémère sous le règne de Louis XV. L'abbé Chauvelin, ou le portrait du sapajou en Grand Homme, in: Thomas W. Gaehtgens [et al.] (Hrsg.), L'art et les normes sociales au XVIII siècle (Passagen; 2), Paris 2001, S. 213-239.

Raymond Waddington, Looking Into Providences. Designs and Trials in Paradise Lost, Toronto 2012.

Gerald Wagner, Keiner weiß, wie der Landser tickt, in: Frankfurter Allgemeine Zeitung, 25. Februar 2015, S. N 4.

Anita M. Walker / Edmund H. Dickerman, The King Who Would Be Man. Henri III, Gender Identity, and the Murders at Blois, 1588, in: Historical Reflections 24, Heft 2, 1998, S. 253-281.

Alexandra Walsham, "A Very Deborah?” The Myth of Elizabeth I as a Providential Monarch, in: Susan Doran / Thomas S. Freeman (Hrsg.), The Myth of Elizabeth, Basingstoke 2003, S. 143-168.

Dies., Providence in Early Modern England, Oxford 1999.

Gerrit Walther, Protest als schöne Pose, Gehorsam als Event. Zur Formation des ludovizianischen Absolutismus aus dem Geiste der Fronde, in: Lothar Schilling (Hrsg.), Absolutismus, ein unersetzliches Forschungskonzept? Eine deutschfranzösische Bilanz / L'absolutisme, un concept irremplaçable? Une mise au point franco-allemande (Pariser Historische Studien; 79), München 2008, S. 173-189.

Ellis Wasson, Born to Rule. British Political Elites, Stroud 2000.

Tom Webster, Early Stuart Puritanism, in: John Coffey / John C. H. Lim (Hrsg.), The Cambridge Companion to Puritanism (Cambridge Companions to Religion), Cambridge 2008, S. 48-66.

Ders., Godly Clergy in Early Stuart England. The Caroline Puritan Movement, c. 1620-1643 (Cambridge Studies in Early Modern British History), Cambridge 1997. 
Michael West, Dryden and the Disintegration of Renaissance Heroic Ideals, in: Costerus. Essays in English and American Literature 7, 1973, S. 193-222.

Susan E. Whyman, Art. Verney, Sir Edmund (1590-1642), in: Oxford Dictionary of National Biography, 2004, DOI 10.1093/ref:odnb/28228.

Alexander S. Wilkinson, Mary Queen of Scots and French Public Opinion 15421600, Basingstoke 2004.

Carolyn D. Williams, Pope, Homer and Manliness. Some Aspects of EighteenthCentury Classical Learning, London 1993.

Andrew Wilton, The Swagger Portrait. Grand Manner Portraiture in Britain from Van Dyck to Augustus John, 1630-1930, London 1992.

Austin Woolrych, Britain in Revolution 1625-1660, Oxford 2002.

Blair Worden, Roundhead Reputations. The English Civil Wars and the Passions of Posterity, London 2001.

Ders., The Sound of Virtue. Philip Sidney's "Arcadia" and Elizabethan Politics, New Haven, CT 1996.

Ders., Ben Jonson among the Historians, in: Kevin Sharpe / Peter Lake (Hrsg.), Culture and Politics in Early Stuart England (Problems in Focus), Basingstoke 1994, S. 67-90.

Ders., Andrew Marvell, Oliver Cromwell, and the Horatian Ode, in: Kevin M. Sharpe / Steven N. Zwicker (Hrsg.), Politics of Discourse. The Literature and History of Seventeenth-Century England (New York University Ottendorfer Series; 39), London [u.a.] 1987, S. 147-180.

Ders., The Politics of Marvell's Horatian Ode, in: Historical Journal 27, Heft 3, 1984, S. 525-547.

Martin Wrede, Des Königs Rock und der Rock des Königs. Monarch, Hof und Militär in Frankreich von Ludwig XIV. zu Ludwig XVI., in: Martin Wrede (Hrsg.), Die Inszenierung der heroischen Monarchie. Frühneuzeitliches Königtum zwischen ritterlichem Erbe und militärischer Herausforderung (Historische Zeitschrift, Beihefte N.F.; 62), München 2014, S. 382-408.

Ders., Die Welfen im Reich. Selbstverständnis und Selbstdarstellung einer - mehr oder weniger - patriotischen Dynastie, 1648-1714, in: Ronald G. Asch (Hrsg.), Hannover, Großbritannien und Europa. Erfahrungsraum Personalunion, 17141837 (Veröffentlichungen der Historischen Kommission für Niedersachsen und Bremen; 277), Göttingen 2014, S. 149-177.

Ders., Ohne Furcht und Tadel - Für König und Vaterland. Frühneuzeitlicher Hochadel zwischen Familienehre, Ritterideal und Fürstendienst (Francia, Beihefte; 75), Ostfildern 2012.

Ders., Zwischen Mythen, Genealogen und der Krone. Rivalisierende Familiengedächtnisse im französischen Hochadel des 17. Jahrhunderts: die Häuser Bouillon, Noailles und Bourbon, in: Zeitschrift für Historische Forschung 32, Heft 1, 2005, S. 17-43. 
Anthony D. Wright, The Divisions of French Catholicism, 1629-1645. The Parting of the Ways (Catholic Christendom, 1300-1700), Farnham 2011.

Robert Zaller, The Discourse of Legitimacy in Early Modern England, Stanford, CA 2007.

Ders., Breaking the Vessels. The Desacralization of Monarchy in Early Modern England, in: The Sixteenth Century Journal 29, Heft 3, 1998, S. 757-778.

Hendrik Ziegler, Der Sonnenkönig und seine Feinde. Die Bildpropaganda Ludwigs XIV. in der Kritik (Studien zur internationalen Architektur- und Kunstgeschichte; 79), Petersberg 2010.

Melinda S. Zook, Radical Whigs and Conspiratorial Politics in Late Stuart England, University Park, PA 1999.

Dies., Violence, Martyrdom and Radical Politics: Rethinking the Glorious Revolution, in: Howard Nenner (Hrsg.), Politics and the Political Imagination in Later Stuart Britain. Essays Presented to Lois Green Schwoerer, Rochester, NY 1997, S. 75-96.

Dies., "The Bloody Assizes". Whig Martyrdom and Memory after the Glorious Revolution, in: Albion 27, Heft 3, 1995, S. 373-396.

Steven N. Zwicker, Lines of Authority. Politics and English Literary Culture, 1649-1689, Ithaca, NY 1993. 


\section{Personenregister}

Abbot, George, Erzbischof von Canterbury 51

Abbt, Thomas 122

Acarie, Barbe, OCarm 68

Achilles 42, 47

Addison, Joseph 110

Alexander d. Gr. 18, 71, 75-6, 84-85, 119

Alexander Severus 52

Alfred d. Gr., König von Wessex 117

Andromeda 37

Angiviller, comte de siehe Flahaut de La Billarderie

Anna von Österreich, Königin von Frankreich 77-79

Anna, Königin von Großbritannien 109-10, 113, 115

Apollo 86

Argenson, comte d' siehe Voyer de Paulmy

Artagnan, comte d' siehe Batz de Castelmore

Artus, König 46

Augustinus, Heiliger 71

Augustus 62, 85, 95-96

Austria, Don Juan, d' 93

Batz de Castelmore, Charles de, comte d'Artagnan 87-89

Bayard, Chevallier de siehe Terrail

Bossuet, Jacques-Benigne 90

Boucher, Jean 27

Bouillon, Gottfried von, König von Jerusalem 33

Bourbon, Anne Geneviève de, duchesse de Longueville 78-79

-, Anne Marie Louise d'Orléans de, duchesse de Montpensier 78

-, Antoinette de, duchesse de Guise 33

-, Armand de, prince de Conti 79

-, Charles de, connétable de France 132

-, Henri-Jules, prince de Condé 92

-, Louis II de, prince de Condé 25-26, 75-77, $79-80,84,90-93,106,129,131,140$

Bourgoing, Edmond, OP 28

Brutus 103

Buckingham, Herzöge von siehe Villiers

Buirette de Belloy, Pierre-Laurent 126-129

Burroughs, Jeremiah 55-56

Burton, Henry 56
Byron, John, 1st Lord Byron 54

Capell, Arthur, Earl of Essex 103-104

Carlyle, Thomas 25, 135, 138

Cäsar 23, 62, 85, 95, 109

Castel, Charles Irénée, de, abbé de SaintPierre 107, 119, 132

Castiglione, Baldassare 55

Catinat de La Fauconnerie, Nicolas, de 130132

Cato Censorius 109

Chamberlain, Neville 137

Chapman, George 47

Châtel, Jean 27

Chauvelin, Henri-Philippe de 120

Chergé, Christian de, OCSO 14

Choiseul, Étienne-François, duc de Choiseul-Stainville 126

Churchill, John, 1st Duke of Marlborough 109, 133, 137, 143

-, Winston 137

Cicero 98

Clément, Jacques, OP 28, 31, 37, 139

Coligny, Gaspard II de, Admiral von Frankreich 34

Condé, Prinz von siehe Bourbon

Corneille, Michel 92

Corneille, Pierre 17, 75

Cornewall, James 115

Costentin, Anne Hilarion de, comte de Tourville 130

Coudenhove-Kalergi, Richard Nikolaus 21

Courtilz de Sandras, Gatien 87-8

Cromwell, Oliver 23, 60-63, 65, 95, 101, 107

David 28, 38-39, 46, 120

Deborah 38-39

Dejoux, Claude 130

Devereux, Robert, 2nd Earl of Essex 42-43, 47, 139, 143

-, Robert, 3rd Earl of Essex 55

Diderot, Denis 127

Dobson, William 54

Drake, Sir Francis 117

Dryden, John 95, 100-101

Eduard III., König von England 108, 114, 126

Ehud 28 
Elisabeth I., Königin von England 31, 3840, 45, 108, 139

Essex, Earls of siehe Devereux und Capell

Fénelon siehe La Mothe-Fénelon

Flahaut de La Billarderie, Charles Claude, comte d'Angiviller 129-130

Foxe, John 29, 104

Franz II., König von Frankreich 31, 33

Friedrich II., d. Gr., König von Preußen 122

Friedrich II., Kaiser 18

Froissart, Jean 21

Gassion, Jean de 75, 89, 106

Gauden, John 57

Georg I., König von Großbritannien 114115

Georg II., König von Großbritannien 114116

George, Stefan 22

Godard d'Aucourt, Claude, gen. de SaintJust 125

Goliath 32, 38, 45, 120

Gombaud, Antoine, chevalier de Méré 111

Gonzague, Charles de, duc de Nevers 67, 74

Grenville, Thomas 116

Greville, Fulke 41

Guibert, Jacques Antoine Hippolyte, comte de 132-133

Guise, Herzöge von 30 (siehe auch Lorraine)

Gustav Adolf, König von Schweden 53

Guyonnet de Vetron, Claude-Charles 85

Hampden, Edward 117

Harcourt, comte de siehe Lorraine

Hasdrubal 126

Heinrich III., König von Frankreich 27-28, 30, 32, 34-35, 40-41, 45-46

Heinrich IV., König von Frankreich 27, 30, $32,35-36,43,46-47,64-66,83,119,139$

Herkules 37, 46, 70, 85-87, 108, 123

Hiob 72

Hobbes, Thomas 99

Hotman, François 30

Hume, David 110

Hutchinson, John 55-56

-, Lucy 55-56

Jakob II., König von England 100, 103, 107, 109

Jakob VI. und I., König von Schottland und England 25, 43, 45-46, 48, 65, 139

Jansen, Cornelis 72

Jeanne d'Arc 78, 141
Jefferson, Thomas 138

Jonson, Ben 46

Josiah 38

Josua 55

Joyeuse, Anne de, duc de Joyeuse 32

-, Henri de, comte de Bouchage, duc de Joyeuse, OFMCap 32-33

Judith 28, 31, 39

Jung, Edgar 21

Karl I., König von England 50-53, 56-58, 95, 104, 107

Karl II., König von England 25, 95-98

Karl IX., König von Frankreich 35

Knox, John 135, 139

La Baune, Jacques, SJ 90

La Harpe, Jean-François de 131-132

La Mothe-Fénelon, François de Salignac de 22, 119

La Rochefoucauld, François, duc de 111

La Tour d'Auvergne, Emmanuel Théodose de, cardinal de Bouillon 93

-, Frédéric Maurice de, duc de Bouillon 93

-, Henri de, vicomte de Turenne 79, 91-94, $123,129,131$

Languet, Hubert 41

Laud, William, Erzbischof von Canterbury 99

Le Clerc du Tremblay de Maffliers, FrançoisJoseph (Père Joseph), OFMCap 48, 74

Le Moyne, Pierre, SJ 16

Le Roy, Marin 76

Le Tellier, François-Michel, de, marquis de Louvois 77

-, Michel 77

Leigh, William 38-39

Lincoln, Abraham 138

Locke, John 117

Lorraine, François de, duc de Guise 33

-, Henri de, comte d' Harcourt 76

-, Henri I de, duc de Guise 30, 33-35, 43

-, Louis de, cardinal de Guise 30, 34-35

-, Philippe-Emmanuel de, duc de Mercoeur $67,73-74$

Louvois siehe Le Tellier,

Ludwig IX., der Heilige, König von Frankreich 16,70

Ludwig XIII., König von Frankreich 58, 66, 70-72, 76-77, 93 
Ludwig XIV., König von Frankreich 22, 53, $59,67,81,83-90,92,97,106,114,118-$ 119,121, 123, 140,

Ludwig XV., König von Frankreich 107

Ludwig XVI., König von Frankreich 129, 132

Maria I., die Katholische, Königin von England 29

Maria Stuart, Königin von Schottland 31, 34, 40, 139

Mariana, Juan de, SJ 28

Marlborough, Herzog von siehe Churchill

Marvell, Andrew 62

Mazarin, Jules, Kardinal 64, 79-80

Medici, Maria de', Königin von Frankreich 78

Mercoeur, Herzog von siehe Lorraine

Merlin 46

Milton, John 58-59, 61-62, 139

Mohammed, Prophet 138

Montfort, Simon de 59

Napoleon III., Kaiser der Franzosen 141

Napoleon, Kaiser der Frankreich 18, 37, 141

Nebukadnezar 86

Nevers, Herzog von siehe Gonzague

Odysseus 47

Outram, Sir James 21

Perseus 37, 70

Philipp II., König von Spanien 33

Philipp IV., König von Spanien 93

Pigalle, Jean-Baptiste 123

Plessis, Armand-Jean du, cardinal de Richelieu 48, 69-72, 77, 93

Poltrot, Jean de 33

Pope, Alexander 118

Prometheus 37

Raleigh, Sir Walter 117

Rapin, René SJ, 91-92

Rathenau, Walther 21

Ravaillac, François 27, 139

Reynolds, Joshua 117, 124

Richard II., König von England 102

Richelieu, Kardinal siehe Plessis

Rochester, Earl of siehe Wilmot

Rousseau, Jean Jacques 122, 132

Rubens, Peter Paul 47, 52, 78

Russell, Bertrand, 3rd Earl Russell 105

Russell, John, 1st Earl Russell 105

Russell, William, Lord Russell 103-106
Sachsen, Hermann Moritz Graf von (maréchal de Saxe) 121, 123-125

Saint-Pierre, Eustache de 126

Sales, François de 73-74

Samson 28

Scipio Africanus 42

Secondat, Charles de, baron de Montesquieu 119

Shakespeare, William 117, 127

Shovell Cloudesley, 115

Sidney, Algernon 102-106

-, Robert, 2nd Earl of Leicester 102

-, Sir Philip 40-43, 58, 61, 103, 116, 139 , 143

Sotomayor, Alonzo de 32

South, Robert 60-1

Sprigge, Joshua 56

St. Georg 114

St. John, Anne 96

Steele, Richard 110

Stuart, Elizabeth, Königin von Böhmen 47

Stuart, Henry, Prince of Wales 46-47

Sulla 109

Swift, Jonathan 115

Tacitus 42

Temple, Richard, Viscount Cobham 116

Terrail, Pierre du, Chevalier de Bayard 21, $32,80,129$

Theresa von Ávila (Teresa de Ahumada), OCarm 68

Thornhill, James 114

Toland, John 105

Townsend, Aurelian 52

Turenne siehe La Tour d'Auvergne

Van Dyck, Jan 54

Vane, Sir Henry, d. J. 50, 101-105

Vergil 95

Vernon, Edward 119, 133

Villiers, George, 1st Duke of Buckingham $47-48$

-, George, 2nd Duke of Buckingham 101

Voltaire, François Marie Arouet de 132

Voyer de Paulmy, René de, comte d'Argenson 69

Walpole, Robert 116

Washington, George 19, 138, 140

Wellesley, Arthur, 1st Duke of Wellington 140-141

West, Benjamin 124, 134 
Wilhelm I. von Oranien, der Schweiger 27, 109

Wilhelm III. von Oranien, König von England, Statthalter der Niederlande 25, 63, 108-109
Wilmot, John, Earl of Rochester 96-100

Wilton, Joseph 123, 125

Wolfe, James 122-127, 133 